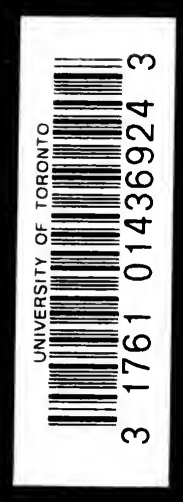

1. H: inf

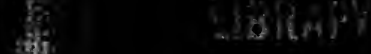




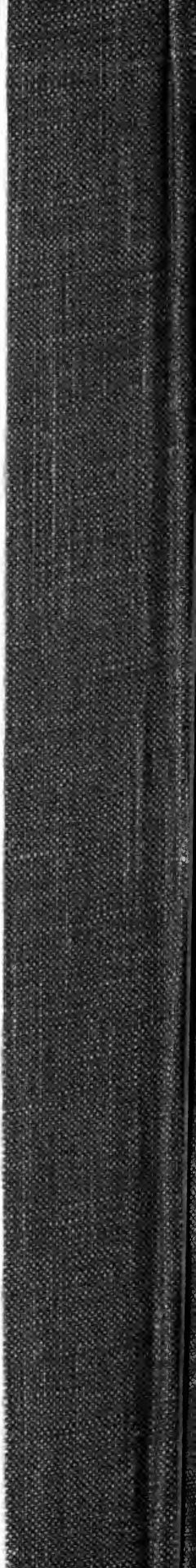




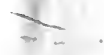




\section{CIVILIZATION AND CLIMATE}


1

)

).

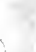

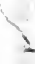

\}-1

1

$=1$

$-1$

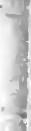

1 


\section{Civilization and Climate}

By

Ellsworth Huntington

Author of "The Pulse of Asia"

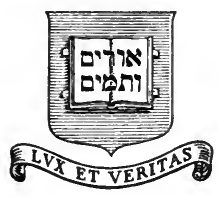

Second Edition with a

Nero Introduction

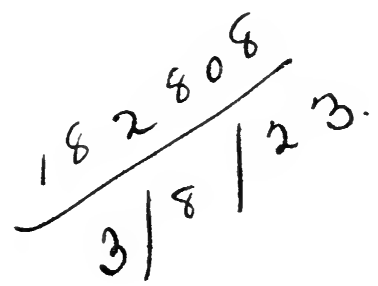

New Haven:

Yale University Press

London: Humphrey Milford, Oxford University Press

Mdeccexxii 
Copyright, 1915, 1928

By Yale University Press

Published, 1915

Second Printing, 1916

Third Printing, 1919

Second and Enlarged Edition, 1822

$$
\begin{aligned}
& \text { GF } \\
& 31 \\
& 48 \\
& 1922
\end{aligned}
$$




\section{I}

\section{PREFACE}

This volume is a product of the new science of geography. The old geography strove primarily to produce exact maps of the physical features of the earth's surface. The new goes farther. It adds to the physical maps an almost innumerable series showing the distribution of plants, animals, and man, and of every phase of the life of these organisms. It does this, not as an end in itself, but for the purpose of comparing the physical and organic maps and thus determining how far vital phenomena depend upon geographic environment. Among the things to be mapped, human character as expressed in civilization is one of the most interesting and one whose distribution most needs explanation. "The only way to explain it is to ascertain the effect of each of many coöperating factors. Such matters as race, religion, institutions, and the influence of men of genius must be considered on the one hand, and geographical location, topography, soil, climate, and similar physical conditions on the other. This book sets aside the other factors, except incidentally, and confines itself to climate. In that lie both its strength and weakness." When the volume was first planned, I contemplated a discussion of all the factors and an attempt to assign to each its proper weight. The first friend whom I consulted advised a directly opposite course, whereby the emphasis should be centered upon the new climatic facts which seem to afford ground for a revision of some of our old estimates of the relation between man and his environment. In writing the book I have growingly felt the wisdom of that advice, and have been impressed with the importance of concentration upon a single point, even at the expense of seeming 
to take a one-sided, view. If the reader feels that due weight is not given to one factor or another, he must remember that many unmentioned phases of the subject have been deliberately omitted to permit fuller emphasis upon the apparent connection between a stimulating climate and high civilization.

The materials for this volume have been derived from a great variety of sources. Although personal observation and investigation are the basis of much that is here stated, still more has been derived from the world's general store of knowledge. Except in a few special cases $I$ have not attempted to give references. To the general reader footnotes are not only useless, but often a distraction and nuisance. The careful student, on the other hand, cannot form a fair estimate of the hypothesis here presented without reading previous publications in which $I$ have set forth the reasons for many conclusions which are not fully discussed here for lack of space. These publications contain numerous references. Accordingly, the needs of the student will be met by giving a brief list of books and articles which have served as preliminary steps to the present volume. These publications form a logical series with only such repetition as is necessary to make each a complete unit. It is scarcely necessary to add that the rapid growth of the subject during the past ten years has led to important modifications in some of the earlier conclusions.

(A) Books and longer articles on changes of climate and their effect on man:

(1) Explorations in Turkestan. Publication 26 of the Carnegie Institution of Washington, 1905, pp. 157-317.

(2) The Pulse of Asia. Boston, Houghton Mifflin Company, 1907, $415 \mathrm{pp}$.

(3) Palestine and its Transformation. Boston, Houghton Mifflin Company, 1911, 433 pp. 
(4) The Climatic Factor as illustrated in arid America. Publication 192 of the Carnegie Institution of Washington, 1914, $341 \mathrm{pp}$.

(5) The Solar Hypothesis of Climatic Changes. Bulletin of the Geological Society of America, vol. 25, 1914, pp. 477590 .

(B) Shorter articles dealing with phases of the problem of climatic changes not treated under (A):

(6) The Burial of Olympia. Geographical Journal, London, 1910, pp. 65\%-686.

(7) The Oasis of Kharga. Bulletin of the American Geographical Society, New York, vol. 42, 1910, pp. 641-661.

(C) Articles dealing with the relation of climate to civilization:

(8) Physical Environment as a Factor in the present condition of Turkey. Journal of Race Development, Worcester, Mass., vol. 1, 1911, pp. 460-481.

(9) Geographical Environment and Japanese Character. Journal of Race Development, Worcester, Mass., vol. 2, 1912, pp. 256-281. (Reprinted in a volume entitled "Japan and Japanese American Relations," edited by G. H. Blakeslee, N. Y., 1912, pp. 42-6\%.)

(10) Changes of Climate and History. American Historical Review, vol. 18, 1913, pp. 213-232.

(11) The Adaptability of the White Man to Tropical America. In "Latin America." Clark University Addresses, 1913, edited by G. H. Blakeslee, pp. 360-386.

In addition to the works listed above a number of articles have appeared in Harper's Magazine. I am especially glad to mention these, because the liberal policy of the editors of that magazine has been an important factor in making it possible to carry on some of the investigations described in this book. 
The facts set forth in this volume have by no means been derived wholly from observation and reading. Not far from a hundred people have given direct personal assistance. They are so numerous that it is impossible to mention them all by name. Therefore it seems best not to single out any for special thanks. Many of my colleagues among the Yale faculty and among the geographers of America have gone out of their way to offer suggestions, or friendly criticisms, or to bring to my attention publications and facts that might have escaped my notice. Others connected with such organizations as the Carnegie Institution of Washington and the United States Weather Bureau have placed me under obligation by the kind way in which they have taken a personal rather than official interest in answering queries and providing data. Equally great courtesy has been shown by officers and other members of the teaching force at West Point and Annapolis, and by officials connected with various factories, including some whose figures it has not yet been possible to tabulate. Another large group comprises contributors to the map of civilization, many of whom devoted to this work time which they could ill afford. Lastly, I owe much to personal friends who fall in none of the groups already specified. I suppose that the total time given to this book by all these scores of people makes their contribution larger than mine. My chief hope is that they may feel that their kindness has not been wasted. To each and all I can only express my deep sense of gratitude, and most of all to the one whose advice from the beginning has done more than anything else to keep this book true to a single aim.

E. $H$.

Yale University,

New Haven, Conn.,

July, 1915. 


\section{TABLE OF CONTENTS}

Introduction . . . . . . . . . . . . xiii

Chapter I. Civilization and Climate . . . . 1

Chapter II. Race or Place . . . . . . . 11

Chapter III. The White Man in the Tropics . . . 35

Chapter IV. The Effect of the Seasons . . . . 49

Chapter V. The Effect of Humidity and Temperature . . . . . . . . . . 83

Chapter VI. Work and Weather. . . . . . 111

Chapter VII. The Ideal Climate . . . . . . 129

Chapter VIII. The Distribution of Civilization . . . 148

Chapter IX. Vitality and Education in the United States . . . . . . . . . 183

Chapter X. The Conditions of Civilization . . . 199

Chapter XI. The Shifting of Climatic Zones . . . 220

Chapter XII. The Shifting Centers of Civilization . 251

Chapter XIII. The Climatic Hypothesis of Civilization 271

Appendix . . . . . . . . . . . . . . 297

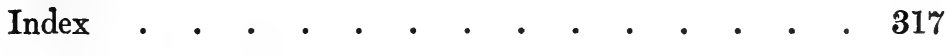




\section{LIST OF ILLUSTRATIONS}

Figure A. Distribution of Climatic Energy in Europe xxii

Figure B. Distribution of Health in Europe . . . xxiii

Figure C. Distribution of Civilization in Europe . . xxiv

Figure D. Seasonal Variations in Health and Energy in Connecticut and Pennsylvania . . . xxv

Figure 1. The Effect of the Seasons on Factory Operatives in Connecticut and at Pittsburgh

Figure 2a. Human Activity and the Seasons . • . 66

Figure 2b. Human Activity and the Seasons . . . 67

Figure 3. Seasonal Variations of Mental Compared with Physical Activity . . . . . . 80

Figure 4. Relative Humidity and Work in Connecticut 86

Figure 5. Average Weekly Temperature during the Summers of 1910-1913 in Connecticut . .

Figure 6. Effect of the Days of the Week on PieceWorkers . . . . . . . . . . 95

Figure 7. Variations in Daily Wages . . . . . 96

Figure 8. Human Activity and Mean Temperature . 99

Figure 9. Growth of Wheat at Various Temperatures 103

Figure 10. Mean Temperature and Vital Processes in Plants, Animals and Man . . . . . 105

Figure 11. Human Activity and Changes of Mean Temperature from Day to Day . . . . . 115

Figure 12. The Stimulus of Storms . . . . $\quad$. $\quad$. 122

Figure 13. Distribution of Human Energy on the Basis of Climate . . . . . . . . . . 142

Figure 14. Distribution of Civilization in Europe . . 165

Figure 15. Distribution of Civilization in Asia . . 168

Figure 16. Distribution of Civilization in Australia . 169

Figure 17. Distribution of Civilization in Africa . . 170

Figure 18. Distribution of Civilization in South America

Figure 19. Civilization in North America, According to All Contributors . . . . . . . . 173 
Figure 20. Civilization in North America, According to Twenty-five Americans . . . . . . 174

Figure 21. Civilization in North America, According to Seven British Contributors . . . . . 176

Figure 22. Civilization in North America, According to Six Germanic Europeans . . . . . 178

Figure 23. Civilization in North America, According to Six Latin Europeans and one Russian . . 179

Figure 24. Civilization in North America, According to Five Asiatics . . . . . . . . 181

Figure 25. Climatic Energy in the United States . . 184

Figure 26. Mortality in the United States . . . . 184

Figure 2\%. Education of Native White Children in the United States . . . . . . . . 185

Figure 28. Civilization in the United States . . 185

Figure 29. Illiteracy among Persons of Native White Parentage in the United States . . . . 190

Figure 30. Distribution of Human Energy on the Basis of Climate (Repeated) . . . . . . 200

Figure 31. Distribution of Civilization (World Map) . 200

Figure 32. Birthplaces of Persons of Unusual Ability in the United States . . . . . . . 212

Figure 33. Changes of Climate in Western Asia and Growth of Trees in California . . . . 228

Figure 34. Changes of Climate in California for 2000 Years . . . . . . . . . . 230

Figure 35. Comparative Storminess at Times of Maximum and Minimum Sunspots in the United States . . . . . . . . . . 246

Figure 36. Comparative Rainfall at Times of Maximum and Minimum Sunspots in Europe . 246

Figure 3\%. Major and Minor Sunspot Cycles. . . 248 Figure 38. The Shifting of the Storm Belt . . . . 264 
代 


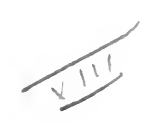

\section{INTRODUCTION TO SECOND EDITION}

One of the most interesting facts about a book is the kind of people who accept its conclusions, and the reasons for their acceptance. The non-scientific public, which has doubtless been the widest audience of Civilization and Climate, has accepted the book on the reasonableness of its main hypothesis, and with an open mind as to future proof or disproof. Geologists, archæologists, and those geographers who have had a geological training are the types of scientists who have found the hypothesis most convincing. This is because this volume employs methods of reasoning and lines of evidence such as are commonly used in geology, archæology, and geography. The thesis is that certain climatic conditions are especially favorable to human progress, and that the greatest progress usually takes place in regions where those conditions are most closely approached. One of the main steps leading to this conclusion was the theory of pulsatory climatic changes first set forth in The Pulse of Asia. The evidence of such changes consists chiefly of ancient lakes and streams, old roads in deserts, dead vegetation, abandoned fields and irrigation systems, and especially ruins and other traces of man, which are really human fossils. Such evidence appeals to geologists, archæologists, and geologically trained geographers.

Anthropologists, economists, and historians, on the other hand, have been slow to believe that climatic changes have had much influence upon human history. They accept, indeed, the geologists' conclusion that previous to recorded history great climatic changes drove man this way and that, destroyed ancient types of culture, and either wiped whole races out of existence, or profoundly modified them, physically, mentally, 
and socially. They apparently have no difficulty in accepting the geological evidence that among primitive men, as among plants and animals, climate has been one of the most powerful factors in determining the distribution and vigor of different types. But when it comes to the period of written history many historians, and some anthropologists and economists, no longer trust the geological methods of reasoning. Their opinions are more or less unconsciously molded by two conditions which do not apply to earlier times. First, there is a widespread idea that climatic uniformity is the normal condition; second, the anthropologist, economist, and historian are in the habit of basing their conclusions either upon exact measurements and statistics, or upon written records.

As to the assumed uniformity of climate, meteorologists do indeed find that so far as records are yet available, which means for scarcely a century, there are no certain indications of progressive climatic changes. But there is overwhelming evidence of pulsations which increase in magnitude and duration as the records become longer. In the same way the geological record continually discloses new evidence of climatic pulsations. Where one glacial period consisting of a single epoch was generally recognized half a century ago, at least six are now recognized. These date from all parts of geological time, and some have several epochs and subepochs. Moreover, the studies of Barrell, De Geer, Sayles, and many others are rapidly showing that during practically the whole of the earth's known history smaller climatic variations have occurred. Thus pulsations of climate are now almost universally regarded as characteristic of the vast periods covered by geology as well as of the short period covered by exact climatic records. The presumption is that similar pulsations of intermediate magnitude have been characteristic of the intervening historical period.

This presumption is confirmed not only by the author's own work but by that of his critics. A good instance of this is 
Woeikof's book on Turkestan. Apparently that Russian author had not read or had failed to understand The Pulse of Asia, but had become thoroughly familiar with a book of his countryman, Berg, written for the express purpose of proving that the present author is wrong as to changes of climate in central Asia. At any rate Woeikof pronounces the conclusions of The Pulse of Asia "inane," and then proceeds to prove the very thing that led to the choice of the title of that book, namely, that during historical times the Caspian Sea and other lakes in central Asia indicate alternating periods of more and of less rainfall than at present. Herbette, a French critic, also agrees that the Caspian Sea affords unmistakable evidence of climatic pulsations. In general, there has been a tendency to give up the idea not only of climatic uniformity during historical times, but of a progressive change in one direction which was the original belief of the author, as set forth in Explorations in Turkestan. The alternative to which almost all authorities turn is climatic pulsations having a greater intensity in the past than at present. Over nine tenths of the geographers of America, if we may judge from the fifty whose opinions have been expressed in writing, hold this view, although they differ as to the degree to which climatic pulsations have influenced history.

The reliance of historians upon written records rather than upon geological evidence may be illustrated by two eminent geographers who follow the historical method. Brunhes and Semple both reject the idea that climatic changes have had an important effect upon history, but neither gives reasons for such rejection. Miss Semple, for example, in an admirable paper on the Mediterranean lumber trade merely states that, having studied the evidence, she does not think it convincing. Her work, with its remarkably complete references even when minor matters are discussed, shows that to her the real evidence on this point is the written word. With her usual fair- 
ness, however, she points out that the accounts of widespread forests in ancient Cyprus suggest a different climate. She also gives many other facts which seem much more consistent with climatic changes than with uniformity. At least, they seem so to persons with a geological training. Such persons have become more and more accustomed not only to the idea of repeated climatic fluctuations of all grades throughout geological times, but to the idea that such fluctuations have caused the destruction of many types of plants and animals, and have hastened the development and migration of new types. The historian, on the contrary, is accustomed to attribute almost everything to purely human action. Hence, in the absence of records to the contrary, he assumes that human causes are mainly responsible for such facts as deforestation, changes in trade routes, the apparent drying up of sources of water, the abandonment of settlements in the drier parts of the world, and the migrations which so largely originate in dry regions.

Fortunately the progress of science is more and more leading the historian to understand and accept geological evidence in regard to historical times. In the United States men like Douglass, Hewett, Henderson, Gale, Free, Colton, and Bryan are constantly bringing to light new facts which indicate that the ancient climate of the Southwest was different from that of today. In the Old World the Great War and its aftermath have largely prevented investigation since 1914, but Stein has published further evidence of climatic changes in Chinese Turkestan, while Butler has presented one of the most convincing statements of the evidence that the climate of ancient Syria was radically different from that of today.

In addition to this, new value is being added to certain lines of botanical evidence which permit fairly exact climatic measurements. This evidence, together with a full discussion of other phases of the subject, is set forth in a new book entitled Climatic Changes: Their Nature and Causes, which appears 
synchronously with the present edition of Civilization and $\mathrm{Cli}$ mate; while a more technical discussion of the causes of present variations in the weather is contained in Earth and Sun: An Hypothesis of Weather and Sunspots, which is now ready for publication. When the present book was first issued there had not been time for scientists to appraise the value of the measurements of the growth of the great sequoia trees of California, as set forth in The Climatic Factor. Since that time, however, further work by Douglass and others has shown with constantly increasing certainty that the rings of growth of trees preserve an approximately accurate record of climatic variations. In dry climates such as that of California the rate of growth depends upon rainfall far more than upon any other single factor. A comparison of the present rainfall and tree growth in the Sierras with the rainfall of the eastern Mediterranean region during the fifty years since records have been kept shows that the main fluctuations in the two regions are unmistakably the same. Presumably this has been true for an indefinite period in the past.

Another matter which has become much clearer since this book was written is the nature of climatic changes. Much indeed remains to be done along this line, but at least it is becoming fairly certain that many of our present changes of weather are due to variations in the activity of the sun's atmosphere. The terrestrial effect of solar disturbances, as explained in Earth and Sun, is especially clear in certain centers of atmospheric action belonging to two opposite types. When one kind of center is warmer than the normal for the season, the other is cooler than usual. Similar contrasts in barometric pressure are observed. This peculiar contradiction seems to be associated with the fact that when the sun is active not only do storms increase in number and intensity, but their paths are altered. Where storminess decreases, the air is relatively clear, and the hot sun has an opportunity to warm the earth's sur- 
face. Where storms are abundant, on the other hand, not only does the increased cloudiness shut out the sunlight, but great amounts of warm air are carried aloft so that their heat is dissipated at high levels, leaving the earth's surface relatively cool. For our present purpose the essential point is that western Asia, the eastern Mediterranean, and the southwestern United States belong in general to the type of regions which today become relatively stormy and slightly cool at times of solar activity.

A growing body of evidence suggests that the variations of weather observed in our own day from year to year or decade to decade are of the same nature as historical pulsations of climate and as glacial epochs. One of the best examples of this, so far as is yet known, is the fourteenth century, whose storms, floods, droughts, cold waves, and glaciers are described in Climatic Changes. That period is important because it shows how different the changes in climate may be in different parts of the world, and because it serves as a connecting link between variations in the weather at present and fluctuations in climate during the periods covered by history and geology. Similar periods of climatic stress appear to have culminated about 1000 A.D., at the time of Christ, 400-500 B.C., and 1000 B.C., the earlier periods being more intense than the later.

In regions such as western Asia and eastern California the general conditions at such times of climatic stress appear to have been approximately as follows: (1) The average temperature for the year as a whole was probably a little lower than at present, but it is doubtful whether the difference amounted to more than two or three degrees at most. (2) The temperature of the seasons may have varied somewhat more than that of the year as a whole. The greater mixing of the air from wide areas by means of the winds that accompany storms would presumably lower the summer temperature a little over the lands and raise the winter temperature.

(3) The amount of rain was 
apparently considerably greater than now. Doubtless the rain then, as now, came chiefly in winter, while the summers were very dry just as at present, but the length of the rainy season appears to have been increased. That is, the rains began earlier in the autumn and lasted longer in the spring than at present. (4) The amount of atmospheric moisture over the lands was greater than now. This would arise partly from the increased cloudiness and rainfall and partly from the fact that the winds were presumably more efficacious in bringing moisture from the neighboring seas. (5) The winds were apparently stronger than at present, and varied in direction much more than now because of the frequent storms. (6) The greater storminess and the more frequent changes in the winds, as well as their greater strength, must have caused great or at least frequent variability of temperature as well as variations in other respects. Such variability would occur even in summer when the storms passed to the north of the lands that were most progressive two or three thousand years ago; it would be still more pronounced in the rainy season.

These six conditions are highly important not only because of their effect upon agriculture, but still more because of their effect upon man's health and vigor. As here stated they apply primarily to the region containing Greece, Syria, Egypt, and Mesopotamia. In tropical regions such as Yucatan quite a different type of change appears to have occurred. The number of storms of the type known as cyclonic, which means the common type in the United States and Europe, does indeed seem to be relatively great in that region when the sun is active, and the variability of temperature is apparently greater than usual at such times. The rainfall, however, being of the equatorial type with frequent showers when the sun is nearly vertical in those latitudes, apparently diminishes at the times when the rainfall from storms in the Mediterranean region increases. At least that is what happens now. In regions like Spain, on the 
other hand, while the climate appears to have suffered pulsations just as in other regions, the changes seem to have been less marked than farther east, and of a less distinct character.

Before showing how the climatic changes of the eastern Mediterranean and western Asia probably influenced the people, a word of explanation is needed. Some critics have implied that the author's hypothesis of pulsatory climatic changes was framed in order to support the hypothesis that the distribution of human progress depends on climate. Today civilization and climate vary in close harmony from one part of the world to another, but many regions which formerly had a high civilization now have an unfavorable climate. It cannot be too clearly understood that the hypothesis of pulsatory climatic changes was not framed in order to explain this anomaly. The hypothesis had been fully developed in The Pulse of Asia and Palestine and Its Transformation long before the author had any idea of the close connection between civilization and climate. Even the details as to the nature of climatic changes had been largely stated in preliminary form in The Solar Hypothesis of Climatic Changes and in The Climatic Factor before the close resemblance between the distribution of climatic energy and civilization had been detected by means of the maps on page 200 of this book. Instead of framing an hypothesis of climatic. changes to agree with conclusions based on the present distribution of civilization, the author experienced a most unexpected and illuminating surprise when his studies of the climate of the past finally led him to inquire exactly what effects the climate of today is having upon man's energy and activity. The results seem to show that although the hypothesis of pulsatory climatic changes was framed to fit certain physical facts as to lakes, ruins, vegetation, and so forth, it also fits a vast body of other facts as to human health, energy, progress, and civilization, which were not thought of when the hypothesis was framed.

Since the first edition of this book was published there has 
been even more progress in our understanding of the effect of climate upon man than in our knowledge of the nature of climatic changes. The most important step has been a realization of the extent to which health is an intermediary between climate on the one hand and progress and civilization on the other. In this book certain direct correlations are made between climate and human efficiency as measured by factory work and the marks of students. The conclusion is reached that there are certain optimum conditions of temperature, humidity, and storminess. Because of the combined effect of these climatic conditions the geographical distribution of civilization, or of human progress, is practically identical with the geographical distribution of what is here called climatic energy. In World Power and Evolution a somewhat intensive study of ten million deaths and a less intensive study of another forty or fifty million, shows two things; first, that health is apparently the means by which climate chiefly, though by no means exclusively, influences human progress, and second, that variations in health from year to year arise from variations in the weather and are probably the cause of certain variations in the conditions which combine to mold human progress. Recent investigations by Besson in Paris, and Roesle in Berlin, and by the Italians in Milan point to the same conclusion, and suggest that variations in health from year to year depend upon variations in the weather more than upon any other single cause.

These conclusions as to the effect of climate upon the distribution of human health and energy both geographically and chronologically lead to important practical applications. Some of the more obvious of these are set forth in Principles of Human Geography and Business Geography by means of a series of maps and other data. The geographical relationship is well illustrated by three maps of Europe published in the second of these volumes and reproduced here. The first is a map of the distribution of climatic energy. It shows the degree 


\section{xxii INTRODUCTION TO SECOND EDITION}

of strength and energy that people would have in different parts of Europe if their strength and energy depended wholly on climate. It is based largely on the evidence presented in this book with some modification, because later work shows that the

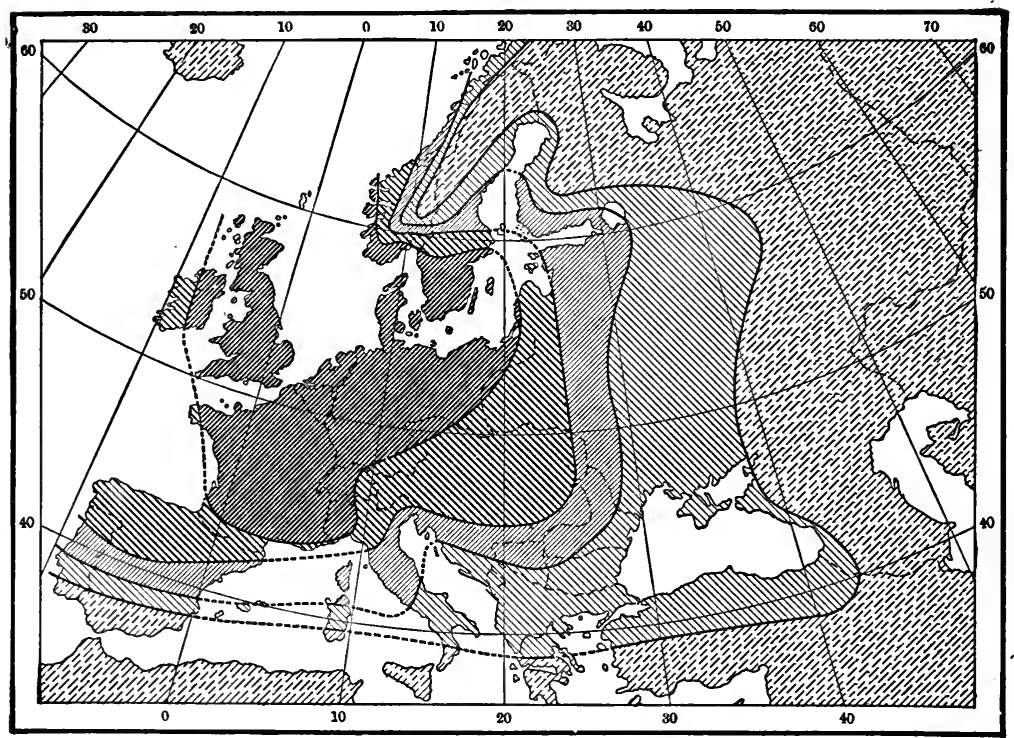

From Huntington and Williams" "Business Geography," by permission of John Wiley \& Sons, Inc.

Figure A. Distribution of Climatic Energy in Europe

optimum temperature for health is $64^{\circ}$ or $65^{\circ}$ rather than $60^{\circ}$ as was inferred from factory work. The second map shows the distribution of health. It is based on the official statistics of the various European countries for the years 1909-1913. Infants under one year of age and old people over seventy-five have been omitted because the figures for those groups, especially the infants, are unreliable. The data for other ages have been reduced to what is called a standard population, so that 
differences in age and in the proportion of children from country to country have been eliminated. The map shows the actual distribution of health in Europe under normal conditions. The third map illustrates the distribution of civilization. It is the

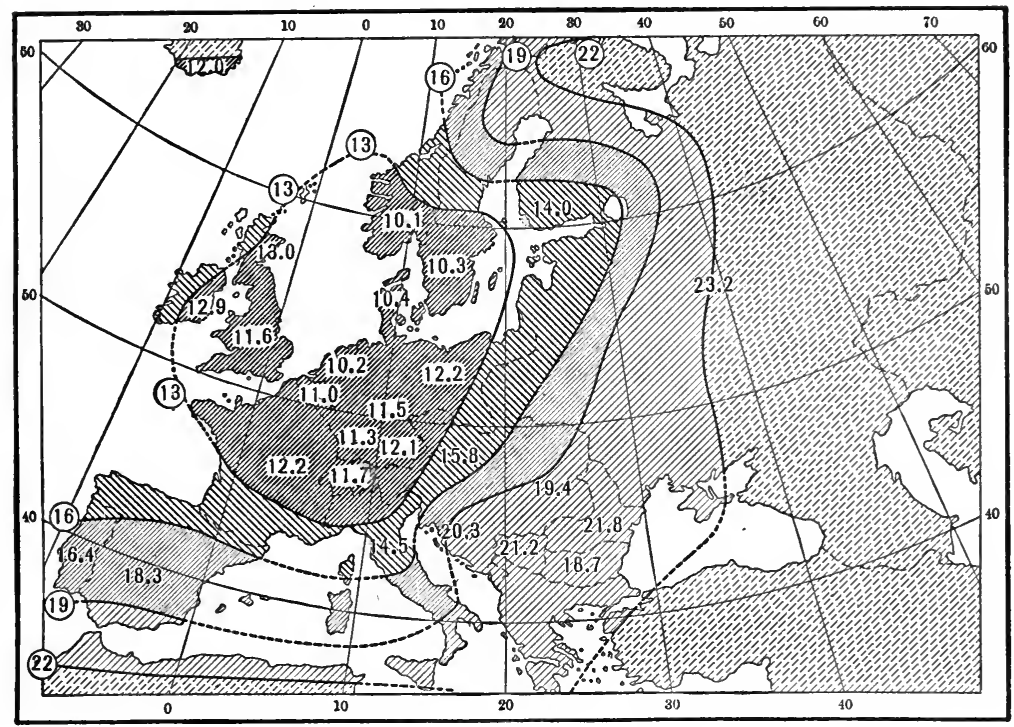

From Huntington and Williams' "Business Geography," by permission of John Wiley \& Sons, Inc.

Figure B. Distribution of Health in Europe

same as Figure 16 in the main part of this book, but is reproduced here in another form in order that it may easily be compared with the other two.

These three maps are so much alike that if the titles were removed, most people would not be able to tell which is which. In each map an area of heavy shading surrounds the North Sea, and shades off gradually in every direction. In each there are three projections of heavy shading, one toward Italy, a 


\section{xxiv INTRODUCTION TO SECOND EDITION}

second toward the Black Sea, and a third along the Baltic. The maps are so much alike that there can scarcely be any question as to the reality of their relationship. And that relationship can be of only one kind. Civilization and progress un-

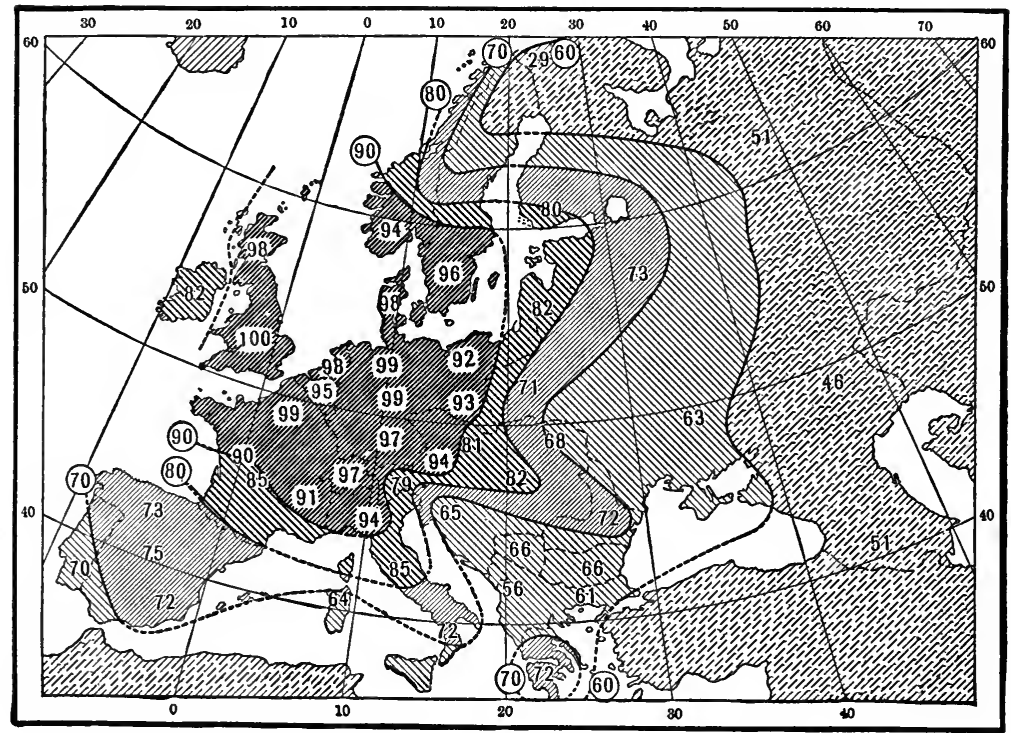

From Huntington and Williams' "Business Geography," by permission of John Wiley \& Sons, Inc.

Figure C. Distribution of Civilization in Europe

doubtedly influence health, and health in turn has an effect on progress. But neither civilization nor health can have any appreciable effect upon the distribution of climate. The only way in which the three maps can be so alike, unless by sheer accident, which is practically impossible, is for climate to exert a direct and dominating influence upon the distribution of health and an indirect and perhaps less dominating influence upon civilization through other agencies, such as agriculture. 
Since health means also energy, it must have an important direct effect upon progress and civilization, while progress in turn means a further reaction to cause improvement in health. The only reason why the geographical relation between climate,

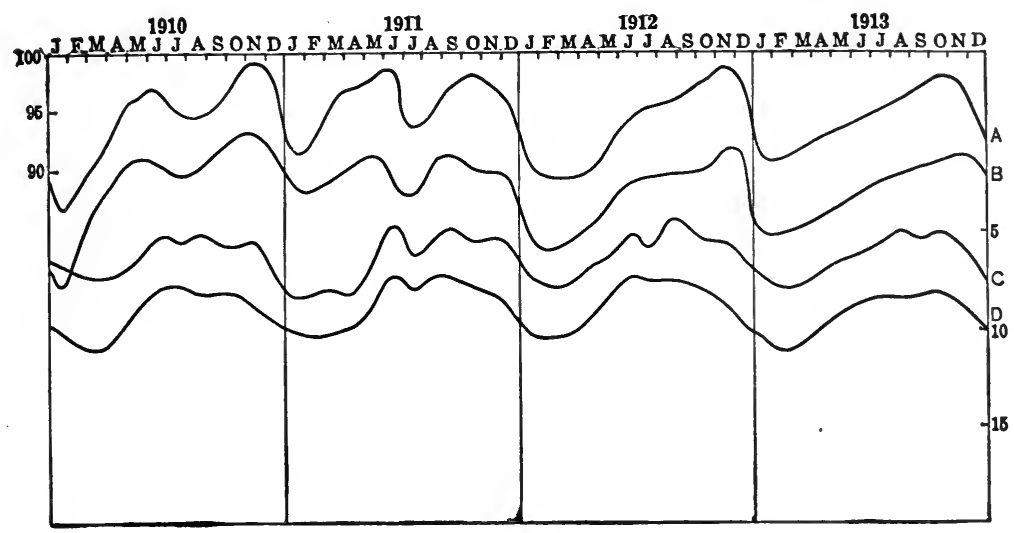

From Huntington and Williams' "Business Geography," by permission of John Wiley \& Sons, Inc.

Figure D. Seasonal Variations in Health and Energy in Connecticut and Pennsylvania

Work of factory operatives in (A) Connecticut and (B) Pennsylvania; health (death rate inverted) in (C) Connecticut and (D) Pennsylvania. Scale for (A) on left and (C) on right. (B) and (D) are placed below the others for convenience, although really belonging at essentially the same level.

health, and progress is less clear in other countries than in Europe seems to be the lack of exact data.

The chronological relation between climate and human energy is illustrated in Figure $\mathrm{D}$, which is also taken from Business Geography. The two upper curves are the same as the four upper pairs of curves in Figure 1 on page 59 of this book. That is, they represent seasonal variations in the work of factory operatives from 1910 to 1913 in western Connecticut 


\section{xxvi INTRODUCTION TO SECOND EDITION}

and Pittsburgh. The way in which the variations depend upon climate is shown at length in the body of this book. Putting the matter in another way, the curves illustrate the fact that man's energy fluctuates from season to season and year to year in response to the weather. The two lower curves in Figure D show the fluctuations in health, that is, the inverted death rates, in Connecticut and Pennsylvania. Their general agreement with the curves of work is obvious, as is the way in which the worst health lags a little after the lowest efficiency because it takes some time for bad conditions of weather to result in death. The only reasonable interpretation of the four curves seems to be that chronologically, as well as geographically, climate is a determining factor. It has a great influence upon health, health influences energy, and energy has much to do with efficiency and progress. Other factors indeed enter into the matter, but it is doubtful whether any other variable factor is at once so widespread and so constantly effective as climate.

A notable example of the effect of climate on health has recently been discovered by a Committee on the Atmosphere and Man appointed by the National Research Council of the United States. The appalling ravages of the influenza epidemic in 1918 have led many students to inquire why the severity of the disease varied so much from place to place. Pearl, Winslow, and others have compared the deaths from influenza and pneumonia during the epidemic with various environmental conditions such as the size of cities, the percentage of foreign-born, longitude, latitude, and the distance from Boston, where the epidemic began. They have also compared the epidemic with other conditions of health, such as the normal death rates from various diseases. By means of the precise and recently developed method of correlation coefficients, they have eliminated the effect of all except any one of these factors. The only environmental factor that seems to have an effect is latitude, and that is barely large enough to be significant. Among the 
other factors the normal death rates from respiratory diseases, heart disease, and all causes combined show an unmistakable correlation with the severity of the epidemic. Where the death rates are normally high the epidemic rose rapidly to a climax after it once started, and the number of deaths was large in proportion to the population.

The Committee on the Atmosphere and Man has carried this investigation farther. It finds that in the thirty-two cities of the United States for which data are available there is a marked correlation between the temperature for thirty days before the epidemic and the severity of the epidemic as measured by the numbers of deaths per thousand of the population. To put the matter technically, the correlation coefficients between the death rate per thousand and the temperature at various intervals before and after the beginning of the epidemic are as follows:

Days before or after beginning of epidemic

61 to 70 days before

51 to 60 days before

41 to 50 days before

31 to 40 days before

21 to 30 days before

11 to 20 days before

1 to 10 days before

1 to 10 days after

11 to 20 days after

21 to 30 days after

31 to 40 days after

41 to 50 days after

\section{Correlation \\ coefficient}

$+0.120$

$+0.102$

$+0.186$

$+0.213$

$+0.524$

$+0.510$

$+0.437$

$+0.166$

$+0.164$

$+0.284$

$+0.606$

$+0.359$
Probable error

$\pm 0.117$

$\pm 0.116$

$\pm 0.115$

$\pm 0.112$

$\pm 0.086$

$\pm 0.088$

$\pm 0.096$

$\pm 0.104$

$\pm 0.116$

$\pm 0.109$

$\pm 0.075$

$\pm 0.104$

For the non-mathematical reader it may be more illuminating to divide the thirty-two cities, and four others for which the data are not quite so complete, into four equal groups on the basis of their average temperature during the thirty days preceding the local outbreak of influenza in 1918. On this basis we get the following preliminary results: 


\begin{tabular}{|c|c|c|}
\hline $\begin{array}{l}\text { Average tempera- } \\
\text { ture for 30 days } \\
\text { before outbreak of } \\
\text { epidemic }\end{array}$ & $\begin{array}{l}\text { Approximate } \\
\text { population } \\
\text { in } \\
\text { 1920 }\end{array}$ & $\begin{array}{l}\text { Deaths from influ- } \\
\text { enza and pneumo- } \\
\text { nia per thousand } \\
\text { inhabitants during } \\
\text { ten weeks of the } \\
\text { frst outbreak of } \\
\text { influenza in } 1918\end{array}$ \\
\hline 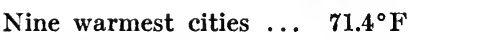 & $5,265,000$ & 6.1 \\
\hline Next nine cities ...... $66.7^{\circ}$ & $7,735,000$ & 4.2 \\
\hline Next nine cities $\ldots \ldots \ldots 62.9^{\circ}$ & $6,047,000$ & 3.1 \\
\hline Nine coolest cities $\ldots . .58 .3^{\circ}$ & $2,552,000$ & 2.9 \\
\hline
\end{tabular}

To return to the correlation coefficients, they show three remarkable features. First, all are positive, indicating that in general the warm parts of the United States, and the cities in cooler parts which happened to be especially warm before and during the epidemic, are the regions where the epidemic was most severe. Second, about thirty days before the outbreak of the epidemic the coefficients suddenly rise from insignificant to highly significant values. When the entire thirty days are considered as a single period, their mean temperature and the severity of the epidemic show a correlation coefficient of +0.581 . Third, the immediate onset of the epidemic was so severe that for three or four weeks the temperature had little effect on its severity. Nevertheless by the time the crisis was reached the temperature again exerted a pronounced effect, the correlation coefficient being $+\mathbf{0 . 6 0 6}$ for the thirtieth to the fortieth days, or eight times the probable error. When absolute humidity is used instead of temperature, and due weight is thus given both to temperature and atmospheric moisture, the coefficients become still higher, rising to more than ten times the probable error, which means a very intimate relationship. These coefficients are larger than any others yet found in the study of the causes of variations in the severity of the epidemic. When other climatic factors are also considered the coefficients rise stil! higher, as appears from the preliminary results. 
The significant fact about all this is that the severity of the great epidemic of 1918 seems to have depended upon the weather more than upon any other known cause. Apparently almost half and perhaps a larger share of the differences among the cities of the United States were due to the temperature and humidity of the air before and in the later stages of the epidemic. Where people were weakened by hot, damp weather, the influenza became virulent, it spread with great rapidity, and entailed a huge death roll not only from its own ravages, but from those of pneumonia. There is no reason to think that the action of the air upon human strength before the epidemic differed from its action at other times. Apparently it is a law of nature that the stamina of the human race varies enormously not only from place to place and season to season, but from one phase to another during a climatic pulsation.

We now come to the crux of the problem of Civilization and Climate, namely, the question of whether the climate of countries such as Greece really promoted health and energy appreciably more in the past than at present. Some indications along this line may be obtained from a study of places which now have climates similar to that which is supposed to have prevailed formerly in Athens, for example. In accordance with the conclusions already set forth, let us assume that since the days of Socrates the mean temperature of Athens has risen $1^{\circ}$ Fahrenheit, but that the summers have grown somewhat hotter and the winters cooler, as indicated by the following table: 


\begin{tabular}{|c|c|c|}
\hline \multicolumn{2}{|c|}{$\begin{array}{c}\text { Assumed Ancient } \\
\text { Temperature }\end{array}$} & $\begin{array}{c}\text { Present Mean } \\
\text { Temperature }\end{array}$ \\
\hline January $\ldots \ldots \ldots \ldots$ & $50^{\circ}$ & $46^{\circ}$ \\
\hline February $\ldots \ldots \ldots \ldots$ & $53^{\circ}$ & $49^{\circ}$ \\
\hline March $\ldots \ldots \ldots \ldots \ldots$ & $55^{\circ}$ & $52^{\circ}$ \\
\hline April $\ldots \ldots \ldots \ldots \ldots$ & $58^{\circ}$ & $58^{\circ}$ \\
\hline May $\ldots \ldots \ldots \ldots \ldots$ & $66^{\circ}$ & $68^{\circ}$ \\
\hline June $\ldots \ldots \ldots \ldots \ldots$ & $71^{\circ}$ & $76^{\circ}$ \\
\hline July $\ldots \ldots \ldots \ldots \ldots$ & $74^{\circ}$ & $81^{\circ}$ \\
\hline August $\ldots \ldots \ldots \ldots \ldots$ & $73^{\circ}$ & $80^{\circ}$ \\
\hline September $\ldots \ldots \ldots \ldots$ & $70^{\circ}$ & $74^{\circ}$ \\
\hline October $\ldots \ldots \ldots \ldots \ldots$ & $65^{\circ}$ & $66^{\circ}$ \\
\hline November $\ldots \ldots \ldots \ldots$. & $57^{\circ}$ & $57^{\circ}$ \\
\hline December $\ldots \ldots \ldots \ldots$. & $53^{\circ}$ & $50^{\circ}$ \\
\hline Average...$\ldots \ldots$. & 62.1 & 63.1 \\
\hline
\end{tabular}

The change thus indicated is no more than may characterize two successive years. Let us also assume that the relative humidity of ancient Athens averaged 20 per cent greater than that of today, while the rainfall exceeded the present amount by at least 50 per cent. The difference in storminess appears to have been even greater, perhaps double that of today, with a corresponding increase in the frequency of changes in temperature and cloudiness. The winds were likewise stronger and more variable than now. These assumptions, of course, are subject to modification as our knowledge increases, but they are reasonable estimates based on purely physical evidence without regard to how they may work out as to health and energy. In fact, the critic is perhaps less likely to question the estimates than to be sceptical as to whether such seemingly moderate changes can produce much effect on health.

No part of the world today possesses exactly the type of climate inferred in ancient Greece. Los Angeles, with an average temperature of $54^{\circ}$ in January and $72^{\circ}$ in July, and Sydney, Australia, $52^{\circ}$ in January and $72^{\circ}$ in July, are much like our inferred ancient Athens so far as temperature is con- 
cerned. Los Angeles, however, has less rain (13.9 inches) than was probably the case in ancient Athens, and Melbourne much more (48.0 inches). Moreover, neither has anything like so many cyclonic storms as had our supposed old Athens, and hence neither is subject to such brisk and changing breezes, such frequent though perhaps small changes of temperature, and such numerous alternations from sunshine to clouds. Thus, although Sydney and especially Los Angeles are considered unusually healthful, neither appears to equal ancient Athens in the stimulating qualities of its climate.

It would be most valuable if we could obtain some exact numerical measurement of how our postulated change of climate has influenced the health of Greece, but that is as yet impossible. Some idea of the nature of the effect, however, may be gained by studying what happens in modern cities from day to day in response to conditions similar to those which we have inferred in ancient and modern Greece, respectively. For example, under the auspices of the National Research Council's Committee on the Atmosphere and Man, an investigation of daily deaths and the weather has been made by the New York and the Metropolitan Life Insurance Companies. For five years in the early eighties, which are all that have yet been investigated, the insurance companies took the weather of each day and compared it with the deaths on the day in question and on each day for two weeks thereafter. Of course the effect of the weather of any given day is largely obliterated by that of succeeding days. Nevertheless, if the people of Athens were influenced exactly as are the people of New York, a change of temperature such as is indicated in the table given above would reduce the death rate at least 5.3 per cent and by enough more to make up for the difference between a permanent change and a change which lasts only a day or two. In the same way, if the Athenians responded to atmospheric moisture exactly as did the New Yorkers during the five years in question, the increased 
humidity which we have supposed in old Athens would reduce the death rate at least 4.0 per cent and perhaps much more.

The data now available do not warrant precise estimates of how the health of Athens has probably been affected by the supposed diminution in rainfall, in windiness, and in the number of storms and amount of variability of weather. There is much evidence, however, as is fully explained in World Power and Evolution, that all of these conditions tended to make the climate of ancient Athens more favorable than that of the modern city. It is probably conservative to say that reckoned on the same basis as temperature and humidity, the effect of these changes would be at least 6 per cent, giving a minimum total of 15 per cent for all the various climatic elements. But this figure ought almost certainly to be multiplied, perhaps several times, to allow not only for the fact that in Greece we are dealing with a relatively permanent change of climate instead of with little daily variations, as in New York, but also because of other factors. These include the much better conditions of agriculture and hence of diet in the past than at present, the better economic conditions arising from the improvements both in agriculture and in health, and the probable effect of purely physical causes in reducing diseases like malaria, hookworm, and pellagra. Taking all the factors into account it seems reasonable to suppose that a change from the present climatic conditions back to those of the days of Herodotus would reduce the Athenian death rate as much as 40 or 50 per cent. That is, it would make the conditions of health and vigor as good as those of modern England and the other countries around the North Sea. Of course this does not mean that the death rate was ever so low as in the modern countries, for sanitation and hygiene were backward. What it does mean is that the climate probably endowed ancient Greece and its neighbors with vigor and energy comparable with those of England and France today. Almost certainly whatever difference there is between the cli- 
mate of Greece now and four or five hundred years before Christ has tended in the direction here indicated. How far it would produce the results which we have inferred must be left to future investigation.

It must not be supposed that the stress laid upon climate in this book means that the author underrates other conditions. He believes firmly in training on the one hand and inheritance on the other. Two illustrations will show how these conditions are related to climate and may overrule its effects. Training is merely another name for man's social heritage. In an article on The Coldward Course of Progress, Gilfillan* has presented an interesting study of how this social heritage, in the form of a constantly growing command over nature, has enabled man to advance farther and farther into regions of low winter temperature. In a savage state, without fire, clothing, or shelter other than caves, he is not likely to thrive where the winter temperature remains for any length of time as low as freezing, and his main development is almost sure to be where the coldest months are not much below the physical optimum of $64^{\circ}$ or $65^{\circ} \mathrm{F}$. With each step of progress he is able to endure greater extremes of climate. The open fire, the grate, the stove, the furnace, and the central heating plant are all steps toward a condition where man is able to resist the cold no matter how severe it may be. The use of the skins of animals for clothing; the invention of the arts of spinning and weaving; the domestication of the sheep, goat, and camel; the cultivation of the flax plant, and especially cotton; the invention of power looms and of the steam engine; - all these are important steps which have tended to make man independent of climate. So too are the inventions which enabled mankind to close the mouths of the caves in which he lived, and then to build huts, thatch them,

* Political Science Quarterly, 1920. The same subject is discussed from another standpoint in Stefansson's The Northward Course of Empire, which appeared while this introduction was in press. 
cover them with close-fitting shingles, construct them of thick bricks, or otherwise make them warm and weatherproof. In like manner man's power to resist unfavorable climates has been increased by every invention that has made it possible to transport food cheaply and quickly, and to preserve it for long periods. Today it is not difficult for large communities to live in health and comfort in the cold parts of the earth where their naked ancestors would have perished in a few days. Human energy may perhaps ultimately rise higher in those regions than in others, for many of the diseases of warmer regions do not flourish there, and the constant changes from the warmth withindoors to the cold without seem to be highly stimulating and healthful provided they are properly guarded against. Moreover, in cold regions man can be free from the effects of undue heat against which he has thus far shown little ability to protect himself. Thus it appears that even without changes of climate the highest civilization would have tended gradually to migrate farther and farther north. How far this tendency will go is not yet clear, but the far northern location of such progressive people as the Scotch, Canadians, Swedes, Norwegians, Icelanders, and Finns seems to suggest that the limit has not yet been reached.

One other phase of GilFillan's work deserves careful notice. He points out that when civilization takes a backward step it also tends to move equatorward. For instance, about two hun-dred years before Christ the leadership of the world had passed from Greece, while Rome was falling into a state of confusion and retrogression from which its recovery was never complete, even in the days of Augustus. At that time the intellectual leadership went back toward the south, and the Alexandrines held aloft the torch of learning. They did not, to be sure, make any great intellectual or material innovations, but they at least kept the spirit of progress alive. In the same way in the Dark Ages the intellectual leadership of the world went back to North 
Africa where lived such men as Saint Augustine and his confreres.

GilFillan suggests an interesting explanation of what happens when the most progressive nations of any given period are suddenly thrown backward by barbarian invasions, climatic changes, or similar occurrences. At such times regions which have formerly ranked high stand out once more as leaders. When the cooler countries fall to a low estate, the eclipsed countries come into prominence. They still represent the highest type of civilization that is compatible with their climate, even though they have not been able to make that type appear great or important because the cooler and more energetic countries have not given them a chance. Thus in the Alexandrine period, when Greece had fallen and even Rome was at a low ebb, northern Egypt took the lead because the stage of progress to which the world had regressed was suited to Egypt's climate. How true this hypothesis may be, it is hard to say, but at least there seems to be much truth in the idea that man's social progress must constantly alter his relation to climate. In the past the greatest inventions have helped chiefly in enabling man to overcome low temperature; in the future perhaps they will help him in equal measure to overcome high temperature, dryness, and monotony.

The last matter to engage our attention in this introduction is the relation of climate to racial inheritance. China will serve as an example. One of the most remarkable facts about the Chinese is the contrast between their character and that of the nomads from whom they are descended. Let us confine ourselves for the present to northern China, chiefly the Hwang-ho basin. While the ancestry of the present inhabitants of that region is not entirely certain, it is known that nomads from central Asia have probably played a predominating part in building up the present race. The Manchus and Mongols are among the most recent examples of invaders from the Northwest. 


\section{xxxvi IN'TRODUCTION TO SECOND EDITION}

In a general way the nomads of all dry regions seem to possess certain distinct characteristics which become a part of their racial inheritance through the processes of natural selection. For example, steady industry is of little or no advantage to a nomad, whereas the power to make a sudden and desperate exertion for a short time is of the utmost value.

Anyone who has lived among nomads, as has been the author's fortune for several years, knows that in ordinary times there is almost nothing for the men to do except lie on the grass, eat, tell stories, go hawking, or play a violent game such as skinning a dead calf while galloping on horseback. The camels, sheep, or other animals meanwhile are feeding peacefully, and need no watching save that of a small boy. But suddenly the boy reports that a camel has fallen into a mudhole, that a band of sheep have strayed into a deep gully, that wolves have driven off half the horses. Or perhaps, on some dark night the nomads are waked by a watchman with word that raiders have driven off most of the animals. These are the occasions when a nomad has a chance to make or mar his fortune. He must be able on the instant to summon all his powers. He must also be able to endure hunger and cold, to run or ride all night, to ford raging glacial streams, to fight wolves or men, and in general to make a supreme effort for a limited length of time. Again, he must have the capacity to take the initiative if left to himself, and to cope with a situation which may develop new possibilities at any moment; in other words, he must have at least enough initiative so that when thrown on his own resources he will be able to cope with an emergency alone. The nomad must likewise be able to lead and command others if the duty falls on him, or to obey if someone else is leader. All these qualities are especially important in the raids which form a part of the lives of almost all nomads in dry regions. The power to lead and the ability to follow a leader are especially important. The modern Turk is perhaps a good example of this last quality. Incompetent as he. 
is in many ways, less clever than his Greek and Armenian enemies, more brutal and ignorant, a poorer business man and artisan, and a much more careless farmer, he nevertheless has the capacity to develop leaders, and when once a leader is accepted, to follow him. Where the Greeks and Armenians are squabbling as to who shall lead, the Turk who wants to be a leader is more often acting as a good subordinate, while the rank and file are obeying implicitly. It is no accident that throughout Chinese history the rulers have almost invariably been invaders who have recently come from nomadic stocks. The Manchus, Genghis Khan, Kublai Khan, Tamerlane, the Turkish Osman, and the Moguls in India are examples of the way in which the nomads have dominated other races in China and elsewhere.

At this point the question arises whether the qualities ascribed to the nomads are the result of racial or social inheritance. The answer seems to be that both types of inheritance play a part, but that after many generations of nomadism a genuine biological selection must take place so that the nomadic qualities become genuinely a racial inheritance. The man who is slow, patient and laborious, the one who is good at a bargain or is a good artisan is not the one who succeeds best. The bold adventurous man who dares cross a raging stream or fight a wolf to rescue his sheep; the one who is a good follower in a raid, and who later becomes a good leader; the one who is quickest to act and has the most initiative; he is the one whose children are best cared for; he is the one who gets the prettiest and most vigorous women as wives; and he is the one who is most likely to leave many healthy children to carry on his qualities.

When the nomads settle down in China what happens? A selective process begins at once. There is nothing a nomad hates more than a settled life of steady work. Suppose a migration due to drought or a great series of raids has caused many nomads to invade an agricultural district. Those who become 


\section{xxxviii INTRODUCTION TO SECOND EDITION}

rulers and proprietors may be willing to settle down. But among the rank and file the most competent from the nomadic point of view begin to drift back into their old life, for practically all nomads despise agriculture. They leave behind them the ones with less initiative, or with more of the steady, plodding, systematic qualities which make good farmers. As time goes on the selective process steadily tends to weed out those whose nomadic inheritance gives them the strongest tendency to rely on sudden exertion and to live idly except in some emergency. Anyone who has seen the unbelievably weedy and unkempt fields of nomads who are in process of settling down in Turkestan because of the advance of Russia will realize how poorly fed are the children of the farmers who have the nomadic character strongly developed. Under such conditions the members of the farming population who have the typical Chinese qualities of steady persevering industry are almost certain to be more prosperous than the rest. They are the ones whose children are well nourished: in a social system like that of the Chinese they are the ones who can have more than one wife and can buy the daughters of their more improvident neighbors. Thus there is a steady tendency for the nomadic type of character to be weeded out, and for the nomads who have most of what we now call the Chinese character to persist.

Among the upper classes, to be sure, the nomadic power of leadership and initiative is more likely to be preserved than among the lower classes. But here the social system of the Chinese has a pronounced effect. In a feudal system, such as that of Japan, the men may take concubines among the lower classes, and thus their traits of leadership be somewhat disseminated among the masses; but the women always marry in their own class. Thus the upper class retains its individuality and its power to dominate. In China, however, the democratic system of universal education steadily tends to make the upper classes share the qualities of the lower classes. Not only are children of men of 
the upper classes by women of the lower classes admitted to marriage with the upper classes far more freely than in Japan, but pure-bred girls of the dominant groups are given in marriage to men of any class who by persistent study in the old Chinese fashion have raised themselves to high positions. 'This may have many good effects, but it apparently tends little by little to cause the qualities of the vastly numerous lower classes to penetrate and in time dominate the upper classes also. Thus the Chinese social system cooperates with the climatic factors which control agriculture to diminish the power of originality and especially of leadership which is strongly developed in the nomads.

Another climatic factor also tends to give the Chinese a peculiar racial inheritance. Nowhere else, not even in India, are the famines more severe than in the Hwang-ho valley. The rainy period there is limited to a few months in summer, chiefly from May to September. In the frequently recurring dry seasons the rains may fail to come until June or even July, and not infrequently the crops that depend directly on the rain are a partial or complete failure over large areas. Many farmers, however, rely on irrigation, and their crops survive the dry weather. But the general rule is that after a drought comes the flood, and north China is a particularly good illustration of this rule. Violent showers falling on the steep slopes of the mountains, as well as on the fields of the lowlands, produce floods which destroy a large part of the irrigated crops. Thus drought and flood together produce famines which often plunge tens of millions of people into desperate straits.

It is a biological axiom that such a famine, with its high death rate, must exercise some sort of selection whereby certain types die and others survive. In order to determine what sort of selection occurs I have consulted various authorities on China, especially famine workers. Professor Harlan P. Beach and Dr. Arthur H. Smith have been especially kind in furnishing sug- 
gestions, while Rev. Henry S. Leiper and Rev. Robert E. Chandler, both of Tientsin, have taken great pains not only to answer my questions but to procure answers from eight or ten other men thoroughly familiar with Chinese famines. Thus it is possible to arrive at a fairly accurate consensus of opinion. Take a typical famine in the old days before there was any such thing as organized relief. It afflicted perhaps ten or twenty million people severely and twice as many to a less extent. The upper classes and all whose economic condition was good at the beginning of the famine generally survived without much difficulty. The rest of the people fall into two groups. One group consists of those who have less initiative and energy. They stay at home and try to exist as best they can until new crops can be raised next year. Those with the best physique and the greatest mental ability are of course most likely to survive with their children. But given two families of equal strength and ability in other respects, the one that is most economical, most self-denying, most self-controlled in apportioning out the scanty rations to last till the next harvest will survive. An advantage will also be reaped by those who are slowest in their activities,--those who lie in bed till perhaps ten o'clock, eat a single meal of rough flour mixed with husks and straw and then go back to bed at three o'clock during the winter days when no work can be done on the farm. That is what many Chinese do, and they are more likely to survive than those who restlessly spend all day trying in vain to get more food. Selfishness, or self-centeredness, and callousness to the sufferings of others are generally agreed upon as qualities promoted by famines.

The other group consists of the people having more initiative, energy, inventiveness, and power of leadership. They migrate, either to other parts of the country where the famine is not so bad, or to the cities. Thus the more progressive elements are drained from the country districts. If they came back no harm would be done, but many fail to return. If the migrants suc- 
ceed in regions where there is no famine, it is by no means uncommon for them to settle there either with the families that they have brought with them, or with new wives. In the cities another element enters into the matter. Oriental cities are notoriously unhealthful. Unless recruited from outside, the cities of the orient, and until recently even those of the occident, would not be able to maintain themselves. Most Chinese cities would almost disappear within a century if no one came to them from outside. Even in the United States the cities which have no special advantage, such as location near the ocean or a large lake, have a death rate about 25 per cent greater than that of the surrounding rural areas. Thus in China the energetic peasants who leave the farms and settle in the cities almost die out in a few generations. They are lost to their homes just as are those that migrate to other regions. The net result of the famines seems to be that there is a premium upon the following qualities: physical strength, endurance, economy, frugality, industry, patience, self-control, self-centeredness. On the other hand, in the lower and middle classes there is a strong tendency for migration to weed out those who have initiative, inventiveness, energy, restlessness, the adventurous spirit, and certain other qualities which tend to make men leaders in one way and another. These selective processes do not directly affect the upper classes, but the social custom of selling girls as servants and concubines, and of encouraging the rise of promising young men who have the capacity for extreme application, perfect memory, and assiduous work rapidly cause the qualities of the lower classes to become more or less common among the upper classes. There is little in all this to foster constructive leadership, originality, and inventiveness, much to foster the kind of character which makes men marvellously industrious, tough, and conservative.

Thus far we have been speaking chiefly of the northern Chinese. There is a great difference between the North and the 
South, a difference which the Chinese themselves frequently point out. The South is relatively alert, progressive, inventive, and restless; the North is slow, conservative, reliable, and uninventive. This largely accounts for the fact that practically all the Chinese in America are from the South, chiefly from Canton. Such a contrast between North and South is the opposite of what one would expect on the basis of the direct effect of climate, and the opposite of what we find in other countries with similar temperatures. But in this lies one of the strongest proofs of the correctness of our reasoning as to the indirect effects of climate through racial inheritance. North China is the part that has famines; South China never has such famines as prevail farther north; at worst it merely has periods of mild distress. Thus through the centuries South China has been receiving a steady, although perhaps small stream of the more energetic and progressive northerners. It has not gained a tithe perhaps of what the North has lost, but it has gained enough so that the famines may be counted a factor in the progressive tendencies of the South and in its ability to furnish leaders and reformers to a degree unknown in the North.

Here, then, is our final conclusion. China, like many other countries, illustrates the power of climate, of social inheritance, and of racial inheritance. But all three are so intertwined that it is extremely hard to separate them. China, in a general way, has about the degree of progress that would be expected on the basis of its climate, but there is a peculiar reversal between the South and the North. The influx of nomads again and again into the North would be expected to have given that region the power of initiative and leadership which the dry climate helps to select for preservation in the desert. But other climatic conditions acting through agriculture and famines tend to weed out the qualities of leadership and inventiveness in the North, and to give the South part of what is thus lost. A peculiar social system increases this tendency not only because 
of the character of the cities, but by facilitating the mixture of the upper and lower classes. If this book were to be rewritten the chief change would be to emphasize and clarify the constant interplay between physical environment on the one hand_and. racial inheritance on the other, for these two largely determine the capacities of a race, and form the background upon which and in harmony with which the social, political, and religious systems are worked out. 
CIVILIZATION AND CLIMATE 
(今)

3
$\because$ 


\section{CHAPTER I}

\section{Civilization and Climate}

The races of the earth are like trees. Each according to its kind brings forth the fruit known as civilization. As russet apples and pippins may grow from the same trunk, and as peaches may even be grafted on a plum tree, so the culture of allied races may be transferred from one to another. Yet no one expects pears on cherry branches, and it is useless to look for Slavic civilization among the Chinese. Each may borrow from its neighbors, but will put its own stamp upon what it obtains. The nature of a people's culture, like the flavor of a fruit, depends primarily upon racial inheritance which can be changed only by the slow processes of biological variation and selection.

Yet inheritance is only one of the great factors in the development of civilization. Religion, education, government, and the many human institutions and customs which surround us form a second great group of influences whose power seems almost immeasurable. They do for man what cultivation does for an orchard. One tree may bear a few wormy, knotty little apples scarcely fit for the pigs, while another of the same variety is loaded with great red-cheeked fruit of the most toothsome description. The reason for the difference is obvious. One tree grows in a tangle of bushes in thin, unfertilized soil, and the other in the midst of a carefully tilled garden. One is burdened with dead wood and suckers, and infested with insects, while the other is carefully pruned, scraped and sprayed. 
In spite of the most careful and intelligent cultivation, a tree of the finest variety may fail to produce good fruit. Too much rain or too little; prolonged heat or constant cloudiness; frost when the blossoms are opening, or violent wind and hail may all be disastrous. The choicest tree without water is worth less than the poorest where the temperature and rainfall are propitious.

For the production of good fruit the three factors of good stock, proper cultivation, and favorable climatic conditions are absolutely necessary. Are they equally essential to the fruit known as civilization? We all admit that race and the thing which for lack of a better name we call cultivation or training are of vital importance, but is it also true that man cannot rise to a high level except where the climate is propitious? From the days of Aristotle to those of Montesquieu and Buckle, there have been men who have believed that climate is the most important factor in determining the status of civilization. Others have held that wherever food is available for a moderately dense population and man can avoid diseases like tropical malaria, human culture can rise to the highest levels. The location of the world's great nations seems to them largely a matter of accident.

The majority of people reject both of these extreme views. Few doubt that climate has an important relation to civilization, but equally few consider it so important as racial inheritance, or as good institutions in the form of church, state, and home. We realize that a dense and progressive population does not live in the far North or in deserts simply because the difficulty of getting a living grinds men down and keeps them isolated. We know that the denizens of the torrid zone are slow and backward, and we almost universally agree that this is connected with the damp, steady heat. We continually give concrete expression to our faith in climate. Not only do we talk about the weather more than about any other one topic, 
but we visit the seashore or the mountains for a change of air. We go South in winter, and to cool places in summer. We are depressed by a series of cloudy days, and feel exuberant on a clear, bracing morning after a storm. Yet, in spite of this universal recognition of the importance of climate, we rarely assign to it a foremost place as a condition of civilization. We point out that great nations have developed in such widely diverse climates as the hot plains of Mesopotamia and Yucatan and the cool hill country of Norway and Switzerland. Moreover, although Illinois and southern Mongolia lie in the same latitude and have the same mean temperature, they differ enormously in civilization. To put the matter in another way, we recognize two great sets of facts which are apparently contradictory. We are conscious of being stimulated or depressed by climatic conditions, and we know that as one goes northward or southward, the distribution of civilization is closely in harmony with what we should expect on the basis of our own climatic experiences. Nevertheless, even in our own day, regions which lie in the same latitude and apparently have equally stimulating climates differ greatly in their degree of civilization. When we compare the past with the present, we find the same contradiction still more distinctly marked. Hence our confusion. From personal experience we know that climate is of tremendous importance. Yet many facts seem to indicate that its importance is less than our observation would lead us to anticipate.

The reason for this doubtful attitude can easily be discovered. The things that we call facts are often not well established. Although we believe in the influence of climate, we know little of the particular climatic elements which are most stimulating or depressing. How much do we know of the relative importance of barometric pressure, wind, temperature, or humidity? What about the comparative effects of the climates of England and southeastern Russia? In addition to 
this, we are far from knowing what type of climate prevailed in Egypt, Greece, or Mesopotamia when they rose to eminence. Many good authorities assert that the climate of those regions was the same two or three thousand years ago as now. This view is rapidly losing ground, but those who believe in a change are not certain of its nature. They are completely in the dark as to whether it has produced an important influence upon the particular climatic elements which are most stimulating to the human system.

This book is written because recent investigations may enable us to explain the contradictions which have hitherto proved so puzzling. On the one hand, a study of the daily work of several thousand factory operatives and students at all seasons has given an approximate measure of the exact climatic elements which most influence efficiency. On the other hand, a prolonged study of past and present climatic variations suggests that the location of some of the most stimulating conditions varies from century to century, and that when the great countries of antiquity rose to eminence they enjoyed a climatic stimulus comparable with that existing today where the leading nations now dwell. In other words, wherever civilization has risen to a high level, the climate appears to have possessed the qualities which today are most stimulating.

The steps which have led to this conclusion may be briefly sketched. In 1903, under the inspiration of the broad vision of Raphael Pumpelly and the careful scientific methods of William Morris Davis, I began to study the climate of the past. Two years' work with the Pumpelly Expedition sent to Turkestan by the Carnegie Institution of Washington led to the conviction that Reclus, Kropotkin, and others are correct in believing that two or three thousand years ago the climate of Central Asia was moister than now. Later, during the Barrett Expedition to Chinese Turkestan, it became evident that the scientists who hold that the ancient climate was like 
that of today have much strong evidence to support their view. It soon appeared, however, that evidences of moist and dry conditions, respectively, are grouped into distinct periods, the beginning of the Christian era being moist, for example, and the seventh century dry. This led to what I have called the "pulsatory hypothesis" which holds that although in general the past was moister than the present, the changes have taken place irregularly in great waves. Certain centuries were apparently drier than today, while others were moist. In 1909 this view was confirmed during the Yale Expedition to Palestine. Then a series of journeys in the drier parts of the United States and in Mexico and Central America in coöperation with D. T. MacDougal of the Desert Botanical Laboratory of the Carnegie Institution showed that the main features of previous conclusions apparently apply to the New World as well as the Old. It also became evident that the climate of different parts of the world has probably changed in different ways. For example, Yucatan appears to have become moist when California became dry.

Having reached this conclusion, the next step was to study the mechanism and cause of the supposed changes. In Palestine variations in storminess and rainfall, rather than in temperature, appear to have been the primary factor. In America the Maya ruins of Yucatan and Guatemala, and a series of measurements of the growth of the big trees of California make this conclusion appear the only feasible one. They also indicate that climatic pulsations probably consist of a shifting of the earth's climatic zones alternately toward and away from the equator, a view recently advocated by the German geologist, Penck. Thus the temperate zone of storms is shifted back and forth. When it was farther south than at present, the subtropical countries which now are subarid must have been relatively moist. Still farther south the arid belt was shifted 
toward the equator so that lands which now are wet were then apparently dry.

If climatic changes have occurred during historic times, they must have had an effect on man. To all students of the subject, one of the most interesting features has always been the

d apparent connection between climate and history. Kropotkin, for instance, has vividly portrayed the way in which a gradual dessication of Asia would drive into Europe the hordes of barbarians whose invasions were so important a feature of the Dark Ages. If the pulsatory hypothesis is true, the relationship between historic events and climatic vicissitudes is even greater than has been supposed. Many of the great nations of antiquity appear to have risen or fallen in harmony with favorable or unfavorable conditions of climate. Such changes may produce their effect in various ways. Not only are the people of dry regions, especially the nomads, forced to migrate in periods of drought, but increasing aridity, even in more favored places such as Greece, must cause economic distress, and thus engender famine, misery, and general discontent and lawlessness. Certain climatic conditions also have a great influence upon diseases like malaria, and upon health in general, thus seriously diminishing the vitality of a nation.

It is noteworthy that at times of favorable climate in countries such as Egypt and Greece the people were apparently filled with a virile energy which they do not now possess. Many authorities attribute the loss of this to an inevitable decay which must overtake a nation, as old age overtakes an individual. Others ascribe it to the lack of adaptability in various institutions, to increasing luxury, to contact with inferior civilizations, or to various other factors, all of which are doubtless of much importance. Previous to 1911 I had often wondered whether 0 . Fraas and others might be right in connecting this with climate, but they gave so few reasons and the whole matter seemed so doubtful that $I$ had little faith in 
their suggestions. At that time, Charles J. Kullmer sent me a manuscript in which he called attention to the remarkable similarity between the distribution of cyclonic storms and of civilization. His article was never published, but was presented at a meeting of the Association of American Geographers. He advanced the idea that the barometric changes which are the primary cause of storms, or perhaps some electrical phenomena which accompany them, may produce a stimulus which has much to do with the advancement of civilization. Although he presented no definite proof, his suggestion seemed so important, that I determined to carry out a plan which had long been in mind. This was to ascertain the exact effect of different types of climate by means of precise measurements. Dexter, in his book on "Weather Influences," had made a beginning. Lehmann and Pedersen had made a small series of measurements whose highly suggestive results have been published under the title "Das Wetter und unsere Arbeit." A few physicians and students of child psychology were also at work, and their results have been summed up in such publications as Hellpach's "Geopsychische Erscheinungen" and Berliner's "Einfluss von Klima, Wetter und Jahreszeit auf das Nerven- und Seelen-leben." Nevertheless, there existed no large series of measurements of the actual efficiency of ordinary people under different conditions of climate.

The ideal way to determine the effect of climate would be to take a given group of people and measure their activity daily for a long period, first in one climate, and then in another. This, however, would not be practicable because of the great expense, and still more because the results would be open to question. If people were thus moved from place to place, it would be almost impossible to be sure that all conditions except climate remained uniform. If the climate differed markedly in the two places, the houses, food, and clothing would also have to be different. Social conditions would change. New inter- 
ests would stimulate some people and depress others. Hence, no such experiment now seems practicable. The most available method is apparently to take a group of people who live in a variable climate, and test them at all seasons. The best test is a man's daily work, the thing to which he devotes most of his time and energy. Accordingly, I have taken the records of over five hundred factory operatives in the cities of New Haven, New Britain, and Bridgeport, in Connecticut, three or four thousand operatives in southern cities from Virginia to Florida, and over seventeen hundred students at the United States Naval Academy at Annapolis, and the Military Academy at West Point. In most cases each person's record covers an entire year, or at least the academic year. All the records have been compared with the various conditions of the weather. The results are surprising. Changes in the barometer seem to have little effect. Humidity possesses a considerable degree of importance, but the most important element is clearly temperature. The people here considered are physically most active when the average temperature is from 60 to 65 degrees, that is, when the noon temperature rises to 70 degrees or even more, This is higher than many of us would expect. Mental activity reaches a maximum when the outside temperature averages about 38 degrees, that is, when there are mild frosts at night. Another highly important climatic condition is the change of temperature from one day to the next. People do not work well when the temperature remains constant. Great changes are also unfavorable. The ideal conditions are moderate changes, especially a cooling of the air at frequent intervals.

The facts just stated are of great significance. From the data described in this book I shall construct a map showing how human energy would be distributed throughout the world if all the earth's inhabitants were influenced as are the people of the eastern United States. We shall find that this agrees to a remarkable extent with a map of civilization based on the 
opinions of about fifty geographers and other widely informed men in a dozen countries of America, Europe, and Asia. Moreover, by reconstructing the climate of the past, it will appear that when the various nations of antiquity were in their prime, they were probably blessed with climates which shared the stimulating qualities which now prevail where civilization is highest.

In concluding this first chapter I cannot refrain from expressing astonishment at the way in which the various lines of investigation fit into one another. When the work was begun I had no idea what the outcome would be. One thing led to another, and now the final results seem explicable only on an hypothesis so sweeping in character that I advance it with genuine hesitation. The hypothesis, briefly stated, is this: Today a certain peculiar type of climate prevails wherever civilization is high. In the past the same type seems to have prevailed wherever a great civilization arose. Therefore, such a climate seems to be a necessary condition of great progress. It is not the cause of civilization, for that lies infinitely deeper. Nor is it the only, or the most important condition. It is merely one of several, just as an abundant supply of pure water is one of the primary conditions of health. Good water will not make people healthy, nor will a favorable climate cause a stupid and degenerate race to rise to a high level. Nevertheless, if the water is bad, people cannot retain their health and strength, and similarly when the climate becomes unfit, no race can apparently retain its energy and progressiveness. This does not mean that we are hopelessly at the mercy of the changes of climate which any century may bring forth. On the contrary, if our diagnosis is correct, we may at last hope to be free from the withering blight which has overtaken every race from which the stimulus of a good climate has been removed. Here, again, the case is like that of a water supply. Suppose that a community had for generations been subject to repeated visita- 
sions of a dread disease which decimated the population. Suppose that it should be discovered that the disease arose from the drinking water. Finally, let the community learn that the water is infested with the bacteria which cause typhoid fever. If no other water supply were available, would there be reason for despair? The disease would be no worse than before, and there would be hope of finding some way of protecting the water from contamination. So it is with climate. For ages the world appears to have been suffering because one of the many conditions of progress has changed repeatedly from century to century. The disease has been clear enough, and we have devised many helpful ways of treating the patients, although none has as yet proved highly satisfactory. This does not mean that the treatment has been wrong, or that we cannot ultimately succeed. It merely means that the neglect of one particular phase of the natter has prevented the other helpful measures from producing their full effect. If nature does not provide the stimulus which seems so effective elsowhere, man must himself provide it. 


\section{CHAPTER II}

\section{Race or Place}

The problem which confronts us is primarily to separate the effects of race from those of place, heredity from environment. It may be made concrete by comparing two of the world's most sharply contrasted races, Teutons and negroes. Suppose that there were two uninhabited Egypts, exactly alike, and that one could be filled with negroes and the other with Teutons. Suppose that these settlers were average members of their races, and were equipped with the same religion, education, government, social institutions, and inventions. This might easily happen if the negroes came from the United States. Suppose, further, that neither race received new settlers from without. Which would succeed best? "The Teutons, of course," is the answer. "What a foolish question." But is it so foolish? You are thinking of the first few generations. I am thinking of the twentieth or thirtieth or later. Does anyone know what five hundred or a thousand years of life in Egypt would do for either Teutons or negroes if no new blood were introduced?

At the end of that time the two sets of people would assuredly be different, for the effect of a diverse inheritance would last indefinitely. The advantage in this respect would presumably be on the side of the Teutons. I wish to emphasize this matter, for I shall have much to say about the effect of climate, and I want to take this opportunity to show that I do not underrate the importance of race. Although the matter is by no means settled, many authorities think that the brain of the 
white man is more complex than that of his black brother. Strong, in the Pedagogical Seminary for 1913, and Morse, in the Popular. Science Monthly for 1914, have shown that in Columbia, S. C., the white children are mentally more advanced than the colored. By applying the Binet tests to 225 children in two white schools and to 125 children in a colored school, they obtained the following table, showing the amount by which the two races exceeded or fell short of what would be expected.

More than one year backward, COLORED

WHITE

Satisfactory, $29.4 \%$ $10.2 \%$

More than one year advanced,

Among the white children those from the middle classes made a better showing than those of factory operatives, but both were ahead of the colored. So far as home environment is concerned, the factory children have almost no advantage over the colored children. A slight advantage may possibly arise from the fact that when the Binet tests were originally devised, they were designed to measure the capacities of white children. The negro race may have capacities which the white does not possess and which do not play a part in the tests. In appreciation of humor, for example, and in equability of temperament there can be little question that the black man surpasses the white. These things, however, can scarcely account for the fact that 29.4 per cent of the colored children showed a mental development more than a year behind that which would be expected from their age, while only 10.2 per cent of the white children were equally backward.

So far as I am aware, every exact test which has been made on a large scale indicates mental superiority on the part of the white race, even when the two races have equal opportunities. For example, in Washington the colored children remain in 
school quite as long as the white, but they do not accomplish so much in the way of study and do not reach so high a grade. In the cities of the South, Mayo and Loram find that where the races are given essentially the same instruction, the proportion of whites who are promoted is greater than that of negroes. Moreover, the difference seems to increase with years, which suggests that the average colored child not only stands below the average white child in mental development at all ages, but ceases to develop at an earlier age. In the high schools of New York, the superiority of the white race is shown by Mayo's examination of the average marks. By the time the children reach the high school, the processes of promotion have weeded out a much larger proportion of colored children than of white. Hence, the negroes form a specially selected group whose superiority to the average of their race is more marked than the superiority of the white high school children when compared with the rest of the white race. Nevertheless, the average marks of the white children are distinctly higher than those of the colored.

In order to test the capacity of the two races in a wholly different way, I have made a comparison of white and colored workmen employed under precisely similar conditions. The first case was a cigar factory at Jacksonville, Florida. The employees were practically all Cubans. Both the whites and the blacks have very little education, and their home environment in Cuba differs to only the smallest extent. They earn good wages, but are often out of work, and are generally shiftless and unreliable. There is, of course, no color line in Cuba, and the same is true in the cigar factories. Black men and white work side by side at the same tables. In such a factory, if the black man is as capable as the white he has exactly as good a chance, for he is paid by the piece, and his earnings depend entirely on himself. What, then, do we find? Taking all the operatives, we have 39 white and 65 negroes. 
Their average earnings, as measured by the wages of two weeks, are in the ratio of $\mathbf{1 0 0}$ for the whites to only $\mathbf{5 1}$ for the negroes. To make the comparison more favorable to the negroes, let us eliminate those who roll low-grade cigars where little skill is required and the pay is low. We then have 39 white men and 44 negroes. They are doing exactly the same work under exactly the same conditions, but the whites earn a dollar where the negroes earn 75 cents. At a similar factory at Tampa, Florida, 17 colored men were at work and 303 white. In this case practically all of the few negroes happened to be men of long experience, while many of the whites were comparatively new. Nevertheless, the whites are still on a par with the colored men, the ratio being 100 to 99.8 .

One of the best places for comparing the two races is the Bahama Islands. For reasons which I shall present later, the process of making "poor whites" has probably gone farther in the Bahamas than in almost any other Anglo-Saxon community. Part of the white people are like their race in other regions, but a large portion have unmistakably degenerated. Witness their intense and bigoted speech, their sunken cheeks and eyes, their sallow complexion, and their inert way of working. In spite of racial prejudice, there is no real color line in the Bahamas. Persons with more or less negro blood are worthy occupants of the highest positions, and are universally accepted in the most exclusive social circles. The British government gives the negro every possible opportunity. The state of affairs may be judged from the remarks of a "poor white" sailor, who said to me: "You want to know why I likes the southern states better than the North. It's because they hates a nigger and I hates him, too. What kind of a place is this where they do everything for the nigger and nothing for the white man? It's bad enough to have to go to jail, but it's pretty hard for a white man to be taken there by a nigger constable." In one Bahaman village I saw negro girls teaching white children 
in the public schools. In that same village a number of the leading white men cannot read or write. When they were children their parents would not send them to school with negroes. The despised negroes learned to read and write, but have now largely forgotten those accomplishments. The proud whites grew up in abject ignorance. Today the same thing is going on. I visited two villages where the white children are staying away from school because they will not go to negro teachers. The homes of such whites are scarcely better than those of their colored neighbors, and their fathers are called "Jim" and "Jack" by the black men with whom they work. Racial prejudice apparently works more harm to the whites than the blacks. So far as occupations go there is no difference, for all alike till the soil, sail boats, and gather sponges.

When the lumber industry was introduced into the islands, whites and blacks were equally ignorant of the various kinds of work involved in cutting trees and converting them into lumber. The managers did not care who did the work so long as it was done. They wanted three things, strength, docility or faithfulness, and brains. They soon found that in the first two the negroes were superior. Time and again persons in authority, chiefly Americans, but also some of the more capable native whites, told me that if they wanted a crew of men to load a boat or some such thing, they would prefer negroes every time. The poor white shirl: more than the colored man, he is not so strong, and he is proud and touchy. Other things being equal, the negro receives the preference. But other things are not equal. The very men who praised the negroes generally added: "But you can't use a negro for everything. They can't seem to learn some things, and they don't know how to boss a job." The payroll reflects this. Even though the negroes receive the preference, the 400 who are employed earn on an average only about 60 per cent as much as the 57 white 
men. If we take only the $5 \%$ most competent negroes, their average daily wages are still only 88 per cent as great as those of the native whites. The difference is purely a matter of brains. Although the white man may be ignorant and inefficient, with no more training than the negro, and although his father and grandfather were scarcely better, he possesses an inheritance of mental quickness and initiative which comes into evidence at the first opportunity.

All these considerations seem to point to an ineradicable racial difference in mentality. As the plum differs from the apple not only in outward form and color, but in inward flavor, so the negro seems to differ from the white man not only in feature and complexion, but in the workings of the mind. No amount of training can eradicate the difference. Cultivation may give us superb plums, but they will never take the place of apples. We have tried to convert the black man into an inferior white man, but it cannot be done. Initiative, inventiveness, versatility, and the power of leadership are the qualities which give flavor to the Teutonic race. Good humor, patience, loyalty, and the power of self-sacrifice give flavor to the negro. With proper training he can accomplish wonders. No one can go to a place like Hampton Institute without feeling that there is almost no limit to what may be achieved by cultivation. In an orderly, quiet way, those negro boys and girls go about their daily tasks and give one the feeling that they are making a real contribution to the world's welfare. To be sure, they work slowly, they are not brilliant in their classes, they rarely have new ideas in their manual work, but yet they are faithful. The willing, happy spirit of their work is something that we nervous, worried white people need sorely to learn. Once in a long time there comes a leader, a man to whom both white and black look up, but such leadership is scarcely the genius of the race. Yet leadership is what the black man must have. At such places as Hampton he gets it, and one realizes that the 


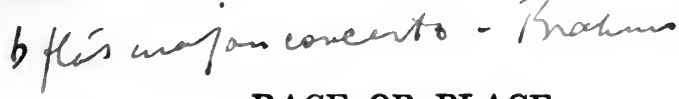

white man's initiative joined to the Christian spirit which is there so dominant can give a training which overcomes much of the handicap of race.

Having turned aside to pay tribute to the potency of race, education and religion, in determining the status of civilization, let us come back to physical environment. What part does this play? Is it so important that a strong race in an unfavorable climate is likely to make no better showing than a weak race in a favorable climate? How far can a bad climate undo the effect of a good training?

In answer to these questions, we may well compare the Teutonic and negro races when each is removed from the climate in which it originally developed. Before proceeding to this a word should be added to forestall any possible misunderstanding of my attitude toward the southern parts of the United States and toward other progressive regions which, nevertheless, suffer somewhat from climatic handicaps. In searching for the truth I shall be forced to say some things which may not be wholly pleasing to residents of such regions. It must be clearly understood, however, that these are not stated on my own authority. All are based either on the consensus of opinion among a large number of persons including many southerners, or upon the exact figures of the United States census or other equally reliable sources. My part has been simply to interpret them. Believing that in all essential matters of inheritance and of ability the people of the South average as high as those of the North, I have tried to find out why the southern part of the United States had prospered less than the northern. This does not mean that I reject the old ideas as to the cause, but simply that I emphasize another which has not received sufficient consideration. It does not discredit the South nor its people. It does not alter the fact that southerners possess a courtesy and thoughtfulness which we of the worried and hurried North need greatly to imitate. Nor does it mean that 
men of genius are not as likely to be born in one section as another. Instead of this, it merely indicates that in addition to the many efforts now being made to foster progress in the South by other means, we should add a most vigorous attempt to discover ways of overcoming the handicap of climate. This book is written with the profound hope that the truth which it endeavors to discover may especially help those parts of the world whose climate, although favorable, does not afford the high degree of stimulation which in certain other restricted areas is so helpful.

Let us first undertake a study of what the census shows as to negroes and whites in different parts of the United States. The only people whom we can compare with accuracy are the farmers, for they are the only ones for whom exact statistics are available. Fortunately they are the part of the community where social prejudices and other hampering conditions have the smallest influence. The prosperity of the farmer, more than that of almost any other class of society, depends upon his own individual effort. If he is industrious, he need never fear that he and his family will not have a roof over their heads and something to eat. Even when the crops are bad, he rarely is in danger of suffering as factory operatives often suffer, at least not in the eastern United States with which alone we are now concerned. Moreover, the prejudice against colored people has little effect upon farmers. No one hesitates to buy vegetables peddled by a darkey farmer. Finally, farming is the occupation in which the South has been least hampered as compared with the North. For nearly half a century the negro has been able to buy land freely in any part of the country. The southerners, whether white or black, have suffered economically hecause of slavery and the consequent war, but they have a good soil and a climate far better for agriculture than that of the North, and they have peculiarly good opportunities to raise tobacco and cotton, two of the greatest money- 
making crops in the world. Taken all in all, the farmers of the country ought to show the relative capacities of different races and of the same race under different conditions better than almost any other class of people.

In 1904 the United States Census Bureau published a bulletin on the negro. From that I have prepared the following table showing the relative conditions in four groups of states in 1900. The first row of numbers (line 1) shows the total number of white and colored farmers. The second row shows that the farms of the northern white men average about 100 acres in size, while those of the southern white men are larger. The colored farms, on the other hand, have an average size of about 50 acres. In the next row of figures, line 3 , we notice that the northerners forge ahead. Even in the relatively hilly states of New York and Pennsylvania, the white farmers have improved 63.5 acres per farm, or 69 per cent of the whole, leaving only 31 per cent in the rough state of bushes or woods. The northern negroes do exactly as well in proportion to their holdings, for they have cleared 33.0 acres, which is also 69 per cent of the average farm. In the Carolinas, Georgia, and Florida, on the contrary, the white men have improved only 34 per cent of their land, and the colored men 58 per cent. For the states farther west (comparison B), approximately similar conditions prevail. The negroes are obliged to clear a larger percentage than the whites because their small holdings would not otherwise furnish a living. The significance of the figures lies in the fact that the northerners, whether white or black, show more energy in improving their land than do the southerners of the same kind. 


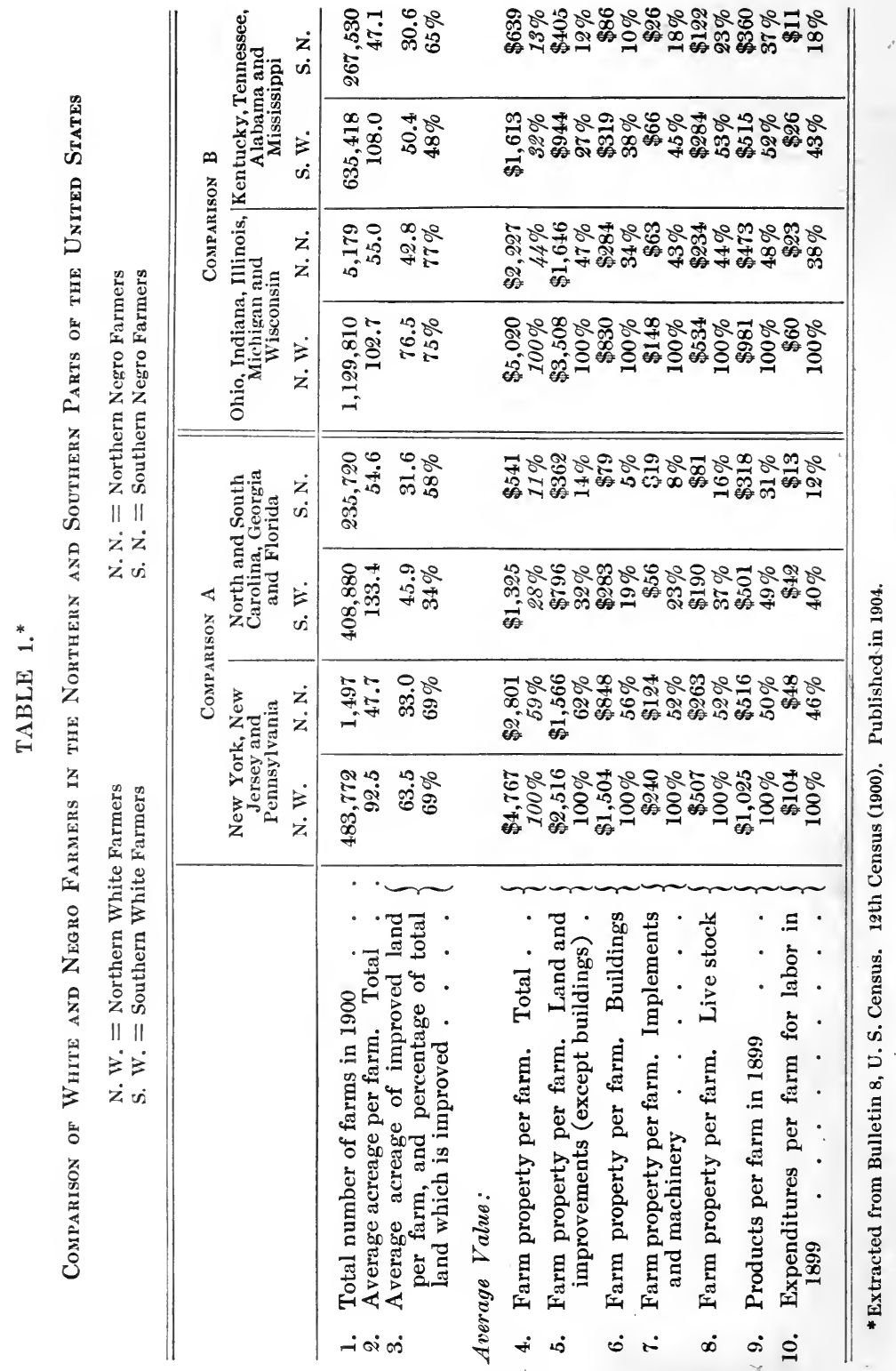


Since this table was in print the corresponding bulletin (No. 129) for the census of 1910 has appeared. Unfortunately it is less full than its predecessor and does not give the value of products, line 9. For line 4 the figures are as follows :

Comparison A

Comparison B

N.w. N.N. S.W.

S.N. N.W. N.N.

S. W.

S. N.

\begin{tabular}{r|r|r|r||r|r|r|r}
\hline$\$ 5,237$ & $\$ 4,237$ & $\$ 2,151$ & $\$ 1,241$ & $\$ 7,917$ & $\$ 3,799$ & $\$ 1,925$ & $\$ 1,099$ \\
$100 \%$ & $81 \%$ & $41 \%$ & $24 \%$ & $100 \%$ & $48 \%$ & $25 \%$ & $14 \%$ \\
\hline
\end{tabular}

In comparison $\mathrm{A}$, the gain of the other divisions in relation to the northern white farmers is noticeable. In $B$, the percentages are almost unchanged.

In both comparisons the figures in lines 4 and 9 are the most significant. They show the value of the farms and the value of the annual products. In each line the values are stated in dollars as given in the census report, while underneath $I$ have added percentages. In computing the percentages the highest value is reckoned as $\mathbf{1 0 0}$ per cent and the rest are figured accordingly. In each item of both comparisons the northern whites stand at the top. In general the northern white man's farm is worth twice as much as that of his colored neighbor, and he gets twice as much from it. The southern white man has a farm worth less than that of the northern negro, but he gets from it approximately the same amount of products. The southern negro's farm is worth about half as much as the southern white man's, and he gets from it about two thirds as much. Taking all the farmers from our four groups of states and reckoning them according to the value of what they actually produce, the census ranks them as shown in Table 2 : 
Table 2. The Relative Efficiency of White and Negro Farmers in the North and South

$\begin{array}{lr}\text { Northern whites, } & 100 \text { per cent } \\ \text { Southern whites, } & 51 \text { per cent } \\ \text { Northern negroes, } & 49 \text { per cent } \\ \text { Southern negroes, } & 34 \text { per cent }\end{array}$

This little table possesses profound significance. It shows unmistakably two types of contrast. First, there is the racial contrast, the result of long inheritance. That, apparently, is what makes the negroes fall below the whites in both the North and the South. There is also a climatic contrast. That, apparently, is why the negroes who come to the North rise above the usual level of their race, while the whites of the South fall below the level of theirs. I realize that the contrast between the two sections is explained in a hundred ways by as many different people. One ascribes it to the fact that slavery was a poor system economically. Another says that the South is cursed for having consented to the sin of slavery. Again, we are told that the predicament of the South is due to the War of Secession, the failure to develop manufactures, the absence of roads and railroads, bad methods of farming, the presence of the negro making the white man despise labor, and many other equally important causes which cannot here be named. Still other authorities ascribe the condition of the South to its supposed settlement by adventurers, whereas the North had its Pilgrims.

I would not minimize the importance of these factors. All are of real significance, and if any had been different, the South would not be quite what it is. All depend upon the two fundamental conditions of race or inheritance, and place or climate. Yet in the contrast between the North and South, the climatic effects seem to be the more potent. [Slavery failed to 
flourish in the North not because of any moral objection to it, for the most godly Puritans held slaves, but because the climate made it unprofitable. In a climate where the white man was tremendously energetic and where a living could be procured only by hard and unremitting work, it did not pay to keep slaves, for the labor of such incompetent people scarcely sufficed to provide even themselves with a living, and left little profit for their masters. In the South slavery was profitable because even the work of an inefficient negro more than sufficed to produce enough to support him. Moreover, the white man was not energetic, and his manual work was not of much more value than that of a negro. Hence, it was easy to fall into the habit of using his superior brain, and letting the black man perform the physical labor. If the Puritans had settled in Georgia, it is probable that they would have become proud slave-holders, despising manual work.

So far as inheritance is concerned, the white southerners, according to the generally accepted principles of biology, must be essentially as well off as the white men of the North. New England has probably had a certain advantage from the strong fiber of her early settlers, but that section is excluded from our comparison because it has so few colored farmers. In New York, Pennsylvania, New Jersey, and the states farther west, the white farmers in 1900 were of highly mixed origin, and there is little reason to think that they inherit any greater capacity than do the white men of the South. Hence, we infer that the difference shown by the census is largely a matter of climate. It has arisen partly by indirect means such as slavery and disease, partly by direct means such as the disinclination to physical exertion. This demands emphasis, for we are told that the South needs nothing but a fair opportunity, plenty of capital, and abundant roads, railroads, and factories, or else it needs only education, a new respect of one race for the other, coöperation between the two for the sake of the common good, 
and a deeper application of the principles of Christ. All these things are sadly needed, but it is doubtful whether they can work their full effect unless supplemented by a new knowledge of how to neutralize the climatic influences which seem to underlie so many southern problems. In the climate of the South a part of the white population becomes a prey to malaria, the hookworm, and other debilitating ailments. People cease to be careful about food and sanitation. Even those who are in good health do not feel the eager zest for work which is so notable in the parts of the world where the climatic stimulus is at a maximum. Thus one thing joins with another to cause a part of the people to fall far below the level of their race, and to become "Poor Whites," or "Crackers." These increase in number as one passes from a more to a less favorable climate. It is their run-down, unkempt farms which bring the average of the southern whites so dangerously near the level of the negroes. The best farms of the South vie with those of the North. They show what could be done if all the inhabitants could be instilled with the energy and wisdom of the best.

Aside from North America the only large area where Teutons and negroes come into direct contact as permanent inhabitants is South Africa. There they meet on practically equal terms. The English and the Boers began to settle in South Africa in large numbers only in the first half of the nineteenth century. In 1911 the South African Republic contained about 1,300,000 Europeans, 4,000,000 natives, and 600,000 from other regions. A large proportion of the white men were not born there, and hence the new conditions have not had time to produce their full effect. The natives consist largely of the Bantu stock of negroes. The majority are Zulus, but the most capable appear to be the Basutos, an allied race who have preserved a large measure of independence in the safe refuge of the Drakenberg mountains. Both the Zulus and the Basutos came from the North a few generations ago. Some preceded the white man and 
some have come since his arrival. In any case they are comparatively newcomers. Their arrival, and still more that of the Europeans, has practically exterminated the former inhabitants, Hottentots and Bushmen.

The colored people are most numerous in the north and east of the Republic, that is, in Rhodesia and Natal. The white men are most abundant in the south and in the central plateau, that is, in Cape Colony, Orange River Colony, and Transvaal. With ever increasing force, however, the blacks are pushing into the white man's country. They are brought as laborers for the mines; they are wanted for the farms; they are in demand as servants; and they are themselves taking up farms and successfully cultivating them. They are doing more than this, however, for they are actually ousting the Europeans. In 1902 the English and the Boers finished a bitter war. Ten years later their enmity had almost vanished in the common fear of the negro. Aside from the disturbances due to the European War of 1914, the great political question has long been the black man. One party advocates segregation, with a white man's South Africa in the highlands from Transvaal southward, and a black man's South Africa in Natal and Rhodesia. No black man, they say, should be allowed to live permanently outside his own country, although he might go elsewhere to work temporarily. The other party holds that such measures are too radical, but it also recognizes the gravity of the situation.

The problem presents itself under an economic guise. The colored men have a lower standard of living than the whites. Hence they work more cheaply. They furnish so abundant a supply of labor that white laborers have no chance. Thus a large number of the Europeans-even a tenth according to ardent believers in the future of South Africa-are "poor whites." They are a shiftless set, living from hand to mouth, proud of their race, yet less efficient than the blacks. The 
problem of preventing them from becoming an immediate charge upon the community is serious. They lack the push and energy which characterize the rest of the white population. According to Stevens, in his book "White and Black," 5 per cent of the white population in certain regions have fallen so low that they would rather resort to crime than work in competition with the black man. The most sinister fact is that these "poor whites" appear to have been largely born in the country. The newcomers are on the whole more energetic. They find employment, and if they have difficulty in one place, move on to another. The poor whites lack the initiative to do this. If they fall into difficulties, they tend to lie down and give up. They need higher wages than the blacks in order to maintain their traditional standard of living. They are not efficient enough to get higher wages. If they had the restless energy which characterizes the children and grandchildren of emigrants from Europe in Canada, for example, they would scarcely fall into such straits.

Since the problem is economic, the South Africans are striving to apply economic remedies. This is wise, but success is doubtful unless other factors are also considered. Back of the economic facts, and in many ways conditioning them, lies the climate. South Africa is supposed to have a climate admirably adapted to Europeans. I shared the common opinion until I began to gather statistics of the effect of climate upon efficiency. These, as will be shown later, indicate that although the South African climate is pleasant, it lacks the stimulating qualities which are so important in Europe and North America. This lack of stimulus increases rapidly as one goes from south to north. Here, then, is the situation that confronts us: In South Africa the white men settled first in the regions most favorable from a climatic point of view and then pushed northward into worse conditions. Even the best parts of South Africa cannot approach England and Holland in the excellence 
of their climate. Hence, the white settlers are everywhere at a disadvantage. On the other hand, the Bantu negroes have come into South Africa from the north, where the climate is far less favorable than in their new homes. Thus the two races face each other under conditions which lessen the white man's energy, while they stimulate the black man. The whites are still far ahead, and will doubtless continue to be so indefinitely. Nevertheless, the weaker ones are being weeded out and prepared for destruction. What the final result will be, no man can say. It depends upon whether we can discover a means of preventing the deterioration which now seems to attack a portion of the population when people move from a good climate to a worse.

A more striking case than that of South Africa is found in the Bahama Islands. At the time of the American Revolution a considerable number of Loyalists were so faithful to England that they sacrificed their all in order to escape from the new flag with its stars and stripes. Leaving their homes in Georgia and other southern states they sought the British territory of the Bahamas. Other colonists came from Great Britain. Now, after from three to five generations, the new environment has had more opportunity than in South Africa to produce its full effect. Almost nowhere else in all the world have people of the English race lived as genuine colonists for several generations in so tropical a climate. What has been the result? There can be but one answer. It has been disastrous. Compare the Bahamas with Canada. The same sort of people went to both places. Today the descendants of the Loyalists in Canada are one of the strongest elements in causing that country to be conspicuously well governed and law-abiding, and the descendants of other colonists, both British and French, vie with them in this matter. In the Bahamas the descendants of the same type of people show today a larger proportion of poor whites than can probably be found in any other Anglo-Saxon community. Although no figures are available, my own observa- 
tions lead to the conclusion that the average white farmer is scarcely ahead of the average negro.

Whatever the exact figures may be, there can be no question that in the Bahamas the two races tend to approach the same level. This seems to indicate a marked retrogression of the white race in regions which are climatically unsuitable. Let me hasten to say that many of the more intelligent Bahamans do not differ from the corresponding portions of the AngloSaxon race elsewhere. At home they feel themselves handicapped, but when the young people go away to the northern United States or England, they frequently show marked ability. Their inheritance is still good. As to the poor whites, who were described in connection with the lumber industry, it is not so certain that their inheritance remains unimpaired, for in some villages genuine abnormalities both of body and mind are seen. This, however, may be due to the intermarriage of cousins which has been common in certain communities.

The inefficiency of many of the white Bahamans, however, is not due to intermarriage, as is sometimes implied, for villages where this prevails are scarcely worse than those where it is no more common than in America. Nor is the inefficiency due to disease. The hookworm is practically unknown. According to a report of Dr. McHattie, Chief Medical Officer of the Islands, only two cases had been reported up to October, 1913. In this report, for which I am indebted to the courtesy of Dr. J. A. Ferrell of the Rockefeller International Health Commission, the author points out that "the remarkably rapid manner in which the soil . . . dries after even the heaviest rain" prevents the development of the infective larvæ. For similar reasons malaria is no more prevalent than in Delaware, for instance, and in general the islands are decidedly healthful. A monotonous diet may be another detrimental factor, but it is scarcely the root of the matter. Many of the people are well fed, and all could be so if they displayed any 
energy. Indeed, many people say that life is altogether too easy in the Bahamas. The soil is wonderfully fertile, crops of some kind will ripen at all seasons, and a man can work less than half his time and still readily procure an abundance to eat and wear for himself and his family. On the other hand, we are often told that the difficulties of life have broken the spirit of the inhabitants. The soil, in spite of its richness, is thin, and rocks are so abundant that the plough is almost unknown. Hand agriculture in little patches in the midst of naked limestone is the rule. It cannot be denied that there are difficulties in comparison with many other tropical countries. For instance, I was talking with a negro whose parents were in a slave ship bound from Africa to Cuba when a British warship captured it. The slaves were taken to the Bahamas and liberated. In answer to a question as to how his parents liked the islands compared with Africa, the son said: "They didn't like it. They used to say, 'In Africa one could lie around all day and do nothing and always find something to eat. Here one has to work or else starve." The truth seems to be that compared with North Prussia or Maine the Bahamas are a very easy place in which to make a living, but that much more work is needed than in some other tropical regions. They are at the happy mean. Other difficulties such as the tropical hurricanes which sweep over the country once in every few years; insect pests, which are neither more nor less harmful than in other countries; the American tariff; competition with Cuba, and above all the isolated position of the islands are frequently cited as causes of the constant Bahaman failures. The islands are always suffering from bad luck, and something must be to blame.

All these various factors doubtless play a part in retarding the development of the Bahamas. Back of them, however, lies a factor of even greater import, namely, an inertia due to the climate. It does not cause the difficulties mentioned above, but 
it aggravates them and makes it almost impossible to overcome them. I talked about this with perhaps fifty of the more intelligent people, including both natives and foreigners who have been there a number of years. Almost without exception they said the same thing. "This climate is one of the best in the world. You can see that for yourself. It is very healthful, and we have very few sicknesses. The only trouble is that it does not make one feel like work. In winter it is all right, although even then we cannot fly around the way you Americans do. We always feel lazy, and in summer we want to sit around all the time." As an American picturesquely put it: "Until I came to the Bahamas I never appreciated posts. Now I want to lean against every one that I see." Many of the men and almost all the women complain of feeling tired. Even the children are listless. One young man stated the case very strongly, "We go to bed tired in summer and we get up more tired, and the summer lasts from April to October." Again and again people said: "Oh, it's all very well for you to think we're lazy, but try living here six months or a year and you'll be as lazy as we are. It's something in the air. Just look at these young ministers who come out from England. At first they are full of energy, but after a year or two it oozes out, though their spirit is still as zealous as ever." Two of the ministers spoke of the fact that when they came out they thought nothing of walking twenty miles, but now they dread the thought of two. Several of the most thoughtful and intelligent islanders, men who have succeeded in business and whose judgment would be respected anywhere, said: "We know that we are physically unable to do what English and Americans can do. We are weaker than our fathers, and they were weaker than theirs. It is a grief to send our children away, but in our hearts we know that this is not a white man's country." All this, it must be remembered, is not due to any specific disease, so far as we are aware. Indeed, I met several people who said that a stay of a few years 
in the Bahamas had improved their health, but at the same time had made them feel inefficient.

Aside from extremely ignorant persons whose opinion is of little value, the only men who spoke of the climate more hopefully were five or six highly trained officials and others occupying positions of authority. These men, without exception, can control their own time. In most cases their office hours are from 9 or 10 a.m. to 2 p.m., or less. They are men of naturally strong physique; they have the opportunity and the will to take regular exercise; and, most important of all, they make long and frequent visits to the United States or England.

The benefit to be derived from a visit to a more bracing climate is astonishing. The contrast between the dull, sallow complexions and thin cheeks of the women and girls who have always lived on the islands and the round, rosy cheeks of those who have recently come back from a long stay at the North is most striking. According to a local saying you cannot tell whether a Bahaman woman is pretty until she goes away, and has a chance to fill out her cheeks and get some color. It is by no means strange that the stronger, more energetic young white people are fast leaving the islands. I asked a Bahaman girl, who had been studying nursing in New York, whether she enjoyed life more in the United States than in the Bahamas. "How can one help enjoying it more there?" she answered. "There one feels like doing things. Here one never feels like anything." Like almost everyone else she was sure that it was the climate even more than the new social environment which made the difference.

One thing that surprised me was to hear the Bahamans speak of the stimulus of living in Florida. A native merchant remarked: "If I hire a new man I don't have to ask whether he has been to Florida. I know it by the way he works, but it does not last long." Here again the social environment is an important factor, but various people told me that the air 
somehow makes them feel more capable of work in Florida than at home. The women of Florida-I heard them say it themselves-are pale and wan compared with their northern sisters. One of them, whose color still shows her northern origin, remarked: "When I come home after a summer in the North, I am full of energy and see all sorts of things that I want to change about the house. But after a month or two I don't care whether things are fixed or not." One hears the same sort of thing everywhere. A factory superintendent from Atlanta, Georgia, told me that the Florida workmen, even the most skillful mechanics, drive him frantic because they are so shiftless and so ready to take a day off whenever they feel like it-far more so than at Atlanta, even though Atlanta scems slow to northerners. Yet, in spite of all these things, Florida is a more stimulating place than the Bahamas. Its summers are not much better, but its winters are sometimes frosty, while in the Bahamas the thermometer practically never goez below $50^{\circ} \mathrm{F}$. Perhaps of greater importance, as we shall see later, is the fact that in Florida the temperature from day to day varies much more rapidly than in the Bahamas, even though both places are in the same latitude. Hence, the mainland is blessed with a genuine climatic stimulus compared with the uniform islands.

The last thing to be said about the Bahamas concerns the effect of the climate on mental activity. Practically all the islanders with whom I talked thought that the effect of the climate on mental activity is at least as great as on physical. Several of the more thoughtful, without any suggestion on my part, put the matter in this way: "The worst thing about this climate is the effect on the mind. Not that people do not have as good minds as elsewhere, but one soon gets weary of hard mental effort. It is extremely difficult to concentrate one's thoughts. At night one cannot seem to make himself read anything serious-nothing but the lightest kind of stories." In our own southern states one hears the same complaint. Even 
in Virginia the booksellers say that during the long summer almost no one touches a serious book. One feels it everywhere, for on the trains, at the railroad stations, and at the newsdealers it is generally difficult to find the higher grade of magazines. Time and again during a recent journey of three months in the southern states I tried to get such papers as the Outlook, Independent, Harper's, Atlantic, the Reviero of Revieres, The Century, and so forth-but all that I could find was trashy story magazines. The dealers rarely keep the better magazines because people will not read them. Lack of training surely has something to do with the matter, but mental inertia due to lack of climatic stimulus seems to be at least equally important.

Let us return now to our question as to a Teutonic and a negro Egypt. The farmers of the northern and southern states, the race problem of South Africa, and the backwardness of the Bahamas, all seem to point to the same conclusion. When the white man migrates to climates less stimulating than those of his original home, he appears to lose in both physical and mental energy. This leads to carelessness in matters of sanitation and food, and thus gives greater scope to the diseases which under any circumstances would find an easy prey in the weakened bodies. The combination of mental inertia and physical weakness makes it difficult to overcome the difficulties arising from isolation, from natural disasters, or from the presence of an inferior, race, and this in turn leads to ignorance, prejudice, and idleness. Thus there arises a vicious circle which keeps on incessantly. From its revolving edge a part of the community is thrown off as poor whites, whose number increases in proportion to the enervating effect of the climate and the consequent speed with which the circle revolves. That climate is the original force which sets the wheel in motion seems to be evident, because it is only in adverse climates that we find the "cracker" type of "poor white trash" developing in appreciable 
numbers. If white men lived a thousand years in Egypt it seems probable that a large proportion of them would degenerate to this type. Whether they would still retain an inheritance of mentality sufficient to keep them ahead of a similar body of negroes can scarcely be determined. 


\section{CHAPTER III}

\section{The White Man in the Tropics}

Thus far we have dealt with the temperate zone. Even the Bahamas lie north of the Tropic of Cancer. Let us now turn to the torrid zone, which contains the world's richest and most inviting fields of future development. Let us inquire into the effect of that region upon Europeans who attempt to live there permanently. The isolation of the tropical regions, their lack of facilities for transportation, and the great difficulties of agriculture will doubtless be overcome, but that will by no means solve the problem. Two great obstacles will still remain-the native inhabitants and the white man's own mind and body.

Whatever may be the cause, it is generally agreed that the native races within the tropics are dull in thought and slow in action. This is true not only of the African negroes, the South American Indians, and the people of the East Indies, but of the inhabitants of southern India and the Malay peninsula. Perhaps they will change, but the fact that the Indians both of Asia and South America have been influenced so little by from one to four hundred years of contact with the white man affords little ground for hope. Judging from the past, there is scant reason to think that their character is likely to change for many generations. Until that time comes they will be one of the white man's greatest obstacles. Experience shows that the presence of an inferior race in large numbers tends constantly to lower the standards of the dominant race. Here in America, although the negro forms only a tenth part of the population, he is one of our gravest problems. Yet he is not so great a 
handicap as are the native races of the tropics. Whatever the negro may have been when he was first brought to America, he is now less stolid and indifferent, more subject to stimulating influences than he was when he came, or than the Indians of tropical America. It is literally true in South America, for instance, that the more an Indian is paid the less he will work. If one day's pay will buy two days' food, he will work half the time; if the pay is increased so that one day's pay will buy food for three days, he will work one third of the time. The experiment has been tried again and again. The most considerate employers of tropical labor agree with the most inconsiderate that in general it is useless to attempt to spur the Indians by any motive beyond the actual demands of food and shelter. Kindness and consideration on the part of the employer undoubtedly promote faithfulness, but they seem rarely to arouse ambition or energy. With the negro in Africa, as everyone knows, much the same condition prevails, but where he has been brought to the United States this is by no means so true. For example, in Central America it is generally thought that a negro from Jamaica is more efficient than an Indian, while a negro from the United States is much more efficient. The negro in the United States is generally considered more efficient than he was in Africa, whereas his stay-at-home brother and the Indian of tropical America, remaining in their old environment, do not seem to have changed.

Doubtless the change in the negro is due to a new social environment quite as much as to a new physical environment, and many authorities believe that the social change is the more important. This, however, does not materially alter the case. As conditions are now, it is extremely difficult to change the physical environment of tropical races so long as they remain in their present habitat, and it seems to be equally difficult to change their social environment. Those who dwell permanently in the white man's cities are influenced somewhat, but the results 
are often disastrous. Here, as in other cases, the general tendency seems to be to revert to the original condition as soon as immediate contact with the white man is removed. This seems to have been the case almost everywhere within twenty degrees of the equator.

I would not be understood as saying that contact with a higher civilization will never produce any good effects upon the people of the tropics, but merely that the process is bound to be slow. The aborigines of tropical America, for example, show no sign of disappearing, or of being swallowed up by a multitude of immigrants, as has been the case in temperate latitudes. On the contrary, in the equatorial countries of Latin America, the only tropical region where the white man has settled in any large numbers, the proportion of Indian blood is apparently increasing at the expense of the white. This is because the white man, except in a few favored places, suffers from tropical diseases more than does the native, and unless he is wise enough to adopt the latest discoveries of medical science his children die or grow up weak. It is notoriously true that in India there is almost no such thing as a fourth generation of Indian-born British. The original stock is so weakened by tropical conditions that the children must either be sent back to Europe to recover their health, or else they become enfeebled and their descendants soon die out. Even with the help of modern medical science, it is not yet certain that the number of permanent white inhabitants can increase greatly, although sojourners are sure to become numerous. Moreover, there is reason to think that that same medical science may prevent the death of children among the natives, and thus gradually increase their numbers. The white man has already caused such an increase of the natives in India, not so much by conquering diseases as by the prevention of famine.

If the conclusion just reached is correct, it seems probable that for a long time to come tropical countries will contain a 
dull, unprogressive population. Contact with such a population constantly exposes the white man to a most deteriorating influence. For example, the inferior mental ability of the lower race, and its incapacity for effective organization lead to the abuse of its labor and to its exploitation in some form of peonage, even though the fact may be disguised by legal phraseology. Again, the presence of a despised race is almost certain to lead to low sexual morality. In the same way, political equality becomes a mere form of speech, for the dominant race will not permit the other to gain rights at its expense. Manual labor, too, is despised, for it is associated with the idea of an inferior race. All these things may be looked upon as disadvantages of the lower race, but I believe that the higher reaps by far the greater injury. The conditions just mentioned appear to be among the most potent factors in rendering it difficult for the white man to attain as much success in tropical regions as in those farther to the north or south. Their evil effect is roughly proportional to the difference between the two races. That difference is at a maximum where a low tropical race remains in its original, unstimulating environment, and is brought into contact with immigrants of a highly developed race who completely change their environment. The newcomers are released from old restraints at a time when they stand in peculiar need of them. Instead of being stimulated to greater love of political freedom and equality, sterner morality, and more intense industry, as was the case among the settlers in New England, the immigrants are in danger of being weakened in all of these respects. The effect on the original immigrants is bad enough, but on their children it is far worse. The settler, or European colonist, who is possessed of wealth and power, can to a slight degree shield his family, but even in such cases the children are in constant contact with servants. They grow up with a supreme contempt for the natives, and at the same time with the feeling that they can treat them as they 
choose. If poorer people, that is, colonists in the ordinary sense of the word, attempt to live in the tropics, especially if they are people who work with their hands, their children are exposed still more to all the contaminating influences of contact with the natives. Hence, the second and third generations, and the fourth and fifth, if there are any, suffer more than their ancestors.

The degree to which the indirect or external handicaps of tropical countries are effective in lowering the standards of civilization depends largely upon the amount of energy and will power possessed by the inhabitants. This, in turn, depends upon physiological conditions. . Obviously, diseases have much to do with the matter. This subject has been so much discussed that I shall here refer to it only briefly. There can be little doubt that malaria, and the many other diseases which are characteristic of tropical countries, play an important part in causing a low state of civilization. The old idea that the people who live in tropical regions are immune to local diseases is no longer accepted by students of tropical medicine. Adults, to be sure, are often immune, but apparently this is not true of the race as a whole. Vast numbers of children die in infancy and early childhood from the diseases which prevent the white man from permanently living within the tropics. Others suffer, but recover. They bear the results with them to the grave, however, in the form of enlarged spleens, or other injuries to the internal organs of the body. The world has of late been astonished at the ravages of pellagra and of other diseases due to such organisms as the hookworm. People who are subject to them cannot be highly competent. Their mental processes, as well as their physical activity, are dulled. So long as a community is constantly afflicted with such disorders, it can scarcely rise high in the scale of civilization. Nothing is more hopeful for the tropics than the rapid progress in the control of these diseases. If they could be eliminated, not only 
would the white man be able to live permanently where now he can be only a sojourner, but the native races would probably be greatly benefited. How great this benefit would be we cannot yet tell, but the elimination of the diseases which especially affect children would probably do much to increase vitality, energy, and initiative. This in itself would be an immeasurable boon not only to the natives, but to the white man, who would thereby be freed in part from some of his worst social dangers.

This highly desirable result cannot be obtained quickly. The achievements of the United States in Panama are sometimes said to prove that diseases can be eliminated anywhere in tropical countries. This is true, but it must be remembered that Panama is a highly specialized case. During the building of the Canal a great number of people were collected in a small area, and enormous sums of money were freely expended. Everyone was subject to strict, semi-military rule, and similar conditions continue under civil rule. Such methods cannot be applied to millions of square miles. The expense would be prohibitive. The ordinary farmer in tropical regions cannot expect to be protected by his government. He must protect himself. In the long run even tropical races may learn this lesson, but it will be a difficult and expensive task, and will require a radical change in the people themselves. Such a change will doubtless come, but not for generations, and not until a long selective process has gone on whereby those who do not adopt modern medical methods will gradually be eliminated, while those who adopt them will persist.

At this point we come to the parting of the ways. Suppose that the white man should succeed in cultivating the forests, traversing the waste places, and conquering the diseases. Suppose also that he should eliminate the deteriorating influences of low social and moral standards among the natives. If all this were suddenly done, and he were set down in a tropical garden of Eden, would he be able to hold his own among the 
peoples of the world? Would Teutons or Latins under such circumstances be able permanently to maintain as high a standard of civilization as is maintained by their brothers in Europe? Or would there be a change in some of the traits which we are wont to call racial? Clearly we are back at the point where we started, and are confronted by the question of race versus place. We must determine how much of our European and American energy, initiative, persistence, and other qualities upon which we so much pride ourselves is due to racial inheritance, and how much to long residence under highly stimulating conditions of climate.

One of the lines along which we may seek for an answer is by a comparison of the character of Europeans in tropical countries with their character in the temperate zone. Whatever differences we may find are presumably due largely to physiological causes, but they manifest themselves chiefly through the will. In tropical countries weakness of will is unfortunately a quality displayed not only by the natives, but by a large proportion of the northerner sojourners. It manifests itself in many ways. Four of these, namely, lack of industry, an irascible temper, drunkenness, and sexual indulgence are particularly prominent, and may be taken as typical. Others, such as proneness to gambling and disregard to the truth, might equally well be considered if space allowed.

In the quality of industry the difference between people in tropical and other countries is well known. We have already touched on it in the Bahamas, but let us amplify it further. Practically every northerner who goes to the torrid zone says at first that he works as well as at home, and that he finds the climate delightful. He may even be stimulated to unusual exertion. Little by little, however, even though he retains perfect health, he slows down. He does not work so hard as before, nor does the spirit of ambition prick him so keenly. On the low, damp seacoast, and still more in the lowland forests, 
the process of deterioration is relatively rapid, although its duration may vary enormously in different individuals. In the dry interior the process is slower, and on the high plateaus it may take many years. Both in books and in conversation with inhabitants of tropical regions one finds practical unanimity as to this tropical inertia, and it applies both to body and mind. After long sojourn in the tropics it is hard to spur one's self to the physical effort of a mountain climb, and equally hard to think out the steps in a long chain of reasoning. The mind, like the body, wants rest. Both can be spurred to activity, but this exhausts vitality. The common explanations of tropical inertia are diverse. One man says that within the tropics hard work is unnecessary, because salaries are high; another asserts that it is because servants are cheap; still another claims that hard work is dangerous to the health; and almost all agree that "anyhow, one doesn't feel like working down here." Probably all four of these factors coöperate, and each, doubtless, produces pronounced results, but the last two, health and "feeling," seem the most important when many generations are considered.

In spite of individual exceptions, white men who spur themselves to work within the tropics as hard as at home are in great danger of breaking down in health. They become nervous and enfeebled, and readily succumb to tropical diseases. This is one of the most powerful deterrents to the development of an efficient white population in equatorial regions. If the more energetic members of the community ruin their health, they are almost sure to die before their time, or else to go back to the North. In either case they are not likely to leave many children to perpetuate their characteristics. Thus if white colonization takes place on a large scale within the tropics, there is grave danger that the less energetic elements will be the ones to persist and to become the ancestors of the future population. In the past this factor must have operated to weed out the more 
energetic members of each of the many races that have migrated toward the equator. The feeling of inertia which prevents the less competent members of a tropical community from working may perhaps be interpreted by teleologists as a merciful provision of Providence to warn man that he must not work too hard in the torrid zone, but that will scarcely help to advance civilization. Few people will question the reality of the tropical inertia. It is the same lassitude which everyone feels on a hot summer day - the inclination to sit down and dream, the tendency to hesitate before beginning a piece of work, and to refrain from plunging into the midst of it in the energetic way which seems natural under more stimulating conditions.

Lack of will power is shown by northerners in tropical regions not only in loss of energy and ambition, but in fits of anger. The English official who returns from India is commonly described as "choleric." Every traveler in tropical countries knows that he sometimes bursts into anger in a way that makes him utterly ashamed, and which he would scarcely believe possible at home. Almost any American or European who has travelled or resided within the tropics will confess that he has occasionally flown into a passion, and perhaps used physical violence, under circumstances which at home would merely have made him vexed. This is due apparently to four chief causes. One is the ordinary tropical diseases, for when a man has a touch of fever, his temper is apt to get the better of him. In the second place, the slowness of tropical people is terribly exasperating. The impatient northerner uses every possible means to make the natives hurry, or to compel them to keep their word. His energy is usually wasted-the native remains unmoved, and the only visible result is an angry and ridiculous foreigner. Yet a show of anger and violence often seems to be the only way of getting things done, and this is frequently used as an excuse for lack of self-control. In the third place, the consequences of becoming angry are less dan- 
gerous than elsewhere. The inert people of tropical countries often submit to indignities which an ordinary white man would bitterly resent. Of course they object to ill treatment, and will retaliate if possible, but they generally do not have sufficient energy or cunning to make their vengeance effective against the powerful white man. Finally, those who have lived in the tropics generally find that, even when things go smoothly, anà they are in contact with people of their own kind and are in comparatively good health, thcy are more irritable than at home. In other words, their power of self-control is enfeebled. Of course there are many exceptions, but that does not affect the general principle.

Drunkenness, our third evidence of lack of self-control, need scarcely be discussed. Within the tropics, the white man's alcohol in the form of rum is scarcely more injurious to the natives of Africa than it is in other forms to himself. In places such as Guatemala and parts of Mexico, drunken men and women may be seen upon the streets at almost any time of day. Nowhere else, during extensive travels in America, Europe, and Asia, have I seen so much drunkenness as in Guatemala. Among white men a large number drink as badly as the natives. Here is an example; a railway conductor was telling me about drinks in Guatemala:

"They've got something here called 'white-eye,"' he remarked. "You know that Mexican 'mescal,' and how strong it is? Well, white-eye's got mescal chained to a telegraph pole. Yes, I drink it. A man's got to drink something. The first time I tried it, I got crazy drunk and smashed things up the way they all do. I was arrested and fined fifty dollars. [This is really only two and a half, for Guatemalan currency consists of non-redeemable paper, which even before the war was worth only five cents on a dollar-a characteristic evidence of tropical incapacity.] I got fined several times that way and didn't 
like it. Then one day when I was going to get drunk, I said to myself, 'I'll go and pay my fine now and then they won't bother me.' I did that several times, and the 'jefe politico' liked it [presumably because it was an easy way of pocketing the money]. Then he said to the police: 'Don't bother this man. Just let him get drunk all he likes, and he'll pay his fines at the proper time.' I tell you, white-eye is bad stuff. The only proper way to drink it is to take a quart bottle in the morning. Find a place that will stay shady all day. Drink the whole thing right down and get so dead drunk that you will sleep till night."

I do not cite this man as typical of all the white men in the tropics. Far from it. Many conduct themselves with sobriety and industry, but such men almost invariably make frequent and protracted visits to the better climate of the North. If a white man stays steadily for long periods in the tropics, however, and if his character has any weak spots, they are almost sure to be exaggerated. The drunkenness of the tropical white man arises in part from the constant heat which makes people want something to drink at all times, partly from the monotony of life, and still more from the absence of the social restraints which exercise so powerful an inhibitory influence at home. Back of all these things, however, among both the white men and natives, there seem to lie two conditions which are directly connected with the climate. One is the same enfeeblement of the will which makes a man burst into anger. The other is a constant feeling of inefficiency which makes a man crave something to brace him up.

The last of the ways in which weakness of will is evident in tropical countries is the relation of the sexes. Its importance can scarcely be overestimated. It leads to the ruin of thousands of northerners, even though they do not yield to drink, to anger, or to laziness. When once they have fallen into pronounced immorality the other weaknesses soon follow. The 
condition of the native races is still worse. Everywhere within the tropics missionaries say that their converts can be taught honesty, industry, and many other virtues, but that even the strongest find it almost impossible to resist the temptations of sex. Many Europeans condone this. They say that it is natural, and that the natives had better be left to their own conventional ways of restricting but not preventing sexual intercourse. Perhaps they are right, although I do not believe so. That is not the point, however. We are at present concerned with the effect which free indulgence has upon civilization and upon the capacity for progress. This may be illustrated by what Gouldsbury and Sheane, for example, say of the Zulus in northern Rhodesia. They hold that one of the greatest reasons why these people remain so backward is that their thought and energy are largely swallowed up in matters of sex. During the years when the young men ought to be getting new ideas and thinking out the many little projects and the few great ones which combine to cause progress, the vast majority are thinking of women, and planning to gain possession of some new woman or girl. Under such circumstances no race can rise to any high position.

The causes of these conditions are various. Many writers dismiss the matter by saying that the social standards of tropical people are low and tend to cause northerners to conform to them. This is true, but it explains nothing. A real, though minor reason for the lowness of the standards is found in the free, open life which is almost universal within the tropics. People are out of doors so much and it is so easy to meet in secret that temptation arises very frequently. Much more important is the scanty dress of the women, and its character which calls attention to their sex. Livingstone speaks with disgust of the way in which his carriers, hour after hour, discussed the breasts of the half-naked women whom they met. Even in the North women seem to be strangely indifferent to the 
effect of their mode of dress upon men. They do not seem to think that they are responsible if their low-necked gowns and the making of their clothing in such a way that each little movement of their bodies can be detected, stir men's passions. They appear oblivious to the fact that the display of their beauty often means that some other woman must pay the penalty. Within the tropics these conditions are exaggerated. I believe I am speaking within bounds when I say that any young man of European race with red blood in his veins is in more danger of deteriorating in character and efficiency because of the women of the tropics than from any other single cause.

The strength of this deteriorating force is not merely external. Either the actual temptation to sexual excess is greater in the tropics than elsewhere, or else the inhibitory forces are weakened by the same processes which cause people to drink to excess, to become unduly angry, and to work slowly. Hellpach states that it is said that in southern Italy sexual irregularities increase greatly at times when the hot, damp wind known as sirocco blows across the Mediterranean from the deserts of northern Africa. This is so well recognized among the people themselves that offenses committed under such circumstances are in a measure condoned. Violence, too, is more common at such times, for self-control of every kind is weakened. In eastern Turkey the hot desert winds cause the whole community to become cross and irritable. I have there seen a missionary, a man of unusual strength of character, shut himself up in his study all day, because he knew that he was in danger of saying something disagreeable. I cite this case because among the people whom I have known missionaries are, on the whole, most completely masters of themselves and the least likely to let minor circumstances turn them from the Christlike lives which they are striving to live day by day before the native communities. For this same reason, to return to our immediate subject, I quote the remark of a missionary in Cen- 
tral America when we were discussing the morality of the country. He was a most austere man, a member of a small and extremely devout sect, and his whole being was devoted to preaching the gospel. Speaking of his own experiences, he said :

"When I am in this country, evil spirits seem to attack me. I suppose you would call them something else, but that is what I think they are. When I am at home in the United States I feel pure and true, but when $I$ come here, it seems as if lust were written in the very faces of the people."

In all the evils which have just been mentioned-laziness, anger, drunkenness, and immorality-social causes undoubtedly play an important part. A strong public opinion would save many a young northerner from drink and immorality, and would keep him faithful to his work. A clear religious faith or a high ideal of duty would do the same thing. Good homes, proper dress, and many other material changes would help greatly. So, too, would a study of how it has come to pass that certain tropical races, in spite of their environment, have developed comparatively high moral codes to which they strictly adhere, while a few have actually learned the lesson of industry. Along with the social aspect of the question, however, and neither more nor less important, goes the physical. We must discover to exactly what extent physical conditions help or hinder the development of strong character. That is the purpose of the chapters that follow. 


\section{CHAPTER IV}

\section{The Effect of the Seasons}

In comparing Teutons with negroes, or tropical people with those of the temperate zone, we have been following a method as old as the days of Aristotle. Such comparisons have led to most interesting generalizations not only at the hands of Aristotle himself, but of many other men such as Montesquieu, Humboldt, and Rätzel. Yet the importance of climate as a factor in civilization is still in doubt. For instance, no one denies that South Africa is confronted by a grave race problem, but many say that it is purely economic, and has nothing to do with climate. They support this view by strong arguments. Thus we are left in uncertainty. The only way to remove this is to devise some method whereby to separate the effects of climate from those due to all other causes, whether economic, historic, social, religious, or of some other sort. Accordingly, the rest of this volume will be devoted to an investigation of the exact effect of various climatic factors upon selected groups of people, and to an attempt to discover how human energy and other qualities would be distributed if all the earth's inhabitants were influenced like these particular groups.

In the study of climate one of the most puzzling features is the diversity of opinion among persons of good judgment. For instance, at what season do people work fastest in the northern United States? Some will say the winter, some the spring, a considerable number the fall, and a few the summer. Most will say that they are least efficient in summer, but others believe that they are at their worst in the early spring or late winter. 
Again, ask a dozen friends whether they work best on clear days or cloudy. The majority will probably answer that the first clear day after a storm is by all means the best. A small number will perhaps think the matter over more carefully, and then say that after a storm the clearness of the air and the brightness of the sun are certainly inspiring, but one really accomplishes more when it rains.

This divergence of opinion is due largely to the fact that climatic effects are of two kinds, psychological and physiological. We are always conscious of the first, but often unconscious of the second. The two are admirably distinguished in Hellpach's book on "Geopsychische Erscheinungen." An example will make the matter clear. It is well known that at high altitudes the number of red corpuscles in the blood increases enormously, and the capacity to absorb oxygen and to give out carbon dioxide is correspondingly modified. Yet many people can go to altitudes of 5000 feet or more without realizing that their physiological functions have been altered. To cite my own case, up to the age of twenty-one I had never been a thousand feet above the sea. Then I went to live at an altitude of 4500 feet. The only physiological effect of which I was conscious was unusual sleepiness for the first few months, but whether this was due to the altitude or to the dryness of the air, I do not know. For two or three years I never thought of the physiological effect of the altitude until one day, happening to have climbed to a height of 7000 feet, I began to run up hill. I lost my breath and became tired so quickly that I was alarmed and thought I must be sick. I was much relieved when it occurred to me that the altitude was not favorable for running up hill. Manifestly my physiological functions were different from what they were at sea level, although I was unconscious of it. On the other hand, psychologically I was daily conscious of living in a place where the air was extraordinarily clear, and where the mountains were always in sight across a 
splendid plain twelve hundred feet below us. Presumably both the physiological and psychological conditions had an appreciable effect upon the work of every day, but which was the greater it is impossible to tell.

In this connection Lehmann and Pedersen state an interesting fact. In Denmark and Norway they made a series of daily tests of the strength of three individuals by means of a dynamometer. They found that the change of atmospheric pressure due to an ascent of two or three thousand feet makes no appreciable difference. A similar descent, however, is accompanied by a marked increase of strength which disappears within three or four days. They suggest that this may be due to the persistence of abundant red corpuscles when people come down from high places. The red corpuscles multiply very rapidly under the influence of low pressure, but are slower in disappearing when the pressure once more increases. Thus, for the first day or two after a person has come down from the mountains, more than the normal amount of oxygen may be absorbed, and muscular strength correspondingly increased. Possibly this is why mountaineers are generally so irresistible when they descend upon the plains in sudden raids. My colleague, Professor H. E. Gregory, suggests that this may account for the fact that in the horse-races of the pioneer days of the southwestern United States, the poor, scrawny animals brought down from the mountains by the Indians usually belied their appearance and outran the better looking animals of the white men. They may have had an excess of red corpuscles. Professor Gregory adds that in some of the highland regions of South America there is a strict rule that before a race the competing horses must spend a certain number of days at the race course. This may have arisen because the animals which race directly after coming from the mountains are apt to win. The whole matter illustrates the fact that the various climatic elements may produce numerous effects of which we are almost unconscious. 
In our opinions as to the effect of the seasons or of daily changes of weather the relation between psychological and physiological influences is probably the same as in the case of altitude. The external conditions which we see and feel make a greater impression than those which prevail within our bodies. For example, most of us think that in the northern United States we work fast in winter. As a matter of fact, the statistics of ten thousand people show that we work slowly. The ordinary impression is apparently psychological. In order to keep warm out of doors in winter we walk fast and this leads us to think that we do everything rapidly.

Again, the blue sky, clear air, bright sunshine, and fresh colors of the first day after a storm are unquestionably inspiring, but does that inspiration make us work any better? May it not lead to a nervous excitement which actually hinders our work, by causing us to look out at the beauties of nature or to be less concentrated in other ways? The actual figures show that, taking the year as a whole, on dull days, especially the second such day when a storm begins to clear, we accomplish more than on bright days, even though we grumble about the clouds and the dampness. A bright day certainly makes us cheerful, but its chief helpfulness, so far as our work is concerned, is felt when it is a change from the monotony of a series of dull days. Clouds and rain produce exactly as much rejoicing when they succeed prolonged clear weather of the kind that we praise so highly. In America I have never seen so much rejoicing over a bright day as $I$ have seen in Turkey when the first rain fell after the long subtropical summer with its truly superb weather. The rejoicing was in part due to the fact that the coming of the rains means good crops, but $I$ have again and again seen exuberant joy among people to whom the crops made no difference whatever. I have seen Americans shout for joy because the clouds had come, and run out into the rain to let the cool drops refresh their faces. 
The questions which have just been asked and the possibilities that have been suggested show how indefinite are our ideas of the effect of climate. We understand its psychological effects fairly well. We know little of its physiological effects, however, except when they are extreme or unusual, or when people are sick or are in some other pathological condition. We need to determine how ordinary people are influenced by ordinary conditions of weather. That is the purpose of our present discussion. The most feasible way to do this, as has already been said, is to take groups of people who live in a variable climate, and measure their efficiency under different conditions of weather. The best and fullest test of efficiency is a person's daily work. If the subject does not know that he is being tested, so much the better. Piece-workers in factories are doing exactly what is required for our purpose. Accordingly, to begin with New England, I have taken the daily records of about 300 men and 250 girls,- most of them for a complete year. The records are distributed over the four years from 1910 to 1913 . The 550 people were employed in three factories in the cities of Bridgeport, New Britain, and New Haven, in the southwestern part of Connecticut. In all cases the officials in charge of the factories were most courteous and helpful in assisting me to obtain the necessary data, and I wish most warmly to express my gratitude to all concerned.

In the selection of operatives for such a purpose, various conditions must be fulfilled. In the first place, they must be pieceworkers who are paid according to their work and not at a fixed rate per day. In the second place, they must be employed in factories where their output is not limited by restrictions imposed by unions, or by the fear that if they earn too much, wages will be reduced. They must be doing work that is of essentially the same kind every day, so that their wages will not vary much because they are sometimes engaged upon new and unfamiliar tasks, or upon easy tasks at some times and 
hard ones at others. Furthermore, the same people must work steadily for month after month, throughout the year, if possible, and without taking much time off, as is such a common practice among factory hands. Finally, they must be working where there is abundant incentive to steady, faithful work, where the conditions of air and light are reasonably good, and where accurate daily records are so kept that the wages of each individual can be determined not only per day, but per hour. The number of factories where all these conditions are fulfilled is small, for they demand special types of occupation and a high standard of management. The three factories from which data have been obtained all meet the requirements. I explained what I wanted to the superintendent or to some other responsible official in each case. He then selected the group or groups of operatives whom he thought proper, and placed the figures in my hands. There was no selection on my part, and in each case I have used all the figures, omitting only a few obvious errors amounting to perhaps a quarter of one per cent.

An investigation such as is here set forth may follow two modes of procedure. One is to take a few persons and investigate each minutely in order to eliminate all accidental variations. The other is to take many people and get rid of the personal variations by averages. The wages of a workman depend upon many factors aside from the weather. One man has been scolded by his wife because he did not earn enough last week, another wants to buy some clothes for his little boy, and a third was drunk last night. A sore toe may have far more influence than any possible climatic variation. To ferret out all these accidental circumstances is out of the question. Fortunately, they do not occur every day, and most people work weeks at a time without being much influenced by them. Moreover, when large numbers of people work in different cities and during different years, the individual circumstances 
neutralize one another. The day that John Jenkins is disturbed because his boy has run away, Tony Albano is working hard because he is going to be married. Hence, by taking five hundred people we are able to eliminate accidental and individual circumstances and thus to reach a reliable result.

All three of the factories whence our data are obtained make hardware, but the work varies greatly. In one factory where Italians are the predominant nationality, brass sockets for electric lights, and other little brass fittings are made. One group of people was here engaged in tending machines. Some were turning out screws, others were putting pieces of sheet brass into automatic machines which turn out perforated plates. The work requires little skill, but much quickness and concentration. Another group, composed largely of Italians, was engaged in rolling and drawing hot brass, a heavy and somewhat difficult kind of work, requiring considerable strength. It is difficult because the brass must be used hot, and hence the men must work in abnormally high temperatures. At another factory, the one from which the largest number of records was obtained during three successive years, there were two main groups of men and two of women. The girls, from sixteen to twenty years of age, were Americans by birth, but of varied descent, being chiefly Irish, Germans, Scandinavians, English, and other north Europeans. Their work was the packing of hinges and screws, which are first wrapped in tissue paper and then placed in pasteboard boxes. This is a light, easy task in which dexterity and accuracy in picking up the right number of pieces are particularly important. For the first week or two when screws are packed, the tips of the fingers become sore, which makes the work proceed slowly. If a girl is changed from packing hinges to packing screws, her wages fall off for a time, but such changes are not frequent, and do not appreciably influence our figures. The men at this factory were of all ages, and 
were of the same races as the girls. They were engaged in grinding and buffing the hinges. The first operation is hard, heavy work. The hinges are held upon rapidly revolving emery wheels in order to grind them to a smooth surface. The other operation, buffing, is similar except that it is easier, for the hinges after being ground are polished upon rapidly revolving cloth buffs covered with emery dust. In the third factory, the operatives were of north European descent, almost all being native-born. Practically all, both girls and boys, were young, only a few being much over twenty years of age. The older girls leave to be married, and the boys, who are comparatively few in number, go elsewhere to find harder and hence better paid work. The work consists of the preparation of armatures and other wire coils for electrical purposes. Some operatives wind the wire upon rapidly revolving spools. Others put together the various parts of an armature. The work is light and not tiresome. It requires much dexterity and accuracy. Strings have to be tied at particular spots, pieces of paper must be inserted, the machines must be stopped when the right point has been reached, and little ends have to be grasped and inserted in their proper places. Taking our three factories together, the work ranges from the hardest to the lightest. It is of many kinds, requiring different degrees of strength and skill. The wages depend not only upon the amount of work completed, but upon the number of pieces rejected. In other words, the wages represent not only speed, but accuracy.

Let us now turn to the actual performance of the operatives. This is summed up in Figure 1. The four upper solid lines represent the work done week after week, each year'from 1910 to 1913. In Figure 1 the work of only about 410 people has been used. The rest have been omitted because the figures are not complete for a whole year. In only one case has there been a deliberate omission of figures which cover an entire year. That was the Italians who draw hot brass and hence are sub- 
ject to abnormal conditions of temperature. The method of procedure has been to find for each working day the average hourly wages for each group of operatives. Hourly wages have been used instead of daily, so as to make it possible to compare half-days with whole. If part of the operatives were absent on any particular day, they were simply omitted, and the average for the rest was taken. When the daily averages had been found, they were averaged together by weeks. In doing this, a half day, such as the Saturdays in summer, was given only half as much weight as a whole day, and days when part of the operatives were absent or when the machinery was shut down for a while, were given a correspondingly smaller weight. Thus allowance is everywhere made for irregularities in the number of employees and the length of time that they work. The final process consisted of combining the different groups. In order that each individual may have an equal importance, all the figures have been reduced to percentages. In this way if a girl earns a maximum wage of twelve cents an hour, it is called 100 per cent, while if a man's maximum wages are thirty cents, this sum also is called 100 per cent. Thus the variations in the wages of the girl and the man have the same weight in our final computations. Because of the enormous amount of work which would have been entailed, it was not possible to reduce the wages of each individual to percentages, but only those of each group. Had it been possible to work out each individual's wages separately, the results shown in our curves would probably have been more striking than is now the case.

In Figure 1 the height of the curves indicates the efficiency of the operatives at various seasons for four successive years. The fifth curve, heavier than the others, is the average of the preceding four. Turning to the upper line, we see that in early January, 1910, the efficiency of about 60 factory operatives in Bridgeport was 88 per cent as much as during the week of 
maximum efficiency that year. By the middle of the month it had fallen to 86 per cent. Later it rose fairly steadily to $\mathbf{9 6}$ per cent at the end of April. 'Then it dropped a little, rose still higher in June, and fell off distinctly during the summer, but not so low as in winter. During the autumn it rose steadily until early November when it reached the highest point of the year, after which it fell rapidly. In the same way each curve may be traced week by week. I shall return to them shortly. Meanwhile, it would be advantageous for the reader to look them over and draw his own conclusions, picking out the features which are common to all, and noting those which show different degrees of intensity from year to year.

In Figure 1 it will be noticed that the solid lines never reach 100 per cent. This is partly because they have been smoothed, and partly because they have been corrected to compensate for the increased efficiency due to practice. The process of smoothing, as everyone knows, is used by mathematicians to eliminate minor variations and thus permit the main trend of a curve to be more apparent. It merely takes off the high points and the low. The figures for three weeks are averaged, and the average is used instead of the original figure for the middle week. In the present case, and in practically all the curves in this book, the process of smoothing has been performed twice on each curve. If the letters $a$ to $e$ represent the average wages for five successive weeks, the figure actually used for the middle week, $c$, is obtained from the following equation:

$$
c=\frac{a+2 b+3 c+2 d+e}{9}
$$

This process of smoothing can add nothing to a curve; it simply takes away the less important details. If carried far enough it would produce straight lines.

In addition to smoothing the curves $I$ have corrected them 


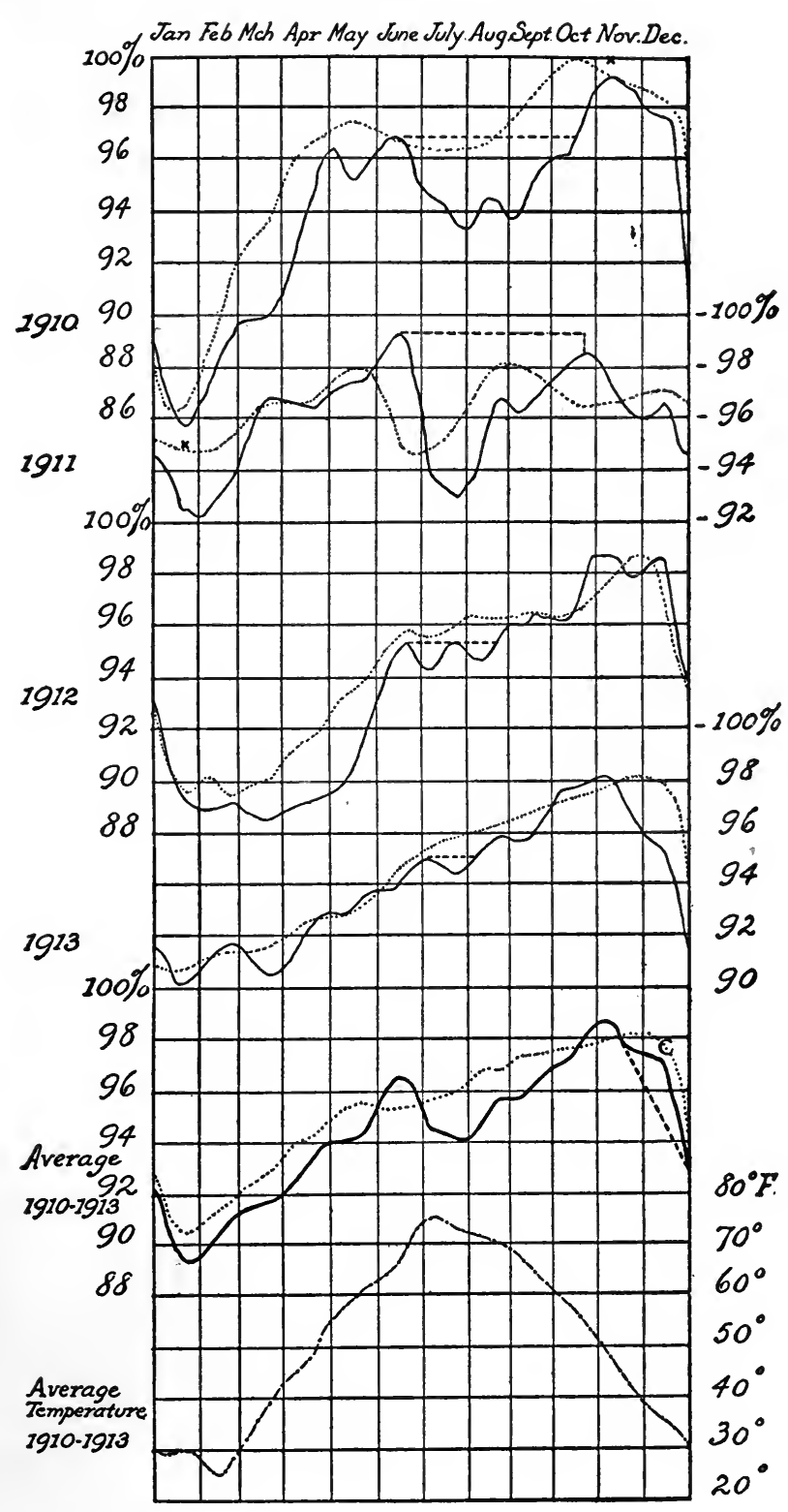

Figure 1. The Effect of the Seasons on Factory Operatives in Connecticut (solid lines) and at Pittsburgh (dotted lines) 
for the effects of practice. The curves for 1911, 1912, and 1913 are all based on the same factory at New Britain. When the wages for each year are averaged, we find that those for 1912 were 1.5 per cent higher than for 1911, and those for 1913 were 1.5 per cent higher than for 1912 . This means that constant practice caused the average employee, including both old hands and new, to be $\mathbf{1 . 5}$ per cent more skillful at the end of the year than at the beginning. Hence, from January onward, the curve rises a little until in December it is 1.5 per cent higher than it would be if the operatives had not grown more skillful. To eliminate this we simply tip the entire curve, raising the January end by three quarters of one per cent and depressing the December end by the same amount. The fluctuations, of course, remain unchanged.

In Figure 1, if there had been no correction, the highest and lowest points of the upper curve would lie at the points indicated by the crosses, and the other curves would be changed in corresponding ratios, there being no change at the end of June.

Turning to less technical matters, let us consider the degree of resemblance in the four upper solid lines of Figure 1. All are unmistakably low in January. Then from February to June we note a general rise, varied by minor fluctuations which differ from year to year. At the middle or end of June all reach a distinct maximum, although in 1912 and 1913 it is of slight proportions. Next we have a drop during the summer, 7 pronounced in 1910 and 1911, but not at all prominent in 1912, and scarcely noticeable in 1913. Following this there comes a series of irregular fluctuations, differing from curve to curve, but in each case culminating in a strong maximum at the end of October or the beginning of November. Six weeks later, in the middle of December, another slight maximum is suggested, and then all the curves drop suddenly. In the average curve the minor fluctuations tend to disappear. They are more or less accidental, and represent peculiar conditions which 
pertain to one year but not to others. The features that have been named, however, show no sign of disappearing. They are five in number, namely, an extremely low place in midwinter, and a less pronounced low place in midsummer; a high point in June, a still higher point at the end of October, and a hump in mid-December. Much the most variable feature is the low place in summer. 'This is highly significant, as we shall shortly see.

Before we discuss the causes of the variability of the summers let us consider the meaning of the curves as a whole. In the first place, it is evident that, although details may vary from year to year, the general course of events is uniformly from low in the winter to high in the fall with a drop of more or less magnitude in summer. To what can this be due? Did the factories shut down in January, or run on part time, or decrease work because of lack of orders, or to overhaul the machinery and so forth? Do the high wages in October and November indicate a special rush of orders at that time? Of course, any variations in the way in which the factory is running must be reflected in the wages of the operatives, but in the present case this does not apply to the main variations, although it may apply to minor details. In neither of the two factories here considered were the responsible heads able to offer any explanation of the peculiarities of the curves on the basis of factory management or the exigencies of business. Both are engaged in making staple articles, the chief demand for which comes in the spring when building operations begin. There is no Christmas rush on hinges and electric light sockets. After Christmas the factories shut down for a few days at the beginning of the year, but that ought to increase rather than diminish the hourly earnings. When operatives are working only part time they feel the need of earning as much as possible each hour. If part of the hands are laid off, that would also increase the average hourly wages, for the weaker ones would be 
dropped, and the average ability of those who remain would be high.

In this connection, it is important to understand that in these factories a man is free to work as hard as he wishes at any time of the year. The managers have deliberately adopted the policy of getting as much work as possible out of each operative. Overhead charges for interest, superintendence, bookkeeping, salesmen, and other outside expenses, and also the charges for unproductive labor such as engineers, janitors, and the like are no greater no matter how hard the productive employees work. If the producing operatives should double their output, most of the other expenses would scarcely increase at all. Hence, it would not only be possible to pay double wages for double work, but it would be profitable to the factory even if it paid perhaps $\$ 2.50$ where now it pays $\$ 1.00$. In view of these conditions, both factories have adopted systems whose special object is to encourage extra exertion. In one case part of the men work upon what is known as the "premium" plan. The management and the men have agreed that the various tasks shall be rated according to the number of hours which they may fairly be supposed to require. If a man performs an eight-hour task, he is to be paid for eight hours' work, no matter whether he does it in six hours or ten. If, however, he finishes the work in less than the stipulated time, he goes to work at another task for the rest of the period. For half of this time he is to be paid, while the factory gets the benefit of the other half. For example, if an eight-hour task is finished in six, the operative works two more hours. He is then paid for nine hours although he has only worked eight, while the factory gets ten hours' work and pays for nine. Thus both are the gainers. In one case the managers made a mistake in deciding upon the number of hours needed for a certain task. It had never been done quickly, and no one knew how rapidly it might be done. The man who does it soon earned ten or twelve dollars 
a day, where he formerly earned perhaps two and a half or three. Inasmuch as the management had agreed not to change the rates, they stuck to their bargain. The task only occupies one day each month, and the matter is not serious. Moreover, even though the operative earns such high wages, the work actually costs the factory less than when he was earning two dollars and a half.

In the other factory the girls are stimulated by bonuses. That is, they are not only paid for their work, but if they do more than is expected, they are paid a bonus. For example, if a girl's wages average about a dollar a day, and she does work worth $\$ 1.20$, she does not receive $\$ 1.20$, but $\$ 1.25$ or even $\$ 1.40$. The factory finds this worth while because so much more can be produced without any increase in charges for interest, office-work and other overhead expenses. When this bonus system was first introduced, it produced only a slight effect. The girls did not seem to care about the bonuses and made little effort to get them. Then the management realized that the parents were getting the extra money, and so it made no difference to the girls, most of whom gave their pay envelopes unopened to their fathers or mothers. Thereafter the bonus was not put in the pay envelopes, but was handed out in loose change. The girls kept it and began to work hard. In the third factory, whose figures are not extensive enough to be used in Figure 1, but which enter into other computations, a similar system is employed. A limit is set for each task. If the work is performed within that time a bonus is paid. Otherwise the operatives receive only the regular pay, no matter how much time they spend. The introduction of this system has increased the output of the factory enormously. Inasmuch as the various systems of bonuses and premiums are equally applicable at all times of the year, it seems impossible to find in the factories themselves any reason why earnings should be 
very low in January, moderately low in July, high in June, and very high in November.

We seem forced to search outside of the factories for the reasons for our seasonal fluctuations of wages. Such things as panics, hard times, or strikes would certainly cause a general change in the conditions of work, but nothing of the kind occurred during the period under consideration. Moreover, such events do not recur at the same time each year. Aside from the seasons, the only event which recurs regularly year after year at the same time and which is important enough to cause variations in wages is Christmas. Its effect can be seen unmistakably in each of the solid year-curves. In that for 1910 it appears in the little hump which culminates during the next to the last week in December. In the other three it comes a week earlier because this factory does not pay the week's wages on the Saturday of the week in question, but a week later, after there has been time to check up the work and make allowances for that which is poorly done. Hence, money for Christmas must be earned before the middle of December. If there were no such thing as Christmas, the wages would probably drop off in the way shown by the dash line in the average curve of Figure 1. After Christmas the wages probably drop somewhat lower than would otherwise be the case, for there must be a reaction from the previous effort, but it is noticeable that the wages do not reach their lowest ebb directly after Christmas, but keep on falling for nearly a month. Something else keeps them low. The Christmas hump is significant chiefly because it shows unmistakably that an outside stimulus which applies to all the operatives produces a distinct result. We may properly infer that the other permanent features of our curves are also due to some outside force which influences all the operatives. That force must be connected with the seasons, and it must be far more powerful than Christmas, for its effects are far greater. There seems to be no 
recourse except to ascribe the fluctuations of the curves to climate.

The verity of the conclusion just reached is strongly confirmed by comparison with other regions and other types of human activity. Figure 2, which, for convenience, is here divided into two overlapping portions, presents a series of curves arranged according to climate, those from regions with cold winters and cool summers being at the top, and cool winters and hot summers at the bottom. The curves range from the Adirondacks in northern New York to Tampa in southern Florida, and include one from Denmark. With them $I$ have repeated some of the curves of Figure 1 for the sake of comparison. The most remarkable feature of this series is that although there is great diversity of place and of activity, all the curves harmonize with what would be expected on the basis of Figure 1.

The first curve, A, is based on the work of Lawrason Brown, a physician who has published records of the weight gained by patients suffering from pulmonary tuberculosis at a sanatorium at Saranac Lake in the Adirondacks. A gain in weight in this disease is a favorable symptom, for one of the most marked effects of tuberculosis is to cause a wasting away of the flesh. In the present tabulation the patients who lost weight are not included, and a drop in the curve does not indicate loss of weight but merely a decreased rate of gain. If the patients who lost weight were also included, however, the form of the curve would still be the same, according to Brown. The Adirondacks, as everyone knows, have long cold winters, while the summers are delightfully bracing, being warm enough to be pleasant, but never hot enough to be debilitating. Hence, from about the first of April to the end of September the sick people make a marked gain. During the other six months, although they may gain more than would be the case in their own homes, 
Figure 2a. Human Activity and the Seasons

A. Gain in Weight of 1200 Tubercular Patients at Saranac Lake, N. Y., 1893-1902.

B. Work of 160 Factory Operatives in Connecticut, 1913. Repeated from Figure 1.

C. Work of 60 Factory Operatives in Connecticut, 1911. Repeated from Figure 2 .

D. Deaths in the State of New York, 1892-1906. Inverted. In the scale of this curve, 100 represents the average death rate.

E. Strength of 90 School Children in Denmark, 1904-6.

F. Work of 410 Factory Operatives in Connecticut, 19101913. Repeated from Figure 1.

G. Work of 65 Girls at Winston-Salem, $\mathbf{N}$. C., 1914 .

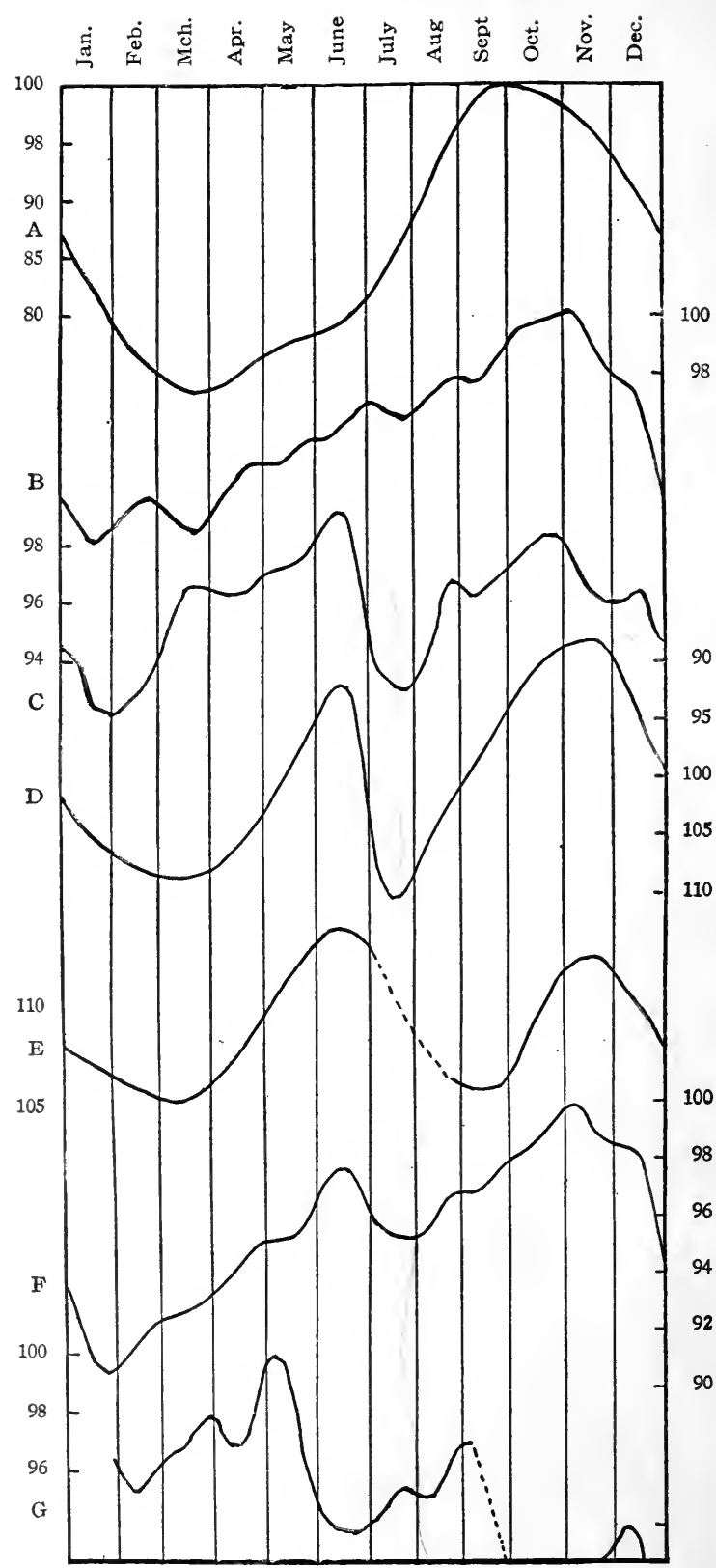




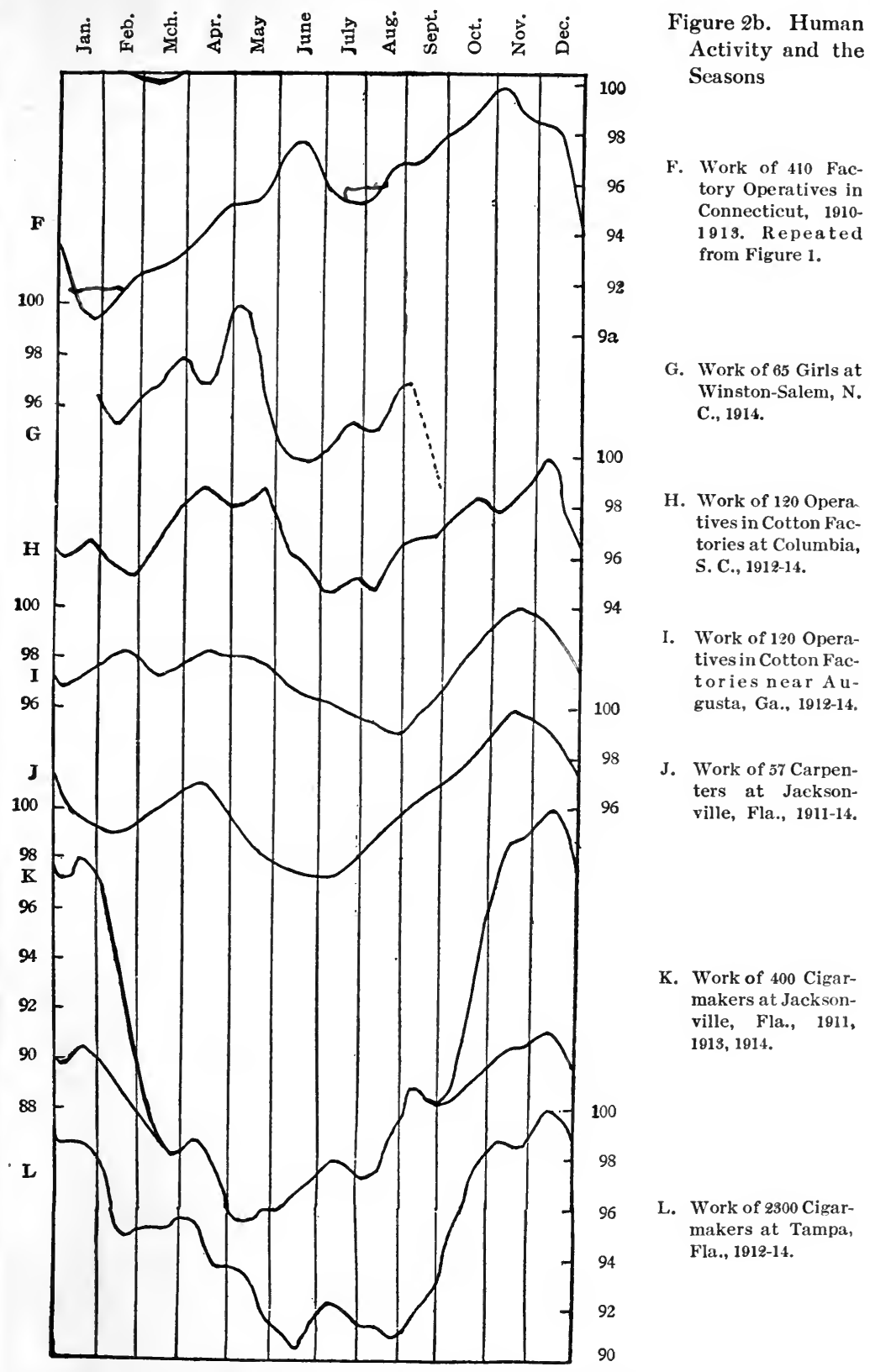

NoтE. In Figures $2 \mathrm{a}$ and $2 \mathrm{~b}$ the unit is a year's work of an individual. Thus "120 Operatives, 1912-14," means an average of 40 per year for three years. 
they do not find the climate nearly so advantageous as in summer, and the disadvantage increases until the snow disappears. The next curve, $\mathrm{B}$, is a repetition of the Connecticut curve for 1913. That year the winter was by no means so severe as is ordinarily the case in the Adirondacks. Hence, the curve does not remain low quite so long as does $\mathbf{A}$, and does not begin to fall so soon. The summer, however, was almost as cool as among the Adirondacks, and hence there is no drop during July.

The next pair of curves represent a year with a hot summer in Connecticut, $\mathrm{C}$, and the death rate for fifteen years in the state of New York, D. The curve for deaths has been turned upside down, so that high places represent few deaths, that is, high vitality corresponding to high energy in the factory operatives. In New York State as a whole the effect of the summers is very different from what it is in the Adirondacks. The cities swelter for a few weeks in July, and that sends the death rate up enormously, especially among children, who are quickly taken sick, and who either die after a few days' illness, or recover. That is why the curve drops so sharply in midsummer. In the winter, on the contrary, although it drops almost equally low, the maximum number of deaths per day does not come till March, although by that time the average energy of operatives has risen considerably. This is because people become sick in January and February, especially those who are elderly, and finally die after lingering illnesses quite unlike those of children.

The death rate of other places might be used quite as well as that of New York. The Japanese rate, for instance, is as follows, the figures being those for the ten years beginning with 1899. The figures represent percentages of the normal. Those for the state of New York, computed on the same basis are added in parentheses: 


\begin{tabular}{lr|lr|lr} 
January, & $104(105)$ & May, & $85(100)$ & September, $118(97)$ \\
February, & $108(108)$ & June, & $84(90)$ & October, & $102(89)$ \\
March, & $103(109)$ & July, & $97(110)$ & November, & $96(86)$ \\
April, & $90(106)$ & August, & $116(104)$ & December, & $98(93)$
\end{tabular}

Here the course of events is almost the same as in New York, but with significant differences which harmonize with the climates of the two places. Winter in Japan is less severe than in New York, and its effects do not last so long, for the highest mortality is in February instead of March. The Japanese summers, on the contrary, are characterized by prolonged heat, and also by great humidity, especially during the rainy season from July to September. At the end of this period the mortality is at a maximum. The debilitating effect of the summer lasts so long that November and December have a higher death rate than May and June. The late spring is especially favorable not only because of its own excellent character, but because it follows a winter which is not severe enough to be highly disadvantageous.

Curves $\mathbf{E}$ and $\mathbf{F}$ represent the strength of ninety school children in Copenhagen as measured by Lehmann and Pedersen, and the average energy of factory operatives for four years in Connecticut. The Danish measurements were carried on during the school years of 1904-05 when sixty children were tested weekly, and 1905-06 when ten were tested daily. By combining the two years into one and making allowance for the fact that children grow stronger from month to month just as factory operatives grow more skillful, we obtain curve $\mathbf{E}$ in Figure 2. Since neither summer nor winter is especially severe in Denmark the dip at the two seasons is the same. The maxima in June and November are almost synchronous with those in Connecticut. The minima are both delayed six or seven weeks, but the winter minimum in March agrees with the maximum death rate in New York. The summer minimum ought possibly to come in July or August, but the figures for those 
months are not obtainable, for during that time the schools in Copenhagen have vacation. In addition to this we should expect the Danish curve to lag a little behind that of Connecticut because of the maritime climate. Inasmuch as Denmark is constantly swept by west winds from the ocean it does not so quickly grow cool in winter nor warm in summer as does Connecticut where the prevailing winds are from the continental interior, which of course becomes rapidly warm in summer and cool in winter. Thus it appears that the strength of Danish children and the energy of factory operatives in Connecticut have an almost identical relation to seasonal variations of climate.

Judging by curves $\mathrm{C}$ to $\mathrm{F}$ in Figure 2 one might hazard the hypothesis that man is subject to a seasonal rhythm which repeats itself wherever he goes without regard to the climate. On this basis one would expect maxima of efficiency in June and November in all parts of the world. In curves A and B, however, we have already seen that where the summers are particularly favorable and the winters unfavorable this rhythm breaks down, and the June maximum and summer minimum dis= appear. If we go farther south to places where the winters are favorable and the summers very hot, we find a change in the opposite direction, for the winter minimum tends to disappear, and the summer minimum greatly increases and shoves the two maxima more and more into the winter until the two coalesce. 'This is evident in curves $G$ to $L$. These represent variations in the wages of piece-workers in southern factories, compiled according to the method used in Connecticut. Curve G shows the work of sixty-five Anglo-Saxon girls in a tobacco factory in Winston-Salem, N. C. They were pasting labels on cans. Notice how their winter minimum does not fall so low as that of summer, while the spring minimum comes in early May instead of June. In September the curve drops suddenly. This is because at that time the effect of the war began to be felt, the 
price of cotton fell so low that the South was in great distress, and the sale of the goods made by this factory began to be curtailed. Therefore the girls were not given as much work as they could do.

Curves $\mathrm{H}$ and $\mathrm{I}$ are from cotton mills in South Carolina and Georgia, and each represents two mills. In South Carolina the two mills are close together at Columbia, while in the other case they are fifteen or twenty miles apart, one being in Georgia near Augusta, and the other across the Savannah River in South Carolina. The operatives in all cases are of pure AngloSaxon stock, chiefly of the "poor white" class. Men and women are included in nearly equal numbers. Part are weavers, while others, engaged in the occupations known as slubbing, spooling, and speeding, tend machines which spin the thread and wind it on bobbins ready for the weavers. In all cotton factories the air in the weaving room, and to a less extent in the others, is kept at a high temperature and a high humidity. This is necessary because when the air becomes cool, or especially when it becomes dry, the thread is apt to break and cause blemishes in the cloth. Hence, in factories where high-grade goods are manufactured the inside temperature is so abnormal and the amount of goods produced depends so largely on the breakage that it is almost impossible to obtain satisfactory figures. In the factories here considered, however, nothing but coarse cloth is manufactured. The breaking of the thread does little harm, and relatively slight attention is paid to the temperature and humidity of the weaving rooms. Moreover, for slubbing, speeding, and spooling, the temperature and humidity make far less difference than for weaving. Hence, the variations in the amount of goods produced per person depend largely on the energy of the operatives in watching their machines and preventing them from standing idle because of broken threads, empty bobbins, or other accidents. The exigencies of business, that is, the demands for goods, make no difference to the opera- 
tives so far as their production per hour is concerned, for the machines run at a uniform speed whether the factory runs one day a week or six. The cotton mill curves are essentially the same as that of the tobacco factory. In $\mathrm{H}$ there is a double spring maximum, due to accidental circumstances, but the true maximum would probably come about the end of April. In I the spring maximum comes still earlier, that is in mid-April, as is appropriate to a place so far south. The autumn maxima, on the other hand, come later than in Connecticut, one being in early December and the other toward the end of November.

The work of carpenters in Jacksonville, as shown in curve $\mathrm{J}$, is different from anything else that is here considered because it is performed out of doors. The fifteen men per year whose records are here used were engaged in making the same kind of repairs time after time. A careful record of the hours that they spend is kept, but the number varies greatly on account of the weather. If it rains they cannot work. Summer is the rainiest period, but that does not tend to diminish the amount of work done per hour. In fact it increases it. The rain comes in hard showers, and while it is falling the men rarely try to work, and the time is not reckoned. When the rain is over they work better than before because the air is cooler, although still far from being cool. In winter, on the contrary, from December to March, the rain is a pronounced hindrance. It often comes in the form of a drizzle, and the carpenters try to keep on working while it is falling. Moreover, after the rain the wood is wet, there is apt to be a chilly wind, the hands feel numb, and everything is opposed to great efficiency. Yet in spite of this, more work per hour is done in February, the worst winter month, than in May, June, July, or August. If these men were at work in well-protected sheds which were heated on the occasional cool days, there is little doubt that in December their curve would reach a maximum higher than that now reached in November, while even if the following 
months were not still higher, they would at least show no pronounced drop.

The lower two curves, $K$ and $\mathbf{L}$, represent the work of cigarmakers at Jacksonville in northern Florida and Tampa in the southern part of the state. Those in Jacksonville were mostly Cubans, nearly two thirds being negroes, and the rest of Spanish descent. At Tampa only a handful of negroes is included, but a large sprinkling of real Spaniards is found among the Spanish Cubans. The curves for the cigar factories are compiled on a different basis from the others. The reason is that there are no definite hours. The factories are open twelve hours a day, usually from 6 a.m. to 6 p.m. The operatives saunter in as they please, provided they do not come later than 8 a.m., and leave when they choose, although an attempt is made to let no one depart before 4 p.m. While at work they sit close together at tables, and talk volubly except when a hired reader is vociferating the news from a Spanish newspaper. At some time in the morning they go out for a lunch, but are rarely gone as much as half an hour. Otherwise they stay at their work till it is finished.

Since there are no fixed hours, we cannot measure the exact earnings per hour, as we have done in other cases, but only the earnings in proportion to the time that a man might have worked if he had chosen to do so. In other words, we measure partly the actual capacity for work, and partly the inclination to work. In general the two seem to vary together, but the work of the New York State Commission on School Ventilation has shown that during short periods of high temperature the capacity may remain unimpaired, while the inclination declines. In the practical work of life a lack of inclination is almost worse than a lack of capacity.

During the warmer half of the year the possible working time in the Florida cigar factories may be properly reckoned as eleven and a half hours. In winter, however, the light at morn- 
ing and evening is not adequate for the somewhat exacting work of cigar-making. Therefore the men are not allowed to begin so early as in summer, nor to work so late. The exact time depends on the degree of cloudiness as well as the height of the sun. The factory managers say that in December the working time is curtailed an hour and a quarter or more for the month as a whole. In order not to make the winter production appear unduly large, I have reckoned that during the shortest week-not month-the working time is an hour and nine minutes, that is, 10 per cent less than in summer. Before and after that date it steadily increases to the solstices, when it reaches the normal. Thus we get the lower curve for Tampa. It drops low in summer and rises to a single maximum in winter. At Jacksonville the variations in the length of the working day on account of light are less than at Tampa because a lower grade of cigars is made, and hence the men are allowed to work under less favorable conditions of light. Inasmuch as the exact effort of dark mornings and evenings cannot be determined, I have drawn two lines at each end of the curve. The lower shows the wages if no allowance is made for light, and the upper if the full Tampa allowance is made. The actual truth lies between the two. For our present purpose this uncertainty makes no difference, since in either case we have the summer minimum and winter maximum which all our other studies would lead us to expect in this latitude.

The exigencies of business have more effect on the work of the operatives in cigar factories than in the others employed in Figure 2, but they do not determine the main fluctuations of the curves here used. In some cigar factories, to be sure, if business is slack the employees are often not allowed to make more than half or two thirds the usual number of cigars. For this reason I have omitted two factories whose figures I worked up, but whose curves I finally found to be almost wholly controlled by the supply and demand of the business. In the three 
factories which were finally used, however, that is, one at Jacksonville and two at Tampa, the operatives are only rarely placed on a limit. It is too expensive, especially where high-priced cigars are made, for four cigars a day have to be allowed to each man for "smokes." Each man smokes his full number, if not more, no matter whether he makes one hundred cigars or two hundred. The rush season for cigars begins in June or July and becomes increasingly intense until about the middle of November, by which time most of the Christmas orders have been received. Business is dullest in January and February. The operatives, however, know nothing about this, except as they see that men are taken on or discharged. The frequency of changes in the number of employees makes the cigar-maker's life hard, and accounts for much of his proverbial shiftlessness.

Another thing which affects the wages of cigar-makers is the dampness of the air. During the warm, damp days so characteristic of the Florida summer, the tobacco is very pliable and easily worked, while on dry, winter days its brittleness causes it to break so that the work is hampered. If it were not for this the difference between summer and winter would be intensified.

The most striking proof of the effect of the seasons is yet to be recorded. After this volume was in type $I$ obtained a series of data corresponding to those of the Connecticut factories and computed in the same way, but based on the work of operatives in a large factory engaged in making electrical apparatus at Pittsburgh, Pennsylvania. The employees whose wages were investigated were employed in winding wire coils, assembling the parts of motors, and other similar operations which demand accuracy and speed. The admirable way in which the records of this company are kept renders the figures of great value, but lack of time and funds has made it necessary to limit the present investigation to monthly, or, in 1912, bi-weekly averages of hourly earnings. For this reason the 
resulting curves, which have been inserted as fine dotted lines in Figure 1 (page 59), are smoother than those of Connecticut where the daily earnings have been utilized. The number of piece-workers on which these Pittsburgh curves are based is shown in the following table:

1910. Approximately 950 men and girls in winding section.

1911. Approximately 750 men and girls in winding section.

1912. Twenty-seven girls, winders; 42 men, tinners, blacksmiths, painters. In this case all the operatives were especially steady hands who worked throughout the year. In the few cases where they were absent, interpolation has been resorted to. Hence this year's curve is more reliable than the others which are based on all the operatives in a given section or in the whole factory without regard to whether they worked steadily.

1913. Approximately 7000 men and girls in the entire factory.

The general form of the curves for Pittsburgh and Connecticut is obviously the same. In 1910 notice the deep dip in January, and the moderate drop in summer. The next year, 1911, presents quite a different aspect. Because of the hot summer, the depressions in January and July are almost equally deep, the difference between the highest and lowest points is less than in most years, and the autumn maximum does not rise high above that of May or June, as is usually the case. The curves for 1912 both show a deep depression in winter which lasts unusually long. During the summer, on the contrary, there is not so great a decrease in efficiency as during the previous two years. Finally, in 1913, both curves rise almost steadily from midwinter to late fall, with only a slight drop in summer.

The agreement between the curves for Connecticut and Pennsylvania is far too close to be accidental. At Pittsburgh, just as at the other factories, variations in the total number of 
employees form an accurate measure of the demand for work, but these by no means vary in harmony with the actual production per operative. Often the average amount of work done by a given group of individuals, or by all the piece-workers, declines when the number of operatives increases, but quite as often the reverse is true. Hence the conditions under which the factories are run do not explain the variations in wages. Moreover, it stands to reason that the same irregular variations would not occur season after season in an electric factory in Pittsburgh and in brass and hinge factories in Connecticut 400 miles away unless all were under the same control. The only common controlling factor which varies in harmony with the curves of Figure $\mathbf{1}$ is the general character of the seasons. This is essentially the same in both places.

We have now seen that from New England to Florida physical strength and health vary in accordance with the seasons. Extremes seem to produce the same effect everywhere. The next question is whether mental activity varies in the same way. Lehmann and Pedersen made a series of tests of the ability of school children in addition. Their general conclusion is that mental work varies in the same way as physical, but reaches its highest efficiency at a lower temperature. This agrees with the investigations of a few other scientists, and with the general conclusions of the world as summed up in the old adage, "No one is worth a tinker's damn on whom the snow does not fall." Before we can accept this, however, tests are needed on a large scale. The most feasible method at present seems to be by means of the marks of students in such schools as West Point and Annapolis. There the young men live an extremely regular life with a minimum of outside distractions. Their recitations are graded with great severity and regularity, and a given subject is often taught six days in the week. The marks are handed to the heads of departments at frequent intervals and are posted where the students can see them. No class is taught 
in divisions of more than ten or twelve, so that every student has a full opportunity to show how well he is prepared. In order to avoid all chance of favoritism the instructors do not keep the same divisions month after month, but change every few weeks. Altogether it would be hard to devise a system which more thoroughly eliminates the human and accidental factors. As an instructor at West Point put it: "We are not really teachers. We are just put here as officers to see whether the cadets have studied their books, and to decide how many marks to take off." This is preëminently true in mathematics where the solution of a problem is either right or wrong and can be marked accordingly.

When I broached my plan to the superintendents at the two academies, it was received with much interest, and every facility was placed at my disposal. I take this opportunity to express my warm appreciation of their courtesy. Some of the instructors were commissioned to see that the proper records were available. The marks of individuals were, of course, not necessary. The various marks for each day or week were merely added, and averaged. The data here employed embrace the following: (1) The weekly averages in mathematics for the first-year, or entering class at Annapolis for the six academic years beginning with 190\%-08 and ending with 1912-13. These classes recite six times a week. (2) The daily marks for the first-year class in English at Annapolis for the year 1912-13. This class recites four times a week. (3) The daily marks in mathematics for a year and a half for the classes entering West Point in 1909 and 1910. Recitations are held six days a week. The classes at Annapolis average about 220 in number and those at West Point about 120. The entire number of students whose marks have been used is between seventeen and eighteen hundred, but as some of the marks cover a period of a year and a half, the total is equivalent to about 1900 students for a single year. 
All these marks have been combined into the three lower curves of Figure 3. Before discussing them a few words should be said as to the method of preparation. The systems of marking at the two academies are quite different. At Annapolis the department of mathematics tries to keep the average as nearly uniform as possible. If the instructors discover that the average is rising or falling they mark more severely or leniently to counteract it. At West Point, on the other hand, the marks regularly begin high at the opening of the term and fall steadily toward the end. There is no attempt to keep them at a uniform level, but the instructors merely mark harder and harder or give more and more work as time goes on. Both systems tend to mask the effect of the seasons. The influence of the deliberate attempt to keep the marks at a uniform level at Annapolis is largely overcome by using a series of six years. The irregularities of one year counteract those of another except where special circumstances such as vacations interpose a disturbing element at the same time each year. In the English department at Annapolis there is less stringency about keeping the marks at a uniform level, and those of a single year show clearly the normal seasonal trend. At the end of the year, however, I have omitted the two weeks before examinations because there was then a sudden spurt accompanied by abnormally high marks. Otherwise all the Annapolis marks without exception have been employed in computing the curves of Figure 3 .

At West Point it has been necessary to eliminate the effect of the steady fall. The method is the same as in the correction for increasing practice. In order to eliminate the effect of such things as football games, holidays, examinations, reprimands, or other circumstances which clearly have nothing to do with climate, I have omitted all the days whose marks fall more than 10 per cent above or below what would be expected at that particular date. Omissions of this sort are such a common procedure in astronomical and physical measurements 
that the mathematician requires nothing more than a mere mention of what has been done. To the layman it may seem that they are of great importance. In reality they rarely alter the general form of the final curves, for exceptionally high figures balance exceptionally low. In the second curve of Figure 3 the effect is slight except upon the first weeks in January. There the minor maximum which occurs just after the Christmas recess is only about half as large as it would be if no data were omitted. At Annapolis it is not necessary to omit the days of special events because the marks are not sub-

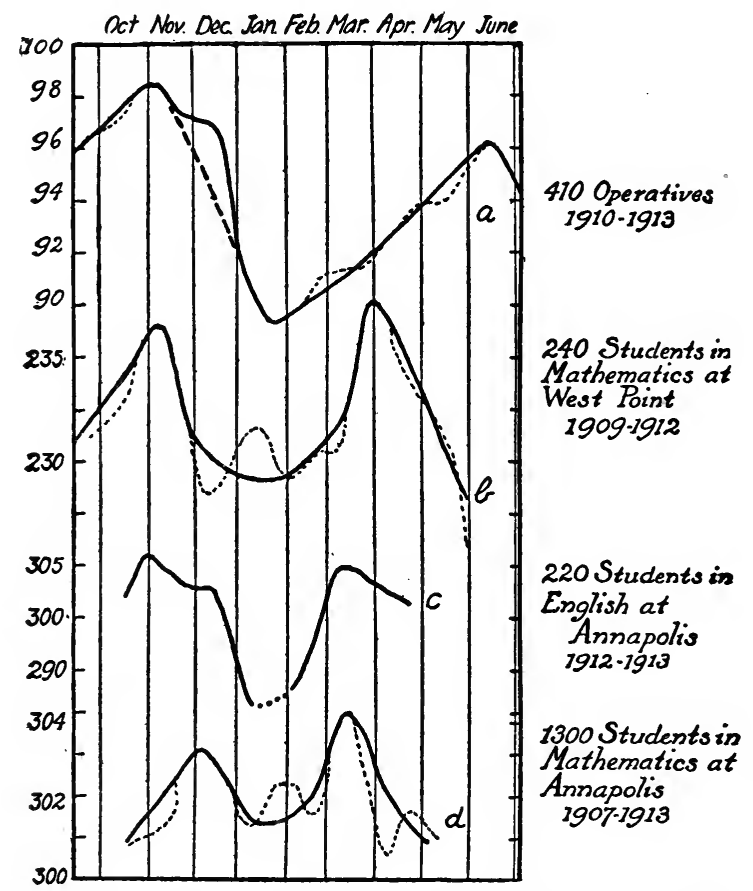

Figure 3. Seasonal Variations of Mental Compared with Physical Activity 
ject to such wide fluctuations. It is interesting to notice that the classes in mathematics there are influenced by the vacation, which comes at the end of January, just as at West Point. The English marks, on the contrary, are uninfluenced, probably because English is an easier subject than mathematics. Moreover, as it is taught fewer days per week, and hence has less weight in determining the final marks for the work of the whole year, the students do not devote so much energy to it.

By this time the reader has doubtless interpreted Figure 3 for himself. The upper line is the standard average curve for factory operatives in Connecticut. It is the same as the average curve of Figure 1, except that it begins in September instead of January. It is placed here to permit a comparison of the physical work with mental. The curves of mental activity all resemble it in having two main maxima, in fall and spring. At West Point, where the climate is essentially the same as in Connecticut, the mental maximum in the fall comes about ten days later than the factory maximum, while the spring maximum comes two and a half months earlier. Both occur when the mean temperature is a little above $40^{\circ} \mathrm{F}$. At Annapolis the maxima are, as it were, pressed toward the winter. The fall maximum in English, to be sure, begins early in November, but lasts till the middle of December. Since it represents the work of only a single year, it is less important than the curve of mathematics, whose fall maximum does not come till the first half of December. The spring maxima of both curves come in the middle of March. At Annapolis, just as at West Point, the time of best work is when the mean temperature is not far from forty degrees.

Summing up the matter, we find that the results of investigations in Denmark, Japan, Connecticut, Pennsylvania, New York, Maryland, the Carolinas, Georgia, and Florida are in harmony. They all show that except in Florida neither the winter nor the summer is the most favorable season. Both physi- 
cal and mental activity reach pronounced maxima in the spring and fall, with minima in midwinter and midsummer. The consistency of our results is of great importance. It leads to the belief that in all parts of the world the climate is exercising an influence which can readily be measured, and can be subjected to statistical analysis. It justifies us in going on with confidence to ascertain exactly what effect is produced by each of the climatic elements, such as temperature, humidity, and pressure. 


\section{CHAPTER V}

\section{The Effect of Humidity and Temperature}

Having seen that both physical and mental energy vary from season to season according to well-defined laws, let us now investigate the special features of seasonal change which are most effective. Temperature is far the most important, but before considering it, let us discuss those of minor importance.

$\$$ One of these is light. Many students have ascribed great influence to sunlight, and to its variations from season to season, or from one part of the world to another. For example C. W. Woodruff, an army surgeon, has written an interesting book on "The Effect of Tropical Light on White Men." Its main thesis is that the backwardness of tropical countries is due to excessive sunlight. The actinic rays at the blue end of the spectrum, especially those beyond the limits of vision, possess great chemical power, as is evident from the fact that by their aid photographs can be taken even when no light is visible to the naked eye. Such rays, when they fall upon the human body, are thought to stimulate the cells to greater activity. At first this is beneficial: if it goes to excess the cells apparently break down. The process is analogous to the ripening of fruit. A moderate change in the green tissues produces the highly favorable condition of ripeness : more brings on decay. Thus while the return of the light after the winter of the temperate zone may be beneficial, excessive light may be highly injurious.

So far as our factory operatives are concerned, no effect of light is to be discerned in the South, while in Connecticut it is at best only slight. The heavy line next to the bottom in Figure 
1 (page 59) shows that from mid-September to the middle of November the amount of work increases, although the days are growing shorter. This is exactly opposite to what would be expected if the shortness of the days were of primary importance. Moreover, in June when the days are longest we find a sudden drop. If the length of the days had much to do with the matter, there is no reason why more work should be done in November than in June. Nor should we find that a shortening of the days during September is accompanied by the same kind of increase in efficiency which is seen in March when the days, although of the same length as in September, are growing longer instead of shorter. For all these reasons we assign only slight importance to variations in the amount of light. Nevertheless some effect can apparently be detected. Compare the two lower curves of Figure 1. In spite of the low efficiency occasioned by the winter's cold, the curve of work begins to rise sooner than does the curve of temperature which is placed below it. The first appreciable lengthening of the days in January may cause this by its cheering and stimulating influence.

The line of reasoning applied to light applies also to the possibility that the variations of the curve of work depend on the extent to which people are shut up in the house. Obviously, this has nothing to do with the two maxima in November and May, nor with the minimum in July. In November people's houses have been shut up for a month more or less, while in May and July they are wide open, or at least as wide open as they ever are. The extremely low minimum in January, however, is probably due at least in part to the necessity of shutting up the house in winter. In October the weather becomes so cold that people begin to shut up their houses; they live in stuffy, unventilated quarters, and fail to take exercise in the open air. By the middle of November this has had time to produce an effect which naturally becomes more and more marked as the 
weeks go on. This would harmonize with the decline of energy from November to the middle of January. In January, however, the decline ought not to cease if it is due chiefly to confinement within the house. It ought to continue until about the middle of March, for not till that time do people in Connecticut begin to let in the outside air, and not even then to any great degree. As the curve of work has risen distinctly by that time, some other factor must intervene, presumably the increase of light to a slight extent, and the rise of the temperature to a larger extent.

A third factor to be considered at this point is the relative humidity of the atmosphere. A sharp distinction must be drawn between the humidity of the outside air and that which prevails within doors. Physicians, students of factory management, school superintendents, and many other people have long appreciated the harmful effects of the dry air in our buildings during the winter. On the other hand, we are well aware that great humidity during hot weather is also harmful. We are more conscious of its effects than of those arising from excessive dryness. This does not necessarily mean that the total effect is worse than that of dryness, however, for hot, humid days are much rarer than the winter days when the air in our houses is drier than that of the majority of deserts.

So far as our curves of work are concerned, humidity does not seem to be responsible for the fluctuations except as it is influenced by temperature. In other words, the average humidity of the outside air from season to season does not vary in such a way as to cause maxima in May and November, and minima in January and July. The average humidity of the outside air in November and in January is not greatly different. Nevertheless, the inside humidity is probably an important factor in causing the low efficiency of midwinter.

The relation of work and humidity among the factory operatives of Connecticut is illustrated in Figure 4. There the year 
has been divided in three parts: (1) winter, (2) spring and autumn, and (3) summer. In each part all the days having a given humidity have been averaged together, and the smoothed results have been plotted. The heavy, solid lines represent what I believe to be the true conditions when other disturbing elements are removed; while the dotted lines show the actuaff figures. In winter the dampest days are unmistakably the times of greatest efficiency. We may shiver when the air is raw, but

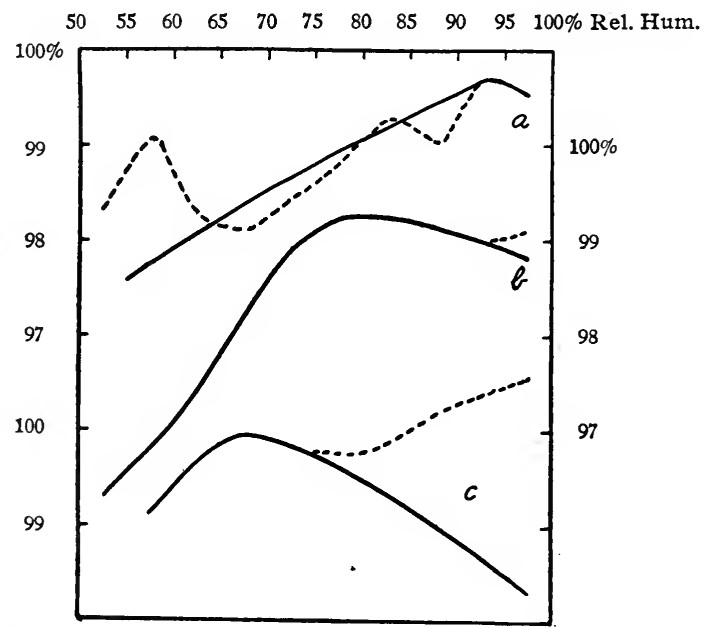

Figure 4. Relative Humidity and Work in Connecticut a. Winter. b. Spring and Fall. c. Summer

we work well. The reason is twofold. In general the temperature rises at times of excessive humidity, and this in itself is favorable. Moreover, the air, when taken into the house, does not need to be warmed so much as under other conditions, and thus it remains comparatively moist.

In the spring and fall, when the temperature ranges from freezing to $70^{\circ}$ with an average of about $50^{\circ} \mathrm{F}$., the best work is performed with a relative humidity of about 75 per cent. 
In other words, neither the dry nor the wet days are the best. 1 The summer curve is the most complex of the three. It rises first to a maximum at 60 or 65 per cent, then falls, and once more rises to a higher maximum. The first maximum seems to be due to humidity, the second to temperature. A hot, damp day is unquestionably debilitating. The majority of the dampest days in summer, however, are comparatively cool, for they accompany storms. The coolness counterbalances the humidity, and people's efficiency increases. Hence, we disregard the right-hand maximum and conclude that with an average temperature of $65^{\circ}$ to $70^{\circ}$ a relative humidity of about 60 per cent is desirable.

The most unmistakable feature of the curves as a whole is that they show a diminution of work in very dry weather. This evidently has a bearing on the low level of the curve of energy in winter. At that season the air in our houses ought to have a humidity of 60 or 65 per cent, but most of the time the figure $\}$ is only 20 or 30 . On very cold days the percentage is still lower. For instance, if the outside air has a temperature of $14^{\circ} \mathrm{F} .\left(-10^{\circ} \mathrm{C}\right.$ ) and contains all the moisture it can hold, which is usually not the case, its relative humidity when it is warmed to $70^{\circ} \mathrm{F}$. will be only 12 per cent. Even on days when the outside humidity rises to 100 per cent and the temperature is $40^{\circ}$, the air in an ordinary steam-heated house has a relative humidity of only 35 per cent, which is far below the optimum. Apparently, this extreme aridity has a markedly debilitating effect. It also probably dries up the mucous membranes in such a way as to greatly increase our susceptibility to colds. In this way it is probably one of the most important factors in causing February and March to have the highest death rate of the year. The agreement of our conclusions as to humidity with those obtained by other students of the problem gives good ground for believing that the method here employed is sound. 
While the effects of light, of closed houses, and of excessive dryness explain part of the fluctuations of the curve of work, they have little bearing on any season except the winter. Another matter which may be suggested in this connection is vacations. These, like many other conditions of human life, are largely seasonal. Do people work fast in the fall because they have been rested by vacations? In professional occupations and in business this certainly seems to be the case, but not among factory operatives. As a rule such people do not take summer vacations. They usually stop work at irregular intervals, or else after Christmas when many factories shut down or work on part time for a few days to prepare for the new year. The form of our main curve, however, shows that neither at this time nor in summer do vacations produce any appreciable stimulating results. If they were the cause of fast work, the curve ought to be highest within a few weeks after the people return to work, but this is not the case. During the vacation. period of July and August the amount of work is moderately low, and in early January, after the Christmas break, very low. At the end of August it begins to increase, and increases steadily for two and a half months. The maximum in November is so long after the vacation period that it can hardly have anything to do with it.

What has just been said has an important practical application. There is a common idea that people need vacations in summer. Of course there are strong arguments for this, since pleasant recreation is then possible out of doors. Nevertheless, the need is apparently greater in winter than in summer. To meet this it is probably wise that work should be light during the winter. Already, as everyone knows, many factories run on part time during the first few weeks of the year, and now we see that there are strong physical reasons for this. Another important suggestion afforded by our curves is this: If the operatives of a factory, or people engaged in any other kind 
of work, are to be speeded up, the time to do it is when nature lends her aid. To speed up at the end of January is analogous to taking a tired horse and expecting him to win a race. Later in the year, however, during the spring, especially in May, people may apparently be pushed to the limit, and will not suffer, because their energies are naturally increasing. This is still more the case in October and early November. After the middle of November pressure may produce important results, as we see at Christmas. Nevertheless, the chances are that if continued it will produce undue exhaustion, followed by a serious reaction. Possibly the nervousness of Americans is due partly to the fact that although we relax somewhat in summer, we keep ourselves at high pressure through the winter when the need of relaxation is greatest.

Turning now to temperature, we see that in Figure 1 (page 59) the lower curve, showing the march of temperature through the year, and the Connecticut curve just above it are similar in many ways. Both are low in midwinter. From February onward they rise together until about the middle of June. Then the efficiency curve falls while the other goes on rising, a condition which fully accords with ordinary experience. The fall of the efficiency curve begins when the average temperature has risen to about $68^{\circ}$. When the temperature stops rising, the work stops falling, and then remains nearly steady through July. At the end of July the mean temperature has fallen to about $\boldsymbol{7} \mathbf{1}^{\circ}$. During the succeeding period of favorable temperature the two curves disagree, for the amount of work goes up while the temperature falls. When the average temperature falls below $48^{\circ}$, however, and begins apparently to be unfavorable to physical exertion, the curve of work turns downward. Thereafter, if we omit the Christmas hump and use the dotted line, the temperature and the amount of work decline together until they reach the lowest point in January. It is worth while once more to call attention to the somewhat surprising fact that in south- 
ern New England, contrary to our ordinary opinion, low temperature seems to be much more injurious than high.

This by no means indicates that high temperature is favorable. Let us consider the effect of the high temperatures of the four successive summers shown in Figure 1 (page 59). Compare the summer dip in the Connecticut curve, that is, the area below the horizontal lines, with the heavily shaded areas of Figure 5, which shows the average temperature each week during the four summers from 1910 to 1913. The black portions indicate weeks having an average temperature night and day of over $73^{\circ}$. The size and distribution of these periods of extreme heat are in close correspondence with the amounts by which the curves of Figure 1 drop below the horizontal lines during the summers. This is illustrated in the following little table. The line marked "deficiency in work" indicates the amount by which the efficiency of the operatives diminished because of the hot weather, that is, the area below the horizontal lines of Figure 1. The year when the diminution was greatest is reckoned as 100 and the others in corresponding ratios. The other numbers show the area of the heavy black shading in Figure 5 and represent the intensity and duration of the hot weather. Here, too, the year of maximum heat is represented by 100, and the others by proportional values.

$\begin{array}{lrrrr}\text { YEAR. } & 1910 & 1911 & 1912 & 1913 \\ \text { Deficiency in work, } & 58 & 100 & 8 & 2 \\ \text { Severity of heat, } & 52 & 100 & 50 & 34\end{array}$

In each case 1911 stands highest, 1910 next, and then 1912 and 1913. In 1911 the heat was not only more extreme than during any year for about a century, but it lasted long, three weeks at one time and two at another. The death rate for July, 1911, in Massachusetts was 50 per cent greater than in the preceding June. In 1910 the hot weather was not so severe, 


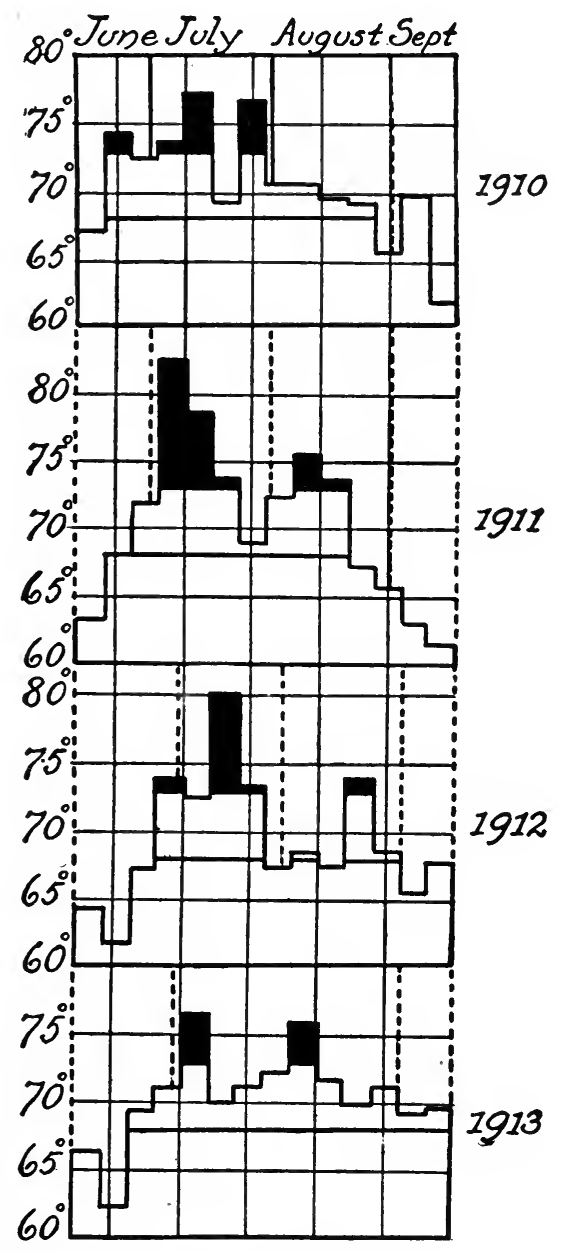

Figure 5. Average Weekly Temperature During the Summers of 1910-13 in Connecticut 
it lasted four weeks instead of five, and was divided into three parts instead of two. In 1912 the number of hot weeks was the same as in 1910. One was extremely hot, but the rest were not bad. Moreover, they did not come together, and the last was separated from the others by three cool weeks during which people had time to recover, which was not the case in 1910. Finally, 1913 was a very mild year with only two extreme weeks which were separated by three moderate weeks. The year 1914 was even milder than 1913, and when its figures are compiled, they will probably show no fall whatever in the rate of work.

An examination of Figure 5 makes it clear that only the extreme weeks are harmful. Thus 1911 was a truly terrible summer and 1913 a delightful one. Yet during 1911 the temperature remained above $69^{\circ}$ for only eight weeks while in 1913 it remained above that figure for twelve weeks. Thus it appears that if the average temperature does not rise above about $70^{\circ}$, and if the noon temperature rarely exceeds $80^{\circ}$, the physical capacity of European races in the United States does not suffer any serious diminution. A slight further rise however-only four or five degrees-produces disastrous consequences. A single week of such weather does no great harm, but when several weeks come together people rapidly become weakened. The weakening is greater than appears in our diagrams, for during hot spells many of the operatives, particularly the girls, stop work entirely or stay at home in the afternoon. Those who remain are the stronger ones, and naturally their wages are higher than the general average. Moreover, in 1911 the heat was so intense that the factory shut down for two or three days. Thus, if allowance is made for these facts, the difference which a few degrees make between two summers such as 1911 and 1913 becomes even more pronounced. The full effect of a hot summer, especially when it is very damp, may be gauged by the death rate in Japan (page 69). Sep- 
tember is there 18 per cent worse than the average, instead of 3 per cent better as in New York.

The relation between the temperature and the amount of work in winter during the four years under discussion is not so pronounced as in summer, but can easily be detected. The hot summer of 1911 was followed, as frequently happens, by an uncommonly cold winter. The reason for both is the same. Unusually hot weather in New England is commonly due to the movement of heated air from the interior toward the coast, particularly from the southwest to the northeast. Cold winters are due to a similar transportation of air from the interior, this time from the northwest. The interior of a continent, as is well known, cools off very rapidly in winter and becomes hot rapidly in summer. When these conditions are carried from the interior to the coasts, they bring to New England what climatologists call a continental climate instead of the more maritime climate which usually prevails.

The effect of the cold winter of 1911-12 can easily be seen in the curve for 1912 in Figure 1 (page 59). That year the average temperature where the factories are located was $19.0^{\circ}$ for the first five weeks compared with an average of $32.7^{\circ}$ for the three other years whose curves are given. For the next five weeks the temperature was $24.4^{\circ}$ compared with $35.3^{\circ}$. The effect of this is seen in the low position of the 1912 curve of work far into the spring. The fact that the energy of the operatives remained low after the temperature began to rise suggests that the effect of extreme conditions may last long after more normal conditions begin to prevail. The same thing is suggested by the fact that after the summer of 1911 the curve of work does not rise so high in November as in the preceding May. During each of the other three years the November maximum is higher than its predecessor. Although a single winter and a single summer are not enough to prove that the effect of extreme conditions does thus persist for many 
months, they suggest that a long stay in an adverse climate may produce results which last for years. In spite of a previous statement, it appears that our plan of escaping from possible extreme heat by taking summer vacations in the mountains or at the seaside is wise. Equally wise is the growing habit of getting away from the severe cold for a while in winter. The only trouble is that those who most need such a change are rarely the ones who get it. If people could spend the summer on the Maine coast, the winter in Georgia, and the rest of the year in New York, they ought to be able to do the best kind of work at all seasons almost without the necessity of a vacation.

The effect of temperature may be shown in more ways than have yet been presented. Let us determine how fast people work on days having various temperatures, no matter in what month they occur. The very cold days, of course, all come in winter, but may be in December, January, or February. The very hot days come anywhere from May to September, while days with a temperature of about $50^{\circ}$ occur in almost every month of the year.

The method can be illustrated by taking all the Mondays, all the Tuesdays, the Wednesdays, and so forth, and averaging the work of each day of the week. This has been done for $\mathbf{2 3 0}$ people. The results are shown in Figure 6, which is inserted to show exactly how our results are obtained, and how necessary it is to have a large number of people. We are striving to separate the effects of one single condition from those of a vast number. We start with the wages of individuals which vary from day to day for hundreds of reasons wholly unconnected with the day of the week or the weather. The variations are so great that even if a man is influenced by the approach of pay-day, for example, we should probably not be able to detect it if we merely looked at his wages for a month or two. Therefore we average all the people of a department together, and 


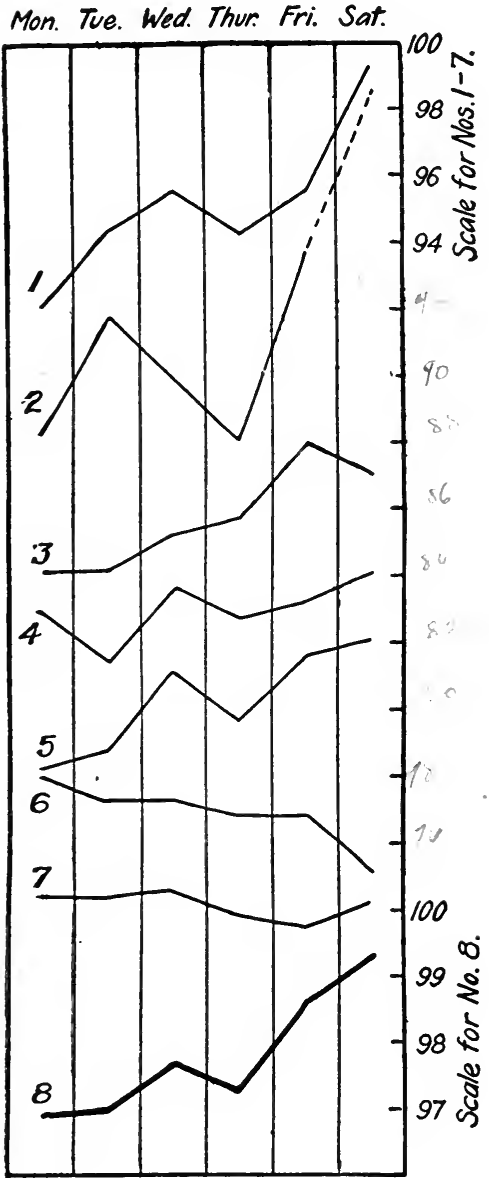

Figure 6. Effect of the Days of the Week on Piece-Workers

1. 60 Men, April-July, 1912.

2. 60 Men, August-November, 1911.

8. 49 Girls, 1912.

4. 31 Men, 1912.

5. 14 Girls, 1912.

6. 24 Men, 1912.

7. 60 Men, January-March, 1910.

8. Weighted A verage of Nos. 1-7, or approximately 230 People for One Year. 
obtain results such as appear in Figure 7. This shows the actual wages -in percentages of the maximum - which were earned by 170 people divided into five departments during five weeks in January and February, 1913. There is little uniformity in the different lines. Where one goes up the other

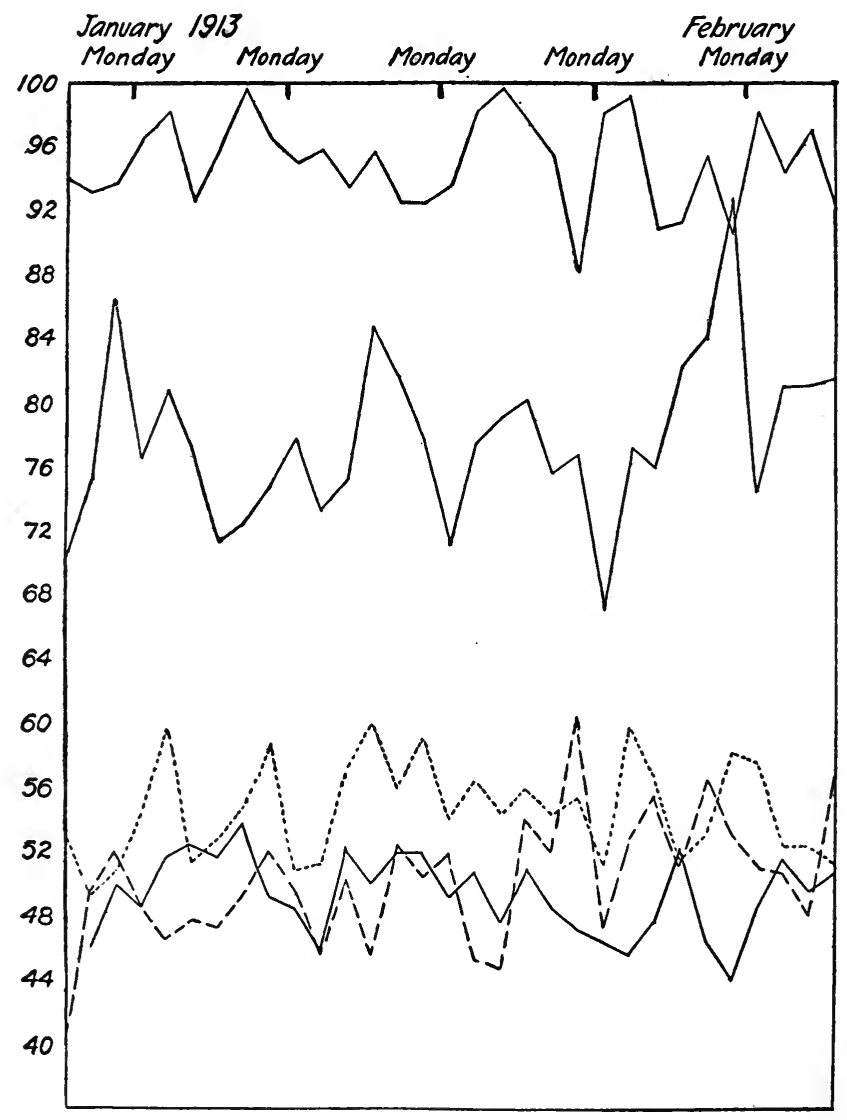

Figure 7. Variations in Daily Wages. Five Departments (170 people) at New Britain, Conn. 
goes down. Yet closer examination shows that in at least four out of the five departments the wages during the last two weeks were a little larger than during the earlier weeks. The variations of the different curves are in part due to the persistence of individual vagaries which have not yet been averaged out, and in part to conditions affecting whole departments. For example, a foreman is cross one day and good-natured the next; a belt breaks and delays work; or some of the operatives converse so much that their work suffers appreciably. If a number of departments are averaged together these accidents, as well as those which pertain to individuals, disappear, but not until a great many people are considered.

To find the effect of the days of the week, we take data such as are illustrated in Figure 7, select all the Mondays, Tuesdays, and so forth, and average each day. This gives the curves of Figure 6. Here we begin to detect a certain degree of uniformity, although the accidents and peculiarities of each department are still in evidence. On the whole, however, the curves are higher at the end of the week than at the beginning. All, to be sure, are irregular, and the two lower-not counting the heavy line-slope in the opposite direction to the rest. The fact that the remaining five slope in the same direction shows, however, that these different people in different factories and during different years were subject to a common influence. Finally, we average all the departmental curves, giving each a weight proportional to the number of operatives. Thus we obtain the heavy lower line of Figure 6. This is still irregular, for although 230 people are included, all influences other than that of the days of the week are not yet eliminated. Nevertheless, the wages clearly increase toward the end of the week. If the operatives were paid by the day instead of by the piece, this would probably not be the case. They would work slowly at the end of the week by reason of being tired. With the pieceworkers, on the contrary, other considerations are dominant. 
If they work a trifle slowly on Monday, they can make it up tomorrow. On Tuesday they can be slow and make it up on Wednesday, but a few who fell behind on Monday are beginning to work harder. So it goes from day to day until on Friday and especially Saturday many feel that their earnings for the week are insufficient, and hence make an extra effort. In some cases this may not be true, as in the curve next above the average curve. Yet it remains a general truth, and the lower curve of Figure 6 is a concrete expression of the fact that in the factory under discussion there is a difference of at least 2 per cent between Monday and Saturday. Possibly the real difference is greater, and is obscured by other circumstances. In the cigar factories of Florida it rises to a far greater value, for the Cubans are much disinclined to work after a holiday. Not only are about 10 per cent of the operatives absent on Mondays, but those who are present come so late or are so indisposed to work that they accomplish only about 80 per cent as much work as on other days. This is so important a matter that allowance for it has been made in computations where individual days rather than weeks are concerned. The figures for each day of the week for $\mathbf{7 8 0}$ men at Tampa are as follows: Monday, 81.9 per cent; Tuesday, 98.7 per cent; Wednesday, 99.8 per cent; Thursday, 100 per cent; Friday, 98.3 per cent; and Saturday, $9 \% .9$ per cent. The other days are reckoned as of equal weight, but the figures for Monday have been increased in the ratio of 82 to 100 .

By the employment of a method similar to that used with the days of the week we obtain the curves shown in Figure 8. These are based on varying numbers of people, from one to over $\mathbf{7 0 0 .}$ Yet all show the same general character. With the exception of the last two, which are distinctly the least reliable, the physical group all reach maxima at a temperature between $59^{\circ}$ and $65^{\circ}$. Even the two less reliable curves reach their maxima within the next four degrees. All the curves decline at low 


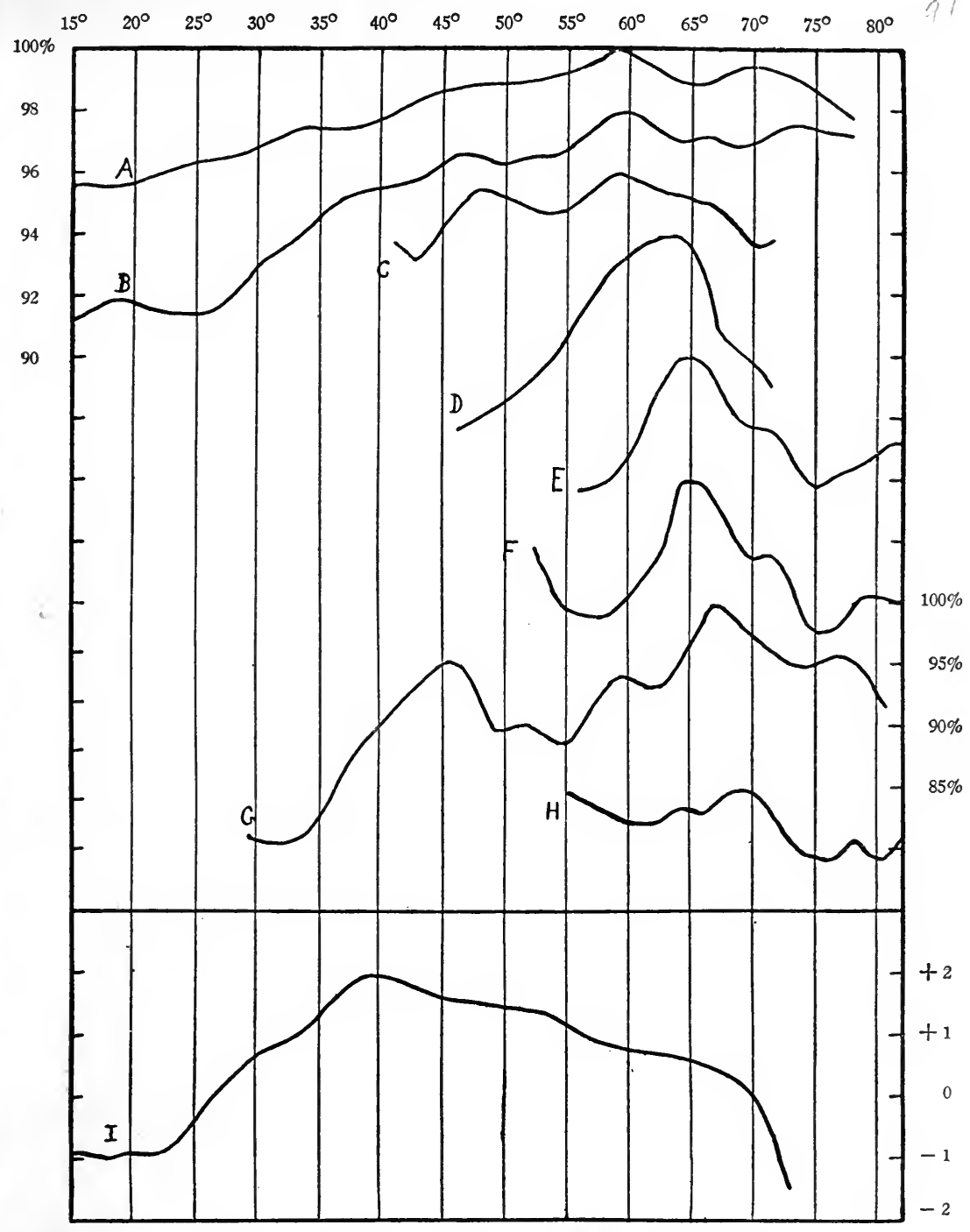

Figure 8. Human Activity and Mean Temperature

A. 300 Men in Two Connecticut Factories, 1910-13.

B. 196 Girls in One Connecticut Factory, 1911-13.

C. One Man (P) in Denmark, June-December, 1906

D. One Man (L) in Denmark, June-December, 1906.

E 380 Cigar-makers in Factory B at Tampa, Fla., 1913.

F. 400 Cigar-makers in Factory $A$ at Tampa, Fla., 1913.

G. 3 Children Typewriting in New York, 1905-6.

H. 880 Cigar-makers in Factory B at Tampa, Fla., 1912

I. 1560 Students in Mathematics and English at West Point and Annapolis, 1909-1913.

Note. All the curves except $G$ and $I$ are drawn on the same scale. The maximum in every case is reckoned as 100 . 
temperatures, that is on the left, and also at high. The irregularities at the extreme limits are largely due to the fact that there the number of days is so small that exact results cannot be hoped for.

Figure 8, with the brief statements which accompany the respective curves, tells the whole story so plainly that it scarcely seems worth while to amplify it. Several points, however, may well be emphasized. For instance, below a certain temperature, which varies from curve to curve, a further reduction does not seem to produce much effect. People apparently become somewhat hardened, or else the conditions within the warmed houses do not change much in spite of a change in the outside air. Another noticeable thing is that the curve for girls has greater amplitude than that for men in the same region. Part of this is due to the inclusion of the group of Italians, already referred to, who are engaged in drawing hot brass and hence are benefited by the coldest kind of weather. Even if they were omitted, however, the girls' curve would still vary more than that of the men. This seems to indicate that either because of their sex or because of their age, girls are more sensitive than men.

Another point brought out by the curves is that as we go to more southerly climes the optimum temperature of the human race becomes higher. It is important to note, however, that the variation in the optimum is slight compared with the variation in the mean temperature of the places in question. For instance, in Connecticut the optimum seems to be about $60^{\circ}$ for people of north European stock. This is about ten degrees higher than the mean temperature for the year as a whole. In Florida, on the other hand, the optimum for Cubans is about $65^{\circ}$, which is five degrees lower than the mean temperature for the year at Tampa. In other words, with a difference of twenty degrees in the mean annual temperature, and with a distinctly northern race compared with a southern, we find that the 
optimum differs only about $5^{\circ} \mathrm{F}$. This seems to mean that for the entire human race the optimum temperature probably does not vary more than ten or fifteen degrees.

We have not yet pointed out all the important matters suggested by the curves of Figure 8 . Above the optimum the curves in general begin to decline quite rapidly, but then cease to do so, and at high temperatures are not so low as would be expected. This is largely because in hot weather many operatives, especially the girls and the Cubans, do not feel like work, and so stay away from the factories. Those who come in spite of the heat are the strongest and most efficient. Naturally, their average wages are higher than those of the ones who stay away, and hence the general level of our curves is too high in the portions based on the hottest weather. The mental curve, how ever, falls off very rapidly at high temperatures. This is because the students are obliged to be present on hot days just as on others. They must recite whether they wish or not. Hence, their curve is more reliable than the others. In this connection some experiments carried on by the New York State Commission on Ventilation are of interest. In an attempt to determine the most favorable conditions of ventilation the Commission placed a large number of persons in rooms where the temperature and humidity were under exact control, and measured their strength, mental activity, food consumption, and other conditions. The experiments lasted six or eight hours a day, and each set of subjects was tested for several weeks. Three temperatures were used, namely, $68^{\circ}, 75^{\circ}$, and $85^{\circ}$. No appreciable effect upon strength could be detected, nor upon mental activity, and various other functions. This is probably because the experiments were not sufficiently prolonged. That is, the subjects were in the experimental rooms only a third or a quarter of each day, and hence their condition did not have time to change appreciably. Although the subjects did not 
lose in actual strength however, their inclination to work declined at high temperatures even within six or eight hours.

Thus far we have been dealing with large bodies of people. It is peculiarly important to find that no matter how small the number, the same relation to temperature is discernible. One of the curves in Figure 8 shows the speed and accuracy of three children who wrote upon the typewriter a few stanzas from the "Faerie Queen" or a page from George Eliot daily for a year, and weekly for another year. Their records were kindly placed at my disposal by Professor J. McK. Cattell. I have corrected them for the effects of practice, and have combined speed and accuracy in such a way that each has the same weight. At one period, for some unknown cause, the efficiency of the children declined greatly for two months or more. If this were eliminated their maximum would come at a lower temperature than now appears, probably not much above $60^{\circ}$. In the curves of individuals, we are fortunate in having careful tests made by two psychologists, Lehmann and Pedersen, at Copenhagen. They tested their own strength daily with the dynamometer, and their curves, copied directly from their monograph, are before us. One is uncommonly regular with a maximum at $64^{\circ}$. The other, less regular, has its maximum at $59^{\circ}$. The agreement of Danish curves based on single individuals with New England curves based on hundreds is highly important.

The last thing to be considered in Figure 8 is the mental curve at the bottom. It is based on so large a number of people, and is so regular, that its general reliability seems great, although I think that future studies may show the optimum to be a few degrees higher than is here indicated. It agrees with the results of Lehmann and Pedersen. Furthermore, from general observation we are most of us aware that we are mentally more active in comparatively cool weather. Perhaps "spring

I fever" is a mental state far more than a physical. Apparently people do the best mental work on days when the thermometer 
ranges from freezing to about $50^{\circ}$-that is, when the mean temperature is not far from $40^{\circ}$. Inasmuch as human progress depends upon a coördination of mental and physical activity, we seem to be justified in the conclusion that the greatest total efficiency occurs halfway between the mental and physical optima, that is, with a mean temperature of about $50^{\circ}$.

Curves such as those of Figure 8 are not peculiar to man alone. They are apparently characteristic of all types of living creatures. To begin with plants, many experiments have determined the rate of growth of seedlings at various temperatures. The commonest method has been to grow different sets of seedlings in large numbers under conditions which are identical except in temperature, and then to measure the average length of the shoots. In all cases growth is slow at low temperatures, increases gradually with higher temperatures, reaches a maximum like that of man, and then falls off quickly. The course of events, however, is not always so regular as here indicated. The curve of wheat, for example, as worked out by MacDougal is given in Figure 9. The peculiar double maximum

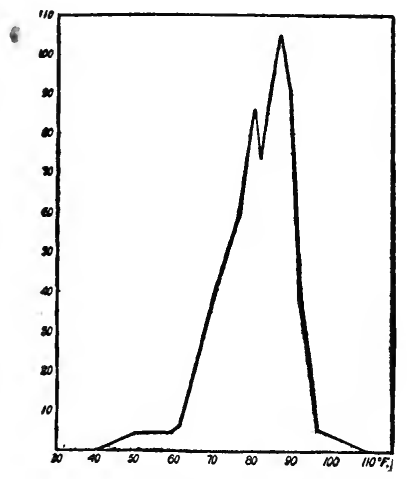

Figure 9. Growth of Wheat at Various Temperatures After MacDougal

The figures on the left indicate growth in $\mathrm{mm}$. during 48 hours 
there seen appears in each case where careful tests are made. It seems to be due to some inherent quality of the plant, and is of especial interest in our present study because we shall soon come upon an analogous case in man. When many species are averaged, such irregularities disappear, and we obtain the curve at the bottom of Figure 10, which has been prepared by MacDougal on the basis of his own measurements and others given in such works as Pfeffer's "Physiology of Plants." Many of the lower plants, such as marine algx, have their optima at lower temperatures than those here indicated, and the same is probably true of Arctic species. On the other hand, certain low algæ which grow in hot springs must have their optimum at a temperature above that of ordinary plants. These differences are immaterial. We are now concerned only with the fact that so far as plants have been measured, their response to temperature resembles that of man.

Apparently, we have to do with a quality which pertains to all kinds of living beings, and is presumably an inherent characteristic of protoplasm. The nearest approach to pure protoplasm is found in unicellular organisms whose bodies show only the beginnings of differentiation into parts having separate functions. The infusoria furnish a good example. One of these, paramocium, has been carefully studied by L. L. Woodruff. His original purpose was to determine whether it was possible for this organism to keep on reproducing itself without conjugation for any great length of time. Under the conditions of nature the small motile cells often spontaneously develop a median cell wall and ultimately divide into two new individuals, thus reproducing the species. This process, however, does not go on indefinitely, for when two cells come in contact they fuse with one another, and then begin a process of fission which, like the other process, ends in two individuals. Thus we have two types of reproduction, asexual and sexual, which apparently give rise to the same kind of paramœcia. Woodruff's purpose 
was to determine whether the asexual method of reproduction can persist indefinitely, or whether, as is often asserted and as previous experiments seemed to indicate, it leads in time to extinction. He has shown that if the media of nutrition con-

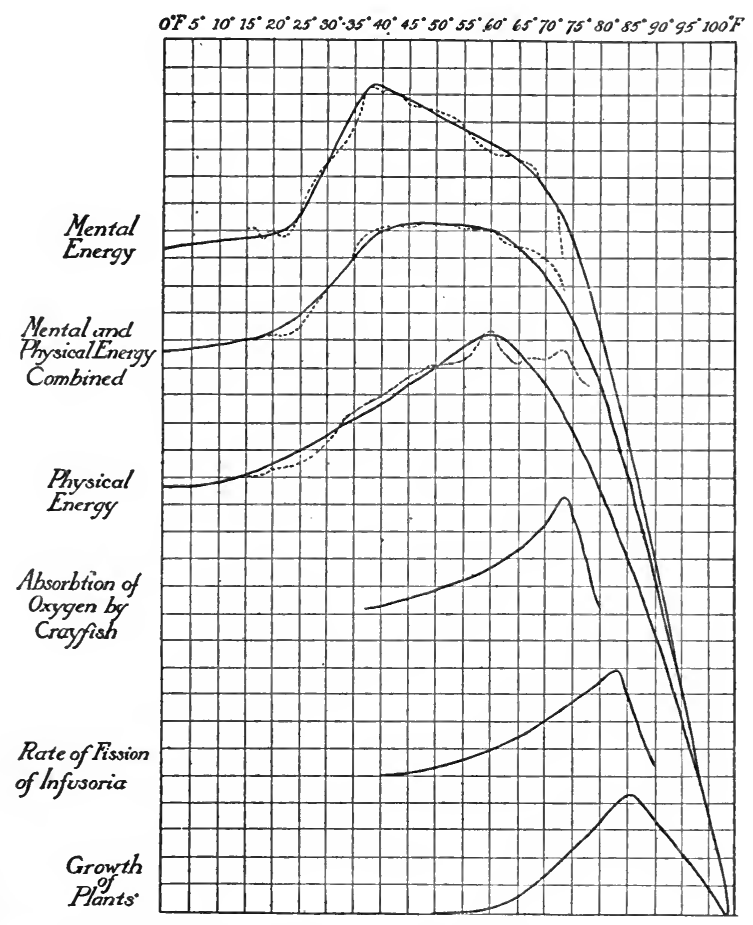

Figure 10. .Mean Temperature and Vital Processes in Plants, Animals and Man

tain a suficient number of elements, paramœcium can reproduce itself indefinitely by the asexual method. Between May 1, 1907, and May 14, 1914, he had carried his cultures through 4417 generations without conjugation. In the course of this 
work he has found that the rate of cell-division is an accurate test of the conditions under which protoplasm exists. For example, when extracts from nephritic kidneys or certain other diseased organs are added to the nutrient solution, even though they are present in such small quantities that they cannot be detected by chemical analysis, they make their presence evident by a falling off in the rate of fission.

One of Woodruff's most important lines of work has been to test the relation of his infusoria to temperature. From many experiments he finds that their activity corresponds closely to van't Hoff's law of chemical activity. According to this wellestablished law, chemical reactions of most kinds at ordinary temperatures become nearly three times as active with every rise of $10^{\circ} \mathrm{C}$. Even in inorganic chemical reactions, however, and far more in those of the living cell, there is a distinct limit where this rule breaks down. This limit forms the optimum of the species. At higher temperatures the degree of activity declines, and finally death ensues. On the basis of these conclusions, Woodruff's data permit us to draw the second curve from the bottom in Figure 10.

The next higher curve shows the amount of oxygen absorbed by the common crayfish at various temperatures. The most extensive work on this subject appears to have been done by Brunnow. The facts here given are taken from the summary by Pütter in his "Vergleichende Physiologie." The amount of oxygen absorbed by an animal is an excellent measure of its physical activity. When supplemented by measurements of the amount of carbon dioxide given off, and of the speed with which certain other metabolic or katabolic processes take place, it gives a true picture of the animal's general condition. Apparently, these various processes follow van't Hoff's law just as do the growth of plants and the cell-division of the infusoria. The optimum in the three cases does not vary greatly, that for 
plants being about $86^{\circ}$, for paramœcium $83^{\circ}$, and for the crayfish $74^{\circ} \mathrm{F}$.

Physiologists are not yet fully agreed as to the cause of the phenomena shown in these curves, although there is little doubt as to the general facts that they imply. One hypothesis may be briefly stated. According to Pütter's summary, the most probable explanation is that activity goes on increasing according to the ordinary chemical law until it becomes so great that the organism is not capable of absorbing the necessary oxygen. That is, at a low temperature the creature easily gets what oxygen it needs, and gives it out again in the form of carbon dioxide or of other oxidized products which remove the waste substances from the body. As the temperature rises, the normal increase in chemical activity takes place, the animal is still able to get rid of all its waste products, and thus its life processes are strengthened. With a further rise of temperature a change sets in. The chemical processes which break down the tissues of the body become still more active, but the supply of waste products to be eliminated by oxidation becomes so great that they cannot all be removed. This is because in every organism there is a distinct limit to the amount of oxygen which the creature can mechanically convey to different portions within a specified time. If the supply of oxygen is not sufficient to oxidize all the waste products, some of these will remain in the system. They act as poisons. Their first effect is to diminish the organism's activity. If they accumulate to too great an extent death ensues.

The discussion of this hypothesis must be left to the physiologists. They must decide whether the hypothesis which explains the curves of cold-blooded animals and plants is also applicable to warm-blooded animals. There can be little doubt, however, that variations in the rate at which metabolism takes place in the human body are at the root of the variations in 
efficiency which we are here studying. The researches of Thomson illustrate the way in which we are beginning to discover the truth. In Manchester, England, from April to July, 1910, and again in March, 1913, he measured the percentage of $\mathrm{CO}_{2}$ given off in the breath of four individuals under different conditions of temperature, humidity, and pressure. From his figures, given in the "Manchester Memoirs," I have compiled the following tables:

I. Percentage of $\mathrm{CO}_{2}$ Exhaled by Four Persons Under Different Conditions of Temperature

Temperature, $50-51^{\circ} 52-53^{\circ} 54-55^{\circ} 56-57^{\circ} 58-59^{\circ} 60-61^{\circ} 62-63^{\circ} 64-65^{\circ} 98^{\circ} \underset{\text { Heat }}{\text { Blood }}$ $\begin{array}{cccccccccc}\begin{array}{c}\text { Percentage of } \\ \mathrm{CO}_{2},\end{array} & 4.77 & 4.72 & 4.66 & 4.71 & 4.61 & 4.41 & 4.38 & 4.62 & 4.80+\text { ? }\end{array}$

II. Percentage of $\mathrm{CO}_{2}$ Exhaled by Four Persons Under Different Conditions of Humidity

$\begin{array}{lcccc}\text { Relative Humidity, } & 70-75 \% & 76-80 \% & 81-85 \% & 86-90 \% \\ \text { Percentage of } \mathrm{CO}_{2}, & 4.75 & 4.60 & 4.60 & 4.45\end{array}$

The interpretation of these tables is difficult, and I can merely offer a suggestion. An increase in the proportion of $\mathrm{CO}_{2}$ exhaled from the lungs obviously indicates an acceleration of the metabolic processes which break down and consume the bodily tissues. This liberates energy which may manifest itself in at least three ways and possibly more. It may give rise to heat which is used to maintain the body at the normal temperature; it may be used to accomplish physical or mental work; and it may cause an excess of heat which gives rise to further metabolism of a harmful nature. In the first part of the table the percentage of $\mathrm{CO}_{2}$ is comparatively high at the lowest temperature recorded by Thomson, and decreases with only slight irregularity till the thermometer reaches $62^{\circ} \mathrm{F}$. This is close to the 
temperature which we have found to be the optimum. Below that point the increased metabolism is probably needed to keep the body warm. At higher temperatures increased production of $\mathrm{CO}_{2}$ is again apparent. This perhaps means that too much chemical activity is taking place, and that toxic substances are accumulating in the way suggested by Pütter. At the optimum, according to this interpretation, the body does not have to use an undue portion of its strength in keeping warm, nor is it injured by too great stimulation. Thus it is in the best condition for work.

The second part of the table shows that in the driest weather which England enjoys, metabolism is more active than in wet weather. Perhaps part of this is due to the fact that in dry air the body loses water and is cooled by evaporation, and hence requires more heat than in wet air of similar temperature. There is more to the matter than this, however, but further measurements are needed before an adequate explanation can be offered. All that can be done here is to point out the fact that in man, as in the lower organisms, activity varies according to temperature. This is evident in Figure 10, where the dotted upper line is the curve of mental activity, while the accompanying solid line shows the conditions if all accidental irregularities could be removed. The third line in the same way represents the physical activity of both men and women in Connecticut. I have not used the figures from the South because they are not quite so reliable as those from Connecticut. Finally, the second line from the top shows physical and mental activity combined, each being given the same weight. It may be taken as representing man's actual productive activity in the things that make for a high civilization. The resemblance of the human curves to those of the lower organisms is obvious. In general, the lower types of life, or the lower forms of activity, seem to reach their optima at higher temperatures than do the more advanced types and 
the more lofty functions such as mentality. The whole trend of biological thought is toward the conclusion that the same laws apply to all forms of life. They differ in application, but not in principle. The law of optimum temperature apparently controls the phenomena of life from the lowest activities of protoplasm to the highest activities of the human intellect. 


\section{CHAP'TER VI}

\section{Work ANd Weather}

'The effect of a given climate depends on two primary facitors. One is the character of the seasons as expressed in averages such as are furnished by our weather bureaus. The other vis the changes from day to day, that is, the weather. The boy quoted by Mark Twain was nearly right when he defined the difference between weather and climate as being that "Climate lasts all the time and weather only a few daýs." Two climates may be almost identical in their seasonal averages, and yet differ enormously in their effect on life, because in one the change from day to day is scarcely noticeable, while in the other there are all sorts of rapid variations. The old Irishwoman who was driving her pigs to market in a pouring rain did not realize it, but she gave expression to a truth of the greatest importance, when a friend pitied her for being out in such weather, and she replied, "Indade it's bad, but sure it's thankful I am to have any kind of weather."

The changes from one day to another depend largely upon our ordinary cyclonic storms. In such storms the barometer goes down and then up; the wind changes in direction and velocity; the air becomes humid, clouds gather, rain usually falls, and then clear skies and dry air prevail; the temperature also changes, often rising before a storm and falling afterward, although the exact sequence depends on the location of a region in respect to the ocean and to the center of the storm; the daily range of temperature also varies, for in damp or cloudy weather the nights do not become so cool nor the days 
so warm as when the air is clear. To understand the influence of the weather all these conditions must be investigated. Most of them, however, appear to be of relatively slight importance when considered by themselves. For instance, Lehmann and Pedersen could find no appreciable effect of the pressure of the atmosphere except where low pressure prevails a long time. The decrease in efficiency at such times, however, is probably due more to prolonged cloudiness and its attendant circumstances than to the barometric conditions. My own work leads to the same result. The curves of efficiency compared with pressure are so contradictory that it does not seem worth while to publish them. The same is true of the range of temperature from day to night, and of the direction and force of the winds. I have no doubt that all these matters are important, and that some day their effect will be worked out. In general, however, their influence is exerted indirectly through changes in temperature and humidity. In hot weather a great range from day to night is unquestionably highly favorable, but at ordinary temperatures it seems to make no special difference, except through its effect upon the mean temperature.

As to the winds, Dexter, in his book on "Weather Influences,"

U shows that they produce a marked effect upon the nerves, as is indicated by the unruliness of school children in Denver when high south winds prevail. Part of this is doubtless due directly to the wind, but the unseasonably high temperature and extreme dryness which accompany it are probably more important. Yet we are all conscious of the effect of a steady high wind. Some people are stimulated. I have seen a small boy, who was usually very quiet, climb to the top of a tall tree when a violent wind came up, and swing in the branches, singing at the top of his voice. For a while such stimulation is probably beneficial, but if continued day after day it makes people excitable and cross. A striking example of the effect of a prolonged wind is seen in eastern Persia in the basin of 
Seistan. During the summer, from June to September, the socalled "Wind of One Hundred and Twenty Days" blows so violently from the north that in the oases trees cannot grow except under the lee of high walls. The acrid wild melon, which ripens its beautiful little green and yellow fruit in the desert, does not spread its slender branches in all directions after the common fashion of plants. The gales crowd the branches into a sheaf which points so uniformly in one direction, a little to the west of north, that it can safely be used as a compass. When Europeans have to endure this wind they say that it is one of the most trying experiences imaginable. Not only does it render them irritable, but it deadens their initiative and makes them want to stay idly in the shelter of the house. The natives, although possessed of many good qualities, are inert and inefficient even in comparison with their fellow Persians who live farther to the north and west. On the whole, we may probably conclude that occasional short-lived gales and frequent light or moderate winds are beneficial, while long periods either of steady calms or of gales are depressing.

Aside from the conditions of weather already mentioned, there are two whose effect appears plainly when curves are constructed according to the method described above. One is the change of temperature from one day to another, and the other is the character of the day as to clouds and sunshine. In considering changes of temperature from one day to the next, we deal with the mean temperature for each day and not with the extremes. A change of as much as $15^{\circ}$ is rare. Suppose that the thermometer stands at $60^{\circ}$ at sunrise, rises to $80^{\circ}$ by two o'clock in the afternoon, then falls rapidly to $50^{\circ}$ at sunset and to $40^{\circ}$ by midnight. Suppose also that the next day the temperature is $40^{\circ}$ at sunrise, rises a little above $55^{\circ}$ during the day, and falls again to $45^{\circ}$ at night. The two days would be very different, and we should speak of them as being marked by a very great change of temperature, a dif- 
ference of $40^{\circ}$ within ten hours. Yet the average of the first day would be about $64^{\circ}$ and of the second $49^{\circ}$, a difference of only $15^{\circ}$ in the mean temperature.

On the basis of this supposition the reader can estimate the importance of the various degrees of change indicated in Figure 11. At the left the curves show the average efficiency on days when the temperature has fallen; in the middle are the days with no change; and at the right are the days characterized by a rise. Taking only the two upper curves, those for men and girls in Connecticut factories, the resemblance is striking. When we consider the heterogeneous character of the original materials the resemblance is still more important. The men's curve is based on 120 men at Bridgeport in 1910 and 1911, and on 180 men at New Britain in 1911, 1912, and 1913. The girls' curve is based on 196 girls at New Britain in 1911, 1912, and 1913, and on 60 girls at New Haven in 1913 and 1914. Even where the girls and men were working in the same factory, there is no reason, aside from the weather, why their wages should be high on the same day. The chief difference between the two curves is that the one for the girls varies more than that for the men, and reaches its maximum slightly farther to the right. Apparently, here, just as in the case of mean temperature, the girls because of their age or sex are more subject to the influence of the weather than are the men, and hence their curve dips deeper.

Let us now interpret the upper curves, beginning at the middle. There they fall to their lowest level. This means that when the temperature of today is the same as that of yesterday, people work more slowly than after a change, no matter whether the change is upward or downward. A variable climate is therefore highly desirable if people are to be efficient. Perhaps the most surprising feature is that the lowest point of the physical curve, and a depression of the mental curve, $\mathrm{C}$, come not at $0^{\circ}$, but at $-1^{\circ}$. The zero point is low, lower than any 
Fall of Temperature

Rise of Temperature

$-14^{\circ} \mathrm{F}-12^{\circ} \quad-10^{\circ} \quad-8^{\circ} \quad-6^{\circ} \quad-4^{\circ} \quad-2^{\circ} \quad 0^{\circ} \quad+2^{\circ}+4^{\circ}+6^{\circ}+8^{\circ}+10^{\circ}+12^{\circ} \mathrm{F}$

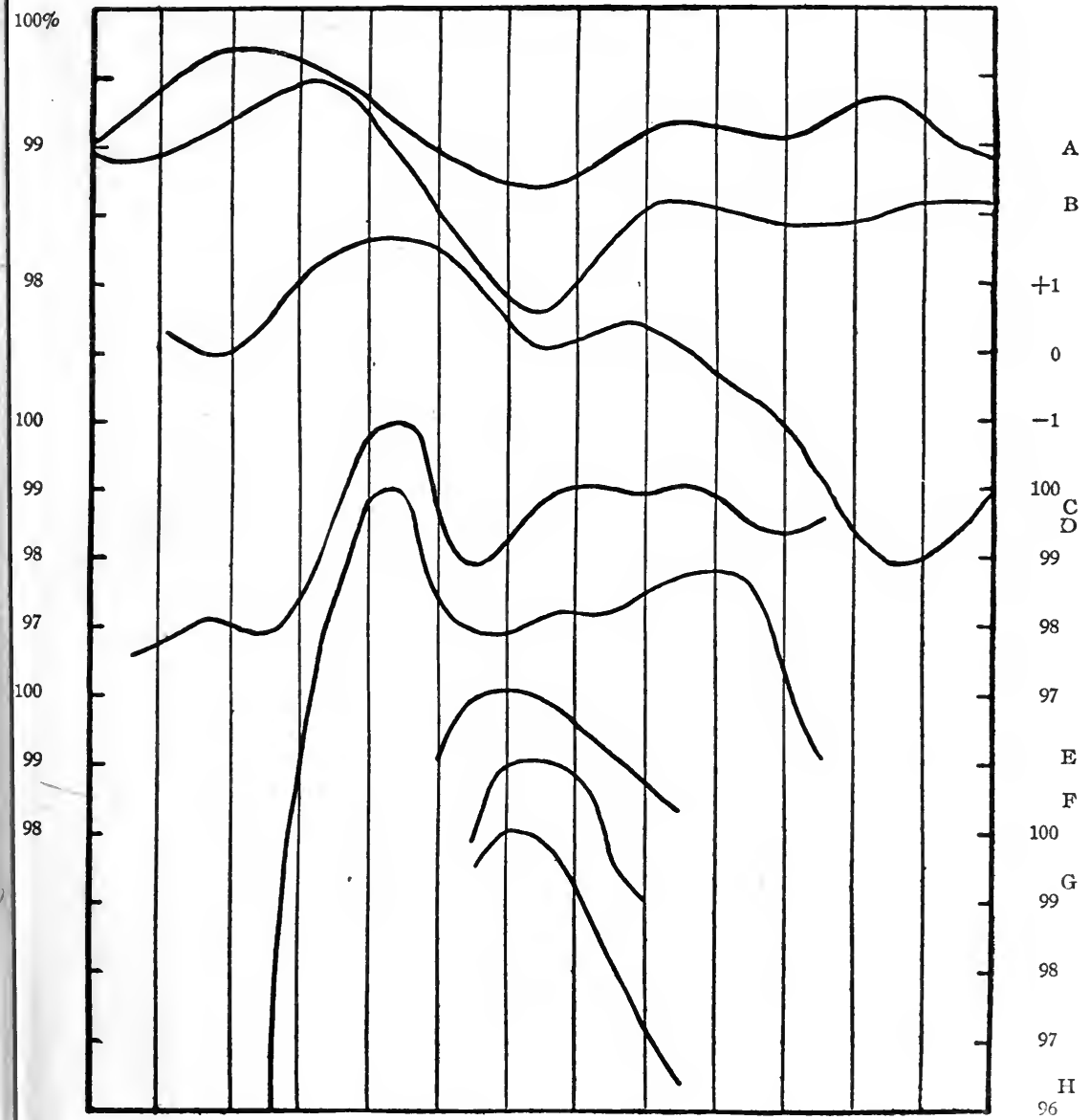

Figure 11 Human Activity and Changes of Mean Temperature from Day to Day

A. 300 Men in Two Connecticut Factories, 1910-13.

B. 256 Girls in Two Connecticut Factories, 1911-13.

C. 460 Students in Mathematics and English at West Point and Annapolis, 1909-1913.

D. 760 Cigar-makers at Tampa, Fla., in Winter (October-March), 1912 and 1913. Factory A.

E. 400 Cigar-makers at Tampa in Winter, 1913. Factory B.

F. 400 Cigar-makers at Tampa in Summer (April-September), 1913. Factory B.

G. 380 Cigar-makers at Tampa in Summer, 1912. Factory A.

H. 380 Cigar-makers at Tampa in Summer, 1918. Factory A. 
point of the physical curves except $-1^{\circ}$. Hence, our conclusion as to the injurious effect of uniform temperature is justified, but that does not explain the curious dip at $-1^{\circ}$. The repetition of the same phenomenon in each of the three upper curves, and a similar occurrence at $-2^{\circ}$ and $-3^{\circ}$ respectively in the two curves for the winter in Florida strongly suggest that we are confronted by a peculiarity which pertains to man as a species, in the same way that a double optimum of mean temperature pertains to wheat as shown in Figure 9. Possibly, a slight fall in temperature causes people to shiver, as it were, and only when the fall is slightly larger is the circulation of the blood so stimulated as to increase the activity of the various organs. In the South it may be that people's blood is more sluggish than in the North, so that the reaction due to cooler weather does not follow quite so soon, and hence the period of shivering is not over until the fall in mean temperature amounts to more than about $3^{\circ}$. I do not assert that this is so, but it is the only explanation that comes to mind.

To go on with our interpretation of the physical curves, a slight rise of temperature seems to be favorable, but beyond that the favorable effects of increased heat, which are strong in cold weather, are neutralized by the unfavorable effects in warm weather. In fact, our personal experience tells us that even when the heat is not extreme, a sudden rise may make us uncomfortable and lazy, as often occurs in the spring. In spite of this, however, a rise is in general better than uniformity. When the temperature falls, on the other hand, a distinct stimulus is received, provided the fall amounts to as much as $4^{\circ}$. The best effects are seen with a fall of from $6^{\circ}$ to $9^{\circ}$ with girls and of $7^{\circ}$ to $11^{\circ}$ with men. Here again the implication is that men are on the whole less sensitive than girls. An extreme drop is not so favorable as one of more moderate dimensions, especially for the girls. Taking the physical curves as a whole, the greatest amount of energy would be expected in climates 
where the mean temperature first rises $2^{\circ}$ or $3^{\circ}$ a day for a few days and then drops $4^{\circ}$ to $8^{\circ}$ a day. If the changes are greater than this, the effect is still stimulating, but not so beneficial as under the more moderate conditions. If there is practically no change, on the contrary, the efficiency falls within the low central depressions of our curves, and is less than under either of the other conditions.

Mental work resembles physical, but with interesting differences. When the temperature falls greatly, mental work seems to suffer more than physical, and declines as much as when there is no change. It receives a little stimulus from a slight warming of the air, but appears to be adversely affected when the air becomes warm rapidly. This last statement, however, must be qualified. The physical curves are based on the complete year, and the conditions of summer have an opportunity to balance those of winter. The results show the net effect for all seasons combined. The mental curves, on the other hand, 'do not include the summer vacation, which lasts from the middle of June to the first of September at West Point, and from the middle of May to the first of October at Annapolis. If this were included, the effect of a pronounced lowering of the temperature would be more noticeable than at present, for such a lowering is naturally more stimulating in July than in January. In another respect, also, the curve of mental efficiency needs modification. It is based on figures from two climatic provinces, namely, southern New York and Maryland. The great decline at times when the temperature rises rapidly is due largely to conditions in Maryland, where the hot days of the spring are much more debilitating than in New York. The students belong to a race which has never learned to endure sudden heat. Hence they feel it strongly. If allowance is made for the two conditions just mentioned, the mental curve will approach much more closely to the physical. A drop of temperature amounting to $8^{\circ}$ or more will appear more 
stimulating than now seems to be the case, and a rapid rise will not seem so harmful. Hence, the general conclusion for both physical and mental activity will be essentially the same. It may be summed up thus: Taking the year as a whole, uniformity of temperature causes low energy; a slight rise is beneficial, but a further rise is of no particular value; the beginning of a fall of temperature is harmful, but when the fall bccomes a little larger it is much more stimulating than a rise; when it becomes extreme, however, its beneficial qualities begin to decline. This conclusion must, of course, be appropriately modified according to the season. A cold wave in January is very different from one in July. In our curves we have given January and July an opportunity to neutralize one another. They have not done so. This means that after all allowances have been made for the seasons, the total effect of cold waves is decidedly beneficial, and of warm waves slightly so. Frequent changes, therefore, are highly desirable.

Let us pass on now to the Florida curves. Here we find a curious difference between summer and winter which is not easy to understand. Let us leave that for the moment, however, and consider only the two winter curves. Their general resemblance is marked. The differences at the extremities are not important because the number of days there concerned is very small. It must be remembered that the two curves are from independent and rival factories. The position of any particular point in either curve depends upon a number of days scattered irregularly through the months from October to March. Aside from a genuine effect of climate, there seems to be no possible way in which 400 men in one factory in 1913 could be made to work so that their curve would be the same as that of 380 men in another factory in the two years 1912 and 1913. Here, as in Connecticut, West Point, and Annapolis, we are apparently dealing with a peculiar quality which is inherent in the human species. 
One of the Florida curves, $\mathbf{E}$, is low at $0^{\circ}$, while the other is medium. This means that days when there is no change of temperature are not particularly favorable. At plus $2^{\circ}$ to plus $4^{\circ}$, however, both are fairly high, which indicates that a moderate rise of temperature is favorable. A further rise seems to be harmful. The effect of a slight fall of the thermometer has already been discussed. A further fall is beneficial. The most notable thing about curves $\mathrm{D}$ and $\mathrm{E}$ is the maximum from $-4^{\circ}$ to $-7^{\circ}$. It comes at about the same place as the mental maximum, and is similar to the Connecticut maximum except that the people in the far South do not seem to be able to stand such extreme changes as do those in the North. In fact, it seems most significant that the Connecticut men, who are the strongest of our various groups, are most stimulated by a strong change of temperature. The Connecticut girls come next, but being less sturdy, they do not enjoy quite such rigorous conditions. The mental curve is largely determined by Annapolis, and as the climate there is less severe than in Connecticut, the students seem to feel more keenly the effects of extreme changes, although they are stimulated by those of moderate dimensions. The same is still more true of the people of Florida in winter. Finally, during the summer the Floridans are stimulated by a slight drop of temperature, not enough to make them feel chilly, but enough to start their blood in motion. A greater drop makes them feel cold, while even the slightest rise of temperature in their long monotonous summer is unfavorable.

We are ready now to sum up our results. The outstanding point is that changes of temperature, provided they are not too great, are more stimulating than uniformity, while a fall is more stimulating than a rise in the latitudes now under consideration. The effect of changes depends largely upon the degree to which people are inured to them. When they are weakened by a long hot period like that of the Florida summer, 
even a slight cooling of the air brings relief and activity, provided it does not go so far as to make people feel chilly. When the same Floridans become wonted to the somewhat sterner, albeit mild air of their winter, the first effect of a lowering of the temperature may be to make them shiver, but soon they become stimulated, and work fast. They are not so tough, however, as to be able to get benefit from the occasional days when really strong cold waves sweep down upon them. On the other hand, a rise of temperature stimulates them, unless it is of considerable severity. Farther north the same applies except that being tougher the people are more benefited by strong changes. Judging by the difference between summer and winter in Florida, it looks as if a little hardening would cause even the Cubans to respond favorably. to changes at least as severe as those in Maryland, thus making the left-hand part of their curve like $\mathbf{C}$ in Figure 8 . Taking it all in all, the one thing that stands out preëminently is that a fall of from $4^{\circ}$ to $y^{\circ}$ is everywhere stimulating, provided people are accustomed to it.

Man is not the only organism that is benefited by changes of temperature. Numerous experiments have shown that plants are subject to a similar influence. If a plant is subjected to unduly low or high temperature, its growth is retarded. As the temperature approaches the optimum, the rate of growth increases. When the optimum is maintained steadily, however, not only does the increase cease, but retrogression sets in, and the rate of growth declines. A moderate change of temperature away from the optimum and then back again after a few hours checks this decline, and keeps the plant at a maximum degree of activity. Thus conditions where the thermometer swings back and forth on either side of the optimum are distinctly better than where the optimum is maintained steadily. Thus it seems to be a law of organic life that variable temperature is better than uniformity.

The physiological process by which frequent changes of 
temperature affect the body is not yet known. The best suggestion seems to be that of Dr. W. B. James. It is universally recognized that one of the most important of the bodily functions is the circulation of the blood. The more active and unrestricted it is, the more thoroughly is the whole system nourished and purified. Provided it does not impose an undue strain on the heart or arteries, anything that stimulates the 1 circulation appears to be helpful. Changes of temperature are a powerful agent to this end. Witness the effect of a bath, either cold or very hot. Few things are more stimulating than a Swedish bath. An attendant holds two hoses, one with cold water and the other with hot, and plays them alternately upon the patient. A man goes into such a bath with hanging head and dragging feet. He comes out with head erect and a new spring in his walk. Apparently, frequent changes of the temperature of the air produce much the same effect. No one change produces so pronounced an effect as a Swedish bath, but the succession of stimuli due to repeated changes throughout the year must be of great importance.

Before leaving this subject, let us test the effect of changes in still another way. Let us see what happens during an average series of days such as make up our common succession of weather in New England. The ordinary course of events is first a day or two of clear weather, then a day or two of partly cloudy weather, next a cloudy day with or without rain, and finally another cloudy day during which rain falls. Then the sky clears in preparation for another similar series. On this basis I have formed the six groups indicated at the top of Figure 12. At the left, the efficiency on all clear days which follow cloudy or partly cloudy days has been plotted, just as in another diagram we plotted the efficiency on Mondays. Next come the clear days which follow another clear day. If several of these follow in unbroken succession, they are all included, but a third or fourth clear day is rare. In the 
next group come the partly cloudy days which follow either a clear or a cloudy day. The great majority follow clear days. A second partly cloudy day is much rarer than a second clear day, and a third is still rarer. The first cloudy day, the fifth column, includes cloudy days which follow either clear or partly cloudy days. Finally, the sixth column includes not only the second cloudy day, but the third and fourth if such are recorded. In general, this column represents days

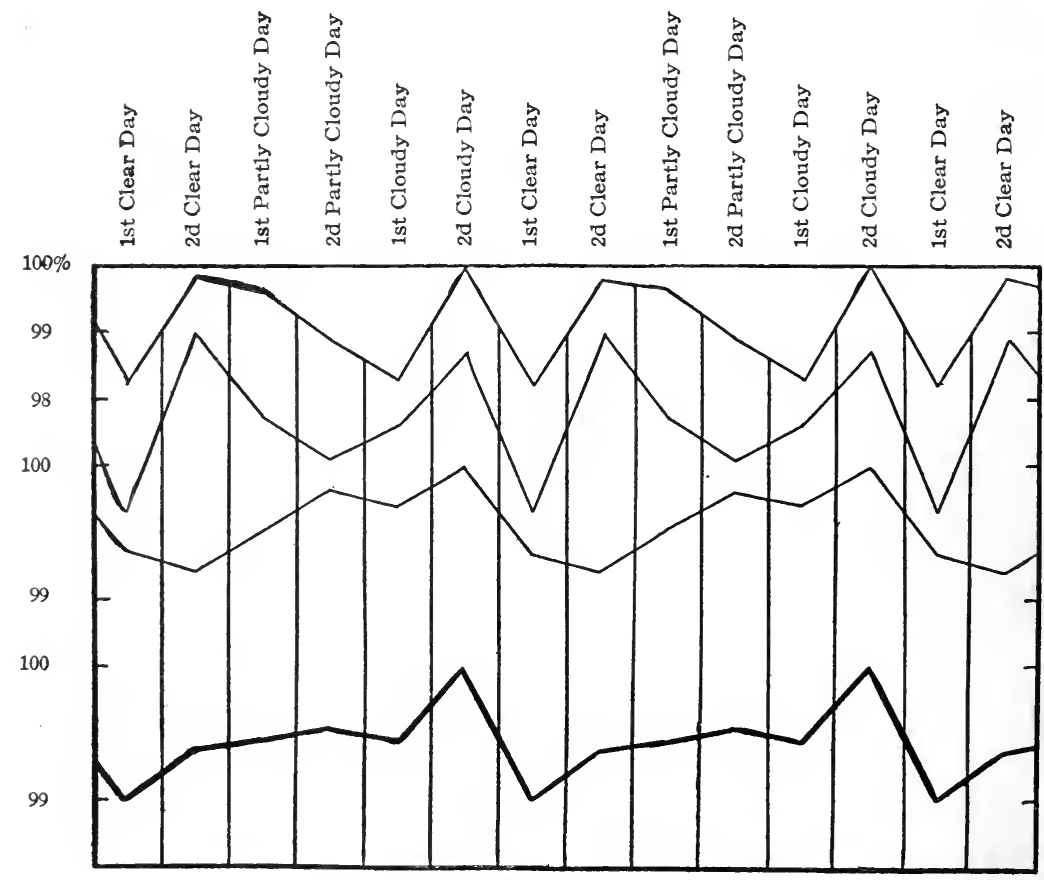

(1)

(2)

(3)

Figure 12. The Stimulus of Storms

(1) 60 Men at Bridgeport, 1910.

(2) 60 Men at Bridgeport, August, 1911-July, 1912.

(3) 170 Men and Girls at New Britain, 1913.

(4) Weighted Average of (1), (2), and (3), Equal to 290 People for One Year. 
when a storm comes to an end, while the one to the left of it represents the time when a storm first becomes well established. The rest of the diagram, to the right of the sixth column, is merely a repetition of the part already described. It is inserted to show how an ideal series of storms would repeat itself.

Figure 12 discloses some surprising facts. For instance, the first clear day is characterized by the slowest work in the two upper curves and by almost the slowest in the third. Our impression of the stimulus of the bright, clear air after a storm receives a flat contradiction. It is apparently psychological, not physical. The second clear day makes a better showing than the first. It stands high in two curves, and low in only one. The first partly cloudy day is high in one curve, and medium in two. The second partly cloudy day is medium in all three. The same is true of the first cloudy day. The last cloudy day is as surprising as the first clear day. In each of the three curves it stands highest. People work fastest at the end of a storm. In the lower curve of Figure 12, the whole matter is summed up in a single line. Here we see that during an average "spell of weather" people are least efficient on the clear days; moderately efficient on the partly cloudy days, and on the first cloudy day; and most efficient at the end of a storm. We may tell ourselves that this is unreasonable, but when we think it over, we are likely to be aware of its truth. Before a storm we may feel depressed, but at the end, when the rain or snow is almost over and the air begins to have that excellent quality which makes us forget all about it, we bend to our work with a steadiness and concentration which are much less common at other times. Hellpach emphasizes this in his book on the psychological effect of geographical conditions. We fail to appreciate it largely because the esthetic impressions of a beautiful, clear day are felt much more consciously than are the physiological conditions which throw us vigorously into our work. Each storm, with its changing skies, varying 
pumidity, and slow rise and rapid fall of temperature, is a
stimulant. Each raises our efficiency.

We have now completed our survey of the effect of climate in the eastern United States. We have considered the influence of the seasons, of mean temperature, of humidity, of winds, of changes of temperature from day to day, and of the character of each day and its relation to storms. We have also seen that although different races, or people under decidedly diverse climatic environments, are at their best at slightly different temperatures, the differences are inconsiderable, and changes of temperature are as valuable to one as to the other. The question now arises whether the climatic effects are really of great importance. In Figure 12, the stimulus of the succession of clear and cloudy days amounts to only 1 per cent. In Figure 11 changes of temperature from day to day produce a variation of only a little over 2 per cent, if we omit the irregular and unreliable extremities of the curves. In Figure 4, the maximum effect of humidity appears to be only 3 per cent. In Figure 8, however, the differences are greater, for the effect of mean temperature upon the girls in Connecticut is 7 per cent. Finally, in Figure 1, the effect of the seasons reaches nearly 9 per cent when four years are averaged, and nearly 15 per cent for individual years.

These figures.are far from representing the full importance of the various factors. This will readily appear from a little consideration. In the preceding paragraph, the percentages increase in proportion to two conditions, first, the degree $t$ which the influence of a single factor is separated from the influence of all other factors, and second, the length of time during which each factor is able to exert its influence. The smallest figure, 1 per cent in Figure 12, does not represent any individual factor, unless it be cloudiness. It does not even represent the fluctuations which attend an individual storm, for the days were selected without regard to their posi- 
tion in a cyclonic disturbance, but simply according to their cloudiness. The variations shown in the curve are due to many factors, including mean temperature, changes of temperature, relative humidity, and others of minor importance. As no two of these are necessarily at their maximum at the same time, they neutralize one another. Moreover, a given condition lasts only a day in most cases, and so has no opportunity to produce any great effect. In the curve of changes of temperature from day to day, which shows the next larger effect, a single factor is singled out. Its full force can by no means be seen, however, for the humidity often varies in such a way as to neutralize it. Moreover, the effects of especially low or high temperatures may often completely overshadow any stimulus arising from the mere fact of a change. Furthermore, the effect of changes of temperature rarely continues more than two days. For example, if the thermometer averages six degrees lower on one day than on the preceding, it may happen that there will be a further drop before the next day, but there is far more chance that the temperature will rise a little or remain stationary, or fall so little that it will not be stimulating. Hence, the effect is rarely cumulative, and the influence of each single day must usually stand by itself. Much the same is true of relative humidity, except that by heating our houses we artificially induce long periods of great aridity. The effects of mean temperature, on the other hand, have greater epportunity to show their full importance, though they, too, are hampered. Relatively low or high temperatures last many weeks, which makes it possible for the effect of day after day to accumulate. Yet our curves by no means show the full effect, for a cold day with a mean temperature of 309 may come in November at a time when efficiency is still at its highest. It produces its normal effect, but a single unpropitious day, or even a week, does not suffice to depress people's vitality to a degree at all approaching the low limit reached after two months of cold weather. 
Likewise, a day with the most favorable temperature, not far from $60^{\circ}$, may be sandwiched between very hot days in July, or between two cold days in March. Hence, people will display little energy on those particular days, and the average efficiency at the optimum temperature will appear correspondingly lower than it ought. Finally, the seasons have more opportunity than the individual climatic elements to produce their full effect. Even here, however, the variability of our climate does not allow any special combination of circumstances to work long unimpeded. Warm waves break the cold periods of winter, and cool waves come in summer. Storms are more active in winter than in summer, and hence their stimulus works towards overcoming the effect of prolonged cold. Moreover, no single season is of great duration, and extreme conditions do not last long enough to produce their full effect. From all this we may conclude that the total influence of climate upon energy is much greater than appears in any one of our $\angle$ curves.

'The difficulty of determining the exact proportions of any individual influence may be made clear by an example. We know that man's power to work depends upon food, drink, sleep, and clothing. Suppose that while he was still supplied with these in normal quantities we were to try to measure the effect of each. We should test his strength at stated intervals after he had eaten his meals, or after he had had a drink. We should find out how many hours he slept each night and compare that with his work. We should measure his achievements before and after he put on his spring underwear or fall overcoat. We might get results, but it is highly doubtful whether they would be as distinct as those here discussed. We have no difficulty in measuring the effect of food, drink, sleep, and clothing, for we can easily vary them to suit the needs of our experiment. With climate the case is different. We must take it as we find it, and must experiment on people who are 
constantly subject to its influence. Some day we shall test people first in one climate and then in another, but that will be difficult because it takes a considerable time for climate to produce its full effect. Being obliged to search for the effects of climate without being able to change them in accordance with the needs of our experiment, we are in almost as difficult a case as the experimenter who should desire to determine the effect of the amount and kind of food consumed by a group of individuals, but who had no control over how much they ate. They might allow him to measure what was set before them at each meal and what remained when it was over, but they would eat as much as they liked and when they liked. He would get results, if he did his work carefully, but they would by no means represent the full effect of food.

The influence of climate upon men may be likened to that of a driver upon his horse. Some drivers let their horses go as they please. Now and then a horse may run away, but the average pace is slow. Such drivers are like an unstimulating climate. Others whip their horses and urge them to the limit all the time. They make rapid progress for a while, but in the end they exhaust their animals. They resemble climates which are always stimulating. In such climates nervous exhaustion is likely to prevail and insanity becomes common. A third type of drivers first whip their horse to a great speed for a mile or two, and then let them walk slowly for another mile or two. They often think that they are accomplishing great things, and they are better off than the two types already mentioned, but they still have much to learn. They are like a climate which has a strong contrast of seasons, one being favorable and the other unfavorable. Still a fourth kind of driver may whip his horse sometimes and sometimes let him walk, but what he does chiefly is to urge the animal gently with the voice, then check him a little with the rein. By alternate urging and checking he conserves the animal's strength, and in the long 
run can cover more distance and do it more rapidly than any of the others. Such a driver resembles a climate which has enough contrast of seasons to be stimulating but not to create nervous tension, and which also possesses frequent storms whose function is to furnish the slight urging and checking which are so valuable in the total effect, although each individual impulse is lalmost unnoticeable. 


\section{CHAP'TER VII}

\section{The Idear Chimate}

We are frequently told that the Riviera or southern California has an ideal climate. Florida lays claim to it in winter, the Alps in summer. Two of the few regions which rarely assert their preëminence in this respect are Boston with its east winds and London with its fogs. Yet in many ways they have a strong claim to high rank. It all depends upon what we mean by "ideal." For rest and recreation a warm, equable climate is doubtless most delightful; for a fishing or climbing trip something quite different is desirable. For most people the really essential thing in life is the ordinary work of every day. Hence, the climate which is best for work may in the long run claim to be the most nearly ideal. At least, it is the one which people will ultimately choose in the largest numbers. The few disagreeable features at certain seasons, provided they are not seriously injurious to health, are no worse than the shiver at the beginning of a cold plunge.

On the basis of our factory operatives and students, the best climate would apparently be one in which the mean temperature rarely falls below the mental optimum of $38^{\circ}$, or rises above the physical optimum of $60^{\circ} \mathrm{cr}$ possibly $65^{\circ}$. From this point of view the most ideal conditions would seem at first thought to be found where the temperature at all seasons averages not far from $50^{\circ}$, but this conclusion needs modification as will shortly appear. In four chief portions of the globe, the winter temperature averages not far from $38^{\circ}$, and that of summer not far from $60^{\circ}$. The first of these is England. At 
London the thermometer averages $38^{\circ}$ in January and $63^{\circ}$ in July, while at Liverpool the figures are $39^{\circ}$ and $60^{\circ}$. If an average of $50^{\circ}$ at all seasons were ideal, southwestern Ireland with a range from $45^{\circ}$ to $59^{\circ}$ and the Hebrides from $42^{\circ}$ to $55^{\circ}$ would be more ideal than London. On the continent, where the seasonal variation is greater than in Britain, the length of the relatively unfavorable periods with temperatures above $60^{\circ}$ and below $38^{\circ}$ also increases.

A second region where the temperature conditions approach the ideal is the Pacific coast of the northern United States and southern British Columbia. Seattle, averaging $39^{\circ}$ in January and $64^{\circ}$ in July has practically the same temperature as London. Southward the seasonal range decreases. San $\backslash$ Francisco, averaging $49^{\circ}$ in January and $59^{\circ}$ in September after the cool summer fogs have passed away, may claim in many ways to be ideal. Still farther south the temperatures of Los Angeles and San Diego, $53^{\circ}$ or $54^{\circ}$ in January and $69^{\circ}$ in August, fluctuate about the physical optimum and would be ideal for physical activity if mean temperature were the only criterion. The mental optimum, however, is lower than the temperature of all except the unusually cold days, and variations from day to day are rare. A short distance inland the Californian climate becomes less favorable than on the coast, for the average in summer at Fresno, for example, is $82^{\circ}$. Even though the heat is mitigated by low humidity, the continuance of such high temperature causes people to feel indisposed to activity.

England and the Pacific coast owe their climatic excellence largely to the fact that ocean winds from the west blow freely over them. Two regions in the southern hemisphere enjoy the same advantage, namely, New Zealand and part of South America, including southern Chili and portions of Patagonia. We are apt to think of these South American regions as sparsely settled places of little importance. This is true, for the pres- 
ent, but it is not because the climate prevents activity. The climate, to be sure, is a drawback, but the harmful feature is not the temperature, but the rainfall. Plants, not man, are the chief sufferers. Unlike our other three regions, this part of the world has a deficient rainfall except in the west, and there high mountains hinder settlement. In spite of this, the few small portions of Patagonia that permit profitable agriculture are making progress and would doubtless do so rapidly if not hampered by remoteness and the absence of railroads.

It must not be inferred that the climates of Patagonia, New Zealand, England, and the Pacific coast of the United States are necessarily ideal. Mean temperature is not the only important factor. Among other things the relative humidity must I be considered. The deficiency of moisture in Patagonia not only is disastrous economically, but, to judge from our factory operatives, it lessens man's energy. A similar effect is produced by excess of moisture, and thus harm is done in Ireland and western Scotland, which would otherwise be almost as fortunate as England. New Zealand, the central Pacific coast of North America, and England itself are sometimes unduly damp for long periods, but nevertheless enjoy a relative humidity of not far from 70 per cent much of the time. Other regions, however, such as the eastern United States and central Europe, seem to be more favored in this respect.

The change of temperature from day to day, as we have seen, seems to be more important than relative humidity, and must accordingly be considered more fully. Its effect on human activity seems to be second only to that of the mean temperature of the seasons. The intensity and number of daily changes depend upon two chief factors, first, the range of temperature from the warmest to the coldest part of the year, and second, the number of cyclonic storms. Where the winters are cold and the summers hot, the changes from day to day are also extreme. For instance in the Dakotas where the mean tempera- 
tures of January and July differ by $60^{\circ} \mathrm{F}$., a change of equal magnitude may take place in twenty-four hours. On the other hand, in a place like the Congo, where the difference between the coldest and warmest months is only three or four degrees, the days are correspondingly uniform. The whole matter is illustrated by maps in many physical geographies and in such pưtblications as Bartholomew's Meteorological Atlas. The parts of the world where the change of seasons favors a highly advantageous degree of change from one day to the next include I most of North America, but omit Florida, the Pacific coast of the United States, and the regions from the Mexican border r southward. All of central and eastern Europe is also included except parts of Italy and Greece. A large area in North I Africa and a small area in the south of that continent also rank high, as do central Australia and the part of South America which includes central Argentina. Finally, all except the southern parts of Asia lie within the high area. Thus this particular favorable condition occurs not only in many regions whose climate is also good from other standpoints, but in a much larger number whose general climatic conditions are decidedly unfavorable. This is not surprising, for the beneficial effect of pronounced changes of temperature from day to day is often nullified by great heat in summer or extreme cold in winter. Moreover, the seasonal range of temperature forms only one of the two factors which determine the amount of stimulation derived from changes of temperature from day to day.

1 The other factor is the number of cyclonic storms. By this, as has already been explained, we mean the ordinary storms which produce our changes of weather from day to day in the United States and Europe. Possibly the storms are more ( important than the range of temperature from season to season, but until further data are available it seems wise to reckon the two as of equal value. The world's stormiest region, so far as 
known, includes the Great Lakes region of the United States and southern Canada. Around this center there is an area of great storminess extending southward approximately to Maryland and Kansas, and northwestward through the Dakotas to Alberta. Eastward it includes New England and the Maritime Provinces, while northward it quickly disappears. 'To the south the storminess diminishes gradually, so that Florida has a moderate degree of variability in winter but not in summer. Southern California is the least stormy part of the United States. In Europe the very stormy regions include Britain, most of France, Germany, parts of Scandinavia and the northern part of Italy, together with western Austria and the Baltic region. In Asia, Japan is the only place where cyclonic storms are at all numerous. The lands of the southern hemisphere generally have few storms. New Zealand is the chief exception, although there they do not cause such great changes of temperature as in America and Europe. The extreme southern tip of South America is likewise stormy, but its storms do not cause much variability. On the contrary, they give rise to a monotony of wind and clouds which is extremely deadening, according to the testimony of those who have lived in such places as Tierra del Fuego or the Falkland Islands. Farther north, in central Argentina, there is a moderate number of storms, comparable to those in the southern United States, and their effect is distinctly favorable.

We are now prepared to estimate the relative stimulating power of the various climates of the world. In England, for example, the mean temperature of the seasons and the degree of storminess are both highly favorable, while the seasonal changes are only moderate. Germany is above medium in temperature, and high in seasonal changes and storminess. In this respect, it resembles the northeastern United States and southern Canada. Japan is similar except that it is somewhat too warm and damp. The coast of British Columbia and the neigh- 
boring states is highly favorable in mean temperature, and medium in storminess and seasonal changes. Around San Francisco, the mean temperature is still better, but both seasonal changes and storms are mild. In compensation for this, however, there are frequent changes of temperature because fogs blow in from the ocean, and are quickly succeeded by the warm, bright weather which generally characterizes the interior. Farther south where the fogs cease, the conditions become less favorable from the point of view of the changes from one day to another, although the mean temperature of the seasons still remains advantageous.

The chief defect of the climate of the California coast is that it is too uniformly stimulating. Perhaps the constant activity $\int$ which it incites may be a factor in causing nervous disorders. When allowance is made for the fact that California's urban population is relatively smaller than that of states like Massachusetts and New York, insanity appears to be even more prevalent than in those states. Moreover, the cities of the California coast have the highest rate of suicide. In proportion to the population the number of suicides is greatest in San Francisco; then come San Diego and Sacramento; while Los Angeles and Oakland are exceeded only by Hoboken and Saint Louis. Possibly these facts may be connected with the constant stimulation of the favorable temperature and the lack of relaxation through variations from season to season and day to day, although other factors may also play a part. The people of California may perhaps be likened to horses which are urged to the limit so that some of them become unduly tired and break down.

In the same way the people of the eastern and central United States are more nervous and active than those of Europe-but not necessarily more efficient-because of still different climatic handicaps. They are alternately stimulated and relaxed by frequent changes from day to day, and in this are like horses 
that are well driven. In the spring and autumn, however, the combined effect of ideal temperature and highly invigorating daily changes spurs them to an astonishing degree of effort. Then comes the hot summer or the cold winter, either of which is debilitating. People do not diminish their activity at once, especially in the winter. They draw on their nervous energy, and thus exhaust themselves. They are like horses which pull on the bit, and when urged a little break into a run, straining themselves by their extreme speed. Then they are pulled up so suddenly that they are thrown back on their haunches and injured. In Germany somewhat the same conditions prevail, although not to so great an extent. England apparently comes nearer to the ideal than almost any other place. The climate is stimulating at all times, both by reason of abundant storms and because of a moderate seasonal range. It never, however, reaches such extremes as to induce the nervous tension which prevails so largely in the United States.

In strong contrast to these highly favored regions are such places as the center of Asia where the winters are depressingly cold and the summers unduly hot. The range from season to season is apparently helpful, but its good effects are largely nullified by the infrequency of storms. Day succeeds day with no apparent change. In the desert of Takla-Makan in Chinese Turkestan in the fall of 1905, I found that one of the most surprising features was the way in which winter came upon us unawares. Each morning the thermometer stood a trifle lower than the preceding morning, but there was never any change such as that which we so often experience in America when the first severe frost suddenly comes after a series of days as warm as summer. Frost at last began to prevail at night, but not until we found the water frozen hard in the morning did we realize that winter was upon us. So it goes, month after month, with deadening monotony. Yet when a storm does come the change is often much more extreme than in more 
oceanic regions. It is frequently so great that its value as a stimulus is much diminished.

Tropical regions suffer even greater disadvantages than do places like the center of Asia. Not only is the temperature unfavorably high, but there are practically no cyclonic storms except in portions where a few hurricanes occur each year. Thunder storms, to be sure, are abundant, but they rarely bring any important change of temperature. Moreover, the seasonal range from the warmest to the coldest month is generally less than the difference between day and night. Day after day displays no appreciable variation from its predecessor. The uniformity of the climate seems to be more deadly than its heat. Such uniformity, even more than the high temperature and high humidity, is probably one of the most potent causes of the physical debility which affects so many white men within the tropics, and which manifests itself in weaknesses such as drunkenness, immorality, anger, and laziness. Even in tropical highlands the same deadening monotony prevails, although to a less degree than in the lowlands. Such monotony is perhaps the condition which will do most to prevent the white man from living there permanently for generation after generation. His general health may not seem to suffer, but if he works hard he is in great danger of breaking down nervously. The temperature of the highlands may be highly stimulating. There are many places where the mean temperature during every month in the year is within a few degrees of the combined physical and mental optimum. At Quito in Ecuador, for example, the coldest month, November, averages $54.3^{\circ} \mathrm{F}$., and the warmest months, February and September, $55^{\circ}$. If we are justified in associating a high rate of insanity on both the -Atlantic and Pacific coasts of the United States with the peculiar climatic conditions, we should expect that white men in tropical regions at high altitudes would suffer still more in the 
same way, or else would become inert, but no figures seem to be available to determine this point.

We might proceed to discuss scores of ways in which a knowledge of the exact effects of climate may assist in the understanding of historic events or help in guiding future development. .Such discussions, however, are bound to be inconclusive until the world comes to a more definite agreement as to the exact physiological effect of climate upon normal human beings who are not under the influence of any specific disease or of any unusual circumstances except those which come in the ordinary course of everyday life. As a help in this direction let us construct a map of the world showing the degree of energy which we should expect among normal Europeans in various regions on the basis of climate. We have seen that the most important climatic factors are (1) the mean temperature month by month, (2) the amount of change from one day to another, and (3) the relative humidity. The conditions which prevail at various seasons in the eastern United States duplicate those of almost every portion of the globe. There are hot, dry days like those of the Sahara; hot, damp days like those in the Amazon forests; cold days like those on the great ice-sheet of Greenland, and days of almost every other description. At this point we must make an assumption which cannot be tested until vastly more data have been collected. Let us assume that the continuance of a given condition produces the same effect as its temporary occurrence. For example, in Connecticut our measurements of the effect of days having a mean temperature of $75^{\circ}$ are based on occasional days scattered through the summers of several years. Only in rare cases do four or five days of such extreme temperature follow in succession without interruption by more moderate weather. The actual figures show that the first hot day does not greatly diminish people's energy, for the human body is able to resist for a while and to carry the impetus of previous good conditions 
into the first part of a bad period. After two or three days, however, the heat takes hold on people and makes them inefficient, or even causes some to collapse. If such weather continued for months we should become somewhat accustomed to it, and the period of collapse would be past. Just what the rate of work would then be we cannot yet determine. It would almost certainly be slower than on the first hot day, but it would probably be faster than on the third or fourth. Because of this uncertainty we are obliged for the present to assume that it would be equal to the average of a number of first days and a much smaller number of second, third, fourth, and so on. Having made this assumption, but recognizing that it needs testing, we may go on to construct our map. We must remember that it is not supposed to be a map of the actual energy displayed by the people of various places, but of the energy that we should expect among Europeans if they lived in these places and were influenced as are the people of the eastern United States.

In making such a map it is fortunate that the most important factor is also the one most carefully tabulated by climatologists, and for which our investigations of energy give the most unequivocal results. The mean temperature for every month ir se year is given for about 1100 stations in all parts of the world in Hann's "Klimatologie." The second curve from the top in Figure 10, it will be remembered, shows the average efficiency of mind and body which would be expected at any given temperature on the basis of the work of operatives and students in Connecticut, New York, and Maryland. A table inserted as an appendix to this book shows the value for each degree of temperature according to the centigrade scale, the maximum being reckoned as 100 . To determine the effect of mean temperature upon human activity we simply take from Hann the mean temperature of each month, and then from the table in the Appendix, or from the curve in Figure 10, find the 
corresponding relative efficiency. Then we add the values for all the months. If every month had an average temperature of $50^{\circ}$, with a corresponding relative efficiency of 100 , the efficiency for the place in question would be 1200. As a matter of fact this is never reached, but London stands at 1196.6, San Francisco at 1198.6, and Quito in Ecuador at 1198.9. The worst place is Massaua near the southern end of the Red Sea, where the figure is 1070 .

The next process in constructing a map of climatic energy is to determine the effect of changes of temperature from day to day. Unfortunately exact statistics are not available in most regions, and we are obliged to employ an approximation. Since changes from day to day depend chiefly upon the seasonal range of temperature and the number of storms, $I$ have combined the two, giving equal weight to each, and giving the two together approximately one half the weight assigned to seasonal temperature. That is, the difference between Quito and Massaua, as stated in the last paragraph, is 128.9. This represents the maximum effect of the seasons, so far as the average temperature is concerned. The maximum effect of the seasons as far as changes from day to day are concerned is reckoned as 30, and the maximum effect of storminess on the same basis is also reckoned as 30. Since highly extreme conditions are not favutable, I have assumed that no seasonal change beyond $30^{\circ} \mathrm{C}$, or $54^{\circ} \mathrm{F}$., is of value, and also that changes below $-7^{\circ} \mathrm{C}$. $\left(19.4^{\circ}\right.$ F.) or above $23^{\circ}$ C. $\left(73.4^{\circ}\right.$ F.) are of no value. In other words, if the range from the mean temperature of the coldest to the warmest month is from below $-7^{\circ} \mathrm{C}$. to above $23^{\circ} \mathrm{C}$, it is reckoned as having a value of 30 , just as it would be if $-7^{\circ}$ were the lowest point and $23^{\circ}$ the highest. If the range should be from $4^{\circ} \mathrm{C}$. to $16^{\circ} \mathrm{C}$., it would be reckoned as having a value of 12 , while if it were from $20^{\circ} \mathrm{C}$. to $28^{\circ} \mathrm{C}$., the value would be only 3 , because the extremely hot weather above $23^{\circ}$ would scarcely be stimulating 
even if there were slight changes from day to day. In the same way extreme storminess does not produce an effect in proportion to the number of storms. One storm may succeed another so rapidly that the weather ceases to have sufficient variety, and becomes dull and lowering all the time. This is the case at Cape Horn, and also in certain parts of the North American Great Lakes region in winter. Accordingly a storminess of 20 centers per year according to Kullmer's scalewhich means far more than 20 storms-is reckoned as the optimum. Greater storminess is held to have the same stimulating value as 20 centers, while everything lower is counted proportionally. The whole matter is so technical that it cannot be understood without reference to other publications which are mentioned in the Preface, and to a report which I hope to publish when fuller data are available.

Humidity has not been considered, because the necessary figures are not available. In most of the cooler parts of the world it would make little difference, although a few unduly damp places like Ireland, or excessively dry regions like Chinese Turkestan wouı de lower than now appears. The chief difference would be in the warm portions of the world. Agra in northern India, for instance, now has a lower rank than Bombay and Calcutta, but if allowance were made for humidity this would probably be reversed, for Agra is pleasantly dry much of the year. The same reversal would probably occur between dry Khartum and wet Equatorville on the Congo. Arizona and other desert portions of the United States would also make a better appearance than on the present map. It must not be forgotten, however, that our data for New England show that extreme dryness does more harm than extreme humidity. This, however, does not apply to high temperatures. Under such conditions great humidity is undoubtedly most debilitating. Yet even when the air is hot, it may be too dry. In such a place as Death Valley in summer with the thermom- 
eter at $100^{\circ}$ to $135^{\circ}$ in the shade, it is almost impossible to drink enough water to preserve normal physiological conditions. Even a brief period of physical activity gives rise to much discomfort, and people who stay through the summer are in danger of suffering permanent injury to health.

Our knowledge of the effect of both extreme humidity and extreme dryness is unfortunately still qualitative rather than quantitative. Some day, however, exact figures for all the various climatic elements will be obtainable, and we shall construct a map showing the actual efficiency to be expected in every part of the world. It will be so accurate that the manufacturer, for example, who contemplates establishing a factory, will be able to determine the precise efficiency of labor in the different places which he has in mind, and can put the matter into dollars and cents for comparison with the cost of transportation, raw materials, and other factors.

Meanwhile, our map makes no claim to be more than a first approximation to the truth. Therefore no maps of individual continents are now presented, but merely a map of the world, Figure 13, and of the United States, 1 ure 20. In preparing these the figures for Hann's stations have been placed on the maps. Then a line has been drawn to include all places falling not more than 25 points below the possible maximum. These are ranked as "very high" and are shaded black. A second line includes places falling from 25 to 50 below the maximum, and the area thus delimited is ranked as "high," and shaded with heavy black lines. The next division, indicated by light lines, is ranked as "medium," and the values range from 50 to 75 below the maximum. The area shaded with thickly scattered spots includes places ranging from 75 to 115 below maximum, and is counted as low. The fifth division, shaded with widely scattered spots, is "very low," and ranges from 115 to 155 . Finally, the hot desert areas which fall below 155 are left unshaded, but if humidity were considered they would probably 
rank as high as the wet parts of the tropics. Aside from the unshaded areas the general features of the map will probably remain unchanged even when the most accurate data are finally available. Undoubtedly, there will be variations in details, but a general map on a small scale, such as Figure 13, will not show

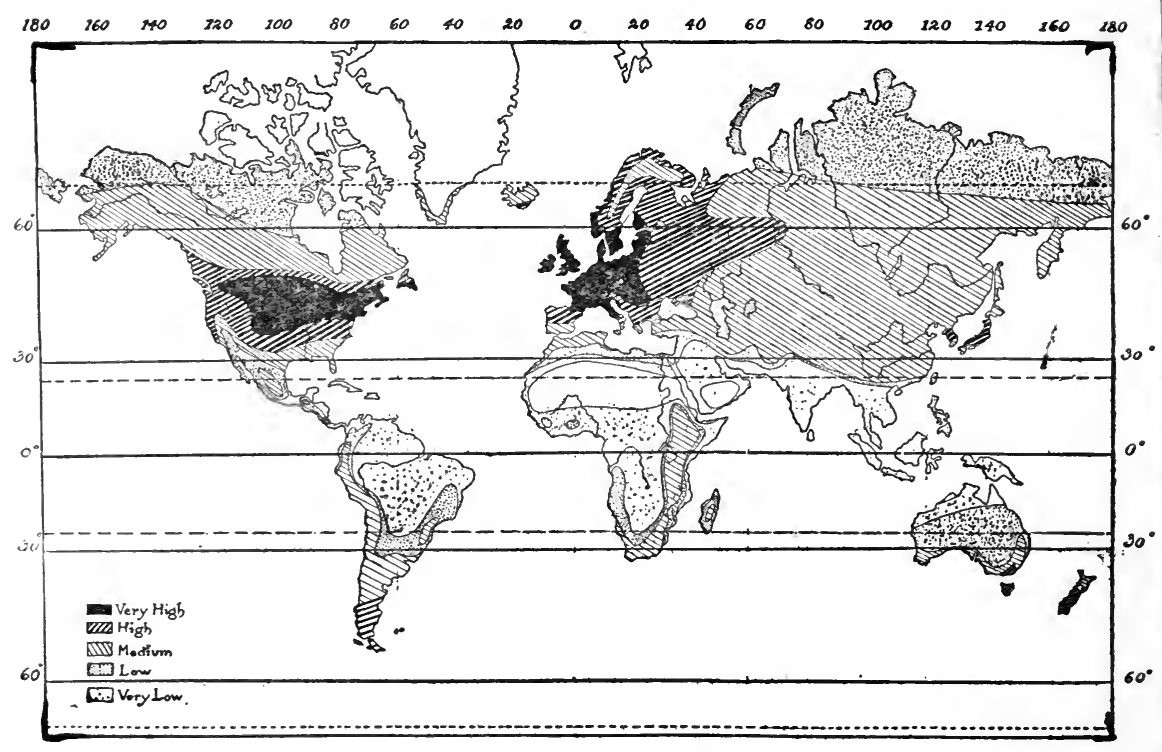

Figure 13. The Distribution of Human Energy on the Basis of Climat.

differences which will materially influence our conclusions. In fact, whatever differences there will be, as far as they can be foreshadowed, will be in the direction of confirming our conclusions, for Ireland will fall below England, southern India below northern, and the Congo region below the Egyptian Sudan.

The most noticeable feature of the map is two large black areas of "very high" energy in the United States and southern 
Canada on the one hand, and in western Europe on the other. Each is surrounded by a heavily shaded "high" area of large extent. The remaining high areas, four in number, are surprisingly limited. One lies chiefly in Japan. It is shown as extending into Korea, but the correctness of this is doubtful, for the records of storms in that region are imperfect. The second lies chiefly in New Zealand, but extends into Australia. The records of storms in this region have been published less fully than in Europe and America, but the general appearance of the map seems to be approximately correct. The third of the minor high areas is located in the southern part of South America. The records here are very imperfect, and the extent of the high area is doubtful. The reason for this uncertainty is not only that reliable records of storms are not sabundant, but that the available data do not enable us to determine how much change from day to day is caused by the average storm. The amount of change must be slight compared with that experienced under similar circumstances in North America and Eurasia, because no part of the southern end of South America is far from the ocean. The fourth of the minor high areas lies along the Pacific coast of North America. As already stated, its southern portion owes its character not to storms or seasonal changes, but to frequent breezes blowing in from the ocean. It extends only a short distance inland, and is too narrow to be prominent on the small-scale maps of this volume.

In the far North human energy appears to decline more than would be expected. We know that population is scanty, and civilization low, but we commonly ascribe this to the difficulties of agriculture. Little can be demanded of people who must get a living by hunting and fishing. From the map, however, it appears that even if other circumstances were favorable we should not look for any great achievements. This accords with the slow, inefficient character of the Eskimos, and 
of the Ostiaks and other inhabitants of northern Siberia. Grenfell in his book on Labrador says that the Eskimo "cannot compare with the Newfoundland white fishermen for perseverance and 'snap.' An Eskimo does not get one fish for the other's ten." This happens even when the Eskimo is in his native habitat, and is doing work to which he has been trained from childhood. Racial inheritance may have much to do with this, but the testimony of white men is that after a long stay in the Arctic they themselves lose ambition and energy.

At the other extreme of climate the regions within thirty degrees of the equator seem to be characterized by essentially the conditions that we should expect. The status of the highlands is striking. A high degree of energy among white men would not be expected permanently in any of them. We are often told that the climate of tropical highlands is as fine as any in the world. Not infrequently people are urged to colonize such regions. In book after book we read that there is not the slightest reason why the white man should not live there as well as at home. I do not assert that this may not be possible. In fact, I strongly hope that some day it will come to pass. Nevertheless, our map seems to indicate that previous to any such desirable consummation we must greatly increase our knowledge of how to adapt ourselves to nature, or rather of how to adapt nature to man. At present, while the white man may learn to preserve his health in tropical regions, he can scarcely expect to retain the vigor which he displays in the more favored parts of Europe.

The most unexpected feature of the map is the diminution of energy as one proceeds eastward from western Europe to central Asia. In the deserts of Turkestan and Mongolia, and especially in the Tibetan highland, the map should probably show lower conditions than are actually depicted, but as records are not available, the medium shading has been extended across the whole of the unknown area. Before making the studies 
here described I should have said that a man in Siberia could be as efficient as in far western Russia in the same latitude. Yet the Baltic Provinces are very high in climatic energy, while eastward there is a steady decline until only medium conditions are reached. The reason is readily apparent. In the first place, the Siberian winter is colder and longer than that of the region near the Baltic Sea. More important than this, however, is the decline in storminess as one passes eastward across Russia into Siberia. The cyclonic centers of low pressure, which constitute storms, are either broken up when they approach Asia in winter, or else swing out toward the sea to avoid the great area of high barometric pressure which lies over the continent during the cold season. Hence, during midwinter the far interior is characterized by clear and extremely cold weather, not hard to bear, but steadily benumbing. In the spring and autumn, on the other hand, storms are fairly frequent, and are often of most terrific intensity. The burans, as they are called, are even worse than our western blizzards, which are the same thing under another name. They destroy cattle and horses by the thousand, and human beings often perish within a hundred yards of their houses. Only when the burans are at an end and the milder storms of the late spring and summer prevail does Siberia enjoy a highly stimulating climate.

The conditions just described afford an interesting commentary on the common idea that the plains of Siberia are to be the scene of a wonderful development of European civilization during the next few centuries. I formerly shared this opinion, but have now been obliged to modify it. While this chapter was being written I spoke of this change of opinion to a Russian friend who has come to America for the sake of greater freedom. "Yes," he said, "that is just what the exiles say. I have many friends who are exiles. When they are sent to Siberia they take books with them and expect to do much work in writing and along other lines. Some plan to carry on linguistic studies, 
and some to make various other kinds of scientific investigations, but they almost never do it. They say that at first they begin to work with great vigor, but after a year or two their energy declines. They have the desire to work, but do not seem able to do so. They attribute this to being so far from home, and to the lack of stimulating contact with civilization. I think there may be more to it than that, for they seem to lose their energy."

Nansen, in his recent book "Through Siberia: The Land of the Future," emphasizes this point. He frequently speaks of the slowness and inertia which he encountered. Here per acre the Siberians raise far smaller crops than the Norwegians, and the main reason assigned by Nansen is lack of care, forethought, and energy in cultivating and fertilizing the soil. "There is no hurry here," he says, "Siberia is still a country that has a superabundance of time, as of everything else; they may think themselves lucky for having so far escaped the nervous stress that we know too well in Europe." He also quotes Rodishev, one of the most enlightened members of the Duma, who sums up his impressions of a journey in Siberia with the statement that the Siberians are "a people without enterprise or initiative."

This suggests that the Russian autocracy has accomplished its purpose more fully than it realizes. It has not only exiled many of its most thoughtful and active people, but has sent them to a place where not only do the isolation and hardships diminish their power, but where nature insidiously accomplishes exactly the kind of repression that the authorities desire. From the standpoint of climate, without respect to the many other factors which may cause quite other results, the relative positions of Russia and Siberia do not seem likely to change. Both, we may rightly hope, are destined to advance far beyond their present position, but while there is reason to think that western Russia may approach the standard of western Europe, Siberia 
suffers from a handicap which may never let her overtake the Baltic portions of the great northern empire.

Turning to China, we find that the summers are often debilitatingly hot, with a steady, damp heat that is apt to be trying. The winters, on the other hand, are by no means so long as in Siberia, nor so severe. Yet they are far worse than in western Europe, and as bad as in any part of the United States. Cold waves often sweep down from the north, and are so severe that instead of being stimulants, they are depressing in regions like Peking. In the south, however, they are beneficial. Everywhere cyclonic storms are rare, so that there is no stimulus of great importance from that source. This is one of the chief reasons why China does not stand high on the energy map. The northern parts of the country are more favored than those in the south or in the far interior, but the difference is not great. Indeed, the uniformity of all parts is surprising. The disadvantages of high temperature in the south are balanced by those of low in the north. If China were part of a smaller continent her nearness to the moderating influence of the sea would help her much more than is now the case. All through the winter she is under the benumbing control of the vast continent to the west, which not only sends out severe cold waves, but prevents the passage of storms. Japan, on the contrary, does not suffer so much in this way. Extremes of temperature are milder than in China, and stimulating storms are frequent. Her greatest drawback is the long period of hot, damp weather in summer. Nevertheless she stands high. Here we must bring our review of the map of climatic energy to a close. We shall come back to it again when we have studied the distribution of civilization. 


\section{CHAPTER VIII \\ The Distribution of Civilization}

Doubtless the reader has already noticed the striking resemblance between the distribution of climatic energy and of civilization. Look again at Figure 13 and see how the black areas agree with the places of highest culture. In view of this it seems advisable to construct a map of civilization to serve as a standard of reference. Only two methods appear feasible. One is by statistics; the other on the basis of opinion. Both present grave difficulties. The statistical method will ultimately prove far the better, but it may not be practicable for centuries. For a fair estimate of the position of a country we need accurate statistics of education, morality, industry, inventions, scientific and artistic skill, wealth, pauperism, charity, crime, and many other aspects of human life which will readily suggest themselves. No reliable figures for many of these things have ever been gathered in any part of the world; no statistics for any of them have ever been gathered in many countries. Statistically it is almost impossible to compare Afghanistan, for example, with Kamchatka. Even where accurate statistics are available, the methods of compiling them are often so diverse as to make comparisons misleading. We may know exactly how many people are arrested and convicted for theft in half a dozen countries, but in one country the police may be so inefficient that few criminals are apprehended, while in another practically every thief may be caught. Thus the better may easily appear the worse. The only way to use statistics at present seems to be as a check upon the other method. We can select 
some country so extensive that its various parts differ decidedly, but sufficiently homogeneous so that the figures for all portions are comparable. Since the United States meets these conditions better than any other country we shall examine its statistics in several cases, and shall use them as a test of a map prepared on the basis of opinion.

For a map of the civilization of the entire world we must rely on the opinion of well-informed persons, but we shall find that this agrees closely with the indications of statistics. The value of a map based on personal opinion depends partly on our definition of civilization and partly on our confidence in the judgment of the persons in question. Even the best and broadest experience does not eliminate personal or racial bias. Therefore, the only safe course is to obtain the opinions of many people belonging to different races and ruled by different ideals. Accordingly, in the autumn of $1913 \mathrm{I}$ asked over two hundred people in twenty-seven countries to help in preparing a map. Most fortunately this was before the great war broke out. Good feeling prevailed everywhere, and among men of sound judgment there was perhaps as little racial prejudice as at any time during the course of history. This is especially important because similar conditions may not prevail again for years.

The persons whose assistance was asked were selected for various reasons. The larger number were geographers whose first duty is to know all parts of the world. Ethnologists in considerable numbers were included for the same reason, but they responded less freely than the geographers. Historians, diplomats, colonial officials, travelers, missionaries, editors, educators, and business men were all included. The only criterion was that each person should possess an extensive knowledge of the world through personal knowledge, or, in a few cases, through reading. Some were selected because of knowledge of special regions not well known to most people and only 
reached by extensive travel. To all these many kinds of people, numbering 213 in all, I sent the following letter :

"May I ask your coöperation in the preparation of a map showing the distribution of the higher elements of civilization throughout the world? My purpose is to prepare a map which shall show the distribution of those characteristics which are generally recognized as of the highest value. I mean by this the power of initiative, the capacity for formulating new ideas and for carrying them into effect, the power of selfcontrol, high standards of honesty and morality, the power to lead and to control other races, the capacity for disseminating ideas, and other similar qualities which will readily suggest themselves. These qualities find expression in high ideals, respect for law, inventiveness, ability to develop philosophical systems, stability and honesty of government, a highly developed system of education, the capacity to dominate the less civilized parts of the world, and the ability to carry out farreaching enterprises covering long periods of time and great areas of the earth's surface.

"In preparing such a map it is evident that statistics may afford much assistance, but they need to be supplemented. They touch only upon material things in most cases, and none are available for a large part of the world. Therefore, our best resource is the personal opinion of competent judges. Accordingly, I am asking a hundred geographers, anthropologists, and other persons of wide knowledge, whether they are willing to take the time to divide the regions indicated in the accompanying list into ten groups according to the criteria mentioned above. Group 10 will include regions of the very highest character, that is, those where the greatest number of valuable qualities are found in high degree. Group 1 will include those which are lowest in these respects. On the basis of this group- 
ing I shall determine the average position of each region and shall prepare a map accordingly.

"The purpose of such a map is threefold. In the first place, it will prove intrinsically interesting to a large number of people, and is likely to arouse considerable discussion. In the second place, in all geographical, historical, sociological, and economic discussions it seems to me that we need a clearer, stronger emphasis upon human character, that is, upon the mental and moral qualities which dominate the civilization of the various nations. If this is so, it is highly important, in the third place, that we should determine much more fully than has yet been the case how far various moral and mental qualities are influenced by physical environment, race, historical development, biological variations, and other causes. In order to determine these things we need a map which shall serve at least approximately as a standard of reference. In discussing the influence of such things as racial character, differences of religion, social institutions, modern means of communication, the form of the land, the relation of land and sea, variations of climate and the like, we shall be able to gain much light by comparing their distribution with that of human character as it now exists according to a consensus of expert opinion.

"The matter can best be illustrated by outlining a specific purpose to which I mean at once to apply the proposed map. [Here follows a brief description of the map of human energy on the basis of factory work.]

"I recognize that those to whom this letter is sent will say at once that they are not sufficiently familiar with all parts of the world, and that they have no means of distinguishing between different parts of China, for example, or between the different portions of equatorial Africa. This is certainly true, but it must be remembered that the classification is very rough. It is only desired that the one hundred and eighty-five names on the enclosed list be divided into ten groups, no group to contain 
less than fifteen names or more than twenty-one, and each preferably to contain eighteen or nineteen. It may not be easy to determine whether all of the divisions of France, for example, fall in the first group, but it is perfectly evident that none of them will fall in the fifth or lower. The chief thing is to place them as nearly as possible in their proper group according to one's own personal opinion. A given region may properly fall in the fifth group, but the purpose of this classification will not be defeated if it is placed in either the fourth, fifth, or sixth, for when the opinions of one hundred persons are averaged, individual idiosyncrasies will disappear. In view of the varying degrees to which each individual is familiar with the different regions of the world, I should be glad if each contributor would underline the names of regions with which he is well acquainted either by travel or reading, and would place question marks after the names of regions as to which his knowledge is especially deficient. Names not underlined or questioned will be considered as intermediate. The three grades of familiarity thus indicated will be weighted in the ratios of 3, 2, 1. [This has not been done, partly because only about half of the contributors made the division into three grades, and partly because the final results are not appreciably changed by using the unweighted values.] The grade of the various regions should be indicated by underlining or questioning the names upon the small slips mentioned below, but may be done upon the accompanying list if that is more convenient, but in that case please be sure to return the list. For convenience of classification I enclose slips containing the names of the different divisions. These may be spread out upon a table and arranged in ten columns and shifted from column to column until an approximately satisfactory arrangement is reached. When thus arranged those of each column should be placed in the corresponding envelope of the ten here enclosed, and all may be 
mailed in the large addressed envelope. Envelope ten is for the highest group, and one for the lowest.

"In making the classification, one or two points need to be borne in mind. In the first place, the past should not be considered: Greece, for example, should be placed in the group where its condition during the past one hundred years would place it without reference to its ancient greatness. In the second place, if two races inhabit a given region, both must be considered, and the rank of the region must depend upon the average of the two, giving each one a weight proportional to the number of people. For instance, in a state such as Georgia where nearly half the people are negroes, they must receive half the weight. Still another point is that the rank of a country can often be determined by considering the position which its people take when they migrate elsewhere. For instance, the position of Syrians as compared with Germans when they migrate to England or the United States is a fair criterion as to the relative merits of the two races. After the first generation, however, this should not be applied, for the younger generation owes much of what it is to the new country. A final point concerns countries which are poor in natural resources, or which are not located in the main centers of the world's activity, but which are nevertheless of high character. For example, so far as importance in the affairs of the world is concerned, England vastly outranks Scotland. Nevertheless, our estimate of the greatness of England owes much to the large number of Scotchmen who have gone out to build up the British Empire. Therefore, in estimating the relative merits of Scotland and England, the matter of size or even of commercial importance should receive relatively little consideration, whereas the character and ability of the people as rulers, merchants, scientists, writers, and men of all sorts should have a predominating weight.

"In publishing the final results I should be glad if I might 
print the names of those who have contributed, but of course this must be as each individual may choose. The individual lists will not be published, and will be treated as confidential. I judge that other contributors will feel, as I do, that their classifications are of necessity so imperfect that they do not care to distribute them to the world at large. Hence, while the list of contributors will be published unless the contributors prefer otherwise, their individual opinions will be withheld. I hope, however, to publish a list showing the average rank of each country and the range of opinion between those who put it highest and those who put it lowest. Inasmuch as the plan here outlined depends upon the coöperation of many contributors, no single individual can in any respect be held responsible for features of the final map which do not meet his approval.

*'In addition to the general list of divisions, I enclose a set of cards bearing the names of the states of the United States, and of the provinces of Canada. Would you be willing to arrange these in groups and place them in the proper envelopes, employing the same method as for the larger divisions? Group 1 will be the states or provinces which are least progressive, or least influential, so far as the general character of their citizens is concerned, and Group 6 the highest. Each group should contain about ten names. The object of this you see is to make a map of the United States and southern Canada on the same basis as that of the world, but on a more minute scale.

"The rough grouping here suggested ought not to take more than a few hours' time. Many days, to be sure, might be devoted to it, but the added accuracy thus gained would not be sufficient to make it worth while. If you can give the necessary time at your earliest convenience I shall be most grateful. If you cannot, would you be willing to return the list, the slips, and the envelopes in order that I may ask someone else to do it in your

* This paragraph was included only in the letters sent to Americans and to one or two Europeans especially familiar with America. 
place? Whether you contribute or not, I shall take pleasure in sending you copies of the final results. Trusting that I may hear from you soon, I am

\author{
"Very truly yours, \\ "Ellsworth Huntington."
}

Replies were received from $13 \%$ persons, while others sent copies of their publications, so that an answer of some sort came from about three fourths of those addressed. The majority of the remaining fourth were foreigners to whom a six-page letter in English might appear formidable. About 90 per cent of the English and Americans sent replies, which is a very large proportion as such things go. I am convinced that the rest failed to answer chiefly because the classification required more time and was more difficult than I at first realized. The fact that classifications continued to be received for an entire year indicates that many meant to answer, but put my letter aside for a more convenient season which never arrived. A third of those who replied, fifty-four to be exact, actually made classifications, and all but two or three conformed so closely to the general plan that it has been possible to use them. The names of the contributors are given in the Appendix. I take this opportunity to express the warmest appreciation of their kind. ness in coöperating so cordially. Not only their classifications, but their letters were of the highest value and in many cases contained suggestions which have been of great assistance in preparing this volume. The same is true of many letters from persons who did not contribute, but who took pains to explain their reasons and to suggest ways in which my plan might be improved. Except where direct quotations are employed I have not attempted to acknowledge my indebtedness for various ideas which distinctly modify the tenor of these pages. This is partly because the same thought was often expressed by 
several persons, and partly because in many cases I cannot tell from which of several letters an idea was derived. Except in two instances I have also refrained from mentioning names, because where so many have contributed materials of great value, it might seem invidious to mention some and not others. Therefore, I can merely express my gratitude to all concerned. The net result of this attempt at scientific coöperation among men of many races and tongues leaves a strong impression of the spirit of fellowship and friendly helpfulness among men of wide interests in all portions of the world.

The countries represented in the final classification and the number of contributors are as follows: Australia 1, Canada 1, Norway 1, Sweden 1, Switzerland 1, Russia 1, Spain 1, Portugal 1, France 2, Italy 2, Japan 3, China 3, Germany 5, Great Britain 7, and the United States 24. The number of Chinese and Japanese is particularly gratifying. The ratio between the number of contributors and the number to whom letters were sent is higher among them than among any other main group except the Americans, as may be seen in the Appendix. It is to be regretted that no one from India or South America coöperated, and only one, a Russian, from the European countries east of Germany.

The difficulty of making the classification is considerable. Several contributors spoke of spending an entire day upon it, or of taking out the slips time after time to arrange them more satisfactorily. Some said that they spent two entire days upon it. All seemed impressed by the way in which a systematic classification of this kind brings out the weak spots in a man's knowledge. For instance, here is the way in which one contributor expressed himself :

"One appreciates what a big world this is and how little one knows about it when he attempts, such a task as you have set. It is a most excellent means of taking the conceit out of one." 
Another puts it in this way:

"I must confess that it is the most difficult and one of the most humiliating games I have ever tried to play! I always knew I was a fraud as a President of a Geographical Society, but I never knew before how great was my deception! The greatest difficulty I found lay through my ignorance of the proportion of the different races inhabiting a district."

An interesting feature of the letters was the diversity of opinion as to the advisability of any such classification of countries. To take the adverse opinions first, one of my best friends, an American geographer, put the matter very strongly:

"I am complying with your request for a sorting of the slips you sent me. It is a very bad plan, and not, I think, of value. Indeed I am not sure that I would have done it for anyone else than you."

I am glad to say that later he expressed a much less severe opinion. Another geographer, a Teutonic European, speaks most cordially in part of his letter, but comes out bluntly in opposition to this particular plan:

"I am wholly unable to take part in this work. I take your scheme as a failure . . I guess you are here, like some other Americans, under the influence of a too systematizing spirit. It seems to me impossible to classify mankind by this simple method."

Still a third, an American anthropologist, is equally uncompromising:

"Speaking frankly I do not conceive that the method you suggest is possible of scientific results. One must choose between statistics which are definite and mere judgments which are general. To apply the geographic method to a compound of statistics and loose generalization may be productive of grave error." 
And a fourth, also an American anthropologist, expresses himself as follows:

"It has been my endeavor, in my anthropological studies, to follow the same principles that are laid down for natural sciences; and the first condition of progress is therefore to eliminate the element of subjective value; not that I wish to deny that there are values, but it seems to me necessary to eliminate the peculiar combination of the development of cultural forms and the intrusion of the idea of our estimate of their value, which has nothing to do with these forms. It seems to my mind that in doing so these obtain subjective values, which in themselves may be the subject of interesting studies, but which do not give any answer to the question that you are trying to solve."

Another anthropologist, this time a European, at the end of a particularly long and suggestive letter, expresses himself thus:

"Taking all that I have written here into consideration, I think that if we were going to grind all the different regions of your long list in the same statistical mill, and to try to compute an average, a highly improbable and fantastic result would be obtained. For my own edification I put some of your criteria to the test, though in a different way. I drew up a list of twelve characteristics of the 'highest value,' in which I included sense for beauty in literature (belles lettres) and a few others, and then distributed them to eleven different regions of the globe. My familiarity with those regions by a long sojourn or travel and reading, covers a lifetime. To each characteristic for each region $I$ assigned a number, from 1 to 10 . I then added the different values or points to try to find a ratio, which might be called 'index of civilization.' I give it valeat quantum valere potest." 
The table possesses so many points of interest that it is inserted below. At the end I have added a column showing the rank of the various regions according to all the contributors, as computed according to the system presently to be outlined. If the plan embodied in this table could be carried out on a large scale, it would undoubtedly be better than mine. The difficulty is that it requires a vast amount of work and a degree of familiarity with the various peoples of the earth which is found only among a few exceptional students who can almost be counted on the fingers. In course of time we may perhaps hope for a map based on some such minute study of human nature. Yet when it is before us, there is every reason to think that its general features, with which alone we are concerned in this book, will be almost identical with those of the map which we shall shortly consider. The reasons for this will be given later.

One important point stands out in this table. I have given too little weight to the esthetic side of human nature. In framing a definition of civilization I consciously thought of art in all its forms, but it seemed as if this were included in "the capacity for formulating new ideas and for carrying them into effect," just as science is meant to be included. Moreover, the course of history seems to show that every nation which rises high in other respects sooner or later experiences a period of high development in art, architecture, literature, and science. Nevertheless, these things should have received more specific recognition in my definition.

To turn now to the other side of the question, those who believe in the utility of the plan presented in my letter naturally do not feel the necessity of stating their reasons. Nevertheless, a considerable number take pains to express approval. For instance, a widely traveled Englishman thinks that "there are tremendous possibilities in all such attempts." An American, who is familiar with most of the countries of the world, says: 


\begin{tabular}{|c|c|c|c|c|c|c|c|c|c|c|c|c|}
\hline & 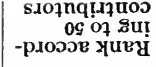 & $\underset{8}{8}$ & ஓ & \% & g & 5 & ஓ & 8 & in & ชి & $\stackrel{\infty}{\underset{\sim}{\alpha}}$ & $\infty$ \\
\hline & 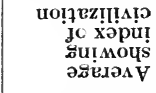 & ஜ & a & \&ి & g & î & \pm & $\stackrel{a}{x}$ & $=$ & 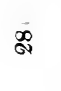 & $\stackrel{0}{-1}$ & $\stackrel{20}{7}$ \\
\hline & 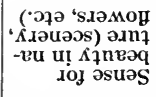 & $\infty$ & + & $\varrho$ & $\stackrel{0}{\circ}$ & + & $Q$ & $Q$ & - & $r$ & -1 & 40 \\
\hline & 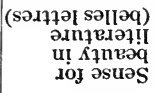 & $\infty$ & $\stackrel{-}{=}$ & $\stackrel{0}{-}$ & $\sigma$ & 0 & $r$ & 0 & + & 0 & $Q$ & 0 \\
\hline ב⿱ & 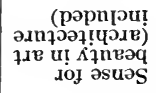 & 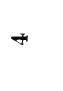 & $\stackrel{\ominus}{\sim}$ & $\stackrel{0}{\circ}$ & $\sigma$ & $Q$ & $\infty$ & $Q$ & -1 & $Q$ & -1 & $x$ \\
\hline$\stackrel{B}{0}$ & 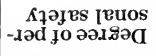 & $x$ & $\mp$ & $\stackrel{-}{=}$ & $\sigma$ & $\sigma$ & مه & $x$ & -1 & 0 & 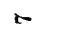 & $r$ \\
\hline 帘 & 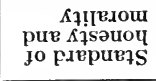 & $r$ & QQ & $\infty$ & 0 & $x$ & $Q$ & 0 & $r$ & -1 & - & -1 \\
\hline as & 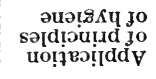 & $x$ & مه & $x$ & $\infty$ & $\infty$ & $\infty$ & $\infty$ & $Q$ & + & - & + \\
\hline$\underbrace{2}_{0}$ & 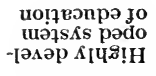 & هـ & $x$ & $\sigma$ & $\infty$ & $\infty$ & $\sigma^{*}$ & $r$ & $\rightarrow$ & $Q$ & $\rightarrow$ & هـ \\
\hline$\underset{\Xi}{\mathbb{Z}}$ & 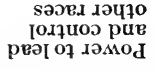 & $\sigma$ & $\infty$ & ת & $Q$ & -1 & - & $\infty$ & -1 & 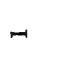 & $\rightarrow$ & -1 \\
\hline $\begin{array}{l}0 \\
0 \\
0 \\
0 \\
0 \\
0 \\
0 \\
0\end{array}$ & 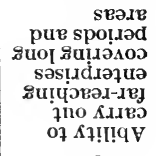 & $\stackrel{ }{-1}$ & $\infty$ & Q & 0 & $r$ & ov & $\stackrel{ }{\ominus}$ & $\neg$ & $\rightarrow$ & $\rightarrow$ & $\infty$ \\
\hline 㟧 & 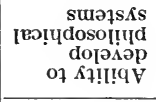 & 0 & $\infty$ & $\infty$ & o & $Q$ & $\infty$ & $a$ & $\rightarrow$ & -1 & $\neg$ & $Q$ \\
\hline คُ & 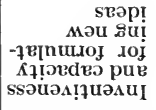 & $x$ & $\infty$ & $\Delta$ & $\infty$ & $Q$ & 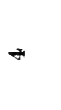 & $\sigma$ & $\neg$ & 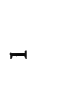 & - & -1 \\
\hline & 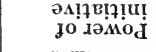 & $\stackrel{-}{\circ}$ & 0 & $\infty$ & $\infty$ & $\infty$ & $\infty$ & 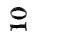 & $r$ & ar & - & $\infty$ \\
\hline & 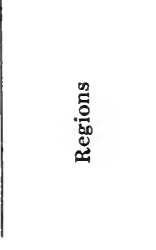 & 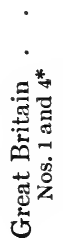 & 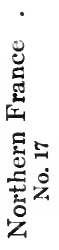 & 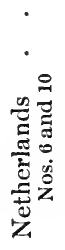 & 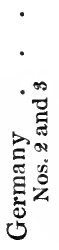 & • & 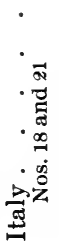 & 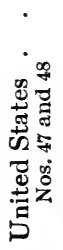 & 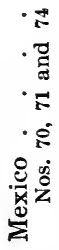 & 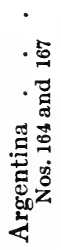 & 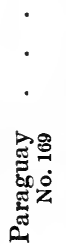 & 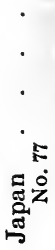 \\
\hline
\end{tabular}


"Permit me to say how heartily I thank you for engaging in this enterprise. Despite any and all sympathetic or hostile criticism of such a work, or the cheap and hasty or really valuable appraisal likely to be made, such a scheme will be invaluable to all students of human progress."

Another American, who has spent a large part of his life in the Orient, is of the opinion that: "It is a fascinating and very significant set of standards by which you have asked us to group the regions. From the time I started after lunch until now, late in the evening, I have done nothing else. But there is more than fascination. There is a very deep issue involved, and I am glad to share in the construction of the map and the charts you are aiming to devise."

One of the fairest estimates of both the advantages and disadvantages of the plan is contained in a letter from "Ambassador" Bryce, as we Americans still like to call him. With his permission I quote it in full.

"Your idea is ingenious and interesting, and I should much like to see how it works out, though it seems to me, on first impressions, that the various factors involved are so many and so complex that the visual presentation you contemplate would need an amount of comment and explanation which would require something like a treatise to accompany the map. You give one instance in the case of the state of Georgia. Another might be found in the other Georgia, south of the Caucasus, where besides the native Georgians (Karthli) there are Armenians, Tartars, and Russians, not to speak of minor races. Or take Japan. If one were to think of the educated and ruling Japanese and the sort of civilization they have created one would make a rating quite inapplicable to the ordinary Japanese. Without therefore doubting that by means of a map presentation very interesting results may be obtained, I should 
think that some modifications would be needed. 'Efficiency' is a very complex conception.

"If I had time I should like to try to think further about the scheme, and lend what aid I could to it; but unfortunately I am so fully occupied by trying to finish a book for the sake of which I retired from the Embassy at Washington that I am, to my regret, unable to coöperate with you. I shall be grateful for any information as to the results you can send me if you have leisure."

P. S. [dated two weeks after the letter].

"I have kept the papers some weeks in order to see if I could help you. I have dealt with the states and provinces of the United States and Canada, though roughly. But I have found the difficulty of any adequate arrangement of the extra-European world in point of efficiency impossible in respect of the extraordinary mixture of races. Turkey and India are nuts too hard to crack; . . . In South America it would be easier, because the races are really so mixed that a new race results. But in India they live side by side and are quite different. [Here follows a classification of South America.] It is quite interesting and makes one think. But after all it is the natural race divisions rather than territorial divisions that count everywhere outside western Europe. Even in Russia and the Balkans, race doesn't correspond to territory."

These various letters give a good idea of the general opinion of the attempted classification. As an illustration of the difficulties to be overcome, let me quote from an Italian contributor, an anthropologist: "What is the standard of these various civilizations? Yours, as it seems to me, is an European one, and this, I think, is a very limited one and cannot solve the problems." A similar objection is expressed in a letter from an English anthropologist. Quoting from my letter, he says: 
" 'The power of self-control, high standards of honesty and morality, . . . high ideals, respect for law' arè eminently characteristic of many savage and barbarian peoples, notably the North American Indians, and in my opinion these latter stand very much higher than the average American citizen, but the latter lead in 'the power to lead and control other races, and capacity for disseminating ideas . . . inventiveness, highly developed systems, etc." "'

I recognize the force of these comments. Races certainly differ greatly, even though they happen to dwell in the same physical environment. Moreover, people of a given race who live under the same environment may differ widely because of diversity in religion, government, or institutions. Furthermore, the definition of civilization here presented does not pretend to be perfect. It is a European definition. Yet it is also a worldwide definition. The contemplative Hindu may perhaps be a higher type than the aggressive citizen of western Europe, but the contemplative type has made relatively little impression upon the world as a whole. If we turn to antiquity, the people who have left their impress are those who had this so-called European activity. The Greeks and Romans had it to a marked degree. The people of India had something of it when they wrote the "Vedas." Gautama had it when he founded the Buddhist religion. $/ \mathrm{He}$ was contemplative, but yet he had the qualities expressed in our definition. He was preëminently possessed of "high ideals, respect for law, inventiveness [in the broad, non-technical sense], ability to develop philosophical systems, and the capacity to dominate the less civilized parts of the world." He dominated through ideas, not force. The Jews had this same power. Such men as Saint Paul, although not aggressive in the ruder European sense, were unsurpassed in "the power of initiative, the capacity for formulating new ideas and for carrying them into effect, the power of self- 
control, high standards of honesty and morality, the power to lead and control" and "the capacity for disseminating ideas." The reason for regarding the standard here set forth as European is that Europe is today its great exponent. In the past, however, not only did Rome, Greece, Palestine, and even northern India possess it, but Egypt, Mesopotamia, and Carthage all displayed it. China, too, in her days of early greatness, and the wonderful Maya people of Yucatan, the only ones to develop the art of writing in America, were animated by the same active, stirring, "European" qualities. That is why we remember them, but have forgotten most of their contemporaries.

Granting that our definition of civilization is imperfect, but admitting that it includes the qualities which are of greatest importance in causing a nation to impress itself upon the world, let us now proceed to ascertain how these qualities seem to be distributed. The fifty contributors whose classifications could be used have been divided into five divisions as follows: (1) 25 Americans, 1 of whom is a Canadian; (2) 7 British, 1 of whom is an Australian; (3) 6 Germanic Europeans, 4 of whom are Germans, 1 a Swede, and 1 a Norwegian; (4) 6 Latin Europeans, namely, 2 Frenchmen, 2 Italians, 1 Spaniard, and 1 Portuguese, with whom has been included 1 Russian because there is no other group in which he fits more appropriately, and (5) 5 Asiatics, 2 of whom are Chinese and 3 Japanese. A third Chinese contribution was most unfortunately lost in the mail. The average opinion of each of these five groups is given in the tables in the Appendix. To obtain the final rank of each country the averages for the five groups have again been averaged. Thus each race, or at least each of our five divisions, has equal weight in determining the figures on which will be based the map used in later discussions. The opinion of twenty-five Americans, for example, has no more weight than that of five Asiatics. This may seem unfair, but on the whole it seems to 
be the method best calculated to give a reliable result. All of us are inevitably prejudiced. The Americans put America, especially its more backward parts, higher than is correct. The Asiatics put their own countries too high. By giving America and Asia equal weight and by dividing Europeans into three groups animated by different ideals and different sympathies, we are able largely to eliminate the effect of racial prejudice. The final results are summed up in Figures 14 to 19, but I shall defer comment upon these for the present.

In the tables in the Appendix the countries of Europe, North America, and Asia have been divided into groups corresponding as nearly as possible to race, while those of Australia, Africa, and South America have each been put in a single group because the racial differences are either not strongly marked,

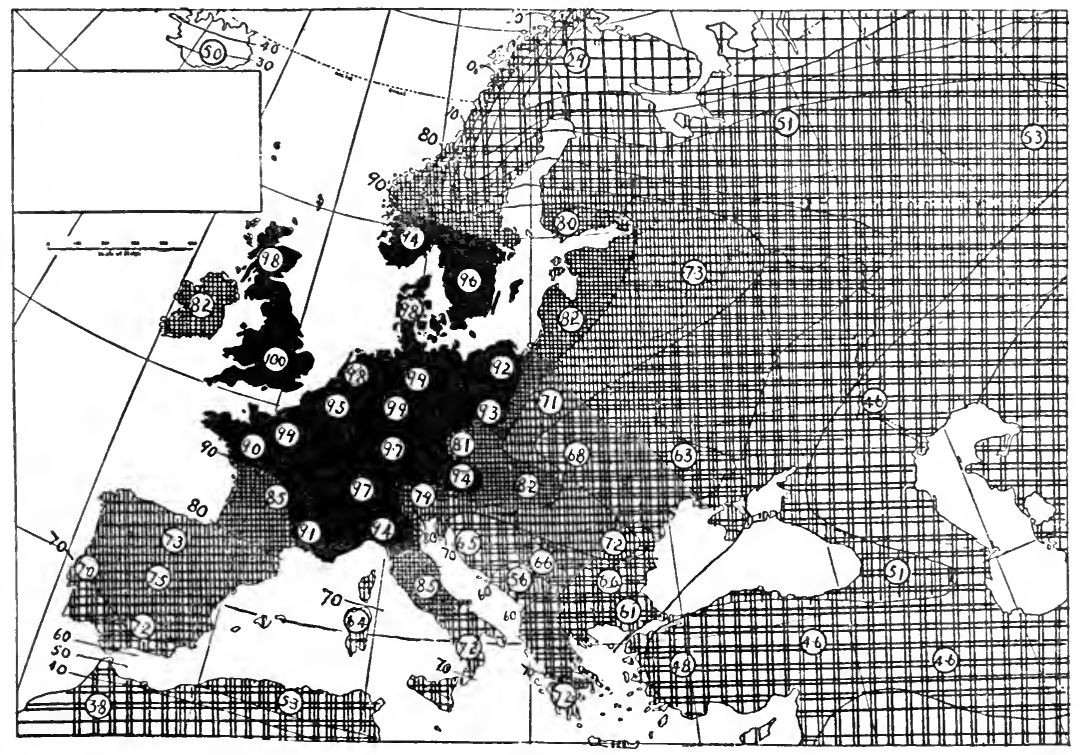

Figure 14. The Distribution of Civilization in Europe 
as in Australia and South America, or are highly complicated as in Africa. Under each group the country whose final rank is highest has been placed first and the rest in consecutive order. To begin with Europe, England heads the list. It is the only region placed in the first rank by every contributor. Northwestern Germany, which includes Berlin, comes next. The Germanic Europeans and the Asiatics all place it in the first rank. The British almost invariably do so, and their opinion, 9.9, averages the same as that of all divisions. Among the Americans and Latins several place this part of Germany in the ninth class instead of the tenth. Hence, its average position according to them is about 9.8. Such slight differences have little significance, for $\mathbf{9 8}$ per cent is almost as good as 100 per cent. Yet they suggest that in 1913 people who live in other parts of the world were on the whole not quite so sure of the Germans as of the English.

Following northwestern Germany we find central Germany, then Scotland, Denmark, Holland, and so on to northeastern Germany. Here for the first time we come to a region which is placed by one group, the Latins, in a rank lower than 9.0. Yet even here the Latins do not assign a rank lower than 8.5and everything above this ranks as "very high." Nowhere in these first fourteen regions does the greatest diversity amount to more than one degree on our scale of ten, or 10 per cent on the scale of 100. This is comparatively insignificant, for it means that while the difference between the highest and the lowest may be 10 per cent, each of them usually differs from the average by only about 5 per cent. Thus so far as numbers 1 to 14 are concerned the difference of opinion among Americans, British, Germans, Latins, and Asiatics is almost negligible. All alike rank these regions very high.

$\rightarrow$ Coming to Ireland, a country which, for lack of any other suitable group, is placed with the Teutonic regions, we find much more diversity of opinion. The English, presumably 
because it is part of their own country, and the Asiatics, perhaps because it seems to them like a part of England, place it very high, with a rank close to 9.0. The Germans, on the other hand, place it at 7.0, scarcely above the medium grade, while the Americans and Latins place it near 8.0, which means that compared with the world as a whole they think that Ireland stands high, but not very high. The fact that all the Teutonic regions except Ireland and the Austrian Alps rank above 9.0 and that these two, which are partly Teutonic, stand in the high group near 8.0, suggests that race is a dominant factor in determining the status of civilization. The same suggestion is enforced when we note that among the Romance nations the most Teutonized portions stand highest. Yet if one looks at Newfoundland and Greenland, or some of the other comparatively low Teutonic regions, or at some parts of Australia, it becomes evident that geographical conditions also play a highly important part.

The Romance nations of Europe seem to possess much more diversity of civilization than do the Teutons. Even if Albania and Montenegro be omitted as not being truly Romance, the range is from medium in Corsica and Sardinia to high in many regions, and very high in parts of France and northern Italy. Some places, such as southeastern Spain and southern Italy, are rated exceptionally high by the Asiatics, although the other contributors agree quite closely.

Among the Slavic nations central Russia stands at only 6.2 in American opinion, possibly because Jewish atrocities were freshly in mind when the classification was made. In general there can be no question that the Baltic Provinces and Bohemia stand at the top, while southeastern and northeastern Russia are at the bottom. The European region whose rank is most doubtful is southern Finland. The Asiatics reduce it to about 6.6, while the Germans rate it at 9.4. Even in so extreme a case the average opinion is not open to much criticism. The 
final rank is about 8.0, which puts Finland at nearly the same level as Bohemia, the Baltic Provinces of Russia, Ireland, and the Austrian Alps.

It would be interesting to go through all the tables and point out their special features, but this must be left for the reader to do by himself. Only one or two additional points can be

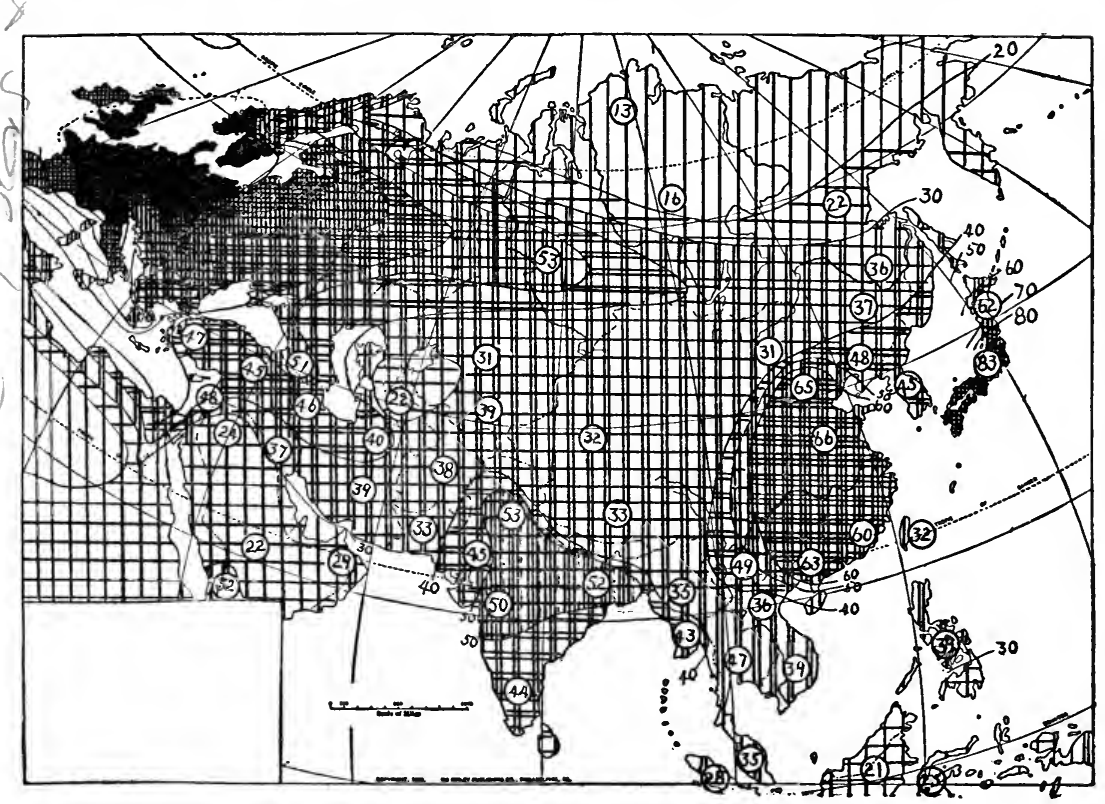

Figure 15. The Distribution of Civilization in Asia

indicated. In Asia the first thing that strikes one is the great diversity of opinion as to Japan and China. This is due to the fact that the Japanese and Chinese place their own countries much higher than do the people of other races. This is natural. The surprising thing is rather that these people, with their justifiable pride in a great past, do not place their own countries at the very top. They recognize that Europe and 
North America have in certain ways surpassed them. Aside from Japan and China the agreement of the different groups as to the position of Asiatic countries is on the whole surprising. Only in rare cases does the opinion of any one group depart from the average opinion by more than a single degree on the scale of ten. Two of the few exceptions are Rajputana and the Syrian Desert, both of which are placed exceptionally low by the Asiatics.

In Australia and North America the diversity of opinion is much greater than in the older continents. It reaches a maximum in Canada, especially in Alberta, and in southern Greenland, and Iceland. In such places opinion ceases to be of any special value. People simply do not know what sort of conditions actually prevail. In Australia, likewise, the comparative

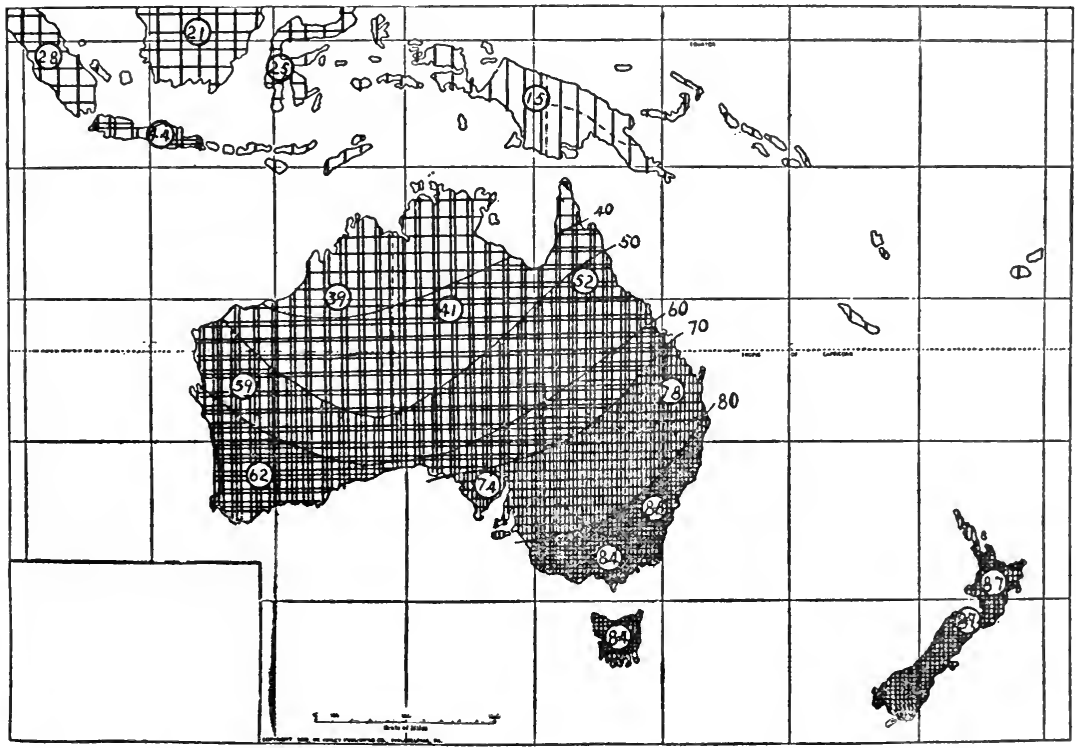

Figure 16. The Distribution of Civilization in Australia 
newness of the country causes some people to overrate it and others to depreciate it. It has not yet reached the stable equilibrium which gives the world as a whole a well-defined opinion.

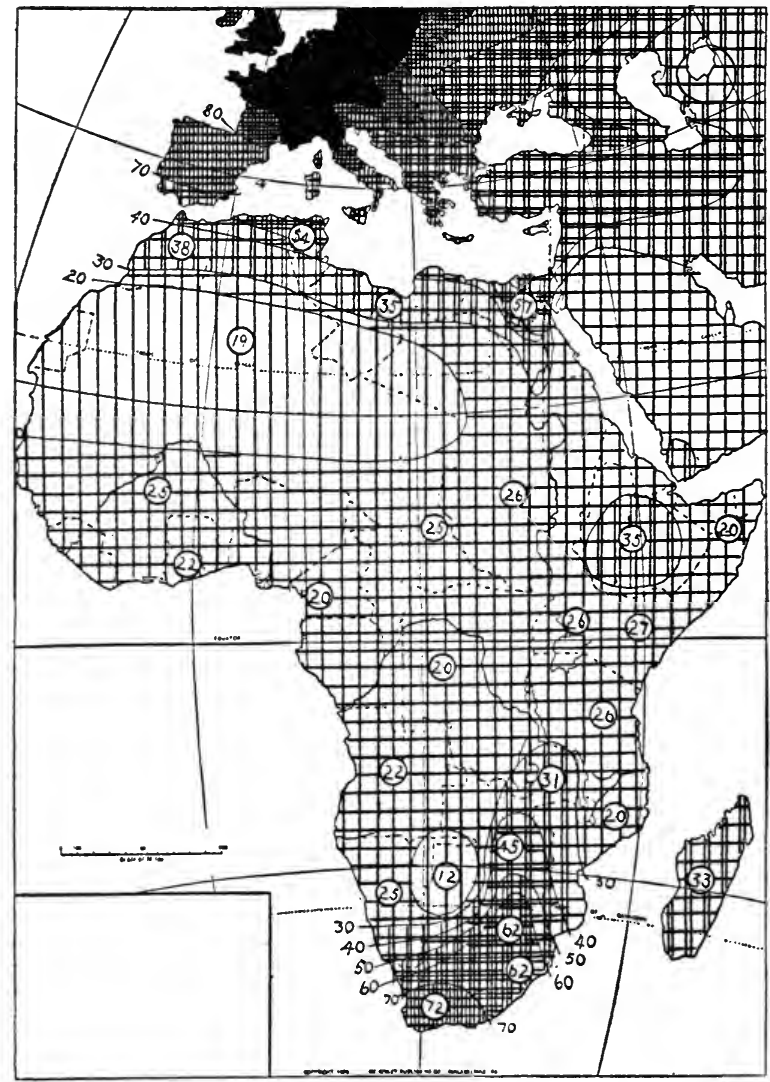

Figure 17. The Distribution of Civilization in Africa

In the United States there is no more diversity of opinion than in Europe, for that country has taken its true place among the nations. In Australia and Canada, on the other hand, out- 


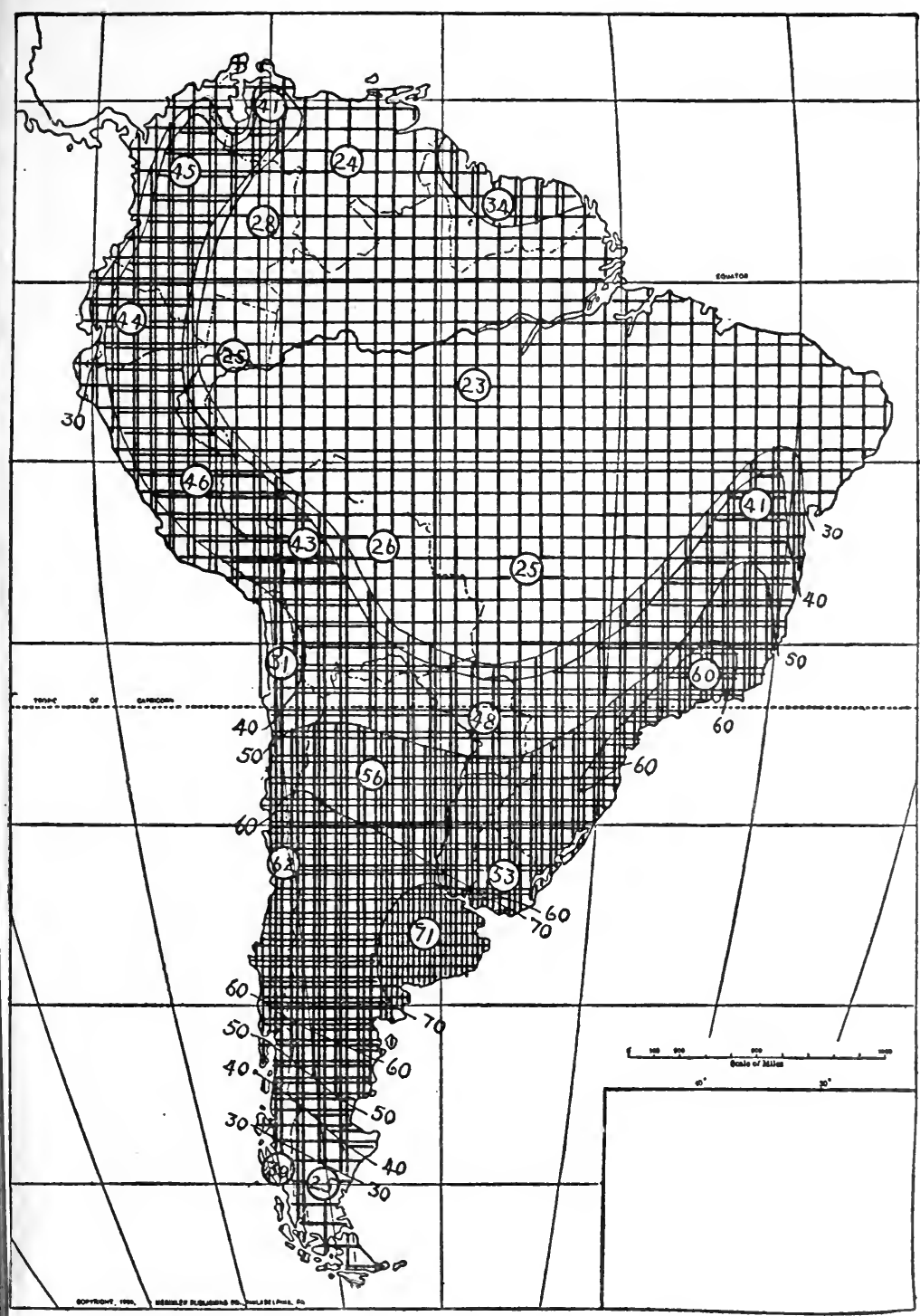

Figure 18. The Distribution of Civilization in South America 
siders who live far away and who are not racially connected with the inhabitants are still sceptical as to whether those countries are actually destined to rise as high as their people claim.

Thus far we have drawn attention to differences of opinion more than to agreements. Let us now examine the matter in another way which brings out the essential agreements. We will take North America because this is the continent as to which there is the greatest diversity of opinion. Figures 19 to 24 present a series of maps based on the average opinion of all divisions of contributors and on the individual opinion of each division respectively. Here, as in Figures 14 to 18, the rank of each region has been written in its proper place on the map. Then lines have been drawn in such a way as to separate the areas above and below 9 , above and below 8 , and so forth. The areas ranking above 9.0 have been heavily shaded, those from 8.0 to 9.0 less heavily, and so on until places below 2.0 are almost unshaded. This gives a map of civilization whose main features can readily be grasped. In Figure 19, which represents the average opinion of all groups of contributors, certain main features stand out prominently. They are (1) an area where civilization declines rapidly northward in British America; (2) a high area extending from east to west across the northern half of the United States and a narrow southern band of Canada; (3) an exceptionally high area in the northeastern United States from the Mississippi to the Atlantic Ocean; (4) a similar small, high area on the Pacific coast; (5) a bight of lower, but not of low, territory extending into Nevada; (6) a rather rapid decline south of the United States, which is interrupted by (7) an area of slight improvement in central Mexico. Let us now turn to Figure 20 and see how the opinion of Americans differs from that of the world as a whole. The general aspect of the two maps is the same, for every one of the seven features just mentioned can be detected. The older 


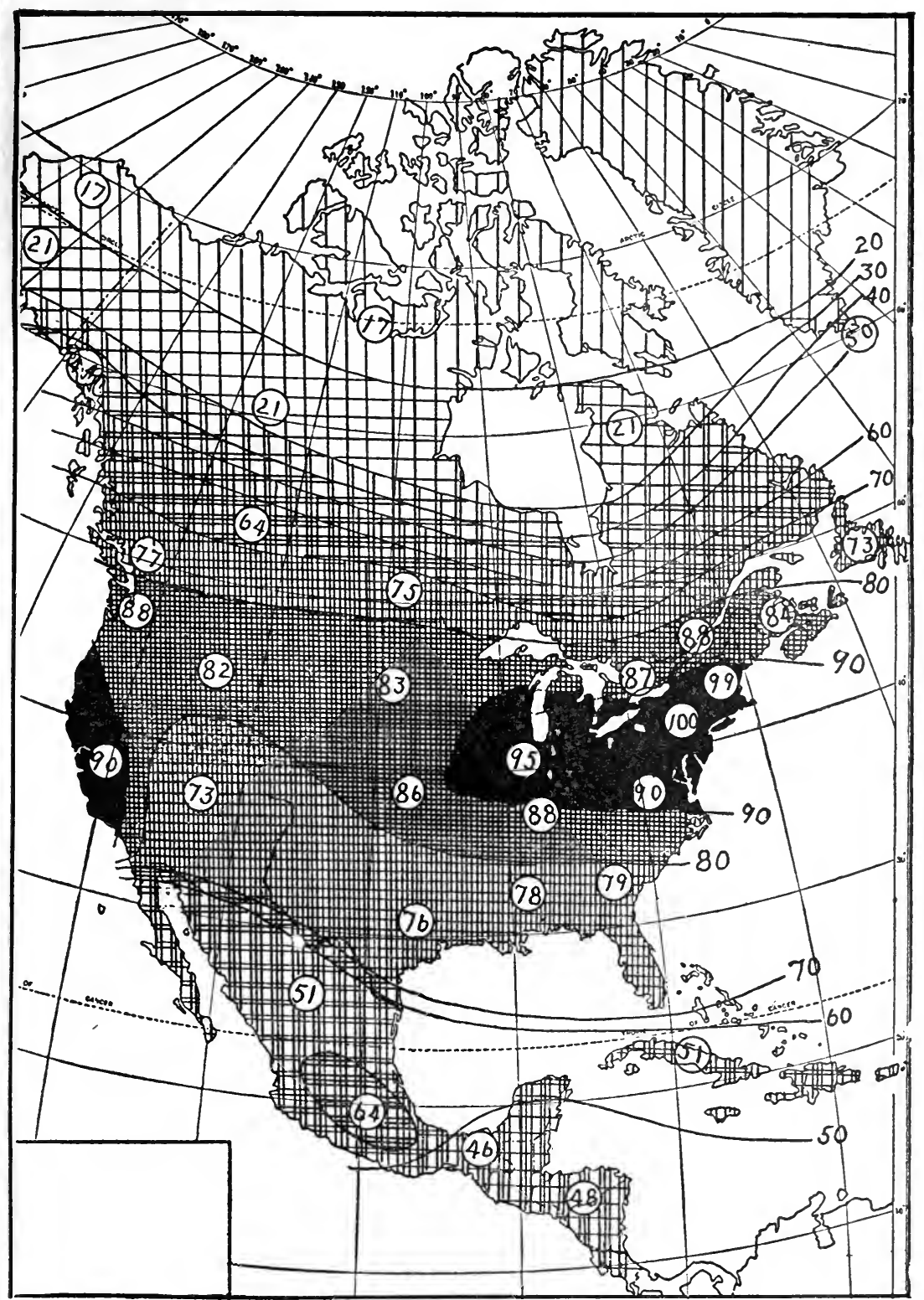

Figure 19. Civilization in North America, According to all Contributors 


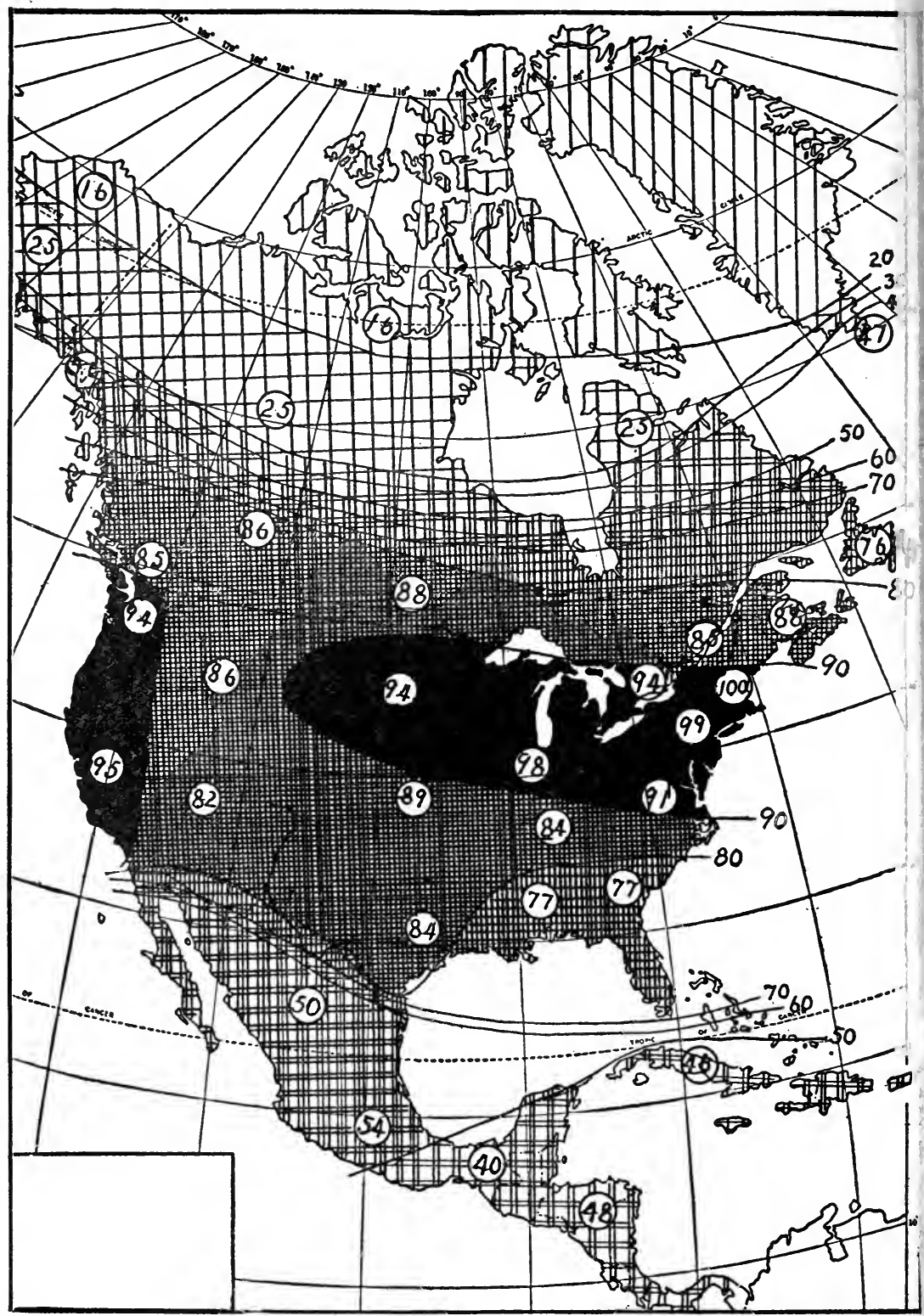

Figure 20. Civilization in North America, According to Twenty-five Americans 
states along the Atlantic from New England to the northern Gulf States have almost identically the same rank in both maps. The chief difference lies in this: the Americans have a higher idea of the new parts of their country and of the new parts of Canada than have the people of other places. They have a correspondingly low idea of the countries immediately to the south of them. In Central America their opinion does not differ greatly from that of the rest of the world, but they place the West Indies and Mexico relatively low. In the West Indies this is probably due in large measure to the fact that in order to prevent internal convulsion the United States has had to intervene in Cuba twice during the brief period of selfgovernment enjoyed by that country. The low estimate of Mexico probably arises from recent revolutions which at the time when the classification was made were producing a most unpleasant impression in the United States. In Europe and Asia the disorders of Cuba and Mexico attract relatively little attention, and the contributors to our classification probably thought of these countries as they were during their periods of long peace.

Now let us study British opinion as expressed in Figure 21. One of the most noticeable things is the English opinion of the southern United States and especially of the southwestern deserts. No patriotic feelings, either conscious or unconscious, lead them to believe that high conditions extend to the Mexican boundary beyond which Americans believe that there is a great and sudden change. Their opinion of the Atlantic portions of the United States is almost identical with that of the Americans and of the rest of the world, and they agree with other races in their opinion of the regions south of the United States. They believe, as does almost everyone, that the Pacific coast of the United States stands higher than the western part of the interior, but they do not think quite so well of it as do the Americans, although the difference is slight. The places where 


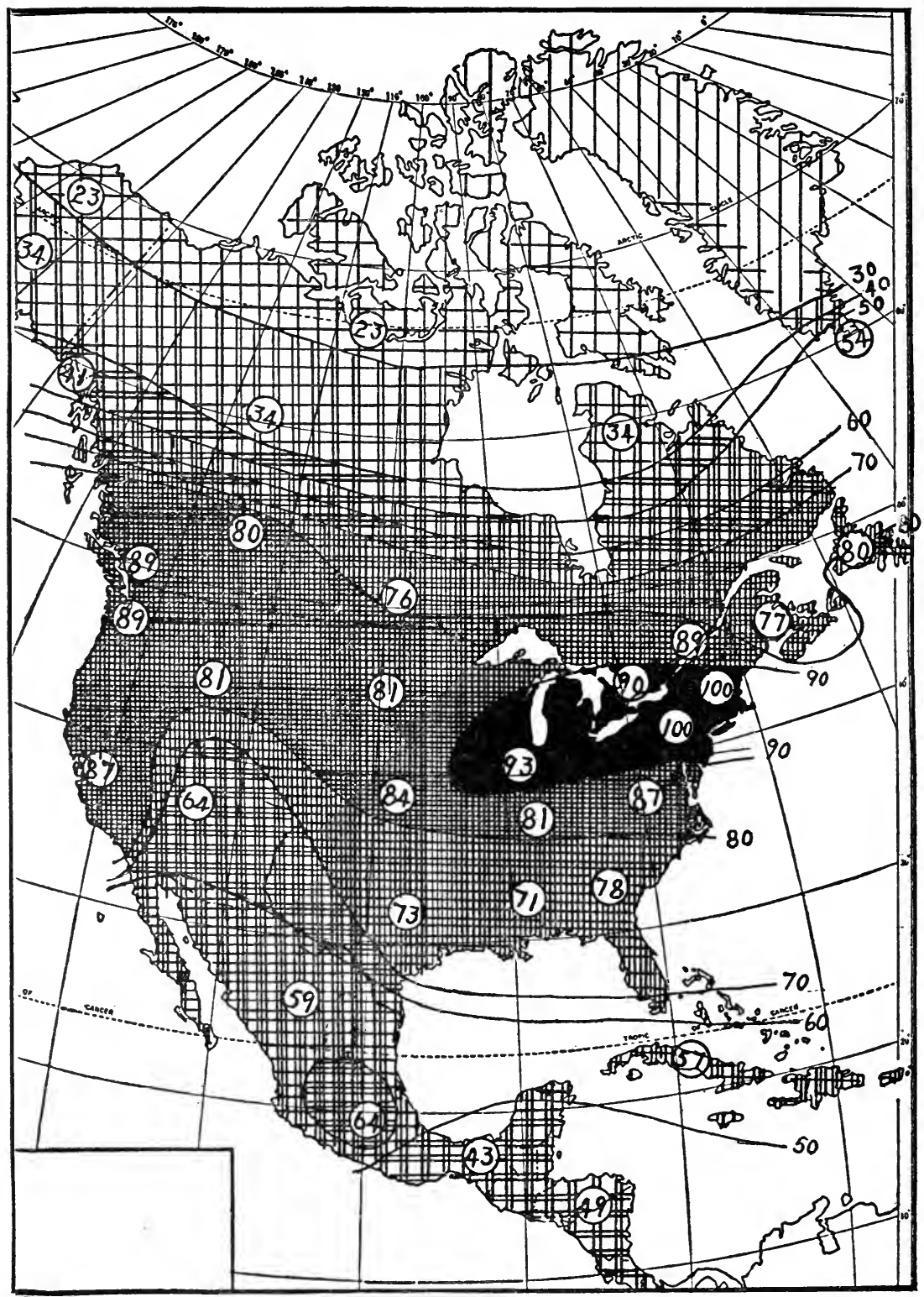

Figure 21. Distribution of Civilization in North America, According to Seven British Contributors 
their national pride comes into prominence are in Newfoundland and the Canadian Northwest. It is interesting to notice that while they place Newfoundland and British Columbia higher than do the Americans, they do not have so high an opinion of the Maritime Provinces nor of Alberta, Saskatchewan, and Winnipeg. In the latter regions this is easily explicable. A great number of Americans have gone to Winnipeg, Alberta, and Saskatchewan during recent years, and their glowing reports have made upon Americans a great impression which has not yet reached England so strongly, and has scarcely touched the rest of the world. Americans perhaps think more highly of the Maritime Provinces than do the English because many of the most energetic Nova Scotians and other provincials come to the States and display marked ability. To cite a case which has come under my own observation, the students from Acadia College in Nova Scotia, who carry on work in the Graduate School of Yale University, have for some years maintained a higher average grade in their studies than have those from any other institution.

In the German map, Figure 22, the seven general features already enumerated can readily be detected, just as in the American and English maps. The differences are largely matters of detail. Such a feature as the assignment of a rank of 9.0 to the northern Rocky Mountain states of Idaho, Wyoming, and Montana, and of only 8.0 to the Dakotas, Minnesota, Nebraska, and Iowa is probably due to lack of familiarity with the interior of the continent. Why Newfoundland should stand so high is not evident, unless it be because the name has long been known and is very familiar. In the high position of Iceland racial-pride-is again evident, for the Icelanders are close akin to the Germans.

The Romance peoples present a map (Figure 23) which again shows all the main features. They know, however, even less of the recent development of the western United States and 


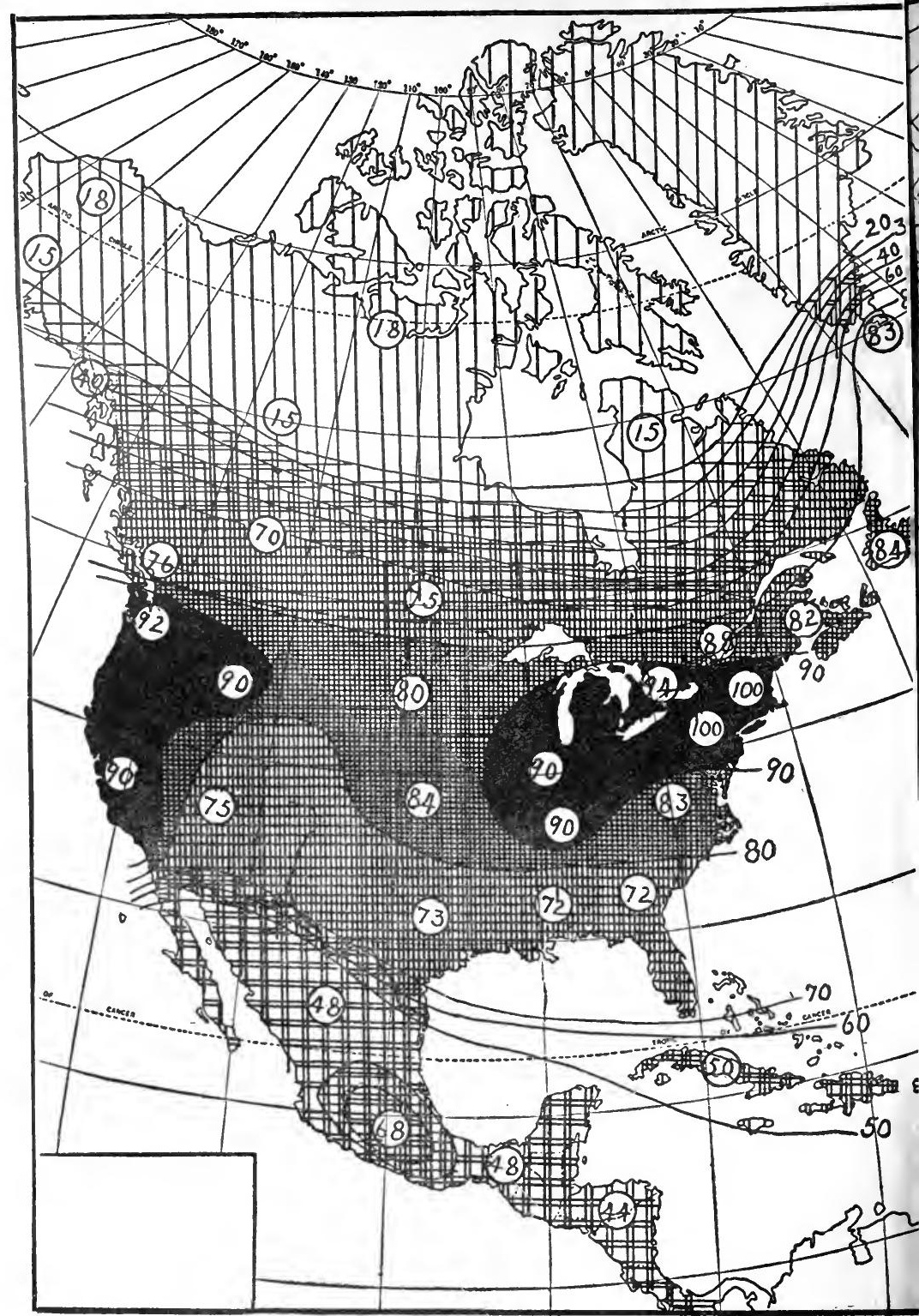

Figure 2\%. Civilization in North America, According to Six Germanic Europeans 


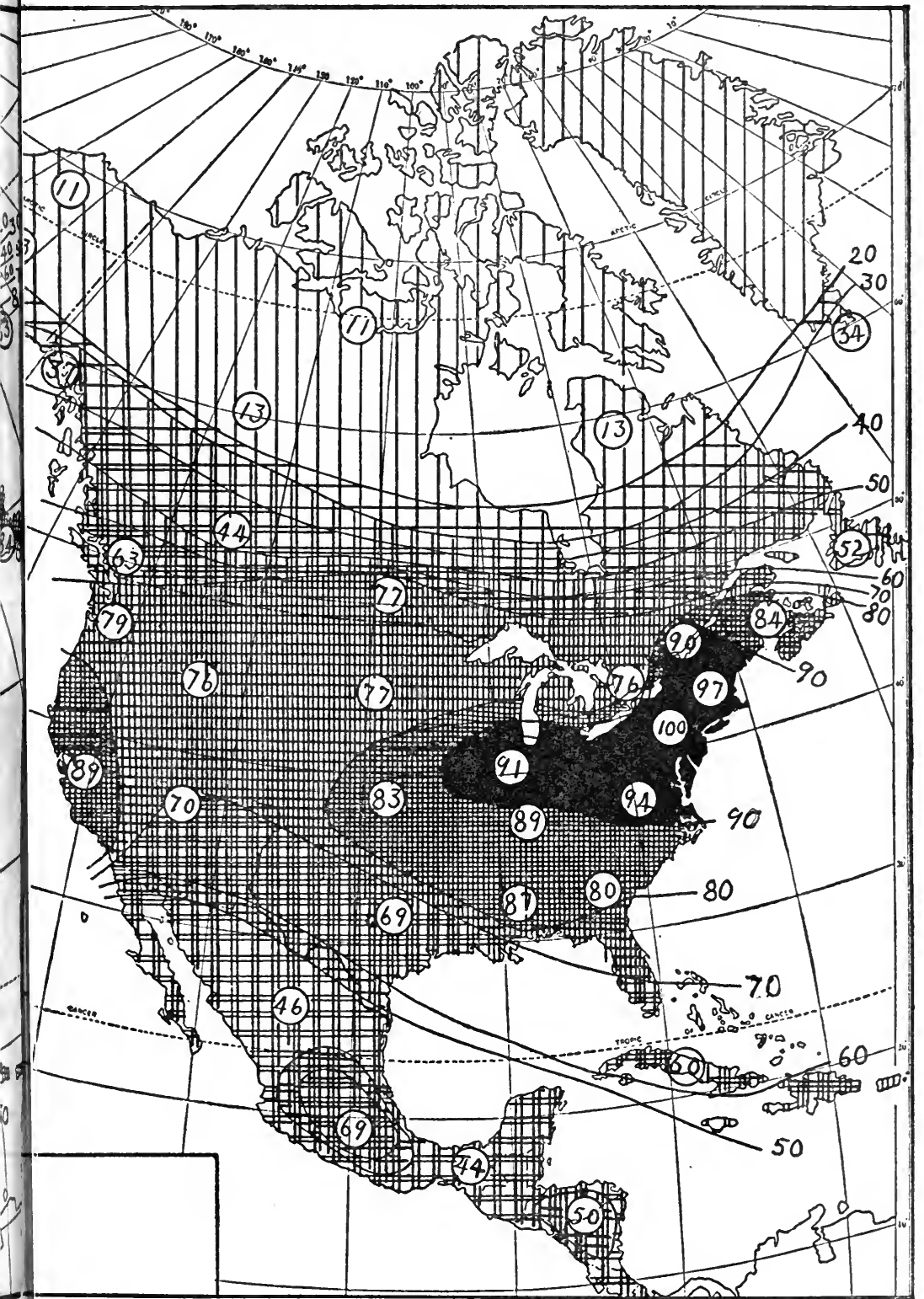

Figure 23. Civilization in North America, According to Six Latin Europeans and One Russian 
of the Canadian Northwest than do the Germans. To them Alberta and Saskatchewan are apparently undeveloped tracts where trappers and Indians still roam, for otherwise they surely would not assign so low a rank as 4.4. Newfoundland for some reason is also placed low, only 5.2, and Greenland still lower, 3.4. On the other hand, just as the presence of Germanic people in Iceland and Greenland draws the high lines far to the northeast in the Germanic map, and as pride of country bulges the high lines to include the whole of the United States in the American map, so a similar racial pride causes Cuba and the Creole region of Louisiana to be much higher on the Latin map than on any other.

Last come the Asiatics with a map, Figure 24, which is surprisingly like the other maps. They do not yet realize what has happened in the Canadian Northwest, but their opinion of eastern Canada and Newfoundland is close to the average. The place where they differ chiefly from others is in their relative ideas of the northern Rocky Mountain states to which they assign a rank of only 7.6, and of the southern states which they place all the way from 8.2 to 9.4. Apparently the eastern United States seems to them highly progressive in all parts, and they do not attach much importance to the presence of the negroes, a disadvantage which Americans themselves feel strongly.

Taking these maps as a whole we see that they all give the same general impression. Where one group goes to a great extreme, as in Newfoundland or Greenland, some other is likely to go to the opposite extreme. Thus the eccentricities of judgment displayed by one race are largely counteracted by those of another. When all are averaged, the number of inconsistencies is greatly diminished. To Americans and English it may seem that Alberta and Saskatchewan, for example, should have a rank higher than is here given them, but we are forced to admit that final judgment is not possible until these regions 


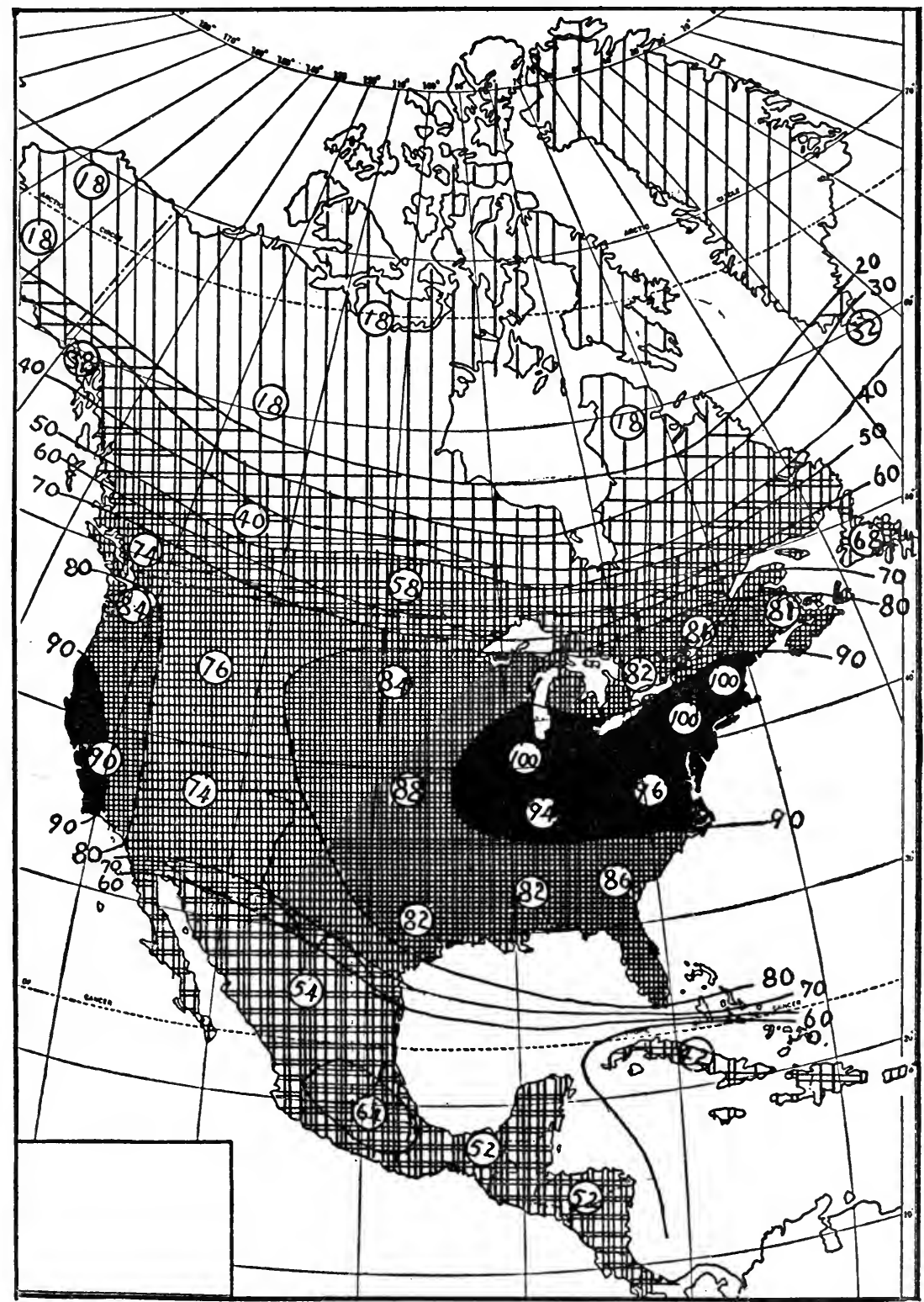

Figure 24. Civilization in North America, According to Five Asiatics 
have been well populated for a generation or two. Taken as a whole Figure 19 seems to contain no important inconsistencies, even though one might wish to change the rank of certain places in which he is particularly interested. The map represents the judgment of thoughtful people in many countries. If fifty other equally well-informed people representing an equally large number of countries in three separate continents were chosen to make another classification, it is highly improbable that their map would differ from Figure 19 so much as this map differs from the others. The chances are that the two would be so nearly alike as to be indistinguishable. Inasmuch as there is more diversity of opinion in regard to North America than to any other continent, the maps of the others approach still more closely to a true representation of the opinion of thoughtful people all over the world. The maps are by no means perfect, for human judgment is fallible. Yet they at least present so close an approximation to the truth that we may use their general features without danger of error. 


\section{CHAPTER IX}

\section{Vitality and Education in the United States}

We now have before us maps of the world depicting the distribution of climatic energy and of civilization. Our ultimate object is to compare them, and see whether they are causally related. It will add to the certainty of our results, however, if we first apply an independent, statistical test to each of our two maps. Since the methods of compiling statistics vary greatly, we can be sure of reliable results only if we confine ourselves to a single country. The United States is easily the best for this purpose. It possesses a large and highly varied area which tends to produce diversity. Its census and such organizations as life insurance companies furnish data compiled according to the same method in all parts. It is homogeneous in government and institutions; equal opportunities are open to all; and the same ideals and methods prevail almost everywhere. Moreover, no part has been devastated by war or any other great disturbance for nearly two generations; the people have moved freely from place to place; and there has been a constant tendency to foster a single type of culture. From all these points of view no other equal area is so nearly uniform. Racially the country is of course complex, but until the last few decades the great majority of the people have been Teutons from northwestern Europe. The various types have mixed to such a degree and have become so strongly Americanized that the native white population is everywhere similar. The only large elements which tend strongly toward diversity are the negroes and the recent immigrants from non-Teutonic coun- 


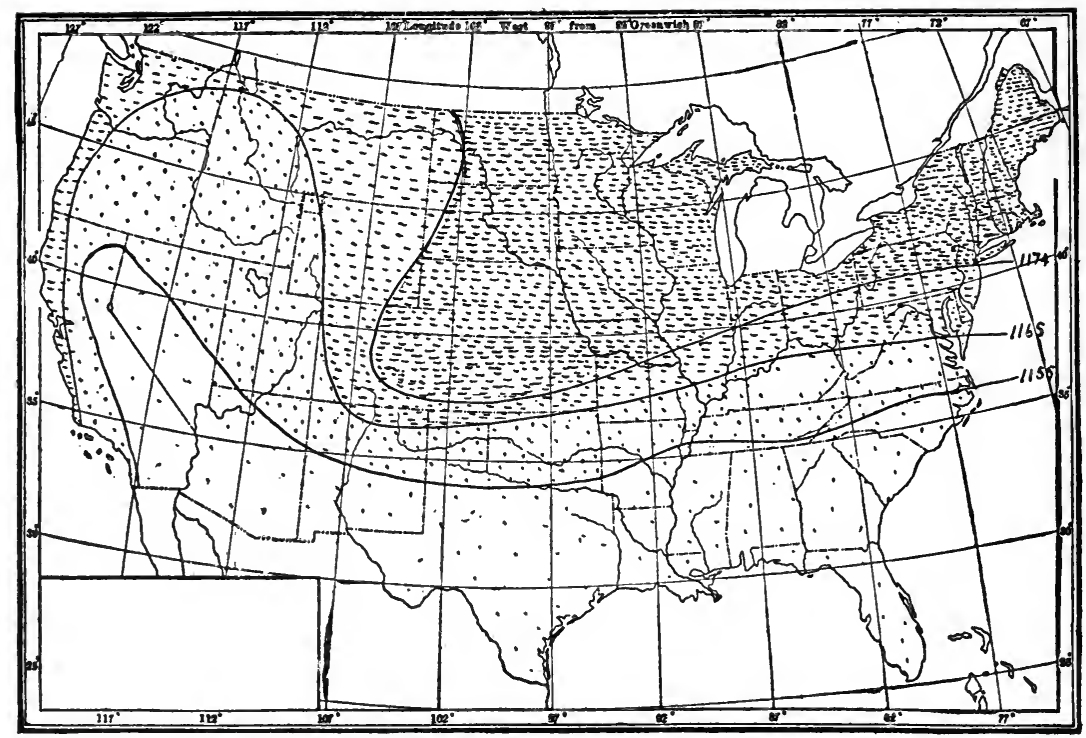

Figure 25. Climatic Energy in the United States

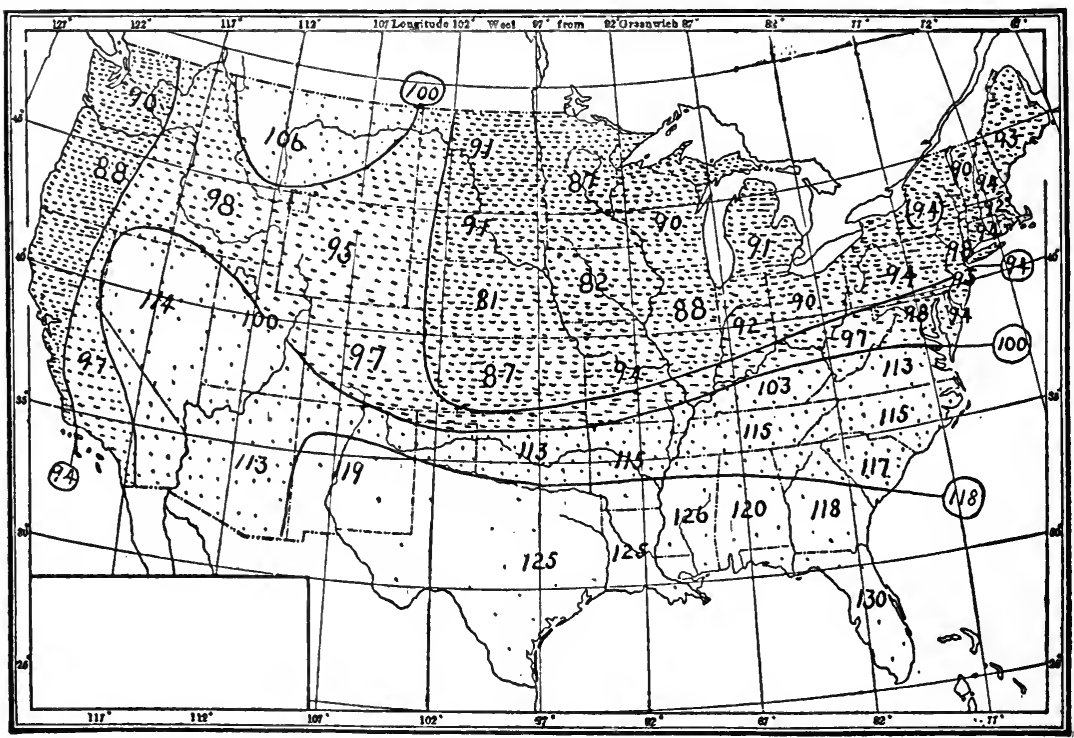

Figure 26. Mortality in the United States 


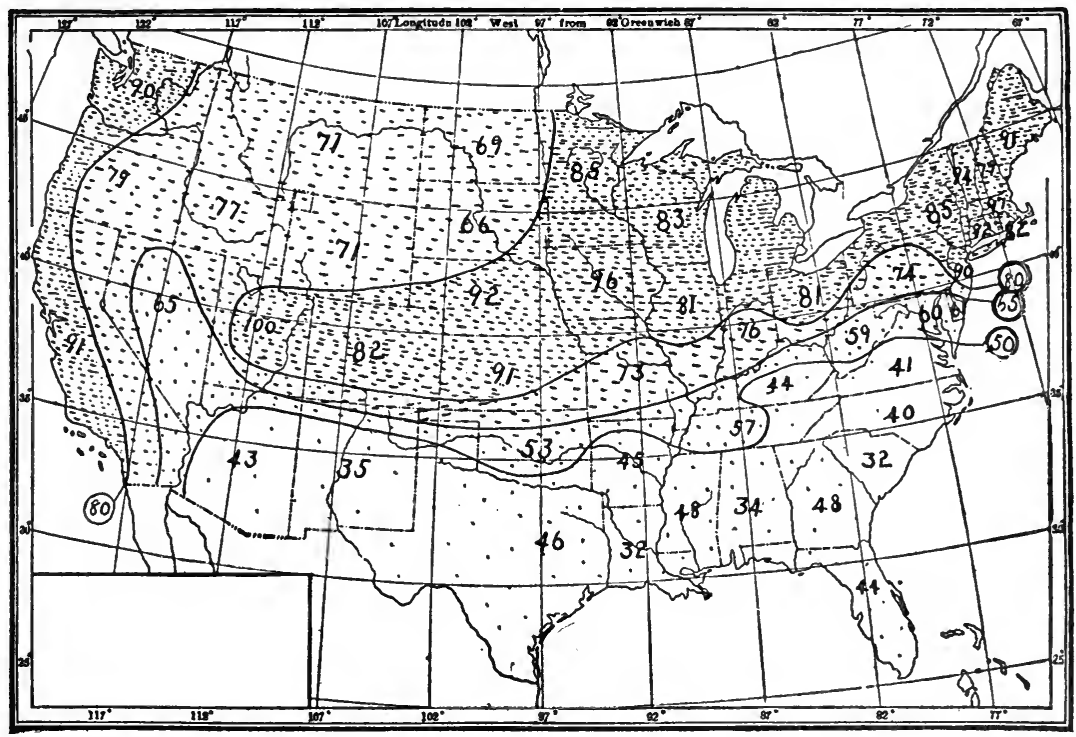

Figure 27. Education of Native White Children in the United States

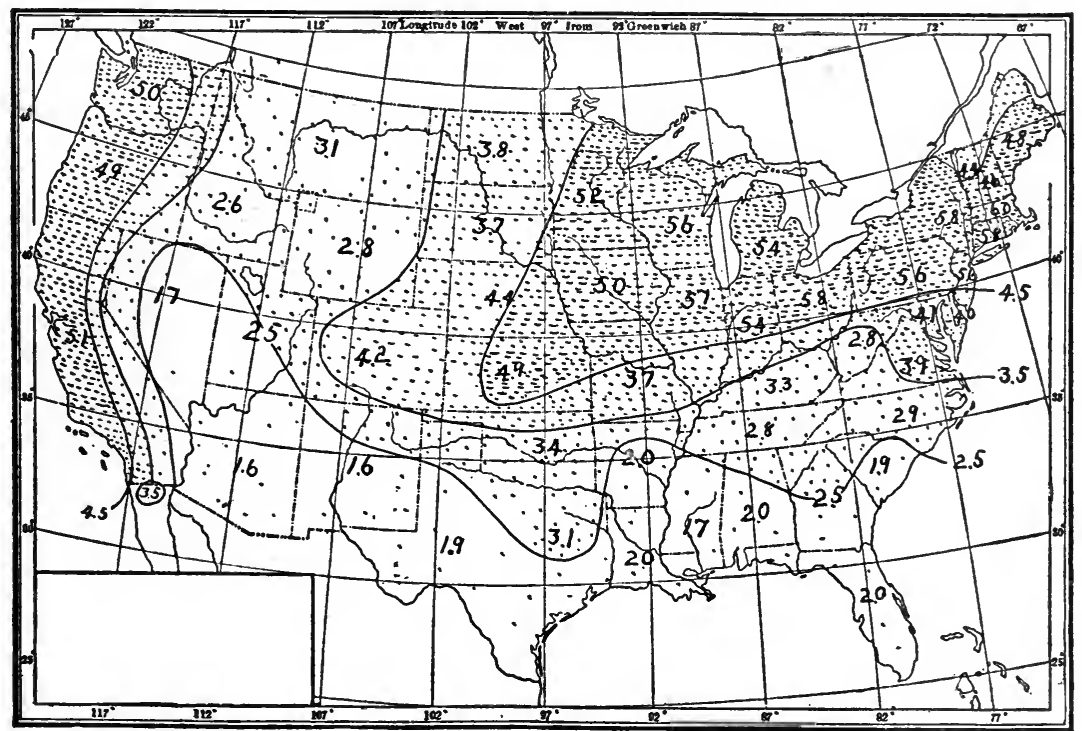

Figure 28. Civilization in the United States. The Numbers Indicate the Relative Rank on a Scale of 6.0 According to 23 Contributors. The Highest Possible Rank is 6.0 and the Lowest 1.0. This Scale is Entirely Independent of the One Used for the World as a Whole 
tries. If these are eliminated, as they are to a large degree in the maps that we shall consider, essentially the same degree of energy and civilization ought to prevail throughout the country except where geographic surroundings, the presence of some special institution, or some other disturbing factor makes itself felt.

One of the best tests of energy is vitality. We have already seen that the death rate varies from month to month in close harmony with variations in the strength of factory operatives. Let us now see whether there is similar geographic harmony. Figure 25 shows the distribution of climatic energy in the United States. It is the same as Figure 13, but on a larger scale. Strong, vigorous people usually live longer than those who are weak. Hence, we should expect that where Figure 25 is heavily shaded people would have a better chance of life than in the lightly shaded portions. We might test this by the mortality figures of the United States census, but the statistics of life insurance companies afford a still better method. As is well known, standard mortality tables show exactly how many people would be expected to die each year at a given age. A comparison of the deaths which actually take place with the number that would be expected on the basis of the table shows the degree of vitality possessed by a community. Figure 26 shows such a comparison. It is based on the combined experience of three prominent life insurance companies whose officials have kindly placed in my hands the figures for hundreds of thousands of people arranged by states. On the map the figures indicate the actual number of deaths compared with the average for the whole country which is taken as 100 . The country has been divided into four grades corresponding to those of the energy map. The most heavily shaded includes regions where the mortality is distinctly less than would be expected from the actuarial tables. The second degree of shading indicates conditions a little better than the average; the third, high mortal- 
ity ; and the lightest, very high. The individual maps for each of the three companies are closely similar, which indicates that the general features are not due to any special policy of one company. Indeed, so far as the policy of the companies is concerned, the southern states ought to present a better record than the northern, for the restrictions upon the issuance of policies are there more rigid. For instance, one company entirely refuses to issue any policies in certain unhealthful sections of the South. Elsewhere only people engaged in special kinds of healthful occupations are accepted. Moreover, in the places where risks are accepted upon the same terms as in the North, the medical examination is often more strict, especially in respect to preventable diseases such as tuberculosis. Various other considerations cause one region to differ from another. For instance, in cities, especially in manufacturing cities, the death rate is higher than in country districts, and this causes New York State to be unduly high. Miners are an especially precarious class from the standpoint of the insurance companies, and, therefore, are excluded by at least one of our three companies in some of the more remote western states, and are accepted only in small numbers by the others. They may account for the poor position of Montana, but the neighboring mining state of Idaho ought in that case to be equally bad. In all the more important respects the tendency would be to cause the death rate in the South to be lower than in the North, were it not for the disturbing element of physical weakness due to climate. In tropical countries the figures are far worse than in the southern states, which is what would naturally be expected. The fact that sick people often go west for their health does not enter into the problem. Such people cannot obtain insurance. If they have been insured before they become sick, they are reckoned as belonging to the place where they lived when the policies were issued, and not to the place where they die. 

It would be interesting to enter into further details, but space
does not permit. The outstanding feature of the vitality map is its agreement with the map of climatic energy. As people die in greatest numbers during months when their energy is low, so they die in parts of the country where their energy would be expected to be diminished on account of the climate. In both Figures 25 and 26 conditions are best in the North from New England to Kansas. Westward and southward they become less favorable. This is probably due in part to the direct effects of climate, and in part to its indirect effects upon sanitation and other methods for the promotion of health. The two conditions almost inevitably go together, for where people's energy is great, they are quick to adopt new means for the prevention of disease and the improvement of health. Moreover, in dry, and still more in warm, regions it is easy to tolerate unsanitary methods of disposing of sewage which thus pollutes the water supply. Yet all these things would apparently lose part of their importance were it not for the weakening effect which certain climatic conditions unquestionably produce, as is so well proved by the variation of the death rate from month to month even in places where the conditions of health are most carefully looked after. Here we must leave the matter. The general agreement of the vitality map with the map of climatic energy affords strong evidence that the climatic map is correct.

We are now ready to test our map of civilization in the same way that we have tested the map of climatic energy, that is, by comparing it with a map based on statistics. Strength and energy of character cannot easily be reduced to statistics, for most of the conditions and activities for which we possess exact data depend too much upon outside circumstances and not sufficiently upon the actual qualities of the people. Professor Mark Jefferson has studied the matter carefully, and I have borrowed freely both from his published and unpublished work. It might. 
seem as if such things as railroads, the number of letters, the amount of manufactures, or other similar matters might furnish a good clue to the intellectual capacity and cultural development of a people, but unfortunately this is not so. Take the case of railroads. Nevada has more miles of railroad in proportion both to the number of inhabitants and the inhabited area than any other state in the Union. In 1912 it had 260 miles for every 10,000 inhabitants, while Rhode Island had only 3.6, and Massachusetts 6.1. This does not mean that Nevada is more progressive than New England. The case is like that of a desert through which a cowboy was riding when he met a friend.

"What you doing here?" asked the friend.

"Nothing," was the answer. "I'm just crossing this here desert because it's here."

In the same way the railroads cross Nevada because it happens to lie between the East and the West. If it were uninhabited, or peopled by savages, it would still have many railroads.

The letters sent out by a community furnish a criterion of its state of civilization, but even this must be used with much caution. A hundred letters sent by a Chicago mail-order house in response to orders averaging two dollars apiece are no more significant than a single letter from Detroit in answer to an order for an automobile. In this case, as in many others, a concentration of activity in certain regions may occur without any correspondingly high ability or culture. The same is true of manufactures. Doubtless, manufactures generally develop wherever a community rises to a high state of civilization, and the manufacturing processes and all that goes with them are in turn a help in the development of a still higher civilization. Nevertheless, the accidents of position, or the presence of natural resources may cause two equally progressive and competent 
communities to differ enormously in the number of factories and other industrial plants.

We are forced, therefore, to turn to something more personal. Illiteracy is a fairly good test, for it depends largely on the immediate surroundings of each individual. It would answer the purpose excellently were it not that people have moved about so much in recent years, and that education has now become so well-nigh universal. The amount of illiteracy in the United States often depends less upon the particular place in question than upon the original home of the settlers. Taking only the native white population over ten years of age, the states of North Dakota, South Dakota, Montana, Wyoming, and Washington stand highest with only three illiterates for every 1000 people, as may be seen in Figure 29. Their good

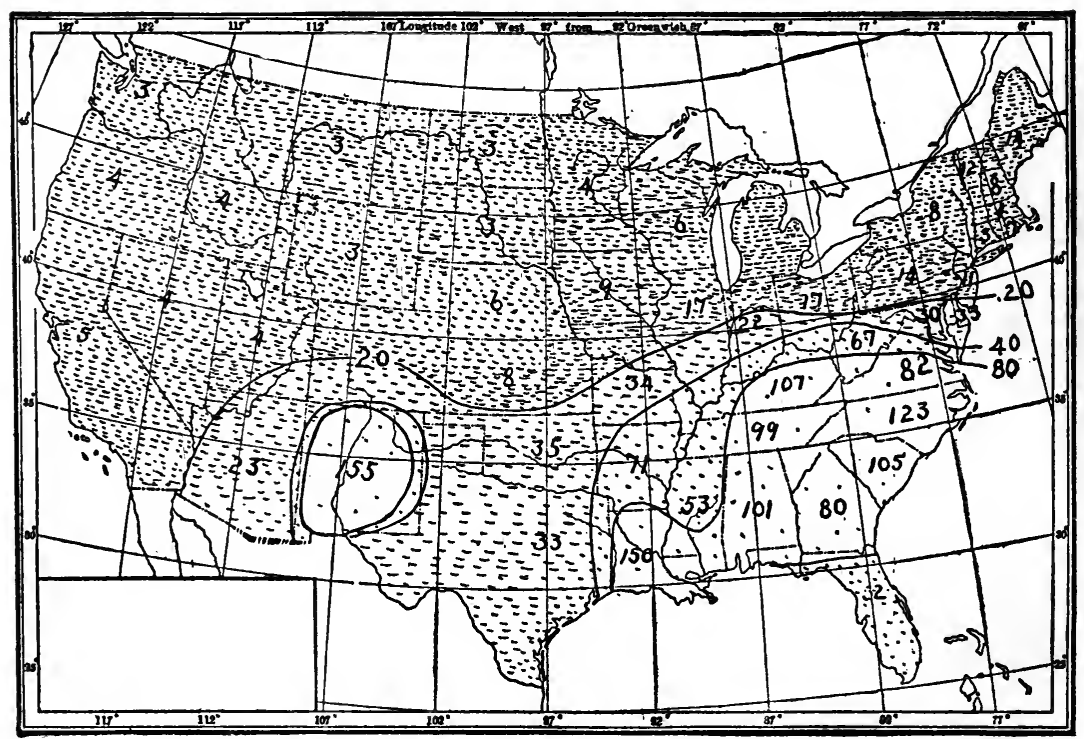

Figure 29. Illiteracy in the United States Among Persons of Native White Parentage and Over 10 Years of Age. The Figures Indicate Illiterates per 1000 
record, however, is due partly to New England and the other eastern states whence much of the adult population was derived. The people who came West were not the poor illiterates, but the wideawake, energetic members of the community. In view of this and of the great number of foreigners whose children are reckoned among the native whites of the East, it is remarkable that Massachusetts, where there are four illiterates for every 1000 people, and Connecticut, where there are five, should be in practically the same class with the new western states. The only other states which rival them are Oregon, Idaho, Nevada, Utah, and Minnesota with four illiterates per thousand, and California which has five. In the South, on the other hand, even when the negroes are omitted, very different conditions prevail. The figures for the worst states are Alabama 101, South Carolina 105, Kentucky 107, Louisiana 150, and New Mexico 155. This last state is particularly bad when we consider the large immigration from the North during recent years. Its low condition is due to the fact that a third of its so-called native white population consists of Mexicans, who furnish a good example of the effect of race as contrasted with place. The figures for other states show how recent movements of population affect the amount of illiteracy. For instance, Florida with 52 illiterates per thousand makes a better showing than the neighboring states, for Georgia has 80 and Alabama 101. This is partly because northerners have recently gone to Florida to raise oranges and enjoy the mild climate. Mississippi, with 53 illiterates, ranks almost as high as Florida, and appears 50 per cent better than Virginia (82). The relatively good showing of some other southern states such as Texas 33, Oklahoma 35, and Arizona 23, is clearly due to the recent influx of settlers from other regions. All things considered, illiteracy as a test of culture seems to be of more value than purely material things such as railroads and manufactures, 
but so long as new territory is being settled, it is misleading in certain respects.

The difficulty of finding a suitable test of the distribution of culture indicates that Jefferson is right in ascribing first place to education. In a country like the United States this is particularly true. Each state, and often each county or town, decides for itself how much it will spend for schools, how long they shall be open, and how stringently attendance shall be enforced. Hence, the schools form an unusually delicate test of the real character of a community. It is impossible, to be sure, to test the quality of education by ordinary statistics, but if the schools are open for a long period each year, and if the children are not permitted to be absent except for unavoidable causes, the quality of the instruction is generally high. Under such conditions better teachers can be secured, and the pupils are not continually hampered by having to make up for absences.

In estimating the value of an educational system on the basis of school attendance, it is necessary to consider not only the percentage of the children of school age who are enrolled in the schools but also the length of time that the schools are open and the proportion of possible school days during which the average child is present. The figures published in the Report of the United States Commissioner of Education give the necessary data: The percentage of the children between 6 and 20 years of age who are in school ranges from 70.2 in Utah to 43.1 in Louisiana. The low figure for Louisiana is partly due to negroes, but even if we omit these, the figures do not greatly change. If we omit not only the negroes, but also all white children who were not born in this country, the figures become $\mathbf{7 4 . 6}$ for Utah and 55.3 for Louisiana. Still greater differences are found in the amount of schooling. In Utah and Massachusetts, for example, the average child is in school 230 days per year. In Louisiana and Alabama, on the other hand, the 
number is only about 100, while in South Carolina it falls to 92. For a true comparison we must multiply the number of days of schooling by the percentage of children who attend. On this basis, if Utah, which stands highest, be given an index number of 100, the index for Massachusetts, which stands next, is 96.5, while that of South Carolina is 31.7, and Louisiana 31.6.

The whole matter is summed up in Figure 2\%. Among native white children education is best cared for in (1) the northeast, (2) the lake states, (3) the middle tier of prairie and Rocky Mountain states as far west as Utah, and (4) on the Pacific coast. In the South it is neglected, and for some reason it falls low in the Dakotas, and to a less extent in the northern Rocky Mountain states. The comparatively recent settlement of some of the states where conditions are relatively low explains the situation in part, but Washington is almost as new as the Dakotas or New Mexico and yet stands in the first rank. The sparsity of population is also another factor. Utah, however, which ranks at the very top, has a population decidedly more sparse than that of the Dakotas, but ranks 100 where they rank 66 and 69. Its density of population is scarcely greater than that of New Mexico, whose rank is only 35. The relatively poor conditions in the Dakotas find a partial explanation in the fact that the population is more completely agricultural than in almost any other part of the United States. There are no large cities, and even villages are comparatively scarce or small. The great majority of the people live scattered over the vast plain, each family on its own quarter-section. Hence, the children are obliged to go long distances to school. Muddy roads often make this difficult in the spring, while the severe storms of winter are an even greater obstacle. In spite of this, the Dakotas stand at the top in the literacy of their people, so that the school system must be fairly efficient. In New Mexico quite the contrary conditions prevail. A part of the people, to 
be sure, live on widely scattered ranches where the children cannot go to school. By far the larger number, however, live in compact settlements where the houses are grouped in a comparatively small area because of the necessity for using a common water supply for irrigation, or else because of mining industries. Under such conditions, schools can be maintained more easily than on huge, townless plains like those of the Dakotas. The same conditions prevail in Utah and Nevada, and to a less extent in Idaho, Wyoming, and Montana. Nevada's rank of 65 is in reality decidedly less creditable than South Dakota's of 66 . Yet the fact remains that the Dakotas are lower than would be expected, while Utah is surprisingly
high.

The proud position of Utah is presumably the result of Mormonism. The leaders of that faith have had the wisdom to insist on a thorough system of schools, and have obliged the children to attend them. The "Gentiles" have in self-defense been forced to do equally well, and the result has been admirable. Whatever one may think of Mormonism as a religious belief, it must be credited with having accomplished a remarkable work in spreading a moderate degree of education almost universally among the people of Utah. Without its influence, the rank of Utah would probably be about 75, that is, between Colorado (82), on one side, and Nevada (65), on the other. I emphasize this because it shows how clearly our maps reflect the influence of any peculiar condition. Manifestly, the distribution of education throughout most of the United States does not depend upon the influence of any particular institution, for essentially the same institutions prevail everywhere. In the same way the map of illiteracy, being based wholly on native whites, does not in most places. reflect the influence of any particular race. Yet in the map of education, Utah is conspicuous because it is strongly influenced by a unique American institution which is capable of producing 
such an effect and which is at the same time limited to one small area. In the map of illiteracy, the presence of a permanently alien and essentially non-European race in the only state where such a race forms a large proportion of the "native whites" causes New Mexico to be unusually low.

Another factor which would be expected to bear an important part in determining the distribution of education is the presence of the negro. Doubtless this has a pronounced effect, for an inferior race inevitably retards a higher. Yet the map indicates that other factors are equally important. Not only is education at a low ebb in New Mexico which has few negroes, but also in Arizona which is comparatively free from both negroes and Mexicans, and which has its people largely grouped into compact villages where schools can easily be maintained. Moreover, Texas, where the colored people form only a fifth of the population, stands lower than Georgia and Mississippi, where half the people are colored. Another signifcant fact is that the education of negroes varies from state to state almost as does that of whites. Although a smaller proportion of negroes than of whites go to school, the two races are well or poorly educated in the same places.

In Massachusetts the proportion of the negro children, six to twenty years of age, who go to school is 66.5 per cent against 73.7 per cent for white children. In South Carolina, on the other hand, the percentage of negro school children is only 45.8, in Georgia 42.1, and Alabama 40.7. In Louisiana it sinks to 28.9 per cent. This state stands lowest in the education both of whites and negroes, its index numbers for the percentage of children in school and the number of days of schooling combined being $\mathbf{3 1 . 6}$ for whites and $\mathbf{1 6 . 7}$ for negroes. Yet its percentage of colored population is only 43 ; while that of South Carolina is 55, although its educational indices are 32 for white children and 25 for colored. In the same way Mississippi with 56 per cent of negroes stands still higher, with 
indices of 48 and 3\%. Thus it appears that the degree of education is not proportional to the number of colored people. The southern states differ among themselves because of special circumstances such as good or bad laws, but all stand low because of more general factors. These factors form our chief subject of inquiry. In order to examine them fairly, we must overlook such minor matters as special laws in Mississippi, a backward race in New Mexico, Mormonism in Utah, and the scarcity of centers of population in the Dakotas. When allowances of this kind are made, the map of white education, Figure 27 , seems to be as good an epitome of the general distribution of culture in the United States as we are yet able to obtain on the basis of the statistics of a single activity.

Let us now compare our educational map with Figure 28, which represents the distribution of civilization in the United States according so the opinion of 23 people. All of these except Ambassador Bryce were Americans. They rrouped the states and provinces of the United States and Canada into six classes, number 6 being the highest. Massachusetts is the only state invariably placed in the highest class. New Mexico and Arizona, which stand lowest, have an average rank of 1.6. In order to judge how much reliance to place on the classifications, I took the first ten that were received and averaged them, and when ten more had come to hand averaged them also. Somewhat to my surprise, and much to my pleasure, the two sets of averages were practically identical. How much they differed may be seen in the Appendix. The average difference is only 0.2 , and the maximum 0.6. The agreement of the two sets probably indicates that any other group of equally well-informed persons would have made essentially the same classification. To be sure, in spite of several attempts, I was unable to obtain any contributor in the states west of Minnesota or south of the Ohio River. Local prejudices, however, have probably not exerted much effect on the final results, for 
California stands in the highest class with practically the same grade as Minnesota and Iowa.

A comparison of the maps of education and of culture in Figures 27 and 28 is interesting. In general aspect the two are similar. Both have two high areas, one in the northeast and center, and the other on the Pacific coast. In both there is a decline from north to south. Two other common features are a tongue of high conditions jutting out toward Kansas, and a low tongue ending in Nevada. If the effects of Mormonism and of the scattered condition of the Dakota farmers are eliminated from the map of education, its eastern high area becomes almost identical with that of the map of civilization. The contributors apparently took little account of either of these factors, and were perhaps right in doing so. In the Dakotas the lack of schooling is presumably balanced by other high qualities such as the scarcity of illiterates. In Utah the good school system is more than overbalanced by the Mormon defense of polygamy. Still other features of both maps appear to be due to special circumstances. For example, the recent growth of Texas, the establishment there of progressive institutions for higher education, and the maintenance of efficient types of city government have raised that state well above its neighbors on the east and west, as appears plainly in both maps. Tennessee also rises above Arkansas on the map based on opinion, and is higher than any surrounding state on the other map. In the Rocky Mountain region the sparsity of population and the newness of the country are usually assigned as reasons why these states are less advanced than those east and west of them. The educational map shows that there is concrete ground for this opinion.

Inasmuch as the educational map is based on only one of many phases of human culture, and is manifestly influenced by special circumstances, its agreement with the map based on opinion is surprisingly close. This seems to afford good ground 
for confidence in the world-map of civilization. If a map of civilization could be based on the opinions of a large number of people, say twenty-five from each of twenty countries, and if a statistical map could be based on numerous activities among which education is only one, it seems almost certain that the main outlines of the two would be nearly identical. Our present map of civilization on the basis of the opinions of 50 people in more than a dozen countries is by no means perfect, yet it stands the test to which we have here applied the part of it embraced within the United States. Our maps, both of civilization and of climatic energy, seem more worthy of reliance now that we have compared them with similar maps based on wholly different criteria. 
which our fifty contributors assign a rank of 8.5 or higher are rated as "very high," and are shaded in solid black. Those from 7 to 8.5 are rated as "high," and are shaded in heavy lines; those from 5 to 7 are "medium," and are indicated by light lines; 3 to 5, "low," shaded with abundant dots ; and under 3, "very low," and dotted only lightly.

The first thing that attracts attention is the general resemblance between the maps of energy and of civilization. Both, for example, show a high area in northwestern Europe. A tongue extends into Italy, another toward Roumania, and a third to the Baltic. Another projection runs out into western Siberia. Here the high area of the map of civilization extends about as far as the medium area of the map of energy. This is not curprising, for even if the people of Siberia have the energy indicat: 1 in Figure 30, they are hampered by the remoteness and newness of their country, not to mention other conditions. In central and northern Siberia, the difference between the two maps is slight. The significant thing is that in both there is the same falling off toward the center of Asia. Still farther east in China and Japan conditions are once more alike, China being medium and Japan high.

In Indo-China and especially in India, the maps differ. Apparently, this arises largely from European domination, and is due to the constant addition of strength from that continent. This does not apply to Siam, however, which has worked out its own salvation. It ranks as very low on the energy map, and only as low on the other. This may have no significance, for our maps are still in their early stages. Further knowledge may change such slight disagreements into agreements. On the other hand, it may increase the disagreement. In that case we may discover that by long residence within the tropics, the races of Indo-China and India have become differentiated from Europeans and are less susceptible to the influence of steady heat. Again, race differs from race 
in its inheritance, and the Siamese may inherit stronger traits than are possessed by their neighbors. Finally, the level of Siamese civilization may have been raised by contact with other races, by the adoption of particular institutions of government, forms of religion, or social organization, or by the inspiration and energy of a few men of unusual gifts. I mention these possibilities not because they are of special importance in Siam, but because they illustrate the many and varied influences which coöperate to determine the position of a country in the scale of civilization.

In comparing the maps of energy and civilization, one of the clearest features is the effect of a strong race upon regions which it rules or colonizes. Again and again the presence of such a race causes a region to be higher in civilization than would be expected on the basis of climatic energy. Java, the Philippines, and India are examples. It is especially noticeable in regions controlled by Great Britain. In Australia, for instance, the general decrease in both civilization and energy from southeast to northwest is the same in both maps, but the presence of the English raises the places of "very low" energy to "low" in civilization, and so on, each grade being raised one degree, so to speak, until the map of civilization shows a large high area in the southeast. In South Africa and Egypt, British influence is displayed in the same way. In the Canadian Northwest, on the other hand, it is not apparent. The northern parts of Alberta and Saskatchewan appear higher in energy than in civilization. We have already seen that according to American and, to a less extent, British opinion, this is not the case, for recent settlement has raised these regions to a comparatively high degree of culture.

In the United States the energy map shows a strip of medium conditions along the southern frontier, but this is rated as high on the other map. Such a condition illustrates how a high type of government causes efficient people to settle in unfavor- 
able regions, and how it also adds to the effectiveness of less efficient people such as Mexicans and negroes, thus in part overcoming the handicap of climate. In the central states, on the other hand, civilization is not rated so high as one would expect on the climatic basis. Probably this is because the country is so new that our Chinese, Russian, Spanish, and other foreign contributors, though they have travelled and studied extensively, do not realize how great is the progress of recent times. California, like the southern states, is higher on the map of civilization than on the other. As already explained, this may in part be due to the impossibility of making a wholly accurate map of climatic energy. It may also arise from the location of California on the seaboard, and from its early development as contrasted with the newer states of the interior. A comparison of the United States as it appears on the world-maps and as it appears on the maps of that country alone is important. Where the country stands by itself, and its parts are classified by people who live in it and are thoroughly familiar with it, the resemblance between climatic energy and civilization is greater than where the classification is on a rougher scale and is made by people less familiar with it. Another reason for the difference is that a classification of places where a uniform standard of culture prevails and where the same race is everywhere dominant is much easier than where many types of culture and highly diverse races are considered. The maps of the United States represent the kind which must be made for each country. The difference between the features of the United States on the world-map and on the other represents the extent to which our general map of civilization is in error. In spite of this, however, the general features of the country are unmistakably the same on both maps. So far as the conclusions of this volume are concerned, it makes no difference which we use. In this lies the importance of our various tests of the United States. They show that although 
much remains to be done before we can construct a map which is approximately perfect, the most important features are reasonably distinct and unmistakable.

Turning to Latin America, we find about what would be expected in Mexico and Central America. The highlands are medium and the lowlands low. South America, on the contrary, presents some unexpected features. The Andean highlands, including Venezuela, Colombia, Ecuador, Peru, and Bolivia, are all ranked as low in civilization, whereas the climatic map would indicate medium energy. In the belt of highlands on the east side of Africa the same phenomenon is observable. Perhaps an equatorial climate is more debilitating than would be expected from the work of factory operatives in summer. In South America the presence of an ancient race whose vigor was already waning at the time of the discovery of the New World has doubtless hindered Spanish immigrants in accomplishing what might otherwise have been looked for. This, however, does not alter the case, for the original inhabitants in the Andean countries, just as in the African highlands, stand lower than would be expected. Argentina, on the contrary, goes to the opposite extreme, and is higher on the map of civilization than on that of energy. The importance of this must not be overrated, for the climatic data are somewhat doubtful because of the paucity of statistics as to changes of temperature from day to day. As the maps now stand, however, they are encouraging, for they suggest that even with a moderately favorable climate, the Latin race in America is competent to rise to a high level.

Let us turn now from these details, and look once more at the general aspect of the two maps. In spite of minor disagreements, the main features are essentially alike. There are, in each case, the same two great high areas in western Europe and the United States. The decline from western Russia eastward to the center of Asia, and the rise to high conditions on the 
eastern edge of Asia in Japan are equally apparent. Likewise, the maps are strikingly alike in the shape of the very low areas in Africa and South America. South of latitude $30^{\circ} \mathrm{S}$. each of the southern continents begins to rise in energy and in civilization, and the rise is more pronounced on the eastern side than on the western. Even where the maps disagree, the explanation of the disagreement is usually obvious from a consideration of the recent movements of European peoples. The few remaining discrepancies are almost all explicable on wellknown grounds, such as the impossibility of agriculture, which hinders civilization in the far northern parts of America and Asia.

When allowance is made for obvious facts like these, the resemblance between the two maps becomes more striking. Call to mind the method of their construction. Neither represents the personal opinion or bias of any one man. Any other person with the same data before him would have obtained similar results. The maps simply give expression to two distinct sets of facts. The first is that the opinion of men of many races agrees as to the general distribution of civilization. The second is that if the various conditions of climate produced the same effect upon all the people of the world as upon students and factory operatives in the eastern United States, the amount of work accomplished in different countries would be closely proportional to the status of civilization.

Aside from the map of climatic energy, it is hard to think of any other which would so closely reproduce the features of the map of civilization. Suppose that race were made the criterion, and that a map were shaded in proportion to the number of Teutons. We should find that in Europe such a map would closely resemble the map of civilization except that places like Finland, southern France, central Italy, Hungary, Bohemia, Servia, and others are relatively high in civilization even 
though none are more than half Teutonic, and some only very slightly, or almost unappreciably so. In Asia, on the other hand, there is much more Teutonic blood in Syria and Asia Minor than in Japan, yet Japan ranks far higher. The Japanese might claim racial superiority almost as fairly as the Teutons, and both the Latins and Slavs may justly point to the fact that they predominate in some of the most advanced portions of the globe. When we look at the low places, we find that Teutonic areas, such as the Transvaal, Alaska, southern Greenland, Iceland, and parts of Australia make a poor showing; the Latins in parts of Latin America are even worse; the Slavs at their worst fall no lower than the Teutons; while the Japanese nowhere fall so low.

A map of religion does not resemble a map of civilization, no matter which religion is employed. Protestant Christianity, indeed, prevails chiefly in regions which are either high or very high; even Iceland is by no means an exception, for its civilization is much higher than would appear from our table, where it is grouped with Greenland. Roman Catholic Christianity, on the other hand, prevails in locations which range from very high to very low; and Greek Christianity from high to low. Buddhism, likewise, ranges from high in Japan to low in Tibet, while Mohammedanism never rises above medium, and in some placesfalls very low. That religion raises or lowers the tone of a country I do not for a moment question, but if a people are physically weak and are lacking in self-control because of something in their surroundings, the history of the world as exemplified by the Abyssinians, Armenians, Latin Americans, and others seems to show that they will drag even the finest religion at least part way to their own level. The higher the form of religion and the more self-sacrifice and devotion it requires, the more difficult it becomes to keep any but the most energetic and determined races even approximately true to it. The only 
cases where people of low efficiency seem to retain a high religion are where they are continually stimulated by the presence of a stronger race.

As a third criterion, suppose that we take form of government, and inquire whether a map of governments would resemble one of civilization. Of course, the excellence of the government is closely related to the degree of civilization, but not so with the form. Republics range from very high in Switzerland and France to very low in Venezuela. Limited, but autocratic monarchies exist in high countries like Germany, or did, at least, before the great war, and also in low countries like Turkey and Persia. Thus we might go on to consider one after another of the great factors which coöperate in giving form to modern civilization. The nature of a nation's religious faith, its form of government, its social organization, its ease of intercourse with other nations, and various other conditions play a fundamental part in the distribution of civilization. Yet each is conditioned by the degree of energy possessed by a people, for if a race lacks energy, no amount of excellence along other lines will place it in the first rank. Energy, in turn, seems to depend upon climate, and thus climate becomes an essential element in determining the status of civilization. We may well reverse our statement, however, and say that no amount of energy will make a nation great if none of its people are gifted with genius, or if it never evolves an orderly form of government or a moral code which allows a man to enjoy life, property, and home without constant fear of outsiders. Thus, the material and immaterial elements of civilization play into each other in such a way that either seems the more important according to the angle from which we view it.

The interplay of diverse factors is so important that it is worth while to examine it in a concrete case. Dr. Scott Nearing in the Popular Science Monthly for 1914 published an article entitled, "The Geographical Distribution of American Genius." 
While it is impossible to measure genius, it is possible to ascertain how many people of unusual ability are born in a given region. That useful publication, "Who's Who in America," though not infallible, forms a good summary of about twenty thousand people who have either achieved "special prominence in creditable lines of effort, making them the subjects of extensive interest, inquiry or discussion in this country," or who occupy positions which could scarcely be attained except by persons of unusual ability. Taking "Who's Who" for 1912-13 as a basis, Nearing has tabulated the birthplaces of the first 10,000 names according to states. He took only 10,000 because that number seemed enough to give reliable results. His tabulation strikingly reënforces the common opinion that New England, especially Massachusetts, has produced far more than its proportionate share of persons of unusual ability. The utility of his investigation seems so great and the method so reliable that I have asked Dr. Nearing for permission to make use of fuller data than were contained in his article, and he has kindly supplied me with the figures for each state. In order to determine the relative status of the various parts of the country it is not fair to compare the number of eminent persons who were born in a given area with the present population. At the time when the men who are now prominent were born many of the western states contained only a handful of settlers. It is equally unfair to compare the number of such persons who live in a given region with the present population, for many persons who have achieved prominence owe it to the place where they grew up and not to that where they now live. The only fair way seems to be to ascertain the relation between the number of eminent persons born in a given region and the population of the region at the time of their birth. Accordingly, the first thing to do is to find when the people in "Who's Who" were born. Nearing gives the following table: 


\section{Number of Eminent Persons in the United States Who Were Born at Certain Times}

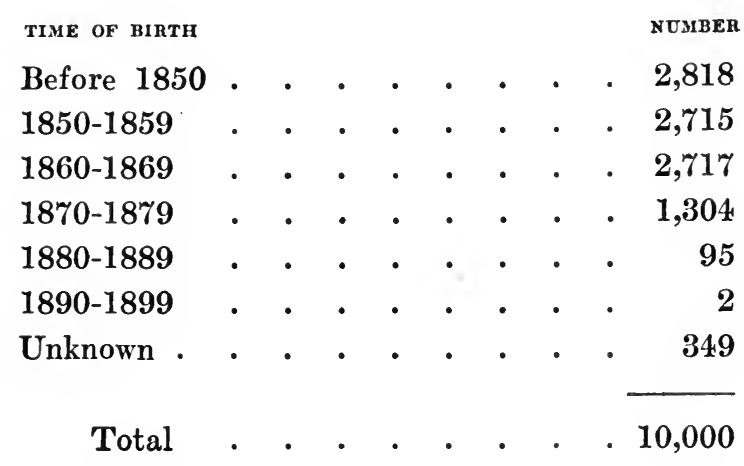

The number who were born before 1840 is not given, but it must be considerable, for the people who attain eminence are among the most long-lived portions of the community. On the other hand, the number who were born after 1880 is too small to be considered. People rarely become eminent before they are at least thirty-five years of age. The forty years from 1835 to 1875 cover the births of practically all who had attained sufficient distinction to be included in "Who's Who" for 1912. Accordingly, we must find the average population of each state according to the censuses from 1840 to 1870 , but inasmuch as the number who were born previous to 1840 is less than in later decades, we shall come nearer to the truth if we give that census only half as much weight as the others. In all cases we employ the figures for the entire white population, whether native or immigrant, but omit the negroes, Chinese, and Indians. The way in which the matter works out is illustrated in the following table, where the population is given in thousands: 


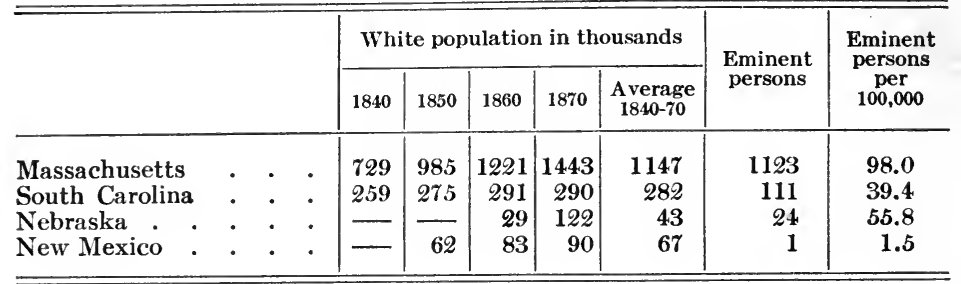

The figures in the last column show the relative rank of these states in the production of persons of unusual ability from 1835 to 1875 . Similar figures for each state are given in Figure 32. Since Nearing used only the first 10,000 names of American-born persons in "Who's Who," or only about 60 per cent of the total, the index figures really mean the number of eminent persons for every 60,000 people instead of 100,000. In a few cases where the average population previous to 1875 was less than 10,000 , two or more adjacent states have been combined so as to give a total large enough to be significant. The numbers thus obtained have been enclosed in parentheses. On the map the United States has been divided into four grades, as was done in Figures 25 to 29. Thus all these maps are comparable. The only essential difference is that Figure 32 belongs to a period averaging more than half a century earlier than the others. It presents the most accurate picture now available of the distribution of ability at that time. New states are at no disadvantage compared with the old, for if a region had no population previous to 1860 , for example, and only a few thousand in 18\%0, full allowance is made for this. Many of our 10,000 eminent pcople have moved away from their early homes, but the great majority did not go until they had at least reached an age approaching twenty and the main elements of their character were already formed. Thus the peculiarities of the map depend not only on whether the population was of such a caliber that children of high ability were 
produced, but also on the conditions which molded the early life of such children.

Aside from accidents three chief conditions determine the number of eminent persons in a community. The first is inherited ability. Unless a man is born with more than the average mental capacity, the chances of his inclusion in "Who's Who" are slight. The second condition is opportunity in the broadest sense of the word. A bright child born on a remote farm in Maine, on a ranch in Arizona, or in a clearing among the Tennessee mountains may be so hampered by lack of education and of the stimulus derived from contact with people outside his own little circle that he never accomplishes anything that attracts attention. The third condition is energy. Many a man of high ability, who is also blessed with the best education and with all sorts of opportunities to develop his talents, fails to make any impression on the world because he is indolent. Frequently, a man of less ability but endowed with energy achieves much more. Energy depends partly on inheritance, but also on climate. So far as it depends on inheritance it should be included under the first of our three conditions. Thus the three may be briefly defined as (1) inherited qualities of all kinds, (2) opportunities, which include education, the degree of culture in a community, and the freedom with which a person can find scope for his particular talents, and (3) energy so far as this depends upon physical circumstances not connected with either heredity or opportunity.

Let us now inspect Figure 32 to see how far our three conditions make themselves evident. Each gives rise to certain features which stand out unmistakably. To begin with inheritance, Massachusetts gave birth to $\mathbf{9 8}$ eminent persons for every 60,000 of its white population during the specified period. That is, 1 white child out of every 600 born at that time has distinguished himself. The figures for the surrounding New England States and New York range from 50 to 78. Such a 
striking difference is certainly not due to climate. It is equally certain that it is not due to opportunity. The average child in New York has as good a chance to go to school and enter any sort of occupation as has the child in Massachusetts. Yet the rank of New York is only half as high as that of Massachusetts. In Maine, Vermont, and New Hampshire the opportunities are distinctly less than in New York. There is much less wealth, the people are more isolated, the number of cities is proportionately smaller, the common school system is no better developed, and the facilities for sending children to college are not so great. Yet even Maine outranks New York, for she produced 54 eminent persons per 60,000 while New York produced only 50. Yet New York itself stands very high.

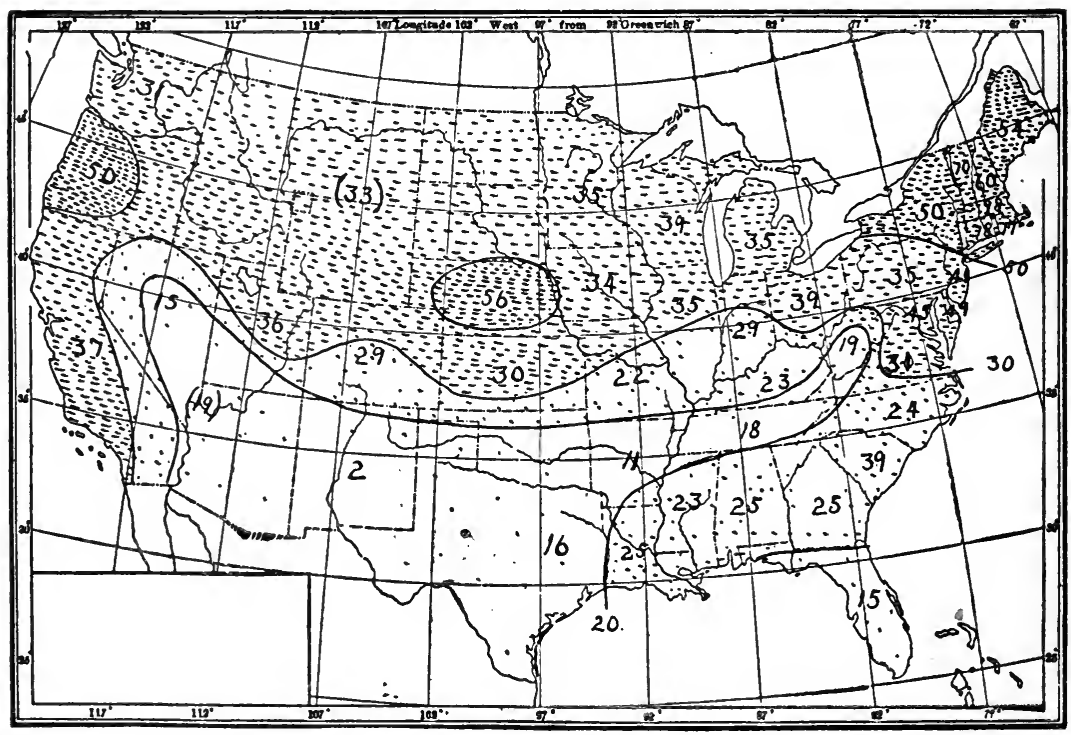

Figure 32. Birthplaces of Persons of Unusual Ability in the United States. The Numerals Indicate the Number of Eminent Persons Born in Each State per 60,000 of the Average White Population from 1835 to 1875 
Aside from the New England States only Nebraska exceeds it, while Oregon and Delaware rival it. South Carolina is another state which stands far higher than its neighbors, for although 39 is low compared with the 78 of Connecticut, for example, it is high compared with the 24 of North Carolina and the 25 of Georgia. Probably, heredity plays an important part here, as in other cases; although, as we shall shortly see, the matter is complicated by other conditions. Oregon and especially Nebraska, however, are unmistakable. Proportionately, they stand as high above their neighbors as Massachusetts, Connecticut, Rhode Island, and Vermont above theirs. The case of these two states is most suggestive. So far as energy is concerned, there is nothing in the climate of either Oregon or Nebraska to give them a special advantage. Previous to 1890 , by which time the education of four fifths of the people in "Who's Who" was completed, these two states did not offer their children especially great opportunities. In fact, the opportunities were much less than in Oregon's next neighbor, California, or in Iowa, Illinois, Indiana, Ohio, and Pennsylvania, the states directly east of Nebraska. Yet Oregon ranks 30 per cent higher than California, and Nebraska exceeds Illinois by 60 per cent, and Indiana by over 90 per cent. In striking contrast to Nebraska we find New Mexico with a rank of only 1.5, which appears as 2 on the map because we have avoided the use of fractions. Here again neither climate nor opportunitics explain why this state falls so far behind its neighbors. The only reasonable explanation is that until 1870 or later its "white" population consisted almost wholly of Mexicans.

In reading the preceding pages it may have occurred to the reader that the preëminence of New England is only apparent, not real. It may be due largely to the local prejudices or limited viewpoint of the compilers of "Who's Who." This is not the case, however. The book is edited and published in 
Chicago. Yet Illinois and the neighboring states all receive a relatively low rank.

The facts just stated are of profound significance. Massachusetts, because she was settled by the strong-willed Pilgrim Fathers and by other Puritans who fled to the wilderness to maintain their high ideals, has produced vastly more than her proportion of the men who have made America what it is. Connecticut and Rhode Island for similar reasons have followed closely on her heels, while the northern New England States have much more than held their own compared with the rest of the country. It has been a fad to decry puritanism, but people of puritan descent have taken the foremost place. They have done so because they inherit the strength of mind which made it possible for the Puritan Fathers to develop their stern conscientious system and carry out their noble purposes in the face of temptation and opposition. When that old stock has been transported to places such as Nebraska and Oregon, where for a while it was dominant before the great tide of later immigration, it raised the average ability to a level reached nowhere else except in New England. In New Mexico, on the contrary, we harbor a group of people, fortunately small, who are even more conspicuous by their lack of ability than the New Englanders are in the opposite way. We may excuse the Mexicars by saying that they do not learn our language and do not merge themselves in our civilization. The competent Mexicans, however, usually those who possess the greatest proportion of Spanish blood, do learn English and make themselves felt among us. The others, perhaps because they inherit an inert disposition from their Indian ancestors, are content to remain backward.

This brings up the great question of immigration and racial character. In the earliest days of colonization we received only the stronger elements of the various European populations. The North had its Pilgrims, Puritans, Quakers, and others, 
while in the southern states a part of the settlers were people who as Huguenots or other religious refugees were notable for tenacity of purpose and high ideals. The rest of the settlers were in large measure people of unusual courage and initiative, for others were not brave enough to come. For this reason, apparently, the states of the Atlantic coast from Georgia northward stand higher than those west of them. After America had been settled so long that migration thither was easy, we began to get immigrants of medium grade, not the best nor the worst, but from advanced countries and from the substantial middle classes. These are what predominate from Pennsylvania to Iowa. They are good material, but not so good as the old. Otherwise why should so fine a state as Wisconsin have produced only half as many eminent men per 100,000 as has Connecticut, and no more than South Carolina which labors under far greater disadvantages? In these last decades we are taking into our midst many people scarcely better than the Mexicans. We may say what we choose about absorbing them and making them good Americans. It is our duty to do so as far as we can, but why blind ourselves to the facts of biology? Plough horses cannot race like thoroughbreds. Do men gather grapes of thorns or figs of thistles?

Today Massachusetts and New England seem to be losing their supremacy in the production of men of special ability. Nearing's figures show that it is by no means lost, but not so marked as formerly. So far as this means that the strong old New England families have sent their sons out over the wide expanse of our land, the loss to the mother states is more than compensated by the gain to the rest of the country. Unfortunately, it means more than that. It means, in the first place, that we are steadily diluting our strength. We are acting as would a dairyman who thought that by adding a dozen lowgrade animals to his herd of a hundred prize-winners and letting them breed together he was going to increase the value of his 
stock. In addition to this we are losing in another and more dangerous way. It is as if the dairyman should not only add poor animals, but should also prevent his best animals from bearing young. No amount of care would make the low-grade animals give as much milk or be of as much value as the prize-winners. Man is subject to the same biological laws as animals. High mental ability and strength of purpose are his most valuable qualities. Yet we act as if we thought that though these are not reproduced, our country can continue to advance. Our unwillingness to live simply either prevents a large proportion of our most competent men and women from marrying, or causes many of those who marry to have few children. All men are not created equal biologically, and it is the best who are dying out. We must recognize that fact, and act upon it before we have worked irreparable injury. All this has been said many times by eugenists, but it must be repeated again and again until it is not only believed but acted upon. Biology teaches it; common sense insists upon it; and now our purely geographical studies enforce the same conclusion.

The second condition which controls the distribution of people who attain eminence is opportunity. This appears unmistakably in only one portion of Figure 32, but there it stands out sharply. Notice how West Virginia with 19 eminent persons per 100,000, Tennessee with 18, and Arkansas with 11 fall below the surrounding states. This is apparently because these are the portions of the South where mountains and other physiographic disadvantages cause the people to degenerate into "poor whites" and "crackers" in spite of a good inheritance. What these backward communities need is a "chance." They need the opportunities that are brought by schools, railroads, factories, and the other appurtenances of civilization. They need also the opportunity brought by freedom from such bodily afflictions as the hookworm disease. Kentucky, which now has a rank of 23, would probably stand much higher were 
not a large part of the state peopled by mountain whites. The same is true of North Carolina. Perhaps this state would not equal South Carolina, which had a large number of old families of unusual ability, but the two would be much nearer than now. A large fraction of North Carolina consists either of mountains or of swampy, unhealthy tracts along the coast, while South Carolina is almost free from such disadvantages. In another portion of the country it may be that Maine lags behind New Hampshire and Vermont in part because of her relative remoteness and lack of opportunity. Doubtless other places show the same conditions, but the matter is not certain. For example, Nevada's low position with a rank of only 15 is probably due in part to this cause, but it is doubtful whether she has been much worse off than Utah, which has the respectable rank of 36. Idaho, Wyoming, Montana, and the Dakotas certainly had no more opportunities than Nevada previous to 1890, for they were supplied with fewer railroads, and were much less easily in touch with the rest of the world. Yet their rank is 33, or more than twice that of Nevada. Taking the map as a whole it seems that although opportunity is highly important, it is less important than heredity.

Turning now to our last factor, that is, energy as determined by climate, we see that in general the outlines of Figure 32 are like those of the climatic map in Figure 25. To be sure there are important differences. For instance, the very high area which covers all the northeast and center of the country in the energy map is split into a New England and a Nebraska portion in the map of ability. Yet the Nebraska area of many eminent people displays an interesting resemblance to the tongue which projects out in the same direction on the energy map. The Pacific coast is likewise high on both maps, although there are differences of detail. Nevada, too, is at the head of a tongue of low conditions in both cases. On the Atlantic coast both maps rise from Maine to Massachusetts, and decline from 
New York to Florida. In the map of ability, however, high conditions go somewhat farther south than in the other map, and South Carolina, presumably because of heredity, rises unexpectedly. The other southern states from Georgia to Louisiana are also a little higher on the ability map than on its companion, probably because of the wealth and opportunities which prevailed in them previous to the Civil War, or else because of the abundance of old families with high ideals and strong minds. Yet even these states are lower than the tier of northern states from Pennsylvania to Iowa, where the average inheritance is probably no higher, if as high, but where the climate gives energy.

Taken as a whole the map of ability is an admirable example of the way in which a variety of factors coöperate in determining the status of civilization. Climate, as it were, paints a broad background shading gradually from very high in certain areas to lower in others. Then the other factors come into play. They paint fresh colors which may or may not resemble those of climate. In some cases, such as Massachusetts, the same color is laid on by climate, heredity, and opportunity, not to mention proximity to the sea and to Europe, facilities for manufacturing, and various other factors which perhaps may be considered as opportunities. Where that happens, high civilization is sure to prevail. In other cases, such as South Carolina, the climate paints only a moderately high color, inheritance paints a higher one, education $a \mathrm{w}_{\mathrm{w}}$, the presence of the negroes a still lower, and so on indefinitely.

Such, then, is the meaning of our maps. They do not indicate that climate is the only factor in determining the condition of civilization, or even the main one. Far from it. Yet they indicate that it is as essential as any other. Today civilization seems to make great progress only where a stimulating climate exists. A high civilization may be carried from such places to others, but it makes a vigorous growth and is fruitful 
in new ideas only where the climate gives men energy. Elsewhere it lags, or is kept at a high pitch only by constant reënforcements from more favored regions. In the past men have perceived that climate is apparently one of the most important conditions which favor or retard the growth of civilization. They have been greatly impressed not only by its effects upon their own bodies and minds, but by the fact that in warm countries the amount of progress is closely in harmony with what would be expected on the basis of one's own feelings. At the same time they have realized that among countries located in the same latitude there are differences of culture almost as great as between temperate and tropical countries. This has seemed to indicate that climate is not so important as the tropical regions would suggest. Now, however, we see that when people's actual achievements under various climatic conditions are measured, we must revise our opinion. Variations of temperature from day to day are much more important than has been realized. Therefore, in the same latitude the stimulating effect of the climate may differ greatly. The civilization of the world varies almost precisely as we should expect if human energy were one of the essential conditions, and if energy were in large measure dependent upon climate.

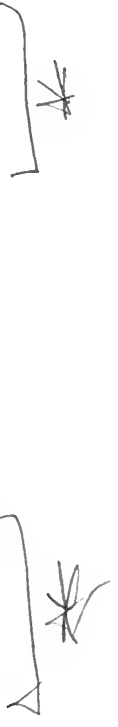




\section{CHAPTER XI}

\section{The Shifting of Chimatic Zones}

In our study of man and climate two distinct methods have thus far been employed. We must now resort to a third. The three lead to conclusions whose degree of probability varies greatly. I cannot too strongly insist that the results obtained by the different methods be sharply distinguished. The first may be defined as the qualitative study of facts which can now be observed or which are so well known that they are not reasonably open to question. This is exemplified in the early chapters where we considered the effect of tropical and temperate climates upon white men and negroes. In the past, from Herodotus to Rätzel, the vast body of geographical reasoning has of necessity been of this type. It consists of picking out typical instances of a given phenomenon in as many regions as possible, and then determining the general law by which they seem to be governed. For example, we compared the white man and negro in the United States, South Africa, and the Bahamas, and found that in each case the race which has gone from a more bracing to a less bracing climate is apparently weakened, while the race which has gone to a more stimulating climate is strengthened. General laws based on reasoning of this sort are extremely valuable, but lack the highest degree of certainty, for they depend largely upon individual judgment. Hence, for two thousand years people have remained undecided whether climate is or is not of primary importance in deter-. mining the distribution of civilization.

The second method may be defined as the quantitative meas- 
urement of facts which are within the range of observation and which can be tested again and again. It is exemplified in our study of factory workers, students, life insurance, and education. It eliminates personal judgment, and thus gives certainty to the primary facts upon which future reasoning is based. A hundred men might examine our factory statistics, and they would all come to the same conclusion. The operatives worked at a certain rate in winter.or summer; they accomplished the most when the temperature was about $60^{\circ}$; and they worked relatively fast after a moderate drop of temperature. These are facts, not inferences. Of course they need to be tested, but that can soon be done. The only requisite is that tests be made by enough investigators to insure against accidental mistakes, and to show that the same conditions recur repeatedly. The final results can be expressed numerically. When once obtained they furnish an unshakable foundation. Therefore, the main portion of this book is far more important than the earlier or later chapters. This does not mean that I delude myself with the idea that the problem of the relation of climate to civilization is solved. Far from it. I mean only that when the statistical method here employed is tested and its imperfections are eliminated, its ultimate results will be a body of facts which cannot be gainsaid. So far as the facts are yet available, they show, for instance, that if all the people of the world were like those of the eastern United States, we should not expect as much energy in central Asia as in western Europe. That is as far as we can go with unassailable facts. We may draw the inference that the condition of civilization is closely related to the degree of energy, but that remains to be tested. The mere fact, however, that diminished energy would be expected not only northward and southward from the main centers of civilization, but also as one penetrates farther into the interior of a great continent, removes one of the two great objections which have 
prevented people from believing that climate and civilization are intimately connected.

The other objection to such a relationship is the supposed fact that many ancient nations grew great in places whose climate was not stimulating. The truth of this cannot easily be tested, for neither of the methods already discussed can be employed. We must resort to a third, less reliable than either of the others. Instead of a qualitative or quantitative study of facts which can actually be observed, we must first reconstruct our facts, and then apply one or both of the other methods. The facts as to the general distribution of the more advanced civilizations two or three thousand years ago can easily be reconstructed from historical and archæological records. The facts as to the ancient climates, on the contrary, can be reconstructed only with great difficulty and uncertainty. No general agreement has yet been reached, and the hypothesis favored in this book is avowedly only one of several. Let me emphasize the fact that it was not in any sense framed to fit the conclusions set forth in earlier chapters, for it had reached practically the present form before the results of the work of operatives and students were known. The fact that it fits into those results so perfectly in spite of its independent origin is one of its strongest claims to recognition. Nevertheless, it stands in a more uncertain position than do conclusions based directly on facts of observation, or, still more, upon exact measurements. Hence, the remainder of this book makes no claim to stand on the same basis as the earlier portions, and should be judged with corresponding leniency. In order to complete our subject it is necessary to investigate the climate of the past, but this forces us to rely not on observed climatic facts, but upon observed facts of quite a different kind which we endeavor to interpret in terms of climate.

The subject of climatic changes during historic times has been warmly debated for many years. It seems to be going 
through stages like those through which the great controversy as to geological changes of climate has passed. A few generations ago scientists believed that the climate of the world had been uniform since the completion of a definite creative act. Then, as geology began to become a real science, the opinion arose that the earth had cooled from a gaseous to a liquid condition, and finally had become solid. As a necessary corollary it followed that since the crust took shape there must have been a progressive cooling accompanied by a freeing of the atmosphere from moisture and by a drying of the lands. This was embodied in the nebular hypothesis which until recently dominated our ideas of the earth's evolution. It seemed to be strongly supported by the presence of fossil corals and other equatorial animals or plants in high latitudes where the temperature is now far too low to permit their existence.

While the nebular hypothesis was entrenching itself, another line of studies was preparing to revolutionize our ideas of geological climates. It was discovered that glaciation once took place upon a large scale in many regions now free from permanent snow. At first this was supposed to have occurred at only one epoch. Gradually, however, geologists perceived that the glacial period consisted of at least four epochs separated by interglacial epochs during which the climate became as mild as at present, or even milder. Then they discovered that in the middle of geological time another glacial period occurred in the Permian era. This, too, appears to have been divided into epochs. Next still other glacial periods were discovered far back near the beginning of the record preserved in the rocks. At last geologists have almost universally concluded that throughout the hundreds of millions of years which form $\checkmark$ geological time the earth's climate has pulsated back and forth. At some times a vast mantle of ice has spread over regions within thirty degrees of the equator, while at others the ice has melted, and almost tropical conditions have prevailed as far 
north as Greenland. Neither has stability prevailed for any great length of geological time, nor has there been a change which has progressed steadily in one direction in response to the gradual clearing of the air demanded by the nebular hypothesis. The idea of climatic instability is now so thoroughly grounded that many geologists have rejected the nebular hypothesis. They are inclined to accept some substitute such as Chamberlin's planetesimal hypothesis which supposes that the earth was formed by the gradual accretion of small planetesimals or meteoric bodies which are thought to have abounded in the space now occupied by the solar system.

In addition to this, another change has come over geological opinion. As the moraines and other remains of the last ice-age were studied more carefully, it became evident that the latest melting of the ice sheet did not take place steadily. At least three times the climate ceased to become milder and either remained nearly uniform for a while, or else reverted somewhat toward the conditions which induce glaciation. These postglacial "stages" are constantly becoming more and more clearly defined. They show that after the main pulsations of the glacial epoch had passed away, there was a series of minor pulsations of the same kind, but less severe. This does not finish the matter, however, for glaciers are by no means the most delicate test of climatic changes. The salt lakes of arid regions where there is not enough rain to enable the water to rise to an outlet are perhaps the best of all rain gauges. In places like the Dead Sea valley in Palestine or the Searles basin in California there are great numbers of old strands, fifteen or twenty in some cases. These lie above the present level of the water, and indicate that an ancient lake fell irregularly. Sometimes it declined rapidly, and again it stood stationary for a while, or else rose toward its former level, although the evidence of this latter change is usually concealed. These many movements up and down indicate climatic changes 
like those of the glacial period except that they are much smaller. They show that during the past twenty or thirty thousand years the climate of the earth has been subject to a great number of small changes, just as during the immense lapse of geological times it has been subject to a large number of great changes, each of which in turn seems to have been diversified by many minor variations. The last of the lake strands are evidently recent, probably only a few hundred years old, and certainly not more than a few thousand. Thus from the earliest geological times down almost to the present day, change rather than uniformity has been the rule. The more the matter is studied, the more numerous do the changes appear, and the more universally are they accepted by geologists.

Coming to historical times we find that the course of thought has been much the same as for the vast periods of geology. The matter has not yet gone so far, however, and there is still an important difference of opinion among people whose judgment is worthy of respect. In many parts of Asia, Africa, and America ruins of towns and cities are located where now the supply of water seems utterly inadequate. Old roads traverse deserts where caravans cannot now travel; traces of dry springs are seen; bridges span channels which carry no water for years at a time; old fields are carefully walled in places where now the rainfall is too scanty to permit agriculture and where no water can be brought for irrigation. These things and many others, which almost every traveler in semiarid or desert countries has seen for himself, seem to be almost irrefutable evidence that at some time the climate was moister than now.

This has given rise to two hypotheses, which are now almost abandoned, those of deforestation and of progressive desiccation. According to supporters of the first hypothesis, the reckless cutting of forests has not only allowed the rains to denude the mountain sides of soil, but has caused an actual 
diminution in rainfall. This view once had a considerable popular vogue, but for various reasons it has now practically ceased to be considered among scientists. In the first place modern measurements of rainfall before and after the deforestation of large tracts are contradictory. At best they show only slight differences, too small to have any appreciable effect, and in practically every case so doubtful that they may be due merely to the accident of an especially dry or rainy period of a few years coming not long before or after the forest was cut. Moreover, many of the strongest evidences of desiccation are found in places such as southeastern Syria where there is no reason to think that the country has ever been forested since it was first occupied by civilized man. Finally, there are thousands of square miles in Chinese Turkestan where the forests themselves have died because of lack of water, and are still standing as gaunt skeletons preserved for a thousand years or more because of the extreme dryness of the air.

The hypothesis of progressive desiccation assumes that during historic times the earth has steadily been growing drier. This view has been widely held, and many careful students still uphold it. The majority of its supporters, however, apparently think that it needs modification along lines which will shortly appear.

While evidence of more water in the past than at present is prominent in many places, there is also much of the contrary nature, less noticeable, but no less convincing. For example, ruins are located on the floor of lakes which must have been partially dry when the structures were erected. Elsewhere one finds irrigation canals in places now so damp that their construction would seem to be a waste of energy. In north Africa and Syria huge irrigation works are located in regions of another kind, which not only are dry now, but must have been dry in the past. Otherwise the Romans would not have expended such enormous labor to get water. These things and 
others furnish almost irrefutable evidence that at certain periods the water supply of many semiarid regions was no greater than at present. Because such evidence is less abundant and noticeable than the other kind, the believers in progressive desiccation have overlooked it. On the other hand, other students have been so impressed by it that they have held that there have been no changes of climate during historic times, and that the fluctuations which followed the last glacial epoch came to an end before the beginning of history.

There seems only one way to reconcile these two opposing views, each of which is based on unassailable evidence. That way is to group all the evidence according to its date, and see whether the indications of moisture come at one time and of aridity at another. Such seems to be the case. For example, at the time of Herodotus, between 400 and 500 B.C., all the evidence points to moist conditions in western Asia and northern Africa; about 200 B.C. a somewhat drier climate apparently prevailed, although not so dry as now; then at the time of Christ conditions were once more favorable. After about six centuries of gradually increasing aridity, the worst conditions during historic times were reached about 650 A.D. An improvement followed which culminated about 1000 A.D., then came another bad time, reaching its worst in the thirteenth century. It was followed by a rapid recovery, which did not last long enough to be of great value. Since the fourteenth century the tendency apparently has been toward aridity. The whole matter is summed up in the dotted line of Figure 33. There the high parts of the curve represent moist conditions and the low dry. The curve is only approximate, and does not represent all the data now available, but it seems wise to reproduce it unchanged from "Palestine and its Transformation" and "The Climatic Factor."

From what has been said, it appears that during historic times climatic pulsations have taken place. They seem to be of 


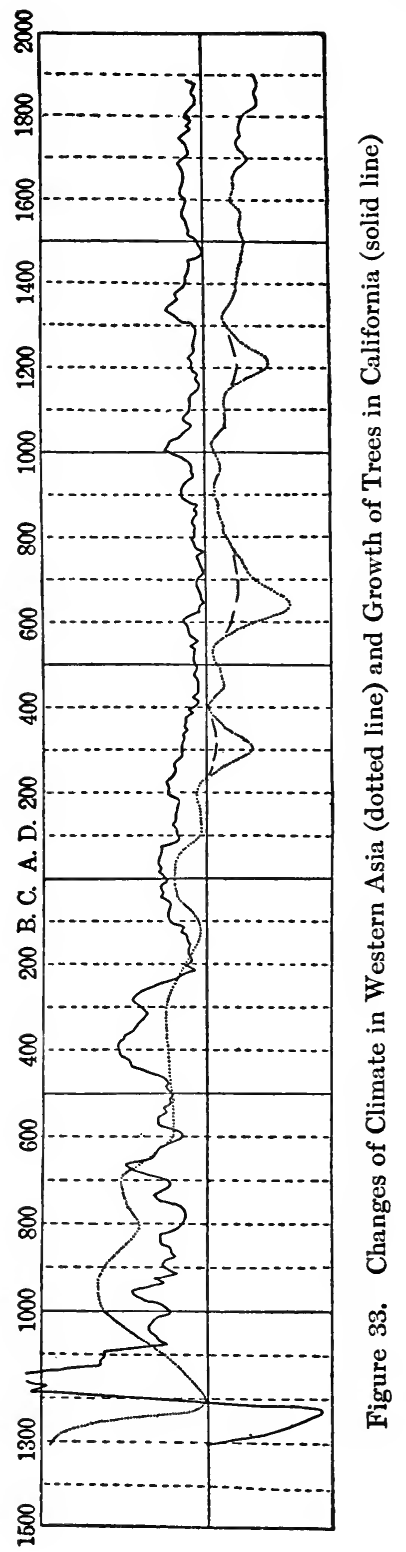


essentially the same nature as glacial epochs and post-glacial stages, the difference being only in degree. Apparently, the conditions of the geological past merge without break into those of the present. While this "pulsatory" hypothesis meets with much opposition, its critics are almost unanimous in admitting that the Caspian Sea, for example, stood lower in the seventh century or thereabout than at present, and higher than now in the tenth. They also admit that the climatic pulsations thus indicated were more important than any that have been observed since records began to be kept. They do not admit, however, that the pulsations were large enough to possess appreciable historic importance. They also deny that between the end of the last post-glacial stage, say 2000 B.C., and the dry period in 600-700 A.D., there is any proof that the climate as a whole was moister than at present. The reader who would know more about the matter should consult the works listed in the Preface.

In order to test the pulsatory hypothesis, some means of actually measuring the climate of the past seems necessary. In the southwestern United States there appear to have been changes like those in western Asia. In that region, Professor A. E. Douglass has found that the thickness of the annual rings of trees furnishes a reliable indication of variations in the water supply from year to year. Corrections must be made to eliminate the effects of age, but this can be done by mathematical methods of considerable accuracy. It is difficult to determine whether the climate at the beginning and end of a tree's life was the same, but it is easy to determine whether there have been pulsations while the tree was making its growth. If the trees from various parts of a given district form thick rings for a century, then thin ones for another hundred years, and again thick ones, we may be almost sure that they have lived through a long period of unfavorable climate. 
During the years 1911 and 1912, under the auspices of the Carnegie Institution of Washington, I measured the thickness of the rings of growth on the stumps of about 450 Sequoia trees which had been cut for fence posts, shingles, and pencil wood in California. The trees varied from 250 to nearly 3250 years of age. The great majority were over 1000 years old, 79 over 2000, and 3 over 3000. Even where only a few trees are available, the record is surprisingly accurate except for occasional accidents. Where the number approximates 100 , accidental variations are largely eliminated. Accordingly, in California we have a climatic record which is fairly accurate for 2000 years and approximate for 1000 years more. This is expressed graphically in the solid line of Figure 33. In order to bring out the details the more reliable portion from 100 B.C. to the present time has been reproduced in Figure 34. This is identical with the corresponding part of Figure 33 , except that the vertical scale is three times as great.

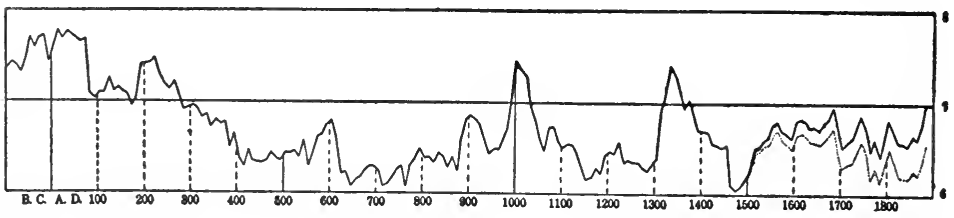

Figure 34. Changes of Climate in California for 2000 Years. At the Right Hand End the Dotted Line is Probably Correct

In general, the tree curve resembles that of changes of climate in Asia, although there are differences in detail. Beginning with 1000 B.C., both curves have a maximum. They dip down about 800 B.C., and rise high not far from $\boldsymbol{\gamma} 00$. About 400 B.C. they disagree, but this is probably due largely to the absence of reliable data for the Asiatic curve. In the second century before Christ both are low, but not so low as at present; at the time of Christ they rise high, and continue to 
fluctuate together till 300 A.D. At that time they show a difference which may have arisen because I was unduly impressed by the abandonment of many ruins in Chinese Turkestan at the end of the third century. The dash line is probably more accurate than the dotted and should be used. In the seventh century both curves reach their lowest point. Then, from 650 A.D. onward, their general course is closely similar, especially about 1000 A.D.

'The general agreement between the two curves seems to indicate that the main climatic variations of western Asia and of the similar region in the United States are approximately the same. This means that we are dealing with a phenomenon which is presumably world-wide, although its precise form may differ from place to place. It also means that in the only case where exact figures are available year after year, the inferences drawn from isolated facts in another continent are confirmed. The case is like that of the measurements of factory work. After employing the qualitative method and determining what kind of events have apparently taken place, we have turned to the quantitative method and have tested our conclusions by actual measurements. The results confirm the pulsatory hypothesis. They indicate not only that climatic pulsations have taken place, but that as we go back toward the dawn of history, they become more pronounced.

The only serious objection raised by opponents of this view is that various types of vegetation, such as the palm tree, grew in places like Palestine in the past and grow there today. This, they say, precludes a change of climate, for if Palestine were colder two thousand years ago than now, the palm could not have flourished. The truth of this statement is undeniable if we are talking about pronounced changes in the mean temperature. As a matter of fact, however, the evidence points toward changes of precipitation much more than of temperature. The best students of glaciation agree that during the 
glacial period the mean temperature of the earth as a whole was probably not more than $10^{\circ}$ or $15^{\circ} \mathrm{F}$. cooler than at present. If the climate at the time of Christ differed from that of the present time by one tenth of the difference between our modern climate and that of the glacial period, the temperature of Palestine would only have to be about $1^{\circ} \mathrm{F}$. cooler than now. That would scarcely produce any appreciable effect upon vegetation. The actual figures show that Palestine might be at least $2^{\circ}$ or $3^{\circ} \mathrm{F}$. colder than now without preventing the growth of the palm tree. Moreover, the extremes may have been greater than at present without much change in the average temperature. If the winter storms were colder than now by a few degrees, that would not hurt the palm tree. In Seistan in eastern Persia I have camped in six or eight inches of snow almost under the shade of a palm grove whose dates, packed in a sheepskin, were uncommonly delicious. The thermometer fell below $20^{\circ} \mathrm{F}$., and a strong north wind overturned the tent, but the palm trees did not suffer, for in two or three days the air was again as balmy as spring. So far as has yet been shown, the conditions of vegetation nowhere seem to be out of harmony with our hypothesis.

The general attitude of geographers towards the problem of changes of climate seems to be that expressed by Professor D. W. Johnson of Columbia University in a recent review of "The Climatic Factor."

The volume, he says, "does not solve all the problems presented by a theory of climatic pulsations. It does not pretend to do so. It does aim to show that the evidence thus far available strongly supports the belief that there have been within historic time climatic changes of a pulsatory nature. In this the author has, in the opinion of the reviewer, been successful."

One of the strongest reasons for believing that the climate of the historic past was distinctly different from that of the present has come into notice so recently that it is not yet 
generally known, even to geographers. It is peculiarly important because it employs a method absolutely different from those already mentioned, but reaches the same conclusion. Every river holds in solution a certain amount of sodium, chlorine, calcium, carbon dioxide, and various other materials. Under ordinary circumstances this cannot be detected except by chemical analysis. If the river flows into a lake which has no outlet, however, the water is evaporated, but the dissolved constituents remain, and gradually increase until a brine is formed. Certain materials, such as the calcite, which forms tufa or other kinds of limestone, are removed by algæ or bacteria, and certain others, such as potassium, seem to be absorbed by the clays of the lake bottoms. Sodium, and especially chlorine, however, do not appear to be removed until the brine becomes completely saturated so that crystals of common salt are formed. Hence, if we know the amount of sodium and chlorine brought in by the rivers each year and the amount dissolved in an unsaturated lake, we can easily calculate the time that has elapsed either since the lake was first formed, or since it last overflowed. A body of water that overflows, as everyone knows, soon becomes essentially as fresh as the rivers that supply it.

On the eastern side of the Sierra Nevada mountains the bodies of brackish water known as Owens Lake, lying in southern California, and Pyramid and Winnemucca lakes near Reno, Nevada, are peculiarly well adapted to our present purpose. Owens Lake receives most of its water from the river of the same name. Both have been measured and analyzed with unusual thoroughness because part of the river is carried to Los Angeles in a remarkable aqueduct nearly 250 miles long. H. S. Gale of the United States Geological Survey has carefully gathered all the available data. He concludes that, according to the figures of the aqueduct engineers, the accumulation of the chlorine of Owens Lake would require 4200 years, 
and the sodium 3500, the average being 3850. A series of fresh strands and an old outlet channel show clearly that the lake overflowed not long ago. Hence, Gale concludes that "4000 years or considerably less" is the length of time since the lake stood at the outlet level, 180 or 190 feet higher than at present. These figures, however, require modification. The reason why Gale gives the period as " 4000 years or considerably less" is that the figures of the engineers omit the lower third of the drainage area of Owens Lake, and this is the part where the waters flow most slowly and where the clays and other deposits which surround them are most saline. Hence, more salt proportionately should be accumulated here than higher up. Moreover, as he carefully points out, no allowance is made for the well-ascertained fact that when the rivers are more abundantly supplied with water, as must have been the case when the lake was full, the amount of dissolved salt is also greater although not in direct ratio to the water supply. When due allowance is made for these conditions and for others of minor importance, the time since the last overflow is reduced to about 2000 years. In other words, 2000 years ago, more or less, the climate of the Owens Lake region was so moist that the lake expanded to two and one half times its present size and sent a stream down the outlet channel.

At Pyramid and Winnemucca lakes the conditions are essentially the same as at Owens. The measurements, especially those of the lakes, however, are much less exact than at the California lake because no great aqueduct has demanded precise figures as to the volume and constitution of the water. Hence we do not find so close an agreement between the sodium and chlorine. Pyramid and Winnemucca lie almost adjacent. Both are supplied mainly by the Truckee River, which sometimes flows to one and sometimes to the other. According to J. Claude Jones of the University of Nevada, the Truckee River would require 2400 years to supply the sodium in the two 
lakes, and 4400 for the chlorine, the average being 3400. Here, as in the other case, a considerable allowance must be made for salts washed in from the surrounding saline lake deposits by small streams not tributary to the Truckee, and for the much larger amount of dissolved material which the Truckee itself must have contained when its volume was larger than now. Thus we are led to conclude that not much more than 2000 years ago, and possibly less, the climate of this region was such that Pyramid and Winnemucca lakes united and formed a large lake which overflowed to the north at a level about 70 feet above that of Pyramid at present. The outlet channel can plainly be seen winding away to the Smoke Creek Desert. The agreement of this region with Owens Lake is striking. It indicates that about 2000 years ago the dry, western parts of the United States were still under the influence of a pronounced moist period.

The lakes do more than indicate a change of climate within two or three thousand years. They also show that the change has been highly irregular. This is proved by a large number of strands lying below the level of the outlets, and by the way in which these vary in character and in the extent to which they have been covered by fresh detritus washed down from the mountains. At Owens Lake there are four series of strands. These apparently correspond to the four chief periods when the climate has grown moist as shown by the growth of the big trees in Figure 34. Fortunately, Owens Lake lies only fifty miles east of the region where the trees were measured. The general climatic fluctuations of both districts are the same. The uppermost strand, the huge gravel beach at the level of the outlet, must date from about the time of Christ, for both the chemical evidence and the trees point to this conclusion. A series of similar, but much smaller beaches at lower levels record the approach of a dry period during which the lake fell to a low' level whose exact position cannot be de- 
termined. Judging by the trees this must have culminated about 650 A.D. During this period gravels were washed in by mountain streams and deposited what are known as fans, or low, flattened cones, which may be several miles long. These covered the old strands in many places, and extended far below their level to the diminished lake.

Next the waters rose again, but not halfway to their former level. They formed two small strands, not gravelly like their predecessors, but faint and sandy as if the winds were weak. They must date from about 1000 A.D., when the trees indicate a wet period, for they are younger than the gravel fans of the preceding dry time. The next phase of the lake was a dry period, which was most extreme about 1250 A.D. More gravels were then deposited, and the fact that they cover the preceding strands and extend to a much lower level shows that the lake then stood low, as would be expected from the trees.

The next high period of the lake, about 1350 A.D. according to the trees, is unusually interesting. The water did not reach so high a level as formerly, because the rainy period was short, but it formed a large, high beach of gravel quite different from the preceding beaches. This seems to indicate great storminess, a condition which is also suggested by the fact that the growth of the trees at this time increased more rapidly than at any other period for nearly 3000 years. In Europe during the same century, unprecedented storms caused great floods in France, while the severity of the waves was so intense as to break through beaches and sand dunes, and convert large marshy areas into portions of the sea along the coasts of Holland and Lincolnshire. During the winters the rivers froze to an unheard-of degree, and three or four times men and animals passed from Germany to Sweden on the solid ice of the Baltic Sea, an occurrence unknown in our day. In England the summers were so rainy that the average yield of grain diminished disastrously. In 
self-defense many landowners gave up grain-raising, and turned their attention to sheep and cattle. Distress and discontent were the inevitable result among the peasants. Far away in central Asia the Caspian Sea and the lake of Lop Nor both rose with great rapidity between 1300 and 1350 A.D. Thus from California to China evidence of various kinds unites to indicate that during the fourteenth century there occurred a short period of unusual storminess. Such conditions, if intensified and prolonged, would probably cause the accumulation of enormous glaciers.

To return to Owens Lake, the lowest series of strands is sandy and small compared with the large gravel bar of 1350, and was evidently formed under different conditions. Presumably the lake fell to a low level about 1500 A.D., and rose during the next century or more to form the highest strand of the latest series. The evidence of Owens Lake is much strengthened by that of its neighbors. At Mono Lake farther north in California, the character and relations of the numerous strands, as I hope to show in detail in a later publication, are almost identical with those at Owens, although there are also some older ones at higher levels. At Pyramid Lake the same is true. Thus on all sides there is the strongest evidence not only that the climate of the past differed from that of the present, but that many minor pulsations have taken place, and that these have grown less intense during the historic period.

It must not be supposed that the same kind of climatic changes have taken place in all parts of the world. Penck, who stands at the forefront among German students of the glacial period, has come to the conclusion that this is by no means the case. He shows that on the northern side of arid or desert areas we find densely saline lakes, like Great Salt Lake in Utah, surrounded by old strands. These indicate that the lakes have long been contracting, so that they have abandoned first one strand and then another, while at the same time their 
water has become more and more highly concentrated. On the equatorial side of the desert belt, on the contrary, we have such lakes as Chad in Africa, a shallow sheet of water, only slightly salty and not surrounded by any great series of strands. It has the appearance of being a new lake formed by a recent increase in rainfall. Penck points out a similar contrast between the sand dunes on the poleward and equatorward sides of the desert belt in both hemispheres. On the poleward side, the dunes consist of loose, moving sand appropriate to places that are growing drier. On the other side there are plenty of dunes, but they are covered with a sparse vegetation which is sufficient to keep them from moving and to prevent the formation of new dunes. Since their formation, the rainfall has evidently increased. From the dunes and lakes, as well as from other evidence such as the snowline, Penck concludes that changes of climate consist of an alternate shifting of the climatic zones. During a glacial period he holds that the northern storm belt is shifted southward so that the storminess of Germany and the northern United States is pushed into Italy or the southern United States. In the same way the desert belt is displaced toward the equator. Thus the polar side of the desert has more storminess and moisture than formerly, while on the equatorial side the desert is shoved into an area where equatorial rains formerly supported abundant vegetation. During a time such as the present, on the contrary, the desert expands on its northern border. Its lakes diminish, leaving strands behind them and becoming very saline; vegetation dies; and the wind is free to pile up sand dunes. On the other, or equatorial side of the desert, the amount of rain is greater than before. Hence, basins which formerly contained no water are now filled with shallow lakes, such as Chad, which have not yet had time to become highly saline. Vegetation also spreads into the desert and sand dunes become covered with it and cease to be moved by the wind. Few people 
have studied glacial problems more carefully than Penck. One result of the minuteness and care of his studies is that he is one of the foremost advocates of great climatic complexity. $\mathrm{He}$ distinguishes several post-glacial stages, and in addition brings his conclusions so far toward our own time that he states that a peculiarly dry period prevailed in central Asia as late as the early part of our era.

While Penck was formulating his hypothesis of a shifting of climatic zones as an explanation of the glacial period, I was working out the same hypothesis in respect to historic times. Our work was wholly independent, being based on different lines of evidence, and, so far as I am aware, neither knew what the other was doing. The shifting of climatic zones is by no means a new idea, for it has been vaguely suggested many times. The new thing is to find direct evidence of it, such as Penck presents in his discussion of lakes and dunes. As to historic times, the ruins of Guatemala and Yucatan furnish perhaps the best available test, for those regions are the most notable example of a civilization which developed within the torrid zone. The ruins of that civilization are the most remarkable archæological remains in the western hemisphere. Part lie near the northern coast of Yucatan in a relatively dry region inhabited today by a fairly prosperous agricultural population. Many of the finest ruins, however, and most of the more ancient ones, lie back from the coast in a wilderness of dense forest and jungle. There agriculture is almost impossible. The difficulty of clearing the rank vegetation and getting it dry enough to burn before a new crop of lusty bushes grows up is enormous. Fevers, too, prevail most of the year. They include the worst types of tropical malaria, as well as many other kinds. Foreigners are quickly attacked, and it would be dangerous for a white man to attempt to live there permanently, even with all the appliances of modern medical science. The natives also suffer terribly. Many of the chil- 
dren are apparently killed by malaria and other tropical diseases in infancy. Those who grow up carry the effects with them through life. Seventy-five per cent of the people who worked at the Panama Canal are thought to have had malaria germs in their systems, even though they did not show outward signs of the disease, and the case is probably even worse among the natives of the lowland forests of Quintana Roo, Campeche, and Peten, where most of the early Maya ruins are located. One has only to look at their swollen paunches to see that something is the matter, and their dull, apathetic manner, both in work and play, is another sign of some deep-seated physical ailment.

Here, where today the Indians are so diseased and agriculture so difficult, there dwelt an ancient race characterized by the qualities which we have defined as most essential to a high civilization. The Mayas of Yucatan and Guatemala, alone among the aborigines of America, carried to high perfection the arts of sculpture and architecture. The Incas of Peru, to be sure, made striking buildings, but they had no idea how to adorn their simple structures with columns, rosettes, arches, gargoyles, pediments, and many other architectural devices which were universal among the Mayas. These clever people were also adepts in astronomy, for they framed the most exact calendar ever known except our own. Theirs was better than that which eastern Europe used up to the time of the Great War. Most remarkable of all, the Mayas developed the art of writing and carried it to a pitch higher than that reached by the Chinese, for they apparently began to use signs to denote sounds instead of having a sign for each individual word. Their temples are great structures which sometimes rise three stories in height and have a length of three or four hundred feet. A single city often contained a score of noble buildings and extended over many square miles of territory. The Mayas need not shrink from comparison with any people who had no 
greater opportunities. They were terribly hampered in many ways. They were not blessed with progressive neighbors to spur them on and teach them new ways. They had no beasts of burden. They could not plough the fields, nor transport loads except by their own labor. Every one of the great stones which form their temples and palaces must have been brought by human effort, a task which none but a most energetic race would undertake. Another disadvantage was the absence of metal tools. The Mayas perhaps had a little copper, but not a trace has been found of any metal tool that would be of service in carving their intricate façades and delicately wrought statues. Flint or obsidian was all that they had, and yet with such poor tools they created works of art which command sincere admiration. To do all this with such small opportunities was surely one of the greatest feats ever achieved by any race.

The most surprising thing about the Mayas is that they developed their high civilization in what are now the hot, damp, malarial lowlands where agriculture is practically impossible. A hundred miles away on the coasts of Yucatan or in the Guatemalan highlands far more favorable conditions now prevail. There agriculture is comparatively easy, the climate, while not bracing, is at least good for the torrid zone, and malarial fevers are rare. Today the cities are all in these more favorable regions; the energetic part of the population is there, and the interior lowlands are hated and shunned by all except a degraded handful. In the past the more favorable localities were occupied by people close akin to the Mayas, yet civilization never rose to any great height. Ruins are found there, but they are as far behind those of the lowlands as the cities of Yucatan are today behind those of the United States.

In explanation of these peculiar conditions only three possibilities suggest themselves. First, we may suppose that the Mayas were the most remarkable people who ever lived. They 
were able to carry on agriculture under conditions with which no modern people, not even those of European race, have ever succeeded in coping. They chose the worst place they could find, almost the worst in any part of America, even though far better places lay close at hand and were occupied by an allied people relatively few in numbers and backward in civilization. They were able to preserve their energy for a thousand years or more under the most debilitating climatic conditions; and, lastly, they were immune to the many fevers which today weaken the dwellers in their old habitat. To suppose that they were so extraordinary seems unreasonable. It is possible, but in the highest degree improbable. The second possibility is that in the time of the Mayas tropical diseases were less harmful than at present. We have no shred of evidence one way or the other. Such a thing is possible, but in view of the fact that there are several kinds of malaria, not to mention other diseases, any one of which greatly weakens a race, there is little chance that the Mayas were free from disease unless something else was also different. Even if diseases were not so prevalent as now, this does not explain the other apparent anomalies of the Maya situation. The only thing that seems to explain them is the third possibility, namely, a climatic change such that the dry conditions which prevail a little farther north prevailed in the Maya region when these people attained eminence. Such a shifting of zones would increase the length of the dry season which now comes in February and March. This would diminish the amount of vegetation and cause scrub to take the place of dense forest. Under such conditions agriculture would become comparatively easy. Fevers would also greatly diminish, for in the drier parts of Yucatan they are today relatively mild, and the lowland plain would be the natural site of the chief development of civilization just as is the case in other countries.

When the dates of Maya history are compared with the curve 
of tree growth in California, they seem to agree with the hypothesis of a shifting of climatic zones. The early chronology is so doubtful that we may pass it by. The seventh century, however, is known to hảve been a time when Maya civilization sank to a very low ebb, for scarcely a building dates from that time, and the traditions become most vague. This would be what we should expect, for when the California trees grew slowly, the desert zone would lie far to the north. At the same time the equatorial zone of rains would expand northward over Guatemala and Yucatan; the rainfall would be abundant and the dry season short; the forests would become rank, agriculture would be difficult; disease would be rife; and the vitality of the Mayas would be sapped. From about 900 A.D. to 1100 A.D., on the other hand, the California trees grew rapidly. At such a time the desert belt would be pushed south, and favorable conditions would prevail in the home of the Mayas. At that time occurred the last great revival of architecture and the construction of the great buildings whose ruins now adorn Yucatan. Whatever the cause, there is no doubt that there was a marked outburst of energy. The later history of the Mayas has no great abundance of architectural monuments to serve as landmarks, and hence cannot be correlated with the fluctuations of the California curve. Yet, so far as the indications enable us to judge, the two sets of phenomena are in harmony.

In addition to the Maya ruins, the conditions of Palestine and the growth of the California trees furnish independent evidence that the zone of cyclonic storms has at certain periods suffered a shift equatorward. In Palestine, the rainy zone apparently once extended at least fifty miles south of its present limit, in spite of the fact that the mountains there die out and thus render the conditions doubly unfavorable to rainfall. Today Hebron is the last large town and Beersheba the last village. In the old days, Aujeh, far to the south, was com- 
parable to Hebron, and other ruins indicate that settlements were located still farther southward. The California trees indicate a shifting of zones, because they grow most rapidly during years when storms continue late into the spring. At such times the winter zone of storms is pushed equatorward and continues to give moisture late in the spring.

T'hus far I have spoken as if the shifting of zones were a comparatively simple matter. Recent studies, however, seem to show that it is complex. In a paper entitled, "The Solar Hypothesis of Climatic Changes," I have discussed the matter fully. Here it is possible only to summarize the results. In reading what follows it must be remembered that the truth or falsity of this attempted explanation of the cause of changes of climate has no bearing on the verity of preceding conclusions. It may prove entirely wrong, but this will not alter any of the evidence which leads to a belief in a pulsatory shifting of zones. Let us now consider certain well-established principles, together with some newly discovered facts which seem to necessitate a revision of old ideas as to the cause of climatic variations. It is a universal scientific principle that the present is the key to the past, the near to the far. The sun is unmistakably the cause of the vast majority of climatic phenomena. Hence, men have long wondered whether its changes, as manifested in sunspots, may not be responsible not only for the differences between one year and another in temperature, rainfall, storminess, and the like, but also for the greater changes of the past. The matter has been carefully studied, but there have seemed to be so many contradictions that until recently the general opinion has been that a direct relationship has not been established. Now, however, an important change of opinion seems to be in progress. The main facts appear to be these: When sunspots are numerous the sun sends out more heat than at other times. Yet, strange as it may seem, the earth's surface is unusually cool at such times. This is most 
marked at the equator and diminishes toward the poles. The total difference of temperature between times of many and few spots is less than a degree Fahrenheit, but from the point of view of the climatologist this is highly significant. The next important fact is that, as Arctowski has shown, all parts of the world are characterized by little changes of temperature which occur with such uniformity that they must be due to some outside cause which influences the whole world at the same time. Only the sun can do this. Even in these changes, however, contradictions would seem to be the rule if it had not been discovered that waves of heat are propagated over the earth's surface from places which happen to have been especially exposed to the heating power of the sun. These waves account for many apparent contradictions whereby one place grows warm and another cool without apparent regard to what is happening in the sun. Still another important fact is the discovery by Poey, Kullmer, and others that during the part of the 11-year solar cycle when sunspots are numerous, cyclonic ${ }_{1}$ storms, including both tropical hurricanes and the ordinary storms of temperate latitudes, are more frequent than when spots are few. This seems to explain why the earth's surface becomes cool when the sun sends out more heat. Warm air rises in the center of every storm. If storms are more numerous, a greater amount of warm air is carried aloft. Thus, the upper layers of the atmosphere may be unusually warm when the sun radiates most heat, but the lower layers are cooled.

The last important fact to claim our attention in this connection is the discovery of Bigelow, Hellman, and especially Kullmer, that the location of storms shifts in harmony with variations in the activity of the sun. Both in Europe and America the same general law applies. When sunspots are numerous, storms diminish in numbers along a central belt, while they become more frequent both to the north and south. This is illustrated in Figures 35 and 36. The heavily shaded 


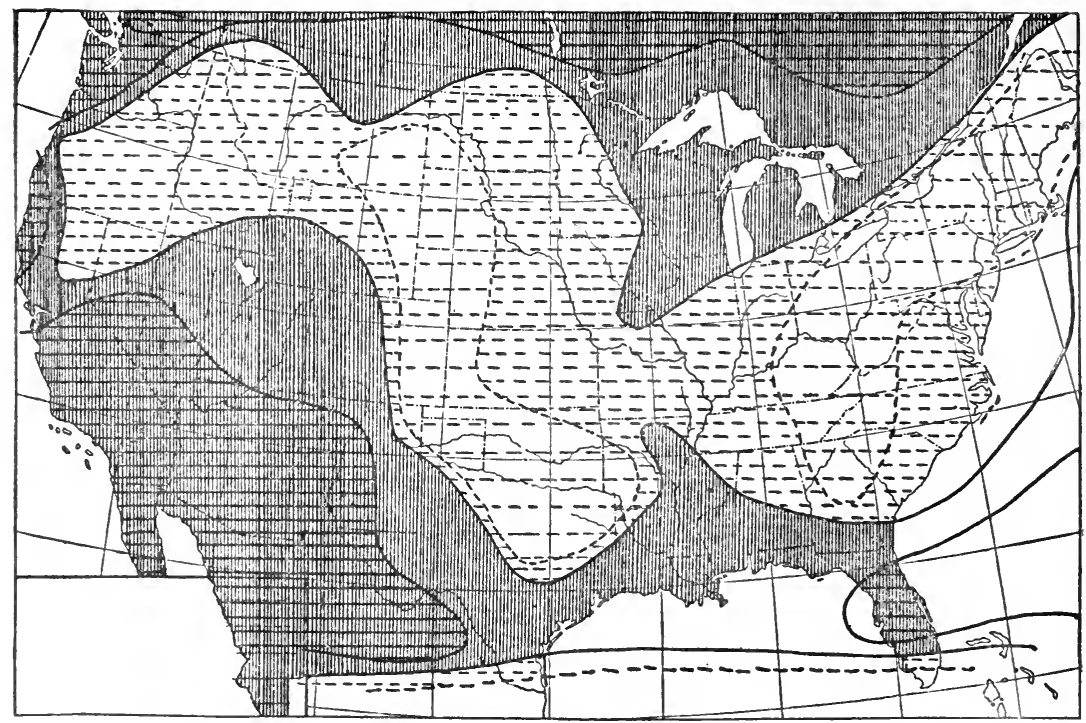

Figure 35. Comparative Storminess of the United States at Times of Maximum and Minimum Sunspots

Heaviest Shading Indicates More Than $24 \%$ Excess of Storminess at Times of Sunspot Maximum. Remainder of Heavy Shading Indicates Less Than $24 \%$ Excess at Maximum.

Light Shading Indicates Less Storminess at Times of Many Spots Than at Times of Few. In the Most Lightly Shaded Areas the Deficiency is More Than $12 \%$.

The Diagram is Based on the Reports of the United States Weather Bureau Since 1876.

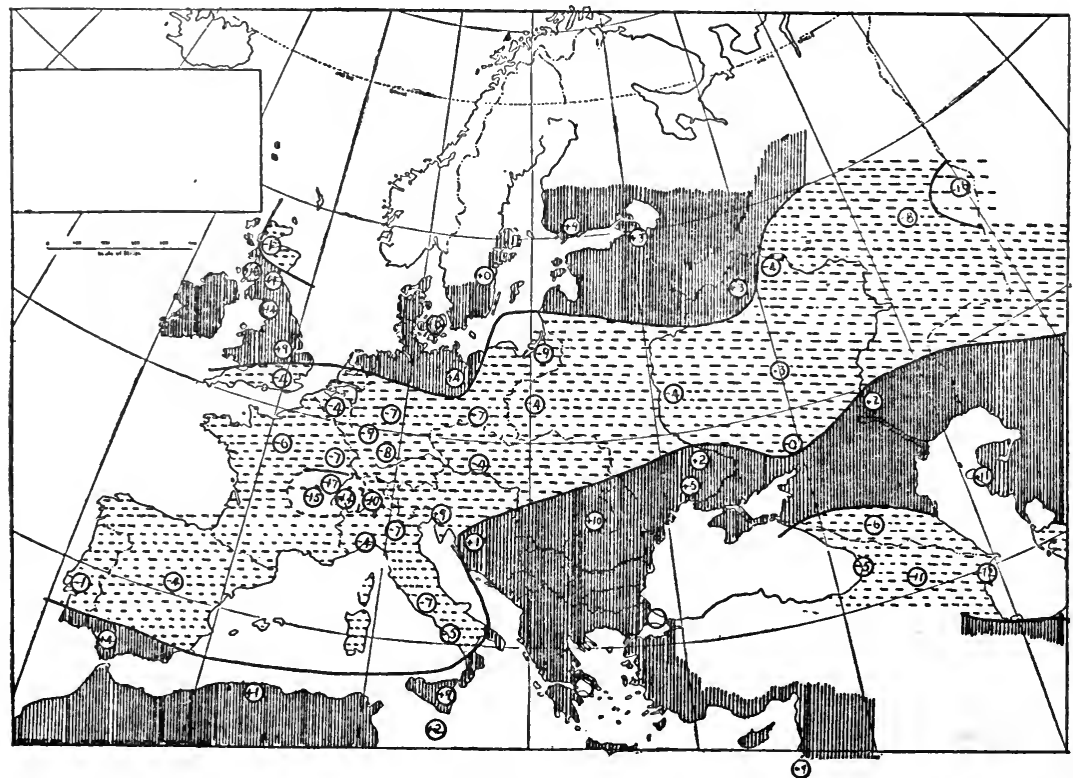

Figure 36. Comparative Rainfall of Europe at Times of Maximum and Minimum Sunspots

Heavy Shading Indicates More Rain at Times of Many Sunspots Than at Times of Few; Light Shading the Reverse. Numerals Indicate Percentages of Excess or Deficiency in Terms of Normal Rainfall The Diagram is Based Chiefly on Hellman's Data, 1850-1900, and on Russian Meteorological Reports 
areas are places where storms are more numerous at times of many sunspots than at times of few, while the lightly shaded portions suffer a diminution of storminess with an increase of sunspots. These diagrams, it must be remembered, are not based on inferences, but represent what has actually occurred during the past forty or fifty years since metcorological records have been available. The changes which they represent, together with those of temperature from one part of the sunspot cycle to another, seem to account for the climatic differences which everyone observes from one year to another. In other words, recent investigations by a large number of persons seem to show that the climatic variations now in progress within the range of ordinary observation are intimately connected with changes in the activity of the sun's surface.

Let us apply this conclusion to our problem of the climate of the past. The first and most important fact is that the changes of the 11-year cycle seem to be of the same nature as those during the larger cycles, both in historical times and in the geological past. To go back to the glacial period, the northerly areas of increased storminess at times of many sunspots correspond with the places where the main ice-sheets were formed. The areas of diminished storminess coincide with the places where the yellow eolian deposits known as loess were deposited during the glacial period. As loess is formed today only in deserts, this indicates that great dryness must once have prevailed in the places where today a moderate degree of dryness characterizes the years of many sunspots. In the southwest of the United States the black area of great increase of storminess at times of many spots is the place where scores of old lake strands indicate that the rainfall was once so abundant that dry basins were filled with water. On the other map the same is true of the heavily shaded areas of North Africa and Syria, where the Dead Sea is one of the best examples of a body of water whose level has fallen greatly since the glacial 
period. Turning back to Penck's hypothesis of a shifting of climatic zones we see that the maps show such a shifting. It is double, however, for the storms shift both poleward and equatorward at the same time, leaving an intermediate dry strip.

Coming down to historic times we see that Figures 35 and 36 agree precisely with the inferences drawn from archæology and other sciences. In the southwestern part of the United States abundant ruins in places where it now seems impossible for people to get a living are located in exactly the area where storms increase at times of many sunspots. In Greece, and especially in the parts of Africa and Asia included in Figure 36, evidences of desiccation during historic times are located in the places where rainfall increases at times of many spots. From whatever point of view one approaches the matter, the present small climatic variations of the 11-year solar cycle seem to be the counterparts of the far larger pulsations of the remote past.

This conclusion clearly leads to the hypothesis that the changes of the past were due to a greater activity of the sun at that time than at present. Of course we have no way of subjecting the matter to the test of exact measurements, for the spots of the sun have been observed with accuracy only since about 1749. All that we can say is this: Solar activity varies not only in small cycles of 11 years and less, but also in larger cycles. This may readily be seen in Figure 3\%. There the

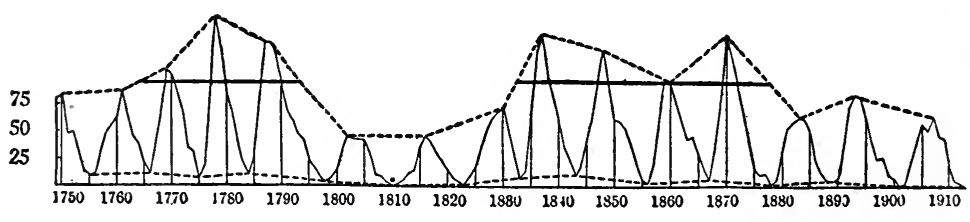

Figure 37. Major and Minor Sunspot Cycles 
zigzag solid line represents the sunspot numbers. Dotted lines have been drawn to connect the maxima and minima respectively. They show unmistakably that the sun's spottedness varies in cycles having a length of a century more or less. In view of this it seems highly probable that there are also solar cycles of still greater length and intensity, and that these are related to the climatic pulsations which appear to have prevailed both in geological and historical times. This hypothesis is so new that there has not yet been time for it to be fully discussed and tested by large numbers of workers. Therefore, the reader must be cautious in accepting it. Its chief claim to consideration lies in the fact that it makes no assumption whatever except that what happens now also happened in the past, but upon a larger scale. If the conditions which now prevail at times of many sunspots were sufficiently magnified, the earth's climate would be like that which seems to have prevailed at the time of Christ and earlier. A stormy belt would cover the southwestern United States and the Gulf of Mexico, and the same would be true in the Mediterranean region. Today the storms which prevail from Malta to Syria have been shown by the Indian Meteorological Service to continue eastward to northern India. Therefore, if the storminess of the Mediterranean region were once greater, the same conditions must have prevailed in Mesopotamia, Persia, and the IndoGangetic plain. In like manner, the storminess of Japan would apparently be shifted southward at times of many sunspots and the storm belt in its new position would probably expand westward into China as if to join the stormy belt of North India. This has not yct been tested, but a similar phenomenon occurs in North America when the sun is active. Here we must leave the matter. The lines of study briefly outlined in this chapter have been pursued quite independently of thase discussed in the rest of this book. Yet both lead in the same direction. The 
investigation of the relation of work and weather shows that cyclonic storms are of unexpected importance. The investigation of the climate of the past gives rise to the idea that important changes in the location of the most stormy areas have $\sqrt{\text { taken place within historic times. }}$ 


\section{CHAPTER XII}

\section{The Shifting Centers of Civilization}

The final stage of our investigation is now before us. We have compared the present distribution of civilization and of climatic energy, and have seen their remarkable similarity. We have examined the climate of the past, and have found that, although the matter is not yet settled, a pulsatory shifting of zones appears to have taken place. Let us now examine the shiftings of civilization, and determine how far the distribution of ancient civilization was in harmony with the distribution of climatic energy at the same time.

Areas of high civilization are primarily centers from which influences radiate outward. Chief among them today stands western and central Europe. Look at the portion of Europe shaded black in Figures 30 and 31. In Figure 30, the map of energy, it includes Britain, France, Germany, Austria, the Baltic portion of Russia, northern Italy as far as Rome, Switzerland, the Netherlands, Denmark, the southern parts of Norway and Sweden, much of Servia, and a fringe of Roumania. As I write this list at the end of October, 1914, it is almost startling to see how the places of highest energy are the ones engaged in war. In Figure 31, Roumania, Servia, Russia, and all except the German parts of Austria-Hungary are excluded from the very highest grade of civilization, but they closely approach it.

The black area of the map of energy, Figure 30, embraces about $1,100,000$ square miles, or two per cent of the total land surface of the earth. Its population is about $260,000,000$, or 
17 per cent of the world's total. Consider what would have happened if all except this small two per cent of the lands had ceased to exist seventeen or eighteen centuries ago. Civilization would probably have differed only slightly from what it is today, although history would have been very different. Consider how few important ideas have come from any other region since a century or two after Christ. If the rest of Europe had ceased to exist, Byzantine art, the works of some of the early Christian Fathers, Moorish architecture and irrigation, and the explorations, conquests, and colonization of the Spaniares would be lacking. Yet this would not seriously change the conditions under which we now live. The European countries within the area of very high civilization have themselves evolved almost every idea which any other country has developed. The chief exception is in the domain of art and architecture, but these things do not greatly influence the ordinary life of the people. Spain figures largely in the history of America, but it was an Italian who discovered the western hemisphere. If there had been no Spaniards, the other European countries would have been fully competent to explore the New World.

Suppose that not only the more backward European countries, but all the rest of the world except the very high European area had been blotted out in 200 A.D. The influence of Greece and Rome would have persisted in Italy. The Roman Church, the Renaissance, and the Reformation would all have played their part. The absence of new lands for discovery in the Middle Ages would doubtless have retarded the development of certain ideas. Otherwise the status of civilization would have been changed only a little. The United States is the only non-European country which has succeeded in touching the daily life of the world as a whole. American inventions have gone everywhere. The denizen of Turkestan who discusses news received by telegraph and whose wife makes his clothes with an American sewing machine is being genuinely 
touched by the New World. Yet America must not boast too loudly, for without her aid, Britain, France, Germany, and Italy would have made most of the world's great inventions. To an even greater degree they would have been able to develop the arts and sciences.

The energetic area of western and central Europe has been the great center of civilization for a thousand years. From it have gone forth more new ideas than from all the rest of the world combined. Its manufactures have flooded all parts of the earth. Politically it dominates about 60 per cent of the earth's surface. Socially its domination is still greater. The United States has long been chagrined because South America has looked to Europe not only commercially but for her inspiration in literature, art, education, and almost every other phase of activity. Politically the United States helped greatly in inspiring the South American republics, and was at the front in stirring Japan to the new life of the last half-century. Yet those countries have turned their faces Europeward, because that is where ideas have been most numerous and have been most fully embodied in the concrete form of institutions, inventions, or scientific principles.

Wherever one turns, he feels the tentacles of the great European center of civilization reaching out and vivifying the life of the whole world. To tell why this is so would require a volume. The position of western Europe, the strong racial inheritance of its people, their legacy from the civilizations of the past, their inspiring religion, their political freedom, and their many powerful institutions, all play an essential partWith these, however, and as one of the conditions which make them possible, stands the fact that western and central Europe is the only large region which for many centuries has had these $h$ advantages and at the same time has enjoyed a highly stimulating climate. 
The American high area differs somewhat in shape on the maps of civilization and climate, but not to any essential degree. In general, it occupies the portion of the United States lying north of about latitude $38^{\circ}$ and east of the Rocky Mountains, together with the adjacent strip of southern Canada. Its area, taking the average of the black portions of the two maps, is approximately the same as that of the similar European region, that is, about $1,100,000$ square miles. The population, however, is only 60 or 70 million. Here, then, we have another two per cent of the earth's land surface, containing between four and five per cent of the earth's total population. Consider how disproportionately great an influence it exercises. To be sure, it falls far behind Europe, but that is partly be= cause it is newer and less densely populated. Yet it differs from Europe only in the degree, not the kind of influence. We have already referred to some of its inventions. All the world recognizes that the telephone and telegraph and many other forms of applying electrical energy are primarily American. In architecture we have evolved such wholly new types as the sky scraper. In art and literature we follow far in the wake of Europe. Yet we have done some things which are widely known in other countries, and which are steadily molding the world's opinion. The same is true in science, for the day is past when Europeans can ignore the work done on the western side of the Atlantic. In the future the disparity between Europe and America along this line bids fair to decrease rapidly, for great institutions devoted to pure science are growing on a scale unknown in other lands.

This is in part the result of another line of effort in which Americans have achieved unusual success. By this I mean what is sometimes called "big business," the amalgamation of many minor industries or branches of an industry into one huge whole. It is illustrated in such organizations as our great railroads, and the United States Steel and Standard Oil Companies. 
These represent in part the effect of unustrat opportunities, but they also indicate a great expenditure of energy in planning and directing such widely ramifying activities. Lastly, and perhaps most important of all, the United States has touched the world upon the political and social side. In spite of political sins, which are many, this country has stood for freedom and justice. Its example has inspired other nations, including parts of western Europe, and has given them a stronger desire for equality of opportunity and for the breaking down of unfair discriminations between man and man. In more backward places a similar influence is felt. Good judges say that in Turkey, for example, one of the most potent causes of the revolution of 1908 and the establishment of representative government was the teaching of American missionaries. The same is true in China, except that there the Americans have been associated with missionaries of many other nations, while in Turkey they have been almost alone. In many other ways the ideas of this small area radiate in all directions. In that lies the essential point. Because this four or five per cent of the world's population are endowed with unusual energy, they are rapidly obtaining an influence wholly disproportionate to their numbers.

The third important region of high civilization and energy is Japan. Although the area is only about one tenth that of the corresponding portion of Europe and America, the population is over $50,000,000$. In proportion to population, its influence upon the world is less than that of the European countries and the United States, which perhaps corresponds with an apparently lower degree of climatic energy. Yet ${ }^{\circ}$ we all recognize that Japan is a factor to be reckoned with. We admire its art and the skill and certainty with which the country has made use of our western civilization. We see students flocking thither from China. In India the news of the progress of Japan causes a stirring of dead leaves as by an autumn 
wind. As Japan has done, so India would do. In India, however, the agitators only talk and commit violence, whereas in Japan they go to work quietly without much talk or violence and make themselves so efficient that they do not need the help of Europeans. When Japan sees an opportunity, such as was afforded by the war in 1914, she takes it, and thus advances another step in her rôle as the most capable nation in Asia. Like Europe and America she makes mistakes sometimes, but they are the mistakes of strength more than of weakness.

Next to Japan among our areas of high civilization comes New Zealand, together with the adjacent corner of Australia. Here we have chiefly a reflection of British civilization. Most of the five or six million people are grouped in an area somewhat more than twice the size of Japan. The question is not whether they show evidences of a high civilization, which they certainly do, but whether they have added to the endowment of ideas and institutions with which they came from England. They have clearly done so, for when we think of Australia there come to mind such things as the Australian ballot whereby a man is enabled to vote freely without undue influence from bystanders. We think also of progressive labor legislation, and of a pioneer attempt at old age pensions, especially in New Zealand. We are made conscious that these people are not mere followers, but are blessed with ideas which they themselves originate, and which spread out from them to other parts of the world.

The last area which rises to the very high grade on the map of civilization is California and the coast farther north. The population is still relatively small, and the majority grew up in other regions. Hence, it is too soon to judge of the ultimate status of this area. It is so bound up with the rest of the United States and Canada that its particular contribution to civilization cannot be clearly differentiated. Yet, through their universities and their readiness to attempt great things, 
the people of the Pacific coast impress the world as unusually <capable and energetic. All together these five regions comprise less than one twentieth of the lands. Though they are densely populated because of the skill of their people in agriculture and manufacture, they contain only about one fourth of the world's population. In influence, however, they many times outweigh the remaining three fourths. If they decide on anything the rest of the world must submit. They never care to imitate the more backward nations, whereas such nations show a growing desire to imitate Europe, the United States, or Japan. The reason seems to be that the favored one twentieth of the land is inhabited by people of great energy ; and this energy appears to be due, in part at least, to the $\checkmark$ frequency of cyclonic storms with their stimulating changes of weather from day to day.

This leads to the question whether similar conditions prevailed in the past. Throughout the course of history there have $r$ been centers of civilization like those which exist today. One lof the most important was the plain of Mesopotamia. Here, in the earliest days, the people of Sumer and Accad invented hieroglyphs, founded great cities, built mighty irrigation works, drained the marshes, and laid the foundations of a complex system of law and religion. They clearly possessed the power of originating ideas and of putting them into effect in a way that is now characteristic of the modern centers of civilization. Where they originally came from we do not know, but apparently they were not Semitic. In course of time, they were overwhelmed by Semites who presumably came in from the desert. Then there happened one of the most characteristic events in the history of centers of civilization. The Semites dropped their old culture and adopted that of the people whom they had conquered. They began also to be inventive like their predecessors, and thus developed cuneiform writing out of the hieroglyphics of the Sumerians. In later 
days, other Semitic invasions took place. In each case the invaders had done no great things in their original homes so far as we know, but when they came to Babylonia they blossomed into people of inventive minds full of new ideas which caused the arts to rise to higher and higher levels. Then the Semites were conquered by a non-Semitic race, the Scythians, who were also called Medes, and they in turn were stirred to great achievements. They were conquered by still another people, the Persians under Cyrus, and once more the old process of stimulation was repeated.

One of the most significant things in Mesopotamian history is the way in which each invading race seems suddenly to have risen in civilization as soon as it reached the new country. This raises the question whether the invaders were of special ability, or were stimulated by the conditions of the lands to which they came. If they were thus stimulated, how much of the stimulus was due to contact with a higher civilization, how much to more abundant opportunities afforded by the new environment, and how much to a direct physical invigoration? I shall not try to answer these questions. That some of the invading races achieved great things because they possessed innate ability seems certain. That their minds were rendered more alert by contact with the achievements of the races which they conquered is likewise beyond doubt. That the wealth and agricultural possibilities of Mesopotamia and the abundance of labor stimulated the invaders to construct palaces and temples, build irrigation works, gather stores of treasure, carve huge monuments, spend money in supporting libraries and students, and carry on other great enterprises also seems certain. These principles are so firmly established that there is no need to discuss them. The question before us is simply whether there may also have been a climatic stimulus comparable to that which now seems so important according to our maps of civilization and energy. 
I do not purpose to discuss the empires of antiquity. I merely wish to point out some of the features of their location and history which pertain to our main hypothesis. While Babylonia was flourishing, Egypt in the same latitude was also developing a great civilization. The two were rivals. Which rose higher it would be hard to say. They moved along parallel lines, and at last both fell during the same general period, although Egypt retained a moderate importance for some centuries after Mesopotamia had lapsed into insignificance. Far to the south the Sabæans in southwestern Arabia also developed a fairly high civilization, but they formed in no sense a great center. We know little about them, but apparently they were behind Mesopotamia and Egypt in the way that modern Bulgaria is behind England. Therefore, we may pass them by for the present although they will come up again in another connection. East of Mesopotamia the high$\checkmark$ lands of Persia were the seat of a comparatively high culture, but it scarcely rivalled that of the two great countries in the river valleys. Going on still farther toward the rising sun, $\checkmark$ we find high civilization in northern India at a very early time. That region never rose to such a pitch as did the countries farther west, and it decayed somewhat earlier. Beyond India the chain of ancient empires is broken until we come to China. In Indo-China, to be sure, traces of a state of culture higher than that of today are found, but they belong to a comparatively late date, and it is doubtful whether they were indigenous. They are important, but do not apply to the period now under discussion. China, however, stands in the same class with Egypt and Mesopotamia. It reached a high state of development about as long ago as they did. Here, too, the art of writing developed, inventions of many kinds were made, strong governments were organized, other powerful institutions were evolved, and in general there was intense mental activity. 
At this point the reader is advised to consult a map of Asia and Europe. Notice how the great countries of the past lie along an arc. They begin on the east with China, whose main center was and is the Yangtse basin. The civilization which flourished there possessed qualities like those of modern Europe and America. The Chinese were an aggressive, active people able to fight or to evolve a new religious system as the case " might be. The sword was in their hands not merely because those were ancient days, but because the people or their rulers wanted to make conquests, or because they were quick to resent infringements of their rights. They were not like their modern successors who see themselves defrauded because they have not the power to cope with their despoilers. Follow the map westward along a band eight or ten degrees wide with the thirtieth parallel a little south of its center. At first we find ourselves among lofty mountains which merge into the great Tibetan plateau. Here we should not expect any great development because of the unfavorable topography. At length, however, our band descends to the plain of northern India. On the flank of the Himalayas lived Gautama, the great thinker who founded Buddhism. Out on the plains around Delhi and Agra and in surrounding regions was the home of the early Aryans, who developed the Sanscrit language, wrote the Vedas, and made a real contribution to human progress. Here, just as in China, a broad expanse of arable land was favorable to the development of a great people. Next our band strikes the high mountain rim of Baluchistan and Afghanistan, and then passes over the plateaus of those countries, high and rugged in the north, lower and intensely desert in the south. In these regions the ancient civilization was higher than that of today, but not until we reach the western side of the plateau do we come upon the really advanced country of ancient Persia.

As our band leaves the Persian highland, let us change its 
direction a trifle so that its central line will point toward the center of the Mediterranean Sea. First it lies over Mesopotamia. There in the highly fruitful plain we find the two great empires of Babylonia and Assyria. They were like their modern successors in the Europe of our own day. When they were weak they were invaded by the more backward people from the mountains on the north and east or from the desert on the south and west. When they were strong they waxed ambitious; they strove to extend their borders; they desired to rule the world; and they were jealous of rival nations. Thus, at their strongest, like the great European nations which are locked in a death struggle as these words are written, they fought tooth and nail for supremacy. The fighting in itself is a proof of superabundant energy. A weak people may fight in self-defense, or to gain new lands wher sorely pinched with want at home, but only a people who have a surplus of both strength and wealth can stand the strain of great wars whose purpose is primarily national aggrandizement.

On the flanks of our band of culture, as we call it, lay the Hittites on the borders of Mesopotamia and Anatolia. Beyond the Syrian desert the Phœnicians, Syrians, and Jews lived in the center of the band. Their degree of culture was equal to that of the Mesopotamians, but displayed itself in different ways, partly because of the accidents of mountain chains and seas, and partly because of peculiar circumstances of their racial character or history. Next comes Egypt, still within the belt. Here still another fertile plain gave opportunity for the accumulation of great wealth and for the leisure which is essential to a part of the population if new ideas are to be developed. They fought the same kind of wars as did their neighbors on the east. When they were most powerful, their strength and energy were such that the mere conquest of their immediate surroundings did not satisfy them. Taking Palestine, they penetrated Syria and even advanced to the 
Euphrates to fight with Assyria, their great rival. And the Assyrians in turn came down through Palestine to wrest the sovereignty from Egypt.

Now we pass on, curving our band a little more, so that its center shall pass along the main axis of the Mediterranean Sea. Rhodes, the Egean Sea, Greece, Italy, and Carthage fall within its limits. Here, too, we see the same phenomena of the rise and fall of great nations. The rise did not begin quite so early in the west as in the east, and the fall did not come so soon. In Greece, as in Mesopotamia, a growth in strength brought with it a great struggle for supremacy, which did not end till Athens had subdued her rivals. The wars of Rome and Carthage were of this same kind in which great nations, jealous of the greatness of a rival, well-nigh destroy themselves.

In this rapid sketch we have mentioned each of the chief civilizations of Asia and Europe up to the time of Christ. All were in their day centers comparable to those which we have seen to exist at present. One main center lay in China, and corresponded to that of modern Japan. A second, less important and less enduring, was located in northern India. It has no modern representative, unless we hold that the vogue of an esoteric Hinduism among a few people in America and Europe is a sign of the existence of a widely pervasive influence derived from an Indian center. The third center extended widely. Its eastern limit was on the western border of Persia. It embraced Mesopotamia, Syria, Egypt, and Greece, and on its flanks included surrounding countries such as Asia Minor. Ultimately it moved westward, so that Mesopotamia and then Egypt ceased to belong to it, while Italy was included. Finally, it migrated still farther westward and also northward until now Italy is on its southeastern border, and its main area is the great European center of our own time.

In the western hemisphere only two centers of civilization $\forall$ seem to have existed in ancient times. One was in Peru. We 
shall not consider it here, partly because it will come up in another connection, and partly because it failed to rise to a great height, and never succeeded in spreading its ideas very widely. The other ancient American civilization, that of the Mavas, is much more important. It falls into the same class with those of Eurasia. Its fertility in ideas has already been discussed. Its influence spread to other lands, and may be seen in various ruins in Mexico, and in the calendars which were employed by several races in that country. It must have lasted many centuries, for we find splendid buildings whose dates are at least seven hundred years apart and possibly more. Moreover, before the first of these was constructed there must have been a long period of development during which the arts of architecture and sculpture were perfected. At that same period the Mayas must have been so far advanced that they kept most accurate records of astronomical phenomena, for otherwise they could not have determined the length of the year with the extraordinary accuracy displayed in their calendar. In all these respects the Maya center resembled those of Eurasia. It differed from most of them in not leaving a successor.

So much for the ancient distribution of civilization. Now for that of climatic energy. - Storms, as we have seen are the most variable of the climatic elements and also one of the most important in their effect on human energy. Figure 38 shows the approximate distribution of storminess in the northern hemisphere at the present time. It is constructed with the north pole in the center to show the complete storm belt encircling the north temperate zone. The lands are shaded to represent three grades of storminess. Heavy lines indicate the centers of the main storm belt and its branches. The region of maximum ystorminess lies in southern Canada north of Lake Ontario. Thence the main belt extends eastward along the St. Lawrence River to the southern edge of Newfoundland, where it is joined by a branch coming up the Atlantic coast. Then it crosses the 


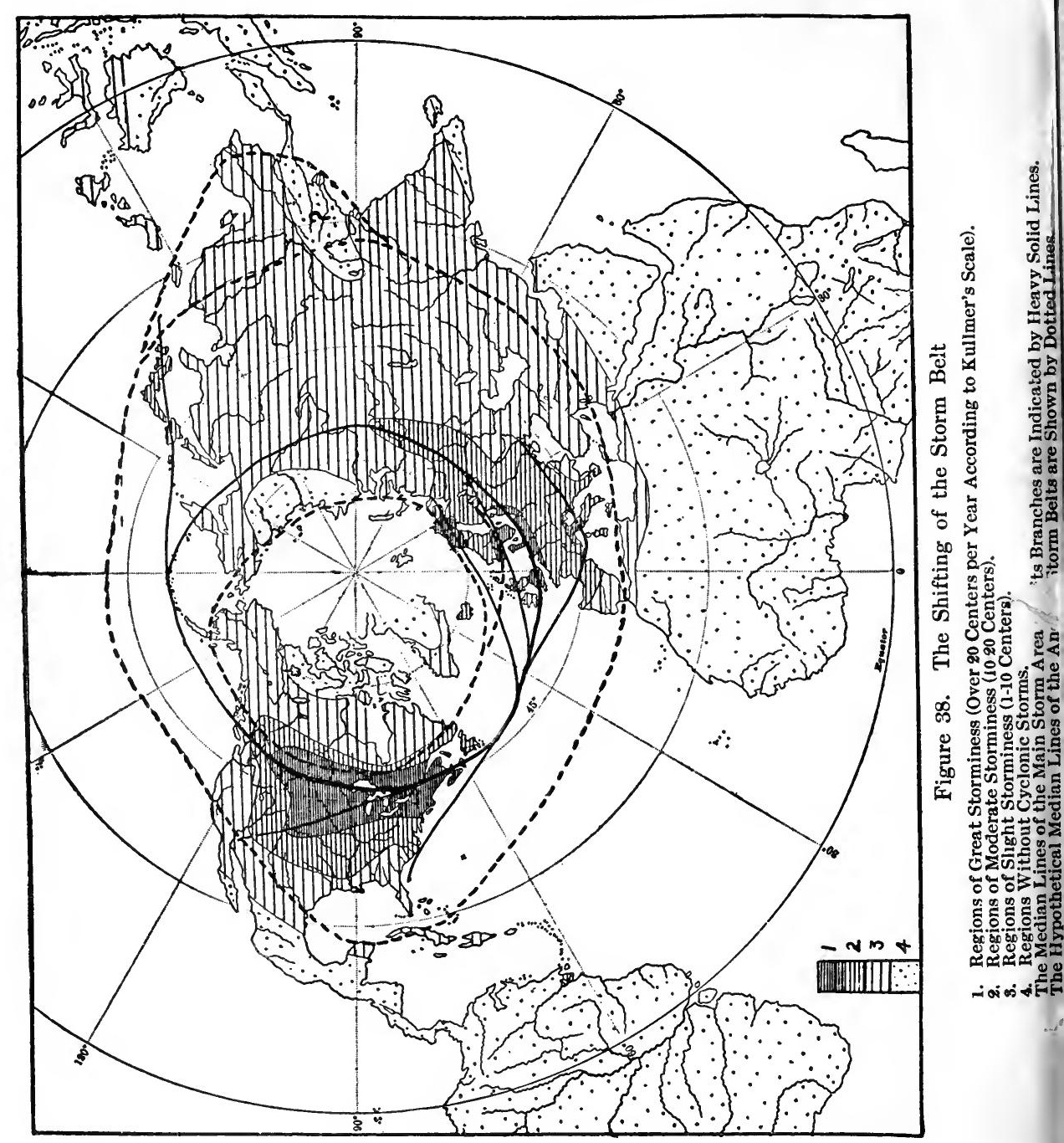


Atlantic with a slight inclination toward the north, and before reaching Ireland splits into three branches. One passes along the northern edge of Scotland, through northern Scandinavia and thence along the Arctic coast of Europe toward Asia where it almost dies out and probably merges with the second or main branch. The latter splits into two parts which unite again. One passes through Scotland and southern Scandinavia. The other goes through southern England, follows the Baltic Sea and then, after joining its companion, extends eastward in the latitude of Moscow for an indefinite distance into Siberia. It apparently passes entirely across Asia, but in an attenuated form. The third branch swings from the central Atlantic toward the Bay of Biscay. It becomes weakened over southern France, strengthens once more in the stormy Gulf of Lions, continues with great intensity in northern Italy, then loses intensity as it crosses the Bosnian highland, and finally passes through southern Russia where it rapidly dies out. Returning to the main belt of storminess we find that after it has crossed Asia it is joined in the Pacific Ocean by a branch which has been highly developed in Japan, but which weakens northward. The combined branches cross the Pacific Ocean to the American shore. Then in southern Canada and the northern United States, after crossing to the east side of the Rocky Mountains, the belt once more becomes extremely stormy. It is joined by a branch from Colorado and so completes its course back to the point of greatest intensity.

Several features of Figure 38 deserve careful attention. In the first place, wherever the storms in their eastward course approach an extensive highland they tend to be weakened or deflected, after which they may or may not recover their former intensity. This may be seen on the western side of North America where storms are relatively rare until the Rocky Mountains have been crossed. The highlands of western Europe are not great enough to destroy the storms, but the main belt 
is broken into several branches, each of which seeks to avoid the high country. The northern branch would apparently skirt the whole of Scandinavia were it not that some unknown force prevents it from going much to the north of the Arctic circle. The next avoids the Welsh and English highlands, crosses into the North Sea over the lowest part of England, receives an accession of intensity, and follows the line of least resistance along the Baltic and across the plains of Russia. Ultimately, however, the vast expanse of Eurasia, especially when it becomes a high pressure center in winter, largely overcomes the tendency of the air to move in the cyclonic fashion, and storms become rare. The third branch, which swings still farther south, is also greatly weakened when it reaches the land of southern France, but becomes very pronounced in the northern Mediterranean, only to be weakened once more by the Balkan highland.

Another important feature of Figure 38 is the peculiar detached areas of high storminess in northern Italy and Japan. In the United States two similar areas are visible on a large scale map of storms, although they are masked in Figure 38. In both cases they are clearly remnants of the southern, or subtropical belt whose existence at times of many sunspots we have already considered. When sunspots are numerous the American areas move somewhat southward, become intensified, and lengthen east and west until they coalesce forming a continuous, although very faint, belt. In Eurasia the same thing seems to happen, although the meteorological records in Asia are not yet sufficient to permit us to test it. If the American subtropical belt were intensified in the way that appears to have occurred in the past, the place of maximum storminess would probably be in the Gulf of Mexico. There the obstacles presented by the highlands of the southwestern United States and Mexico give place to the open sea and allow free play for the development of storms. Under such circumstances the center 
of the stormy area would probably be farther south than the southern belt of increased storms which appears in Figure 36. A southward shoving of the storm tracks seems to be a pronounced feature of the changes which now take place from sunspot minima to maxima, and would presumably be magnified if the changes were on a greater scale than those of the 11-year cycle. Hence, we should infer that when the Mayas made their greatest progress, their country was blessed with a stormy area like that of the Gulf of Lions which now does much to make northern Italy far more progressive than the southern part of the country. Under such conditions the climate of Yucatan would have been comparatively stimulating in spite of its warmth, for during much of the year cool waves from the north would have been frequent.

In Eurasia the same principles apply with appropriate modifications because of the topography and size of the continents. If the subtropical storm belt should be magnified in the way that seems characteristic of times of many sunspots, it would apparently reach its chief development in the places where the great civilizations of the past were located. The present Italian center would presumably move south and then expand eastward along the open Mediterranean. Leaving the highlands of Asia Minor on its northern flank, it would pass over the Syrian mountains because it could not spread eastward in any other way. Possibly it would be forced a little southward so that northern Egypt and Palestine would get its full force. In the lee of the mountains the storminess of the Syrian desert would be less than that of Syria, but by the time the storms reached Mesopotamia they would have had an opportunity to form themselves anew, and we should expect a well-developed center. In Persia, judging by what happens today, this would be weakened but not destroyed. Then the great plains of northern India would permit the storms to gather once more in a center corresponding to the faint one of today. That 
would probably be the end of any distinct belt for a thousand miles, for the eastern Himalayas and the mountains of western China interpose so tremendous a barrier that we should not expect the Japanese center, even though it moved southward and westward, to coalesce with the Italian. The plains of central China, especially the Yangtse valley, would be the place where the present Japanese center would be most highly developed, provided it suffered changes corresponding to those indicated in the corresponding American area. Japan, on the other hand, would presumably be less stormy than now, for the storm tracks would be pushed southward and oceanward.

If these things actually occurred at the times indicated by our California curve, the countries which now stand highest in civilization would then have had long, cold winters, with few storms. The stimulating qualities of the climate would have been less than now, and the possibilities of agriculture, especially in such places as Germany, would have been much diminished. In the countries like Greece where civilization was then at its highest, on the contrary, the number of storms and the duration of the stormy period would have been decidedly greater than now. The rainfall also would have been greater so that agriculture would have been favored. More important than this, however, would have been the high degree of climatic stimulus because of frequent changes of temperature. To apply the matter concretely, lower Egypt has an average temperature of about $80^{\circ}$ during July, and Mesopotamia and northern India are even hotter. Three thousand years ago the heat was probably almost equally intense at certain periods, although somewhat less extreme on an average, and by no means so uniform. All the summers were probably hotter than was the summer of 1911 in the northeastern United States. That summer, in some localities, was the most severe for a century. Yet its effect on work was no worse than that of an ordinary winter. In Mesopotamia and Egypt, summers of that kind doubtless made 
people slow and inert. They were probably not so bad as the present summers, however, for although no appreciable quantity of rain may have fallen, a large number of storms must have passed over regions not far to the north. Such storms would stir the air and bring fresh breezes. Every one knows that in hot weather a change in the wind even without rain is most refreshing. When the summer vas over, the storm belt, according to our hypothesis, would migrate southward in its normal fashion, and soon Egypt and Mesopotamia would be swept by storm after storm. During the early fall and late spring conditions would be about as they are in the homes of our Connecticut factory operatives during cool summers such as 1912 or 1913. For the remaining five or six months the average temperature would range from about $55^{\circ}$ to $65^{\circ} \mathrm{F}$., there would be a constant succession of cool waves, and the conditions would be almost ideal for great physical activity. Thus, even though the summers were distinctly bad, the total debilitating effect would be little greater than that of summer and winter combined in Connecticut. In Greece and Italy, with their more favorable mean temperature, conditions would be still better than in Egypt or Mesopotamia. In the same way favorable conditions appear to have prevailed in each of the / great countries of the past at the time when it made its most rapid progress.

The two phases of our climatic hypothesis are now before us. In point of time, though not of presentation in this book, the first step was a study of the climate of the past. Ten years of work along this line have led to the hypothesis of pulsatory changes, and finally to the idea that the changes consist primarily of a shifting of the belt of storms. After this conclusion had been reached, a wholly independent investigation of the effect of present climatic conditions upon human activity led to two conclusions, neither of which was anticipated. One was that under proper conditions a relatively high temperature is 
not particularly harmful provided it does not go to undue extremes. The other was that changes of temperature from day to day are of great importance. On the basis of these two conclusions it at once becomes evident that the stimulating effect of climates in the same latitude and having the same kind of seasonal changes may be very different. It also becomes clear that the distribution of civilization at the present time closely resembles that of climatic energy. From this the next step is naturally back to our previous conclusion that changes of climate in the past have consisted largely of variations in the location of the storm belt. If this is so, evidently the amount of climatic stimulus must have varied correspondingly. Thus we are led to the final conclusion that, not only at present, but also in the past, no nation has risen to the highest grade of civilization except in regions where the climatic stimulus is great. This statement sums up our entire hypothesis. It seems to be the inevitable result of the facts that are before us. Other explanations may indeed be offered, and modifications will certainly be necessary. Yet unless we have gone wholly astray, the surprising way in which independent lines of investigation dovetail into one another seems to indicate that a favorable climate is an essential condition of high civilization. 


\section{CHAPTER XIII}

\section{The Cimmatic Hypothesis of Civilization}

The hypothesis that a particular kind of climate is necessary to the development of a high civilization is sure to encounter many objections. Some will be directed against the idea that the present distribution of civilization agrees with that of climatic energy. Important as such objections are, I shall not consider them here, for they cannot be properly tested without further statistics. Moreover, they are much less serious than the arguments which may be presented against the idea that a stimulating climate has been an essential condition of the rise of great civilizations in the past. By far the weightiest objection to our hypothesis is the fact that students are not yet agreed as to the reality of climatic changes. Inasmuch as $\mathbf{I}$ have already considered this matter not only in this volume, but at much greater length elsewhere, further discussion does not now seem advisable. Yet the matter ought to be mentioned here at the beginning of our consideration of objections, for the fate of the climatic hypothesis of civilization depends primarily upon the decision of scientists as to the occurrence and nature of historic changes of climate.

Recognizing the limitations imposed by this objection, let us now examine certain others which will arise even if it appear that climate has actually changed. In reading what has been said about Egypt, for example, the reader has probably said to himself: "This book claims that the people there were once energetic because of frequent storms. If that is so, the rainfall must have been much more abundant than now. For the sake 
of argument we grant that at certain periods the precipitation was greater than at present, but we cannot possibly believe that it increased to the extent demanded by this hypothesis."

This objection is so important that I have made a special investigation to determine the exact relation between storminess and rainfall. The word storm, as already explained, does not primarily mean rain. To the meteorologists a storm is an area of low barometric pressure which is always accompanied by inblowing winds, and usually, but not invariably, by rain. Even if there is not a drop of rain, a storm may otherwise be fully developed and may cause strong winds which give rise to changes of temperature. The matter is well illustrated by com$\checkmark$ paring Colorado and Georgia. According to Kullmer's maps, Colorado is one of the stormy parts of the United States. It is crossed by the centers of about three times as many storms as Georgia. Yet its rainfall is only about one third as great. In other words, Georgia has nine times as much rain in proportion to its storms. The reason is simple. Colorado lies far from the ocean, and the air which rises in the centers of its areas of low pressure has already lost most of its moisture. Georgia, on the other hand, lies so near the broad Atlantic and the warm Gulf of Mexico that storms draw in great quantities of moisture. The lands around the eastern Mediterranean and in western Asia have a climate far more like that of Colorado than of Georgia. Part, to be sure, are near the Mediterranean Sea, but that furnishes only a little water compared with the great oceans.

The comparison between Georgia and Colorado shows how two diverse regions differ in relation to storms and rainfall Let us now compare times of many sunspots with those of few. In the entire United States the ratio between variations of storminess and rainfall is about two to one. That is, if the number of storms increases 20 per cent during a given series of years, the rainfall increases scarcely 10 per cent. In the 
arid southwest, however, the ratio is larger, being three to one for all available stations. These figures apply to present conditions where the variations are slight and of short duration. If larger, more permanent changes took place, the rapidity of the atmospheric circulation would be so much increased that the air would have less opportunity than at present to remain over the oceans and become saturated. Hence, the ratio between increase in storminess and in rainfall would probably be greater than at present, and might be four, or even six to one. The drier the region, the greater would probably be the ratio.

Suppose that the ratio were four to one in Syria. A change which would increase the storminess by 200 per cent would involve a change of rainfall amounting to 50 per cent. That is, the number of stimulating changes would be three times as great as now, while the rainfall would only increase by one half. Such a change would render the Phœnician coast much more stimulating than at present. It would also increase the agricultural wealth, and would cause the limits of permanent habitation to advance some miles into the desert. There the stimulating influence might be less than on the coast, because the storms might be somewhat interrupted by crossing the mountains. Nevertheless it would be important. The effect of increased storminess upon habitability, however, would be much less noticeable than upon energy or than in better watered regions. An increase of 50 per cent in a rainfall of twenty inches, such as is now enjoyed by many parts of Syria, would raise the precipitation to thirty inches, a figure which permits great prosperity. A corresponding change in Egypt would increase the rainfall of Alexandria from 8.8 inches to 13.2, that of Port Said from 3.3 to 5, and that of Cairo from 1.3 to 2 . Farther east in Mesopotamia, Bagdad would change from 9 to 13.5, while in Persia, Teheran would rise from 10 to 15 and Ispahan from 5.2 to \%.8. Deserts would still be deserts. They would be easier to cross than at present, and the number of 
inhabitants might be greater, for there would be more pasturage for camels and sheep. The springs would also be larger and more permanent than now, and some new ones would appear. Yet the predominant feature would still be great wastes of blowing sand and barren gravel; the people would have to be nomads; and those who entered the desert would frequently encounter rigors like those of today. Thus a large change in the stimulating qualities of a subarid or desert climate is pos$\Delta_{\text {sible without a change of rainfall greater than that for which }}$ there seems to be good evidence.

Let us turn now to another type of objection, historical rather than physical. "How about the high civilizations of the past in places outside the storm belt?" the objector may say. "Yucatan and Guatemala may possibly have been stormy, but surely not Peru, southern Arabia, Rhodesia, Ceylon, Java, and Indo-China. Yet these have boasted a civilization much higher than now prevails there."

The force of this objection must frankly be admitted. The ruins of Indo-China and northern Ceylon, and any other traces of high civilization located in tropical lowlands, with the exception of Yucatan and Guatemala, do not appear to have any relation to our hypothesis. They may require a modification of it. More probably they represent the triumph of other factors over the climatic factor. They apparently indicate temporary energy due to the incursion of higher cultures from more favored regions such as India or the neighboring highlands. If that is so, they possess no more significance for our climatic hypothesis than do the railroads and other innovations introduced by Europeans within the past few decades. If, on the other hand, they indicate that a highly competent race actually grew up in these regions, they must be weighed most carefully. Under such circumstances they may show that while the hypothesis is true in general, the effects of climate may be entirely. overcome by a race of unusual strength or by some other 
special circumstances. Another possibility is that the supposed subtropical storm belt may have divided in eastern India because of the barrier of great mountains, just as the main belt now divides when it approaches Europe. One branch may have passed over into China, after being much broken by the highlands, and the other may have swung southeast around the lofty Burmese mountains to the neck of the Malay Peninsula. There it may have turned northeast to rejoin the other branch in the Pacific. In crossing the plains of Cambodia, where the most remarkable ruins are located, it may have developed a distinct storm center like that of northern Italy. The conditions would resemble those inferred in Yucatan and Guatemala, although less favorable because cold waves would be checked by the great mountains. Indo-China and Central America lie in the same relative position in their respective continents, a fact which may have considerable significance. In view of the numerous possibilities, it seems wisest to leave Indo-China and its neighbors out of account for the present. They cannot be said to support our hypothesis, but neither do they militate against it.

Peru, Yemen, and Rhodesia furnish admirable examples of comparatively high civilizations which developed in tropical highlands and lasted for a considerable period without much intercourse with regions of higher culture. They lie at such an altitude that the mean temperature never departs far from the optimum. For instance, at Cuzco, where the famous Peruvian ruins are located, the monthly mean temperature according to Hann ranges from $46^{\circ}$ in July to $52^{\circ}$ in November. At Hope Fontein, near the Rhodesian ruins of Zimbabwe, the figures are $54^{\circ}$ in June and $71^{\circ}$ in November. For Yemen none are available, but judging by the altitude its temperature is probably slightly lower than that of Rhodesia. So far as this one factor

- is concerned, the conditions in Peru are almost ideal, while in the other places they are distinctly favorable. When immi- 
grants came to a region with a mean temperature so near the optimum, they would naturally be stimulated. If they happened also to have inherited more than ordinary ability, the combination of the two conditions would speedily enable them to dominate the indigenous population, and to develop many new ideas. Yet we should not expect such a civilization to endure so long or rise so high as those in more favored regions. The people would tend to exhaust themselves for they would never experience any restful changes of seasons, and would be stimulated at all times. To revert to an earlier illustration, their condition would be like that of a horse which is always driven at full speed. Such a horse might go rapidly for a while, but would wear himself out at an age when carefully driven animals were in their prime. The constant nervous excitation produced by such a climate in immigrants from a less favorable region would induce both progress and decay. The most nervous people would die out partly because they would exert themselves too strenuously, and partly because nervousness is a potent agency in reducing the birthrate. (Self-control would also be weakened, thus leading to vice and excesses of various kinds. The chewing of the coca leaf, a narcotic stimulant which is thought by many people to be one great cause of the backwardness of Peru today, would harm the high-strung, competent parts of the community more than the dull, apathetic ones. In various other ways such a climate as that of Peru would be stimulating for a while, but would lead to exhaustion sooner than would one where greater variability prevails.

We now come to perhaps the strongest objection aside from the question of the reality of climatic changes. A large part of this book has been concerned with the United States. The present status of that country is one of the main foundations which originally led to the framing of our hypothesis. Yet before the coming of the white man savagery prevailed where civilization is now highest. In the sixteenth century the cli- 
mate must have been approximately the same as today, so that no explanation can be sought along that line. The contrast between the relatively advanced position of the Incas in a climate of only moderate excellence and the low position of the Indians of the northeastern United States in one of the two most highly favored regions of the world is striking. We may attempt to explain this anomaly by saying that the Incas were endowed with a peculiarly strong heritage, while the northeastern Indians, although belonging to the same great racial stock, had suffered some historic accident which left them devoid I of capacity and unable to rise even under the most stimulating environment. Such an assumption begs the question. We have not an iota of proof that it is true. On the contrary, so far as we know, the opposite is the case. In both the United States and Peru the poor Indian has been oppressed for three centuries or more. At present few people would question that he is more competent and energetic in the northern country than in the southern. An admixture of North American Indian blood is not considered a misfortune. Americans in high stations, senators for example, boast of it. To this day, in spite of a long racial conflict, we admire the activity, self-control, and wonderful endurance of the former owners of the continent. We realize that among the more advanced tribes a high type of social and political organization prevailed. Treaties between tribes such as the Five Nations were honorably maintained. Although the Indian is often accused of treachery, he apparently kept faith with the white man as well as the white man kept it with him. In many ways a strong case can be made in favor of the idea that the Indians were people of high capacity. The matter is well summed up by an eminent English anthropologist in a letter which was quoted when we were discussing the distribution of civilization. I did not then realize that I should want to use his words again, but they are worth repeating. Quoting from my definition of civilization, he says : 
" 'The power of self-control, high standards of honesty and morality, . . . high ideals, respect for law' are eminently characteristic of many savage and barbarian peoples, notably the North American Indians, and in my opinion these latter stand very much higher than the average American citizen, but the latter lead in 'the power to lead and control other races, and capacity for disseminating ideas . . . inventiveness, highly developed systems, etc." "

All this, so far as it goes, is in harmony with our climatic hypothesis. It becomes still more so when we consider that there was a great difference between such fine tribes as the Iroquois, Sioux, and others who lived in the North, and the Seminoles of Florida, the Apaches of Arizona, and the Digger Indians of southern California. The more competent tribes lived in the regions where the climate is the most stimulating.

In spite of this we are still confronted by the stubborn fact that before the coming of the white man no great civilization had ever developed in the northern United States, while Mexico, although far inferior climatically, harbored a relatively civilized population. At first this seems to prove that our hypothesis cannot be correct. Yet more careful examination leads to a different conclusion. The distribution of civilization in pre-Columbian America merely brings out a fact which $I$ have again and again tried to emphasize: although climate is highly important, there are other factors whose weight is equally great. Even if our hypothesis be fully accepted, no less importance will thereby attach to the other great factors which condition the events of history. Because a man dies for lack of air, we do not think that air is more essential than food, drink, warmth, the circulation of the blood, the reproduction of the species, the absence of virulent germs, and many other conditions. So it is in history. Even if our climatic ideas are correct, it will still be true that the ordinary events of the historical record are due to the differing traits of races, the force of 
economic pressure, the ambition of kings, the intrigues of statesmen, the zeal of religion, the jealousy of races, the rise of men of genius, the evolution of new political or social institutions, and other similar circumstances. Yet a comprehension of the part played by the climatic factor will enable us to explain some of the many events which hitherto have puzzled us. Not all will be thus explained, for others must wait until the action of some other set of as yet unknown conditions is understood.

Where so large a number of factors work together no one of them will always be dominant. Even the strongest will sometimes be neutralized. For example, during the Russo-Japanese War the ties of a common religion and a common inheritance of European culture were powerless to make the Americans sympathize with the Russians. England and Germany are probably as closely bound together in race, religion, and culture as any two nations which do not speak the same language. Yet in 1914 a difference in economic interests and in ideals completely nullified these factors. So it is with climate. A great genius like Mohammed may cause his people to occupy a position quite different from what we should expect if climate were the only factor or even the main factor. Many other influences may Lobliterate or neutralize the effect of climate. A race of idiots would not develop a high civilization wherever they might live. Such a race as the primitive Australians might be stimulated under favorable conditions, but there is not one chance in a thousand that they could rise to the level of the French. Nor could the French have attained their present position, even though blessed with the best racial character and with the most stimulating climate, unless great men had been born among them, Christianity had prevailed, and new institutions had developed from century to century. All this is familiar. Scores of people have said it for generations. Yet it needs repetition. Each phase of a subject must be emphasized at the appropriate 
time, and the phase which has been most neglected ought temporarily to receive more attention than the others. Climate seems to be a factor whose importance in human development has not been fully recognized. Hence, it is here emphasized. Nevertheless, it is fortunate that the American Indians remind us that other factors are equally strong, and sometimes stronger.

Two factors seem to be of chief importance in explaining the low culture of the Indians of the northeastern United States. One is the absence of tools of iron, and the other the lack of beasts of burden. These, in conjunction with the type of vegetation, offer such hindrance that the Indians could probably never have developed a very high civilization, even if they had been as competent as the races of Europe. The discovery of the use of iron depends on the coincidence of three conditions whose occurrence is almost accidental. One is the birth of a man with sufficient inventive genius to devise a way of obtaining the metal from rocky ores. The second is the occurrence of ores and other necessary materials within easy reach of such a man. The third is that the genius must be so relieved from the fear of enemies, the danger of starvation, and the ravages of disease that he has both time and strength to elaborate his idea. The combination of these three fortunate circumstances never occurred in America. Although a little native copper was used, we have no assurance that the ore was ever smelted in any large amounts. It certainly never was used to any great extent. Iron was absolutely unknown. Hence, through accidental circumstances, which were no fault of their own, the original Americans were dependent upon such tools as they could fashion from flint, obsidian, and other stones, or from bones, shells, wood, and similar materials.

We are so accustomed to iron tools that we scarcely realize their immense importance. Consider their effect upon agriculture. Go into a virgin forest with its labyrinth of trees. 
Imagine the task of cutting them down with a stone hatchet. The mere physical labor is such that none but people of high energy would ever attempt it. An easier way is to girdle the trees, cutting off the bark in a circle, and then leaving them to dry until they can be burned. Even that, however, is a long process. In the moister parts of the world its difficulty is greatly increased by the fact that while the trees are becoming dry enough to burn, new vegetation is rapidly growing. In many tropical regions, as we have already seen, the clearing of the forests is scarcely feasible even today. In temperate forests the difficulties are not so great, but they are practically insurmountable from the standpoint of a savage who has never known the meaning of hard, steady work. In the hunting stage a man may follow the trail until he falls from exhaustion, but that does not give him the power to wield a stone axe day after day upon stubborn trees. Hence, if agriculture is to be practiced by primitive people, it must originate in regions where there are no forests. The vegetation must be such that the primitive savage with his hands or with a stick or stone can easily grub it up. Or else it must be so scanty that it will not interfere with his crops. Anyone who has seen the agriculture practiced by people who are just emerging from some other mode of making a living knows that the fields are sown in the spring and then generally left untended until the time of harvest. Since the people are not yet able to get their living entirely from the crops, which is always the case during the transition period, they must perforce carry on the old occupations while the crops are growing. Hence, the weeds are allowed to grow as freely as the grain. In a dry climate where the natural growth consists only of bunchy grasses or low bushy weeds which grow apart from one another and can easily be pulled up with the hands before the next sowing, this does little harm. In wetter regions, such as the forested areas, the weeds are much more difficult to eradicate. 
The reader has probably noticed that I have said nothing about grass-lands. The reason is that primitive people never attempt to cultivate them. If grass covers the entire ground and forms what we commonly call sod, crops cannot be raised in it. The dry grass may be burned off in the early spring, and seeds may be dropped in holes punched with a sharp stick, but no crop will be reaped. The roots of the grass are not killed. The new blades shoot up at once, and by the time the seeds begin to sprout are so high as to strangle them. The primitive savage who has no iron tools cannot possibly dig up the sod. Even if he has such tools, the laboriousness of the task bans it as a practical method of making a living. If anyone doubts this, let him spade up a turfy spot ten feet in diameter. Then let him calculate how many days he would have to dig in order to make a living for himself and his family by sowing grain. Let him also determine how a primitive savage who had to do this task would support himself and his children while he was digging before he could get a first crop. Finally, remember that the savage had no good spade to help him, but only a clumsy, heavy stone set in a handle, or a piece of wood rudely shaped into a flat implement.

I have emphasized the difficulties of grass-land because they apply directly to the problem of civilization among the Indians. The part of North America which is highly stimulating climatically is covered either with grass of the prairie and great plains type, or with temperate forest. It is universally recognized that a high state of civilization is impossible unless it is based on agriculture. Otherwise people must wander all the time. They cannot accumulate the appliances which are essential even to the lowest real civilization. They are not attached to the soil, and thus have no incentive to improve a particular tract. If they possess domestic animals, the case is better, for these foster the sense of ownership and various other feelings which serve as uplifting influences. In North America no 
domestic animals except the dog and the turkey were known to the aborigines. This was not the fault of the Indians. The horse and camel families were then extinct in North America. The bison was the only animal of the ox family with which the Indians came in contact. It was too large and fierce to be domesticated. The mountain sheep might possibly have been tamed, but it is very wild, its habitat is the barren mountains, and it is too small to plough sod. Even if the Indians had been familiar with the idea of taming beasts of burden, they could not have achieved any important success.

Without beasts of burden ploughing is impossible. Unless the ground is ploughed, grass-lands, as we have seen, cannot be cultivated. Therefore, civilization could not flourish in the grassy plains of North America before the coming of the white man. A few highly favored spots such as river flood plains where the grass grows in bunches and does not form turf were cultivated, but the areas of that kind were too small and scaty tered to give rise to any widespread progress. They were exposed to the ravages of Indians who had not yet learned the value of permanent abodes and individual property, two primary requisites of civilization. The people who lived upon them were swamped in the flood of surrounding savagery. Moreover, the places which they were able to cultivate were subject to floods and other disasters, so that the cultivators were often forced to rely on the chase. Then again, without iron tools or beasts of burden, a man cannot cultivate a large area because the task is so great. Therefore, the crops were likely to be insufficient to support the family throughout the year even when the harvest was good. The only recourse was the chase. In Asia people who were in such circumstances might rely on domestic animals, but not in America. Hence, it was practically impossible for the Indians of the grassy plains to get away from the savage life of the hunter.

In the forests which covered all the eastern states conditions 
were scarcely better. A man might girdle enough trees and cut enough brush to make a small field. When the wood was dry, he might burn it and obtain a crop of corn. While it was maturing he and his family would make a living by hunting and fishing. The crop would support them through the winter, but it is extremely doubtful whether they would ever cease to regard hunting as a main source of livelihood. The reason is this. The first crop on a burned piece of forest land in the eastern United States meets with little difficulty. For the second crop it is necessary to cut down and burn the weeds and bushes that have grown up during the preceding summer. Remember that the savage has no iron hoe, his seeds are planted haphazard here and there among the stumps, and he cannot tend his garden while it is growing, but must go off and hunt. When he cuts the bushes and weeds the second spring he does not root up the grass. He has no spade with which to dig it up, and no ox or donkey to draw a plough. If he takes good care of his field he soon finds that he has a meadow of tough sod on his hands. If he neglects it, he has a few acres of bushes. In either case if he would make a living from agriculture, he must go through the labor of clearing a new field. Meanwhile he still must be a nomadic hunter. He takes no great pride in his field; he does not care to improve it; he rarely builds a permanent house beside it. Why should he? Next year, or at most in two or three years, he must build another. In a few specially favored spots the conditions may be such that agriculture is not quite so difficult. In the North, where the stimulating climate is found, such spots are few and small. The chief reason for wonder is that the Indians had energy to cultivate any crops whatever. In the southern states the grass does not form so dense a sod as in the North, but even there the difficulties are great. Yet a beginning had been made, and the civilized nations, including the Cherokees and others, lived in permanent villages and practiced agriculture as their main means of 
getting a living. If they had had iron tools and oxen, the chances are that America today would be filled with highly civilized Indians instead of Anglo-Saxons and other Europeans. Thus it appears that although appropriate climatic conditions on the one hand, and an inheritance of strong mental qualities on the other, may be essential to the rise of a great civilization, these two conditions may be at their best, and yet savagery may prevail because other essentials such as iron or beasts of burden are lacking.

It would be easy to discuss other objections to the hypothesis that climate is an essential factor in civilization, but so far as now appears, no new principles would be illustrated. Doubtless I have overlooked many things, and I shall welcome suggestions, no matter whether they harmonize with our hypothesis or demand its revision. Long and careful discussion is essential, for the final decision of scientists as to the truth or falsity of our conclusions will have a deep bearing not only upon the interpretation of history, but upon man's conscious plans for his own future.

As we come to the end of this volume $I$ am well aware that to those who accept the climatic hypothesis, it may seem depressing. To the dweller in the less favored parts of the world it may appear to sound the knell to his hopes for great progress in the land that he loves. To his brother in the center of modern activity a most disquieting vision of possible retrogression is disclosed. If our reasoning is correct, man is far more limited than he has realized. He has boasted that he is the lord of creation. He has revelled in the thought that he alone among created beings can dwell in the uttermost bounds of the earth. One more of the bulwarks of this old belief is now assailed. Man can apparently live in any region where he can obtain food, but his physical and mental energy and his moral character reach their highest development only in a few strictly limited areas. The location of those areas appears to have varied greatly in 
the past; it may vary greatly in the future. In a thousand years, for all that we can tell, - so the prophet of evil will say,no highly favorable region may exist upon the globe, and the human race may be thrown back into the dull, lethargic state of our present tropical races. Even without so dire a calamity, the location of the regions of greatest climatic energy may in a few hundred years change again to Egypt, Mesopotamia, and Guatemala. The consequent rise of new powers and the decline of those now dominant may throw the world into a chaos far worse than that of the Dark Ages. Races of low mental caliber may be stimulated to most pernicious activity, while those of high capacity may not have energy to withstand their more barbarous neighbors.

Even if such extreme disasters should not occur, the prospect is depressing. Take such a favored country as the United States. In the South we find less energy, less vitality, less education, and fewer men who rise to eminence than in the North, not because southerners are in any way innately inferior to northerners, but apparently because of the adverse climate. In the Far West people seem to be stimulated to such a degree that nervous exhaustion threatens them. In the North we see still another handicap. In spite of a wonderfully stimulating climate most of the year, the people suffer sudden checks because of the extremes of temperature. These conditions favor nervousness, and worst of all they frequently stimulate harmful activities. That, perhaps, is why American children are so rude and boisterous, or why so staid a city as Boston has six times as many murders as London in proportion to the population. Our country takes immigrants of every mental caliber, and then stimulates some to noble deeds and others to commit murder, break down the respect for law, and give us city governments that shame us in the eyes of the world. All these things would apparently not happen to such an extent were our climate less bracing and did not its extremes often weaken the power of 
self-control. Other lands also have their drawbacks. Germany is much like the eastern United States, although not so extreme. France on the other hand is less stimulating. England suffers from too great dampness, and in Ireland this becomes a factor of serious import. If the best parts of the earth have such climatic disadvantages, what shall we say of Russia weighted down with benumbing cold and comparative monotony or with changes so extreme that they are harmful? What of China under a much heavier handicap of monotony; or of tropical lands burdened most heavily of all? If climatic conditions influence character as we have inferred, does not our hypothesis weaken man's moral responsibility? Will not people more than ever ascribe their failings to nature, and so excuse themselves? In the favored regions will not men became increasingly arrogant and overbearing, because they will be surer than ever that the rest of the world cannot resist them? If all these sad results are possible, is it well to know that climate so strongly influences us? We cannot change the climate, so why ascribe to it such great effects merely to destroy hope in some and moral responsibility in others?

The answer to these questions may be put in the form of a parable. Ages ago a band of naked, houseless, fireless savages started from their warm home in the torrid zone, and pushed steadily northward from the beginning of spring to the end of summer. They never guessed that they had left the land of constant warmth until in September they began to feel an uncomfortable chill at night. Day by day it grew worse. Not knowing its cause they travelled this way or that to escape. Some went southward, but only a handful finally returned to their former home. There they resumed the old life, and their descendants are untutored savages to this day. Of those who wandered in other directions all perished except one small band. Finding that they could not escape the nipping air, the members of this band used the loftiest of human faculties, the power of conscious 
invention. Some tried to find shelter by digging in the ground, some gathered branches and leaves to make huts and warm beds, and some wrapped themselves in the skins of the beasts that they had slain. Soon these savages had taken some of the greatest steps toward civilization. The naked were clothed; the houseless sheltered; the improvident learned to dry meat and store it with nuts for the winter, and at last the art of making fire was discovered as a means of keeping warm. Thus they subsisted where at first they thought that they were doomed. And in the process of adjusting themselves to a hard environment they advanced by enormous strides, leaving the tropical part of mankind far in the rear.

Today mankind resembles these savages in certain respects. We know that we are limited by climate. As the savages faced the winter, so we are face to face with the fact that the human race has tried to conquer the arctic zone, the deserts, and the torrid zone, and has met with only the most limited success. Even in the temperate zone he has made a partial failure, for he is still hampered in hundreds of ways. Hitherto we have attributed our failure to economic conditions, to isolation and remoteness, to racial incapacity, or to specific diseases. Now we see that it is probably due in part to lack of energy or to other unfavorable effects produced directly upon the human system by climate. This is no reason for despair. We ought rather to rejoice because, perhaps, we may correct some of the evils which hitherto have baffled us.

Again and again in our discussion of factories and other matters we have come upon ways in which a change in our methods may do much to overcome the harmful effects of climate. I do not propose to enumerate them, for the specific application of our results may well be deferred until we know whether our main hypothesis is likely to stand. Yet one or two general lines of progress may properly be pointed out. Take the harmful winters of the northern United States. It is highly 
probable that the loss of energy which occurs at that time may be largely avoided, or at least greatly diminished. Much of it arises from the fact that after the wonderfully stimulating autumn weather, when we have been living under almost ideal conditions of mean temperature, of humidity, and of variability from day to day, we suddenly begin to heat our houses. We create an indoor climate of great uniformity, of unduly high mean temperature, and of the most extreme aridity. All these conditions are harmful. If our houses were kept at lower temperatures, if the temperature were varied from day to day, and if the humidity were kept at the optimum, we should increase our efficiency greatly. We should be comfortable, also, for with proper humidity, and with changes from day to day, we should not feel the need of the high temperatures which we now require because the extreme dryness forces the body to give up much more heat than would be demanded by air of greater humidity. Moreover, the uniform dryness within doors does almost untold harm in parching the mucous membranes and thus rendering us peculiarly liable to colds, grippe, and similar ailments which often lead to serious diseases such as pneumonia and tuberculosis. Of course we could not entirely avoid colds by the method here suggested, but we surely could diminish them. In the autumn before our houses are heated, colds are comparatively rare, and the same is true among people who live out of doors in winter. If the conditions inside our houses could be like those that prevail in the autumn, the general health of the community would probably be much improved. In this one way there might be a saving not only of millions of dollars' worth of valuable time, but of an immense amount of nervous energy which is wasted because persons who are irritated by colds do or say things that they would scorn under normal conditions.

Along still other lines great improvements might be possible. For instance, in many factories the same amount of work is 
expected each month. Hence, at certain seasons many operatives, especially girls, work harder than they ought, while at others they do not work so hard as they easily could without special effort. If factories were run in accordance with a well-established seasonal curve of energy, we should find the machinery running slowly in winter, faster in the spring, and in May perhaps 10 or 15 per cent faster than in January. Then in the summer it would run more slowly than in May, but not so slowly as in winter. Finally, in the autumn it would run at greater speed than at any other time of year. The operatives would scarcely be conscious of the difference, and they would probably do more work and preserve their health better than under the present system.

If our hypothesis is true, it is likely to prove helpful not only to places where the climatic disadvantages are slight, but where they are great. Consider regions which have a winter of great severity, but an invigorating summer. Contrast them with places where the summer is too hot, but the winter favorable. Russia and Mesopotamia may serve as examples. Today we already have a small number of people who move back and forth each year between places of this sort, for instance northern Germany and the Riviera, New England and Florida. Unfortunately, those who do this are usually not the workers, but the idlers or those whose work is almost finished. In the future, however, if the principles here laid down find acceptance, we may expect that such interchanges will take place on a scale to stagger the imagination. Not only the leisure classes, but laborers and farmers may thus move back and forth. In winter most of Russia's peasants have little to do, and their enforced idleness is harmful. They might go to Mesopotamia where most of the farm work is done between October and May. If people could move thus from place to place, not only would there be an enormous increase in production, but many other 
benefits. The part of the population that moved would be stimulated not only by the change of climate, but by contact with other races and new methods. They would be more tolerant, more progressive, and more eager for education. Both countries would benefit by such an interchange of workers, and much of the handicap of places like Russia might possibly be overcome. Perhaps the day will come when only the poorest families will stay in an unfavorable climate more than a few years at a time without going at least for a season to some place where they will receive new stimulus.

In tropical countries the chances for improvement are at a maximum. Already most Europeans and a few natives appreciate the necessity for spending part of the year among the mountains or in a climate different from that where they usually live. For the most part the lowlanders go to the highlands, but in lofty plateaus like Mexico it is not uncommon for foreigners to take a run down to the coast for a change of air. Of course altitude has much to do with this, but even though Vera Cruz has a bad climate for permanent residence, it is stimulating for a short while when one comes from a wholly different environment. In the future we can scarcely doubt that this method of overcoming the evil effects of a tropical climate will be resorted to on a vast scale, not only by foreigners, but by the more intelligent portion of the natives.

In the warmer parts of the earth there is another side to the question. Mankind needs not only seasonal changes, but variations from day to day, or week to week. Two methods of obtaining these suggest themselves. One is by cooling the interiors of houses. Today this is done on a small scale by shutting out the sun and sprinkling water to cause evaporation. There is no reason why the same result should not be produced on a large scale. We already know how to cool houses as well as to heat them. We do it in ice-plants. A thousand years ago 
men would have laughed at the idea that hundreds of rooms would some day be heated by a single fire, yet we see it in every office building or hotel. In equatorial regions there is as much reason for equipping the houses with coolers as there is in temperate regions for equipping them with heaters. In both cases uniformity of temperature is apparently a mistake, for moderate changes from day to day appear to be favorable. Even though a man's work may be out of doors, it seems probable that he would be much stimulated and much better enabled to work hard in the heat if he could sleep in a comparatively cool house. If he lives where the climate is too damp, he would be benefited by having the house relatively dry, just as the northerner in winter apparently ought to have his house more moist than is now his habit. Both need to enjoy the optimum conditions.

A second method of obtaining frequent changes may possibly prove of much importance. Today the seacoast in many regions, for example on the Atlantic shore of America from New York to Boston, is bordered by an almost continuous line of houses. At first people went to these only in the summer. Now many go for week-ends at almost all seasons. Fifty years ago such a thing was almost unknown. Fifty years hence it will probably be many times more prevalent than now. In tropical countries we may perhaps expect that some day millions of people will not only move to other climates during part of each year, but that many will move back and forth from the lowlands to the highlands every few days. Their work may be arranged so that they can spend two or three days a week in the highlands and the rest in the lowlands. Not only the men ought to do this, but the whole family, for all need the stimulus. Schools, factories, and almost all kinds of work except those like farming or mining, which actually take something from the soil, can be located where the climatic conditions are best, a matter which 
is becoming increasingly easy as our facilities for communication improve. Yet if these are to be within the tropics, the people engaged in them must have an opportunity to obtain the stimulus of changes. Perhaps they will frequently go from their places of work in the highlands to the neighboring lowlands or to the high mountains.

The expense of such a system of having two homes for a large part of the population will doubtless be enormous, but that is relatively unimportant. If the farmers of the tropics were as efficient as those of the temperate zone, one man's labor would produce two or three times as much as in Europe or the United States. If white men can devise a means whereby they can live in the torrid zone and retain approximately the energy which they possess in their own countries, or if they can largely increase the efficiency of the natives, they can afford to spend enormous sums in creating favorable conditions. How we shall go to work in detail cannot yet be determined, but that will easily be discovered. For the present it is enough to see that the hypothesis of climate as a condition of civilization is far from depressing. It holds out hope that the inhabitants of even the most favored parts of the temperate zone may improve their condition. It holds out still more hope that the people of the less favored parts of that zone and of the subtropical zone may be benefited. And it holds out far the greatest hope to those who dwell in the tropical regions which now are the most hopeless.

If our hypothesis is true, man is more closely dependent upon nature than he has realized. A realization of his limitations, however, is the first step toward freedom. In suggesting possible ways of obtaining a new ascendancy over climatic handicaps we have dealt largely with material matters. Bound up with these, and far more important, are great moral issues. We are slowly realizing that character in the broad sense of all that pertains to industry, honesty, purity, intelligence, and strength 
of will is closely dependent upon the condition of the body. Each influences the other. Neither can be at its best while its companion is dragged down. The climate of many countries seems to be one of the great reasons why idleness, dishonesty, immorality, stupidity, and weakness of will prevail. If we can conquer climate, the whole world will become stronger and nobler. 



\section{APPENDIX \\ (A) CONTRIBUTIONS TO THE MAP OF CIVILIZATION}

\section{Americans}

J. Barrell, geologist, New Haven, Conn.

P. Bigelow, traveler and author, Malden, N. Y.

I. Bowman, geographer, New York, N. Y.

W. M. Brown, geographer, Providence, R. I.

R. D. Calkins, geographer, Mt. Pleasant, Mich.

J. S. Chandler, missionary, Madura, India.

A. C. Coolidge, historian, Cambridge, Mass.

S. W. Cushing, geographer, Salem, Mass.

L. Farrand, anthropologist, New York City.

C. W. Furlong, traveler and author, Boston, Mass.

H. Gannett, geographer, Washington, D. C.

E. W. Griffis, traveler and author, Ithaca, N. Y.

A. Hrdlicka, anthropologist, Washington, D. C.

E. H. Hume, physician and missionary, Changsha, China.

E. Huntington, geographer, New Haven, Conn.

M. Jefferson, geographer, Ypsilanti, Mich.

A. G. Keller, anthropologist, New Haven, Conn.

E. F. Merriam, editor, Boston, Mass.

J. H. Potts, missionary, Shanghai, China.

E. Sapir, anthropologist, Ottawa, Canada.

J. R. Smith, economic geographer, Philadelphia, Pa.

E. V. Robinson, economic geographer, Minneapolis, Minn.

W. S. Tower, geographer, Chicago, Ill.

R. H. Whitbeck, geographer, Madison, Wisc.

S. W. Zwemer, missionary, Cairo, Egypt.

Anonymous, New York City. 


\section{BrItish}

George Black, Sydney, Australia. James Bryce, statesman, London. Leonard Darwin, soldier, London. T. H. Holdich, soldier, London.

H. H. Johnston, administrator, Arundel, England.

J. S. Keltie, geographer, London.

T. S. Longstaff, geographer, London.

D. Carruthers, explorer, Manningtree, England.

\section{Teutons from Continental Europe}

S. de Geer, geographer, Stockholm, Sweden.

H. F. Helmholt, historian, München, Germany.

A. Kraemer, ethnographer, Stuttgart, Germany.

Mrs. M. Krug-Genthe, geographer, Chemnitz, Germany.

H. H. Reusch, geologist and geographer, Kristiania, Norway.

H. ten Kate, anthropologist, Geneva, Switzerland.

F. von Luschan, anthropologist, Berlin, Germany.

K. F. Sapper, geographer, Strassburg, Germany.

\section{Latins (and Other Europeans not Already Classified)}

D. n Anoutchine, geographer, Moscow, Russia.

L. Gallois, geographer, Paris, France.

V. Giuff rida-Ruggeri, anthropologist, Naples, Italy.

G. Papillault, anthropologist, Paris, France.

B. y Rospide, geographer, Madrid, Spain.

G. Sergi, anthropologist, Rome, Italy.

S. Telles, geographer, Lisbon, Portugai.

\section{Asiatics}

Katsuro Haro, Imperial University, Kyoto, Japan.

Inazo Nitobe, Imperial University, Tokyo, Japan.

Naomasa Yamasaki, Imperial University, Tokyo, Japan.

Jeme Tien-yow, Shanghai, China.

Wang Ching-chun, 'Tientsin, China.

Wu Ting-fang, Shanghai, China. 


\section{Summary of Contributors}

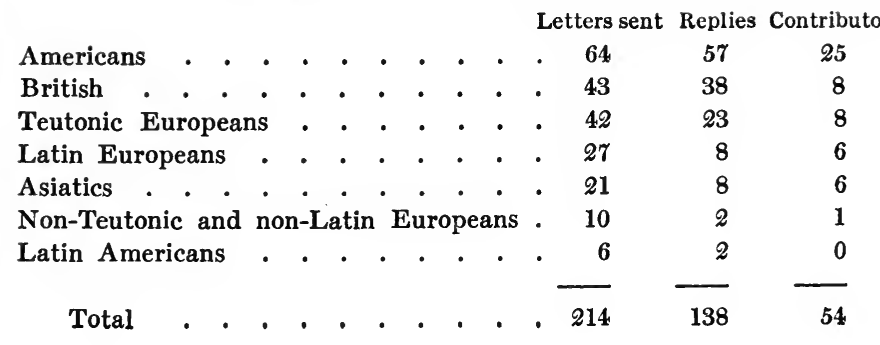

\section{(B) THE RELATIVE CIVILIZATION OF THE COUNTRIES OF THE WORLD}

The following list contains the final results of the classification made by the preceding contributors. In examining this the reader should remember that the division into regions and the grouping of the regions according to race make no claim to perfection. Convenience in obtaining units small enough to give a detailed map and yet to be known to people of many races has been the primary object in dividing the different countries of the world into smaller sections. The sections are small in Europe and the United States because these regions are well known, and large in Siberia because very few people can distinguish sharply between different parts of that country. In a few cases I have added minor divisions such as southern Alaska, with a special object not connected with the present book. The grouping by races in Europe, Asia, and North America has been guided also by motives of convenience. Such places as Ireland, Asia Minor, Bulgaria, Baluchistan, and others might properly be placed in other groups as well as in those where I have put them. The reader can easily rearrange for himself. My purpose has been merely to make a convenient classification for our immediate purpose without respect to its applicability elsewhere. 


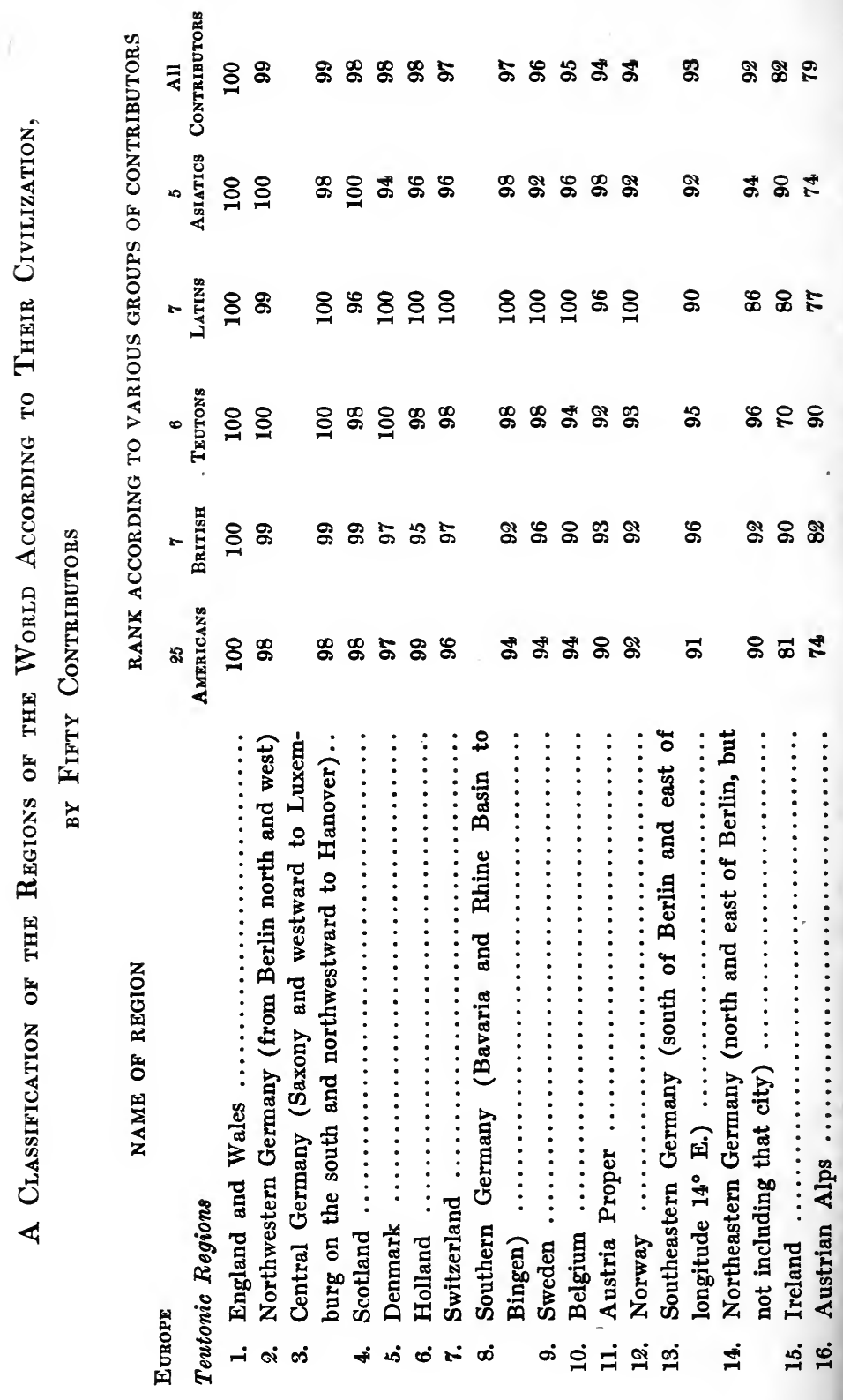




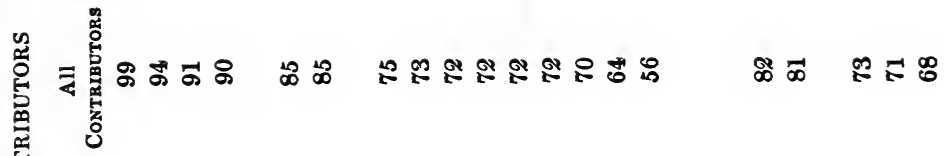

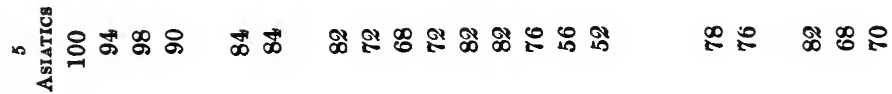

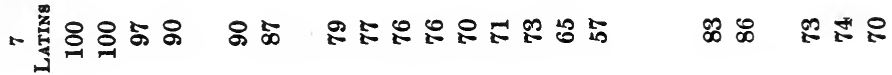

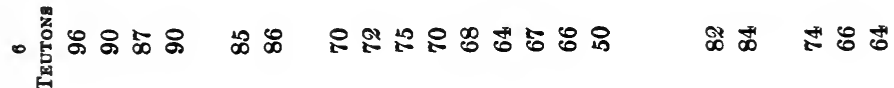
.

尊

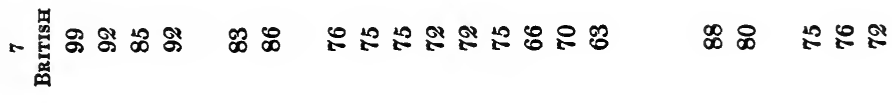

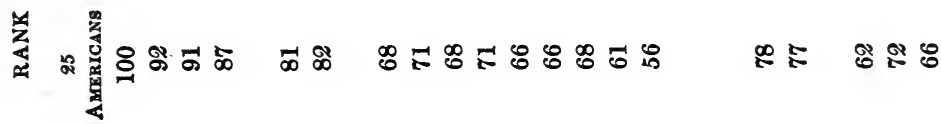

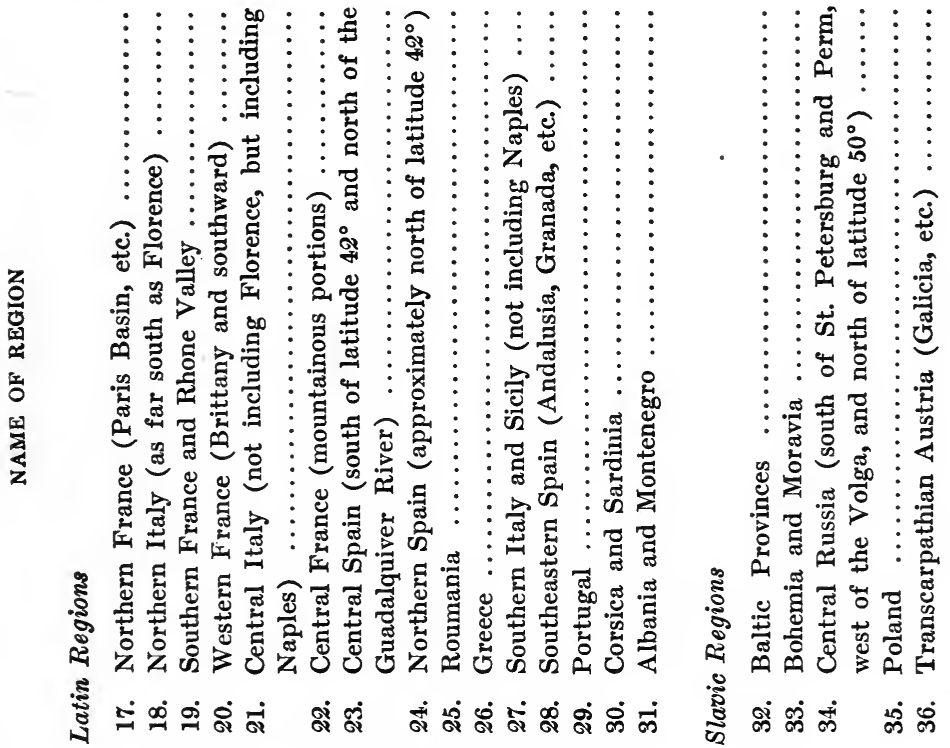




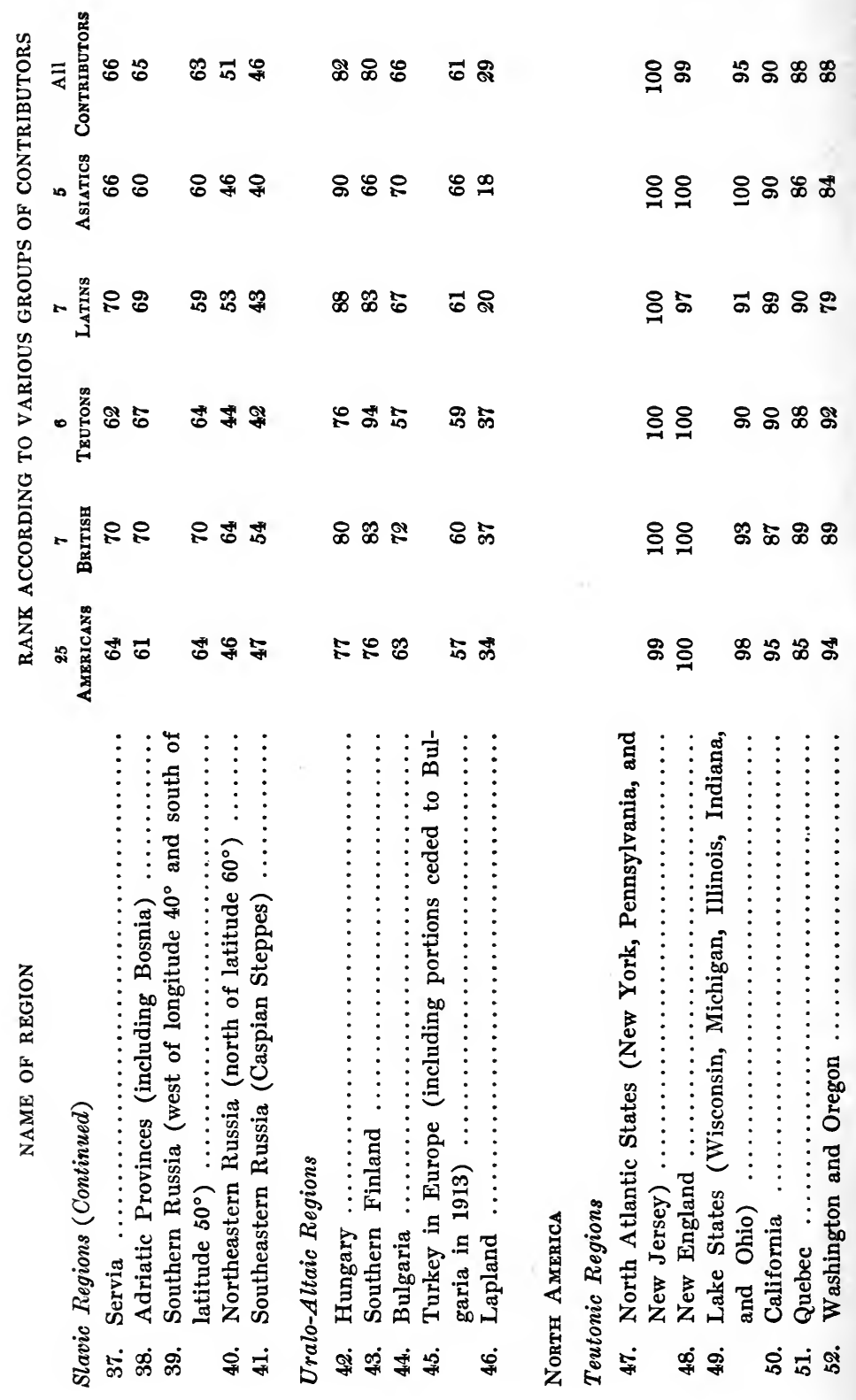




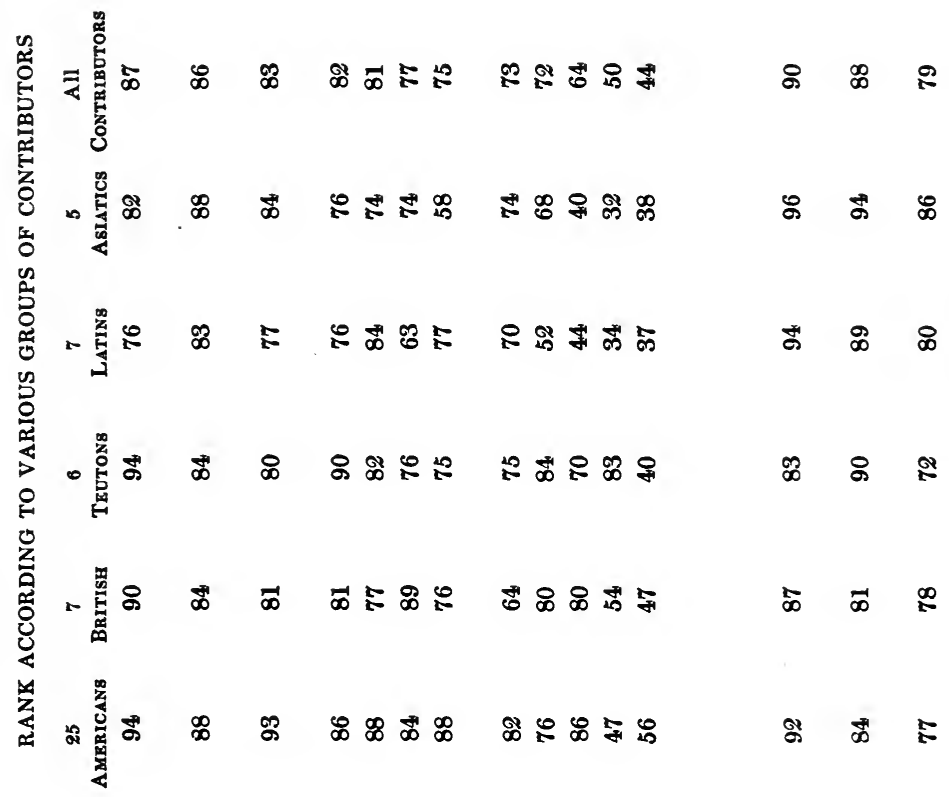

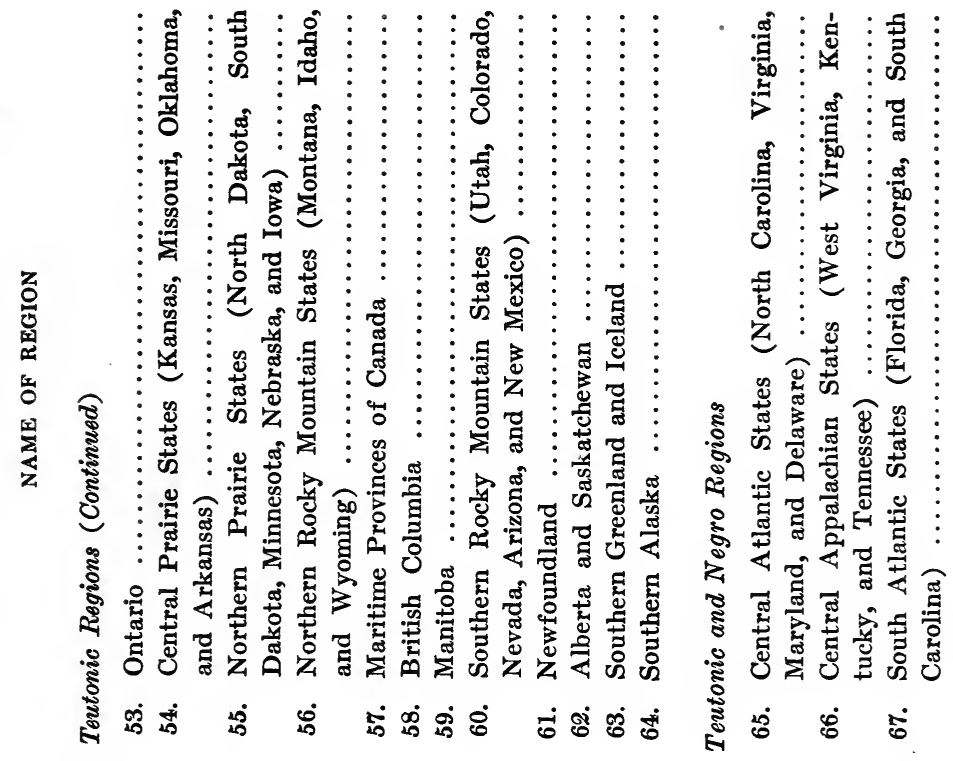




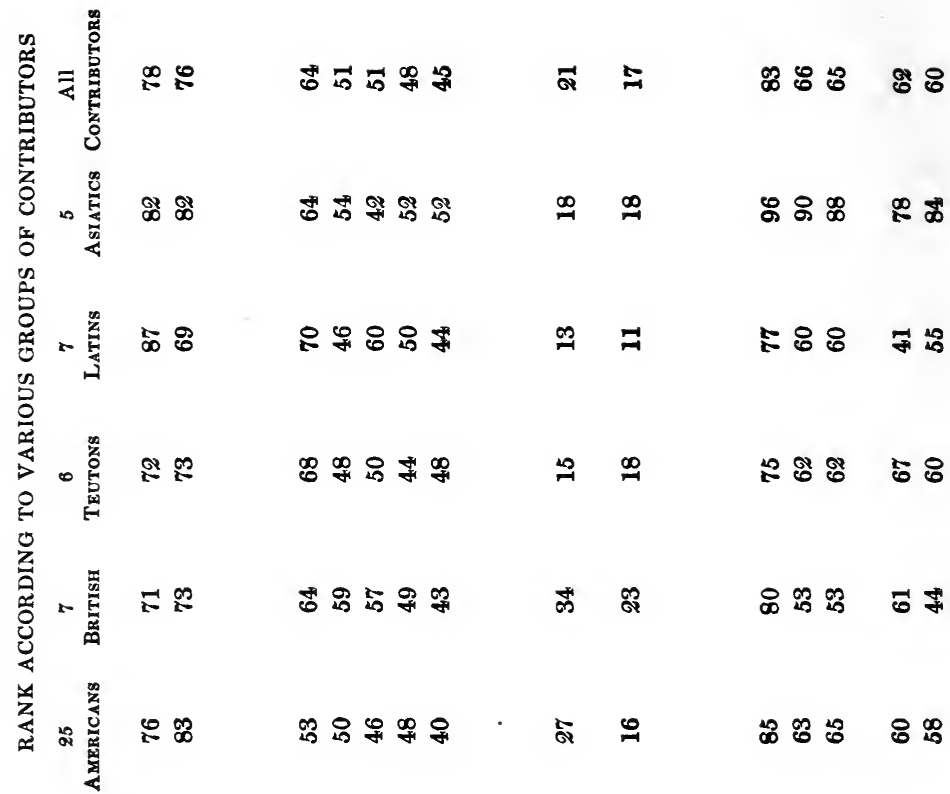

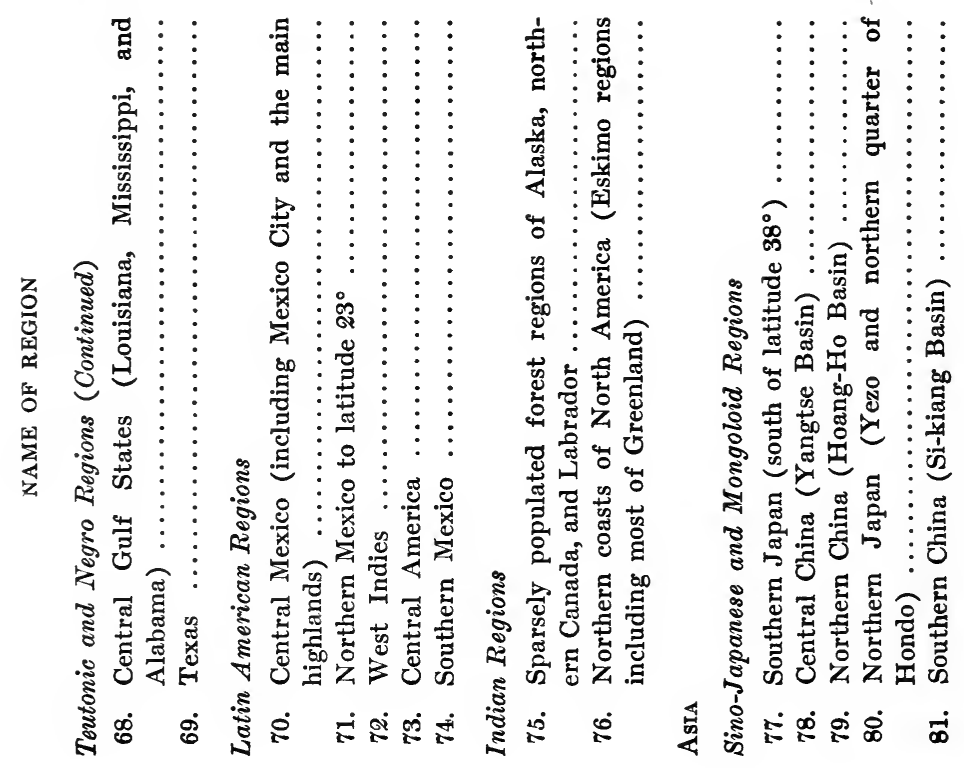




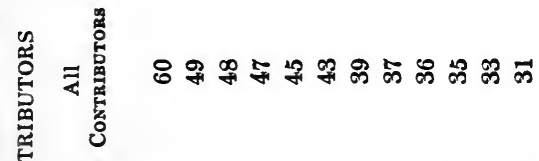

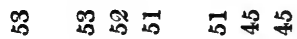

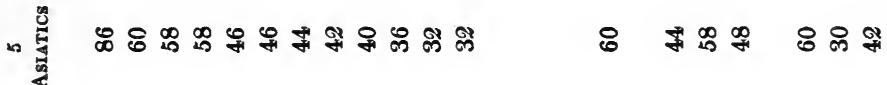

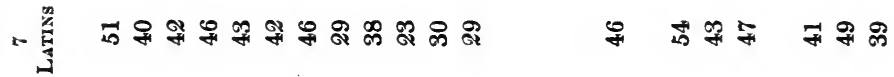

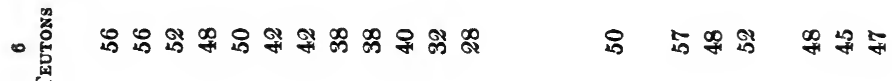

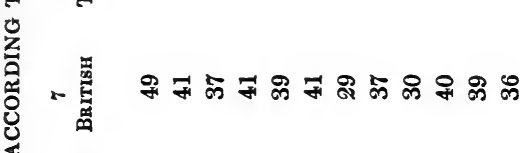

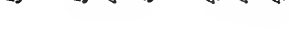

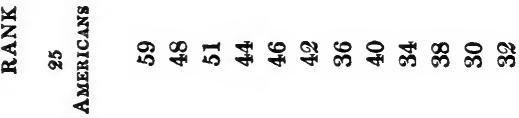

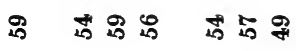

ซ

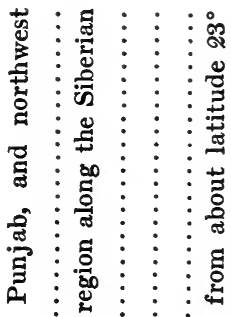

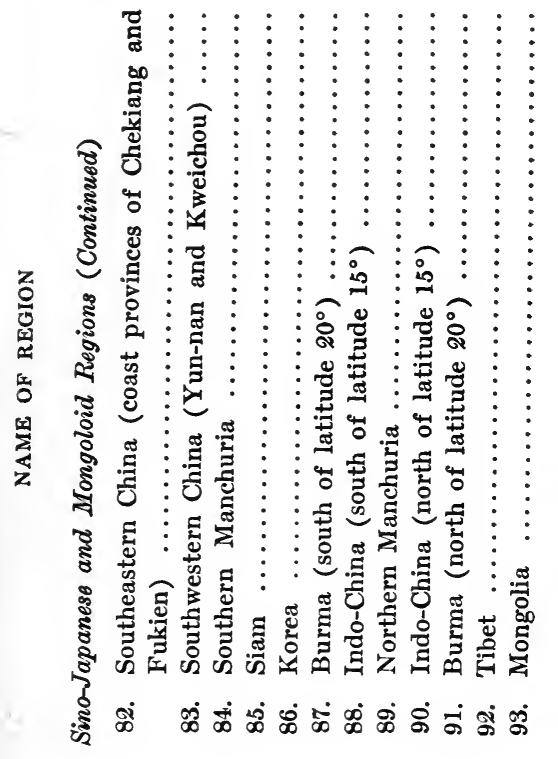

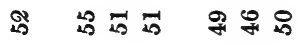

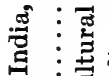

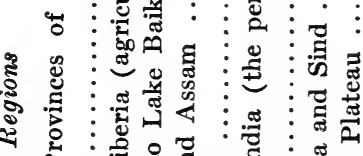

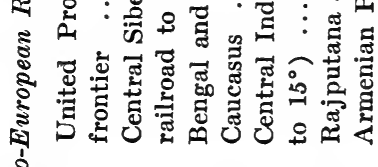
ङ 


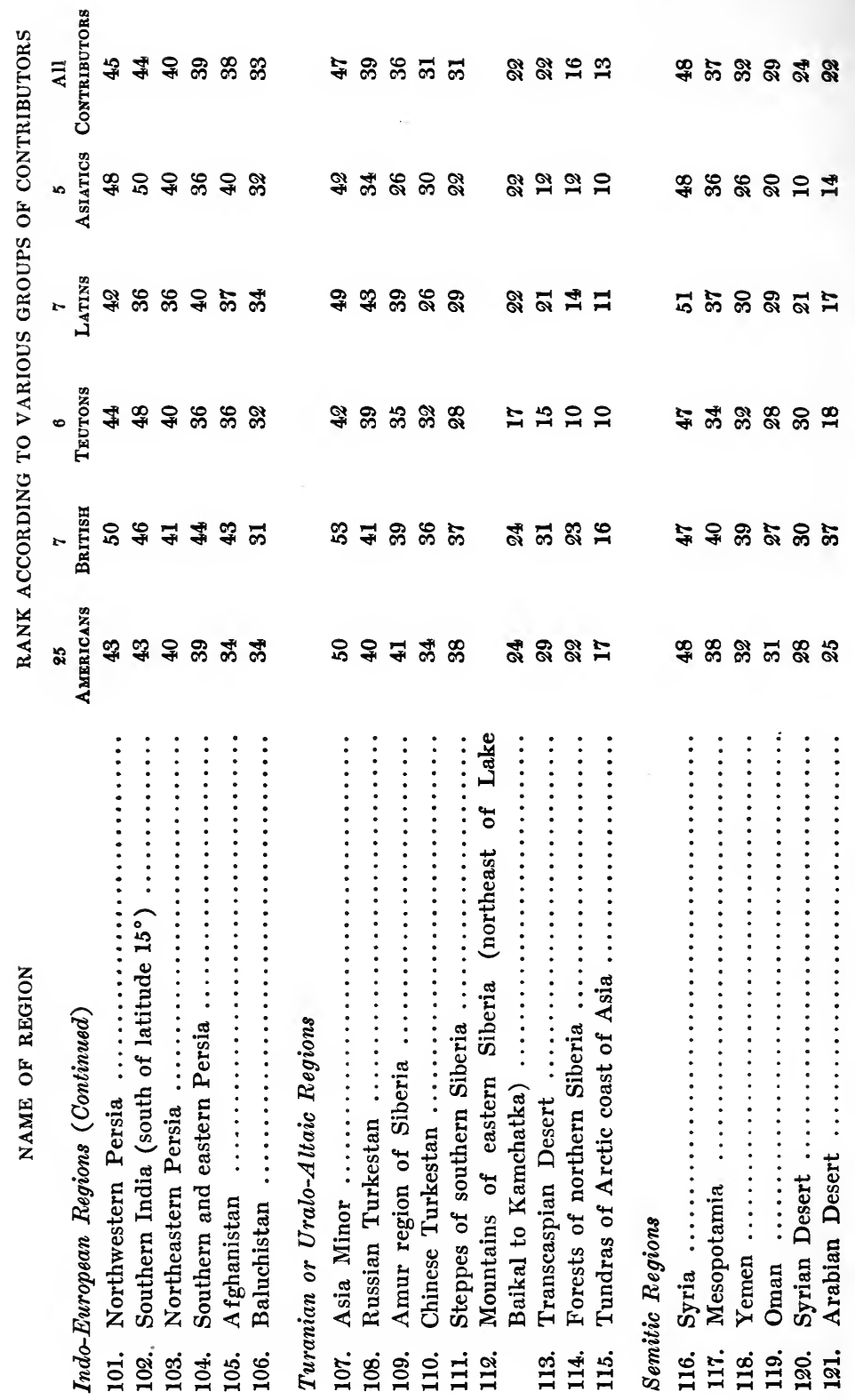




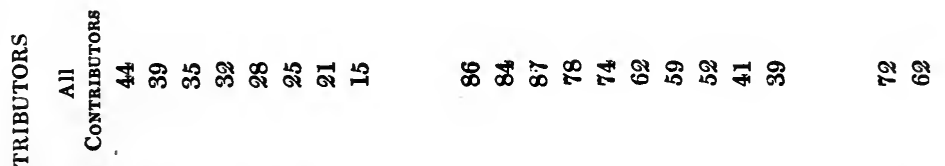

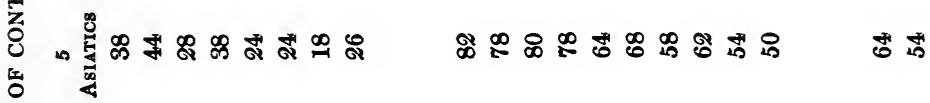

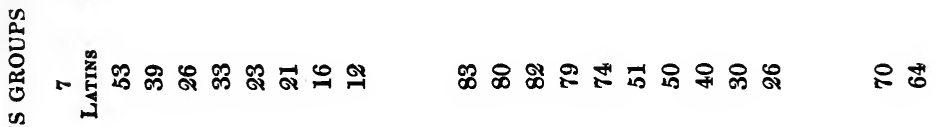

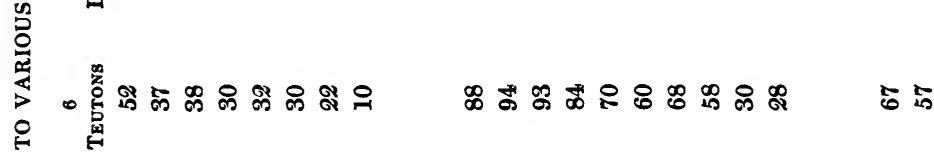

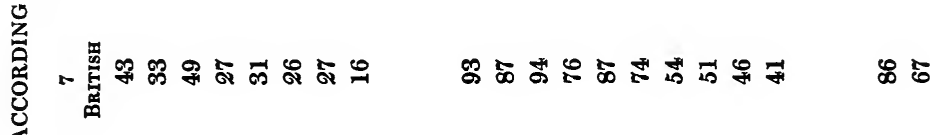

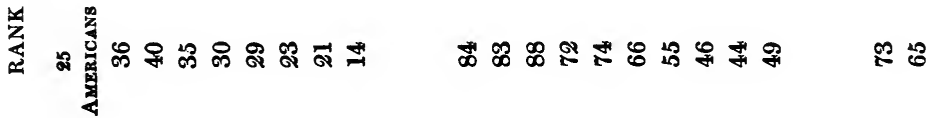

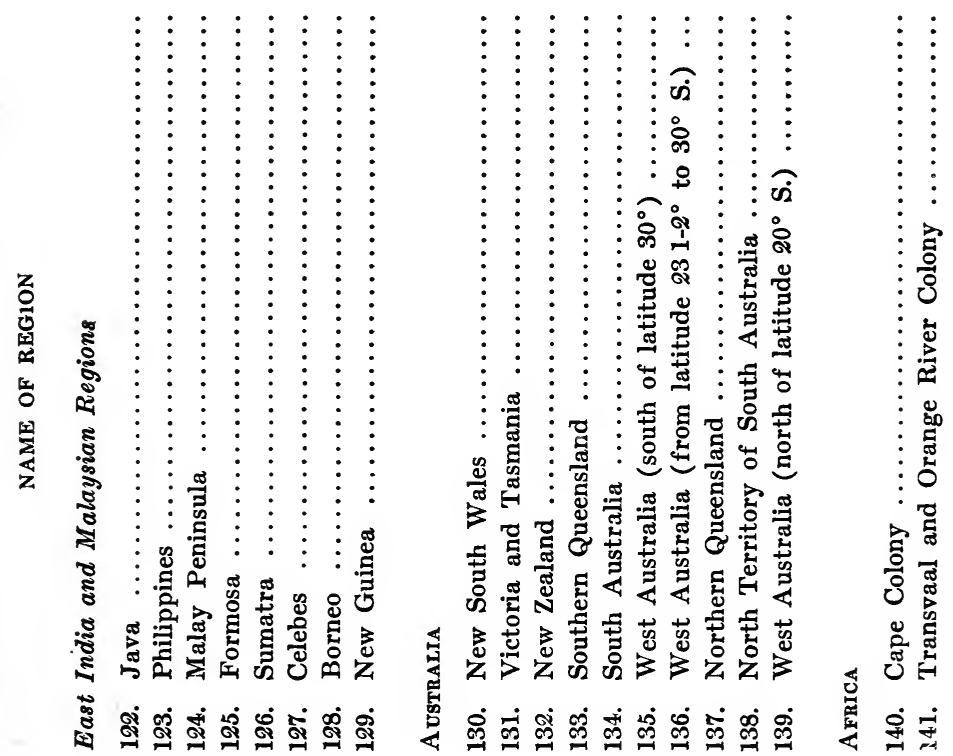




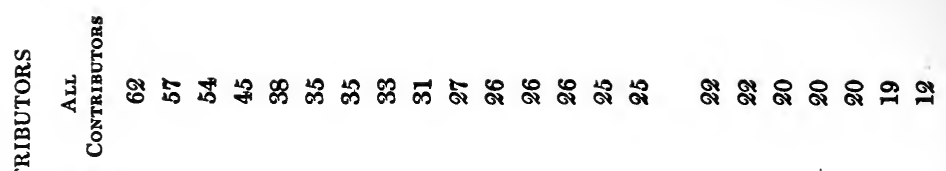

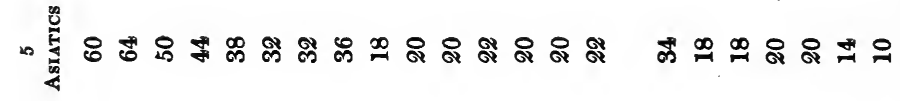

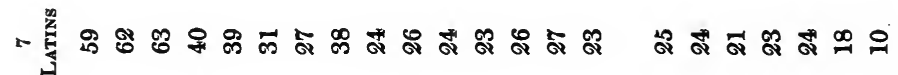
0
0
5
0
0
0
0
0
0
0
0
0
0

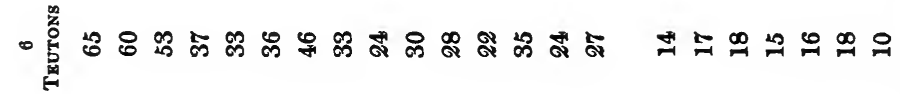
¿

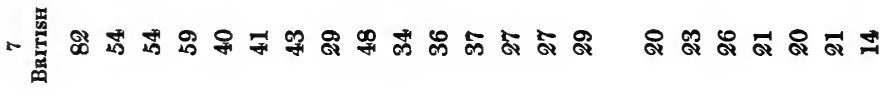

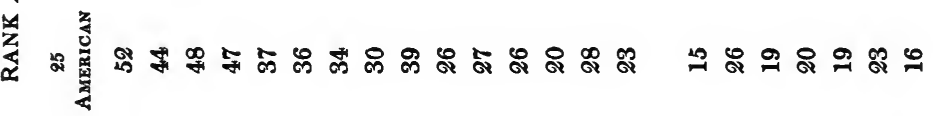

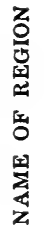

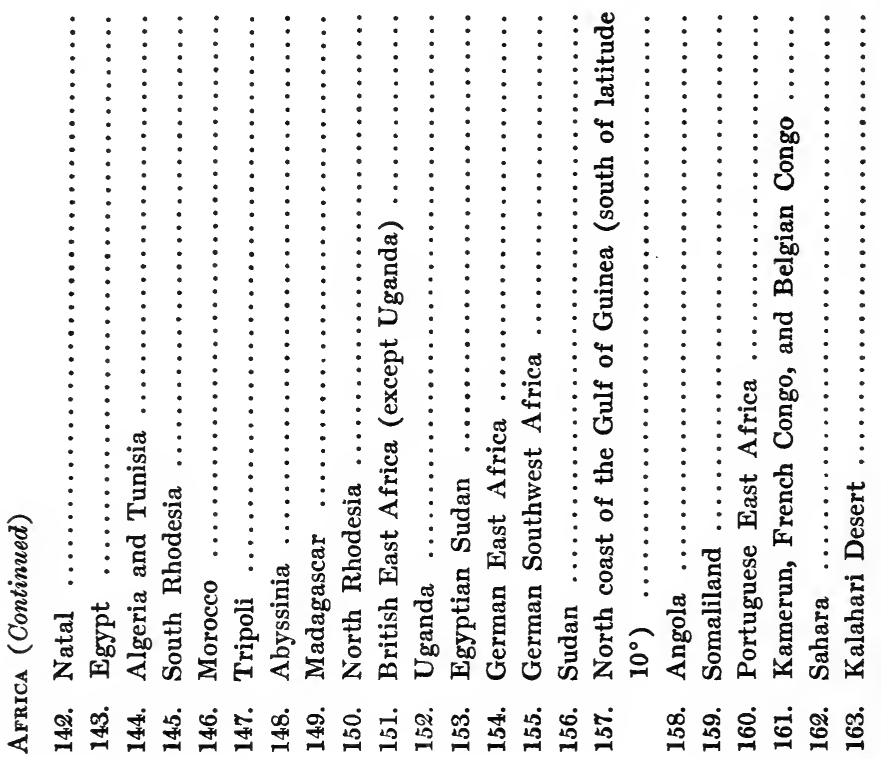




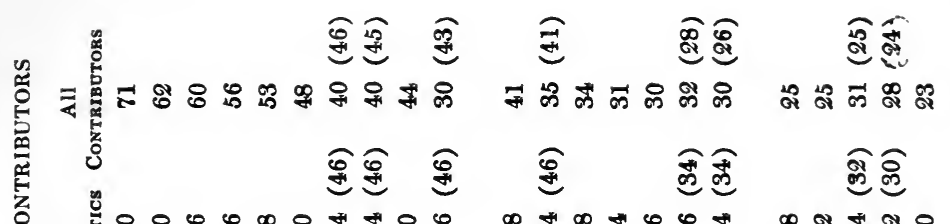

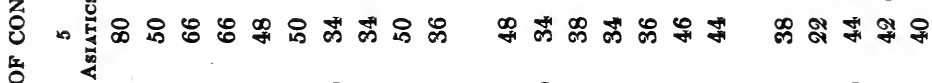

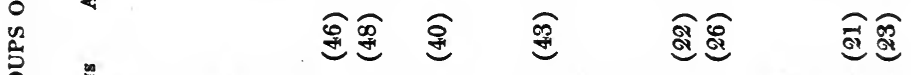

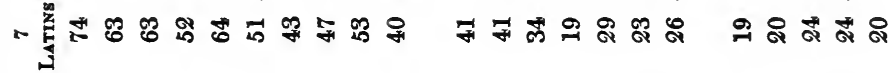

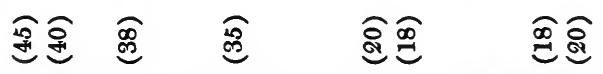

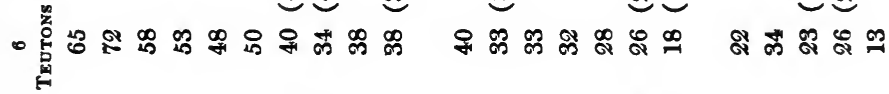

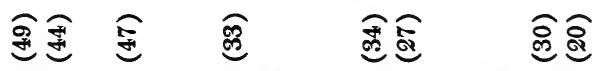

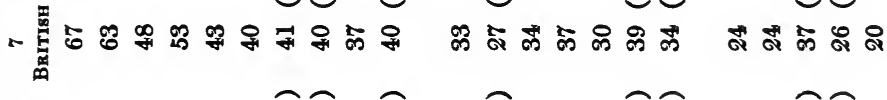

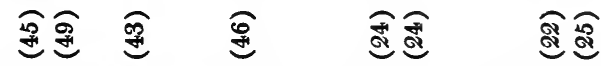

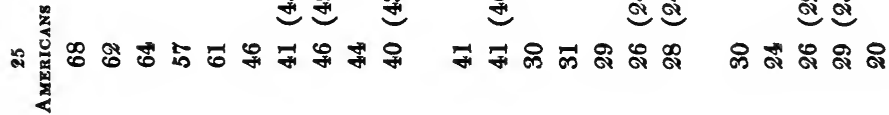

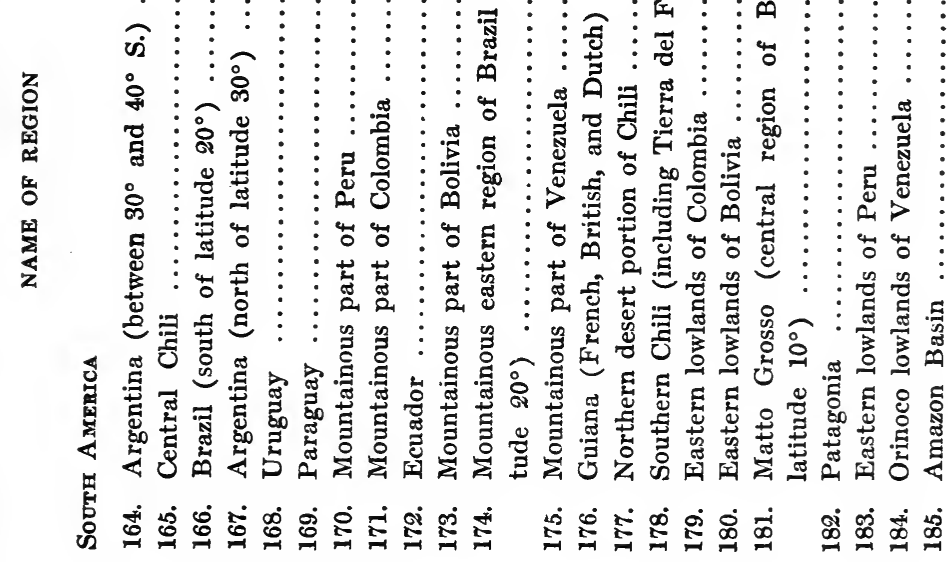


Note.-In the Andean countries of South America, except Chili, the most advanced districts are found in the highlands. The eastern lowland, which is heavily forested or else covered with savannah, contains only a scanty population composed almost wholly of Indians. The way in which each of these countries is divided into a "mountainous part," and an "eustern lowland" seems to have created confusion in the minds of many contributors. They apparently thought of the lofty mountains, and not of the plateau as was intended. Hence they rank the lowlands higher than the mountains. As a matter of fact, the lowlands are in almost the same condition as the Amazon Basin (No. 185). Therefore, after the figures for Venezuela, Colombia, Peru, and Bolivia, I have added in parentheses a series of numbers indicating the rank of these countries if in each case the higher value in any given classification is taken as intended for the more advanced portion, that is, the highlands. The numbers in parentheses are probably nearer right than the others, and have been used in preparing the map of civilization, Figure 4.5 . 
Classification of the States and Provinces of the United States and Canada

\section{UNited States}

1. Alabama

2. Arizona

3. Arkansas

4. California

5. Colorad

6. Connecticut and Rhode Island

7. Delaware

8. Florida.

9. Georgia .

10. Idaho

11. Illinois .

12. Indiana .

13. Iowa

14. Kansas .

15. Kentucky

16. Louisiana

17. Maine

18. Maryland

19. Massachusetts

20. Michigan

21. Minnesoto

22. Mississippi

23. Missouri

24. Montana

25.

26.

27. New Hampshire . . . . . 4.8

28. New Jersey • • • . • . 5.7

29. New Mexico . . . . . . 1.6

30. New York . . . . . . $\quad . \quad 5.9$

31. North Carolina . . . . . 3.1

32. North Dakota . . . . . $\quad .8$

33. Ohio

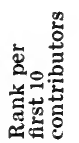

A.

2.1

1.2

2.3

5.3

4.1

5.9

4.0

2.0

2.1

2.5

5.7

5.3

5.2

4.8

3.2

2.0

4.9

4.1

6.0

5.4

5.1

1.7

3.7

3.0

4.4

1.3

4.8

1.6

5.9

5.8
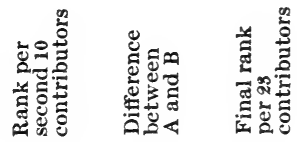

B.

C.

D.

1.9

0.2

2.0

1.7

0.5

1.6

1.9

0.4

2.0

4.8

0.5

5.1

4.1

0.0

4.2

5.8

0.1

5.8

3.9

0.1

4.0

2.0

2.5

0.0

2.0

0.4

2.5

2.5

0.0

2.6

5.7

0.0

5.7

5.6

0.3

5.4

5.1

5.0

3.3

0.1

5.0

4.9

1.7

0.2

3.3

2.0

5.0

4.0

6.0

5.6

0.1

4.8

0.1

4.1

0.1

6.0

5.4

0.0

0.2

5.4

1.4

0.3

5.2

0.3

1.7

3.5

0.2

3.7

3.2

4.3

1.9

0.2

3.1

0.1

4.4

0.6

1.7

4.8

0.0

4.6

5.4

0.3

5.6

1.5

0.1

1.6

5.7

0.2

5.8

2.8

0.3

2.9

3.8

0.0

3.8

5.9

0.1 


\section{United States (Continued)}

34. Oklahoma

35. Oregon . . . . . . . .

36. Pennsylvania . . . . . .

37. South Carolina . . . . .

38. South Dakota. . . . . .

39. Tennessee . . . . . . .

40. Eastern Texas . . . . .

42. Utah . . . . . . . . 2.

43. Vermont . . . . . . 4.4

44. Virginia . . . . . . 3.8

45. Washington . . . . . . 4.8

46. West Virginia . . . . . . 2.5

47. Wisconsin . . . . . . . 5.4

48. Wyoming . . . . . . . 2.9

49. Southern Alaska . . . . . 1.5

\section{Cantad}

50. Newfoundland

51. Prince Edward's Island

52. Nova Scotia . . . . .

*54. Quebec, east of longitude $72^{\circ} 30^{\prime}$

*55. Quebec, west of longitude $72^{\circ} 30^{\prime}$

56. Ontario, east of Lake Huron .

57. Ontario, north of Lakes Huron and Superior . . . .

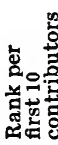

A.

3.7

4.6

5.6

1.6

3.8

3.0

3.1

1.8

.4

4

3.8

8

.5

5.4

A.

1.9

2.6

3.8

3.3

3.1

4.1

5.4

3.0
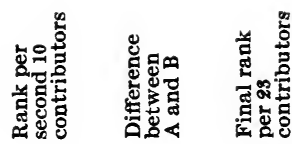

B.

C.

D.

3.1

0.6

3.4

5.0

0.4

4.9

5.5

0.1

5.6

2.2

0.6

1.9

3.7

0.1

3.7

2.6

0.4

2.8

2.8

0.3

3.1

1.6

0.2

1.9

2.3

0.1

2.5

4.7

0.3

4.4

3.8

0.0

3.9

5.0

0.2

5.0

2.9

0.4

2.8

5.8

0.4

5.6

2.6

0.3

2.8

1.2

0.3

1.5

B.

c.

D.

2.0

0.1

2.0

2.1

2.5

3.4

0.5

3.6

2.9

0.4

3.2

2.6

0.4

3.0

2.6

0.5

3.4

4.7

1.5

5.1

2.0

1.0

2.6

* In this case some contributors may have misunderstood what was intended. At least, several of them placed the part of Quebec containing Montreal lower than the sparsely populated portion from Quebec eastward. If each contributor's higher figure be taken as meant for the part of the province containing Montreal, the final numbers in column D become East Quebec 2.5 and West Quebec 3.9. I am strongly inclined to think that many of the Canadian figures are too low, because all but one of the contributors were from the United States. For this reason Canada is not included in Figure 43. 


\section{Canada (Continued)}

58. Manitob

59. Saskatchewan, southern half, i.e., south of latitude $55^{\circ}$. .

60. Saskatchewan, northern half, i.e., north of latitude $55^{\circ}$.

61. Alberta, southern half . .

62. Alberta, northern half . .

63. British Columbia, southern half

64. British Columbia, northern half

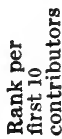

A.

3.5

3.0

1.3

2.9

1.7

3.8

1.3

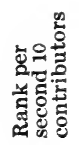

B.

4.4

4.0

3.1

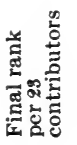

D.

(C) EFFICIENCY AND MEAN TEMPERATURE

A Table Based on the Work of 310 Men and 196 Women at New Haven, New Britain, and BridgePORT IN 1910-1913

$\begin{array}{cccc}\text { TEMP. } & \text { EFFICIENCY } & \text { TEMP. } & \text { EFFICIENCY } \\ \text { C. } & & \text { C. } & \\ -35^{\circ} & 92.8 \% & -21^{\circ} & 93.5 \% \\ -34^{\circ} & 92.8 \% & -20^{\circ} & 93.6 \% \\ -33^{\circ} & 92.9 \% & -19^{\circ} & 93.6 \% \\ -32^{\circ} & 92.9 \% & -18^{\circ} & 93.7 \% \\ -31^{\circ} & 92.9 \% & -17^{\circ} & 93.8 \% \\ -30^{\circ} & 93.0 \% & -16^{\circ} & 93.9 \% \\ -29^{\circ} & 93.0 \% & -15^{\circ} & 94.0 \% \\ -28^{\circ} & 93.1 \% & -14^{\circ} & 94.1 \% \\ -27^{\circ} & 93.1 \% & -13^{\circ} & 94.2 \% \\ -26^{\circ} & 93.2 \% & -12^{\circ} & 94.3 \% \\ -25^{\circ} & 93.3 \% & -11^{\circ} & 94.4 \% \\ -24^{\circ} & 93.3 \% & -10^{\circ} & 94.5 \% \\ -23^{\circ} & 93.4 \% & -9^{\circ} & 94.6 \% \\ -22^{\circ} & 93.4 \% & -8^{\circ} & 94.7 \%\end{array}$




$\begin{array}{rrrr}\text { TEMP. } & \text { ETFICIENCX } & \text { TEMP. } & \text { EFFICIENCY } \\ \text { C. } & & \text { C. } & \\ -7^{\circ} & 94.9 \% & 15^{\circ} & 100.0 \% \\ -6^{\circ} & 95.1 \% & 16^{\circ} & 99.9 \% \\ -5^{\circ} & 95.3 \% & 17^{\circ} & 99.7 \% \\ -4^{\circ} & 95.5 \% & 18^{\circ} & 99.3 \% \\ -3^{\circ} & 95.7 \% & 19^{\circ} & 98.9 \% \\ -2^{\circ} & 95.9 \% & 20^{\circ} & 98.4 \% \\ -1^{\circ} & 96.2 \% & 21^{\circ} & 97.9 \% \\ 0^{\circ} & 96.5 \% & 22^{\circ} & 97.4 \% \\ 1^{\circ} & 96.8 \% & 23^{\circ} & 96.9 \% \\ 2^{\circ} & 97.1 \% & 24^{\circ} & 96.4 \% \\ 3^{\circ} & 97.4 \% & 25^{\circ} & 95.9 \% \\ 4^{\circ} & 97.7 \% & 26^{\circ} & 95.3 \% \\ 5^{\circ} & 98.0 \% & 27^{\circ} & 94.6 \% \\ 6^{\circ} & 98.3 \% & 28^{\circ} & 93.9 \% \\ 7^{\circ} & 98.6 \% & 29^{\circ} & 93.2 \% \\ 8^{\circ} & 98.8 \% & 30^{\circ} & 92.5 \% \\ 9^{\circ} & 99.0 \% & 31^{\circ} & 91.7 \% \\ 10^{\circ} & 99.2 \% & 32^{\circ} & 90.5 \% \\ 11^{\circ} & 99.4 \% & 33^{\circ} & 89.0 \% \\ 12^{\circ} & 99.6 \% & 34^{\circ} & 86.8 \% \\ 13^{\circ} & 99.8 \% & 35^{\circ} & 84.3 \% \\ 14^{\circ} & 99.9 \% & 3^{\circ} & 81.0 \%\end{array}$


INDEX 



\section{INDEX}

Abnormalities, among Bahamans, 28.

Abyssinians, and religion, 206.

Acadia College, 177.

Actinic rays, effect on man, 83.

Adirondacks, consumptives in, $65 \mathrm{f}$.

Africa, civilization in highlands, 204 ; desiccation of, 248 ; distribution of civilization in, 170; seasonal changes in, 132; ease of life in, 29.

Africans, character of, 35.

Age, and climatic resistance, 100, 114.

Agra, 260, 140.

Agriculture, advantages of South, 18; effect on education, 193; relation to tools and animals, $280 \mathrm{ff}$.; in torrid zone, 239.

Alabama, illiteracy, 191; education, 192, 195; negro versus white farmers, $19 \mathrm{ff}$.

Alberta, civilization and energy, 202; opinions as to civilization, 169, 177, 180.

Alcohol, in tropics, $44 \mathrm{ff}$.

Alexandria, rainfall of, 273.

Altitude, effect in tropics, 136; effect upon blood, $50 \mathrm{f}$.

America, ancient civilization in, $262 \mathrm{f}$; ; as a center of civilization, $252 \mathrm{ff}$. (See North and South America.)

American Revolution, emigration due to, 27.

Americans, opinions as to civilization, $172 \mathrm{ff}$; racial character of, $183 \mathrm{f}$.
Anger, in tropics, 41, $43 \mathrm{f}$.

Anglo-Saxons, in Bahamas, 14, 27 (see also Teutons and English); in southern factories, $70 \mathrm{f}$.

Annapolis, marks and climate at, 8, $77 \mathrm{ff} ., 117 \mathrm{ff}$.

Anthropologists, opinion of map of civilization, $157 \mathrm{f}$.

Apaches, 278.

Arctic regions, climatic energy in, $143 \mathrm{f}$.

Arctic plants, temperature optimum of, 104.

Arctowski, H., cited, 245.

Argentina, civilization and energy in, 204.

Aridity, effect on map of climatic energy, $140 \mathrm{f}$.; in houses, $85 \mathrm{ff}$., 289. (See Humidity, and Desiccation.)

Arizona, education in, 195; effect of aridity, 140; illiteracy in, 191; rank in civilization, 196.

Arkansas, civilization in, 197; eminent persons in, 216.

Armenians, and Christianity, 206.

Art, as part of civilization, 159 .

Aryans, civilization of, 260.

Asia Minor, ancient storminess of, 267; relation to civilization, $261 \mathrm{f}$; Teutonic blood in, 206.

Asia, civilization and energy in, 201; climatic character, $132 \mathrm{f}$, 135, 231; climatic energy in, 144; desiccation of, 6, 248; expeditions to, 4; rainfall in western, 272; rank in civilization, $168 \mathrm{f}$. 
Asiatics, opinion as to civilization, 180.

Assyria, ancient civilization, 261.

Astronomy, among Mayas, 240.

Athens, wars of, 262.

Atlanta, Ga., climate, 32.

Atlantic coast of U. S., civilization of, 175, 180; energy compared with eminence, 218.

Atmospheric pressure. (See Barometric pressure.)

Aujeh, 243.

Australia, civilization in, 167, 169, 202 , 256; climatic energy in, 143, 202.

Austrian Alps, rank in civilization, $167 \mathrm{f}$.

Babylonia, civilization in, 258, 261.

Bagdad, rainfall of, 273.

Bahama Islands, English versus negroes, 14, $27 \mathrm{ff}$.

Baltic Provinces, energy in, 145; rank in civilization, 167.

Baltic region, civilization and energy in, 201.

Baltic Sea, freezing of, 236.

Baluchistan, civilization in, 260.

Bantus, in South Africa, 24 ff., 27.

Barbarian invasions, 6.

Barometric changes, and civilization, 7, 8.

Barometric pressure, effect of, 51, 112.

Barrett Expedition, 4.

Basutos, 24.

Baths, effect on circulation, 121.

Beasts of burden, 280, $282 \mathrm{f}$.

Beersheba, 243.

Berliner, cited, 7.

"Big Business" in America, 255.

Big trees of California, 5.

Bigelow, F. H., cited, 24.5.
Binet tests, at Columbia, S. C., 12.

Birthplaces of eminent persons in U. S., 212.

Bison, 282.

Blizzards, in Siberia, 145.

Blood, effect of altitude upon, $50 \mathrm{f}$.; effect of temperature on circulation, 116, 121.

Boers, in South Africa, 24 ff.

Bohemia, rank in civilization, 167.

Bolivia, civilization and energy in, 204.

Bombay, effect of humidity, 140 .

Bonus work, 63.

Books, in warm climates, 33.

Boston, climatic excellence of, 129; murders in, 286.

Brain, white versus negro, 11.

Breath, $\mathrm{CO}_{2}$ in, $108 \mathrm{ff}$.

Bridgeport, factory operatives in, 8, 53 ff., $114 \mathrm{ff}$.

British, children in India, 37; colonists in Canada, 27 (see also English); government, attitude toward negroes, 14; opinion as to civilization, $175 \mathrm{f}$.

British Columbia, relation to ideal climate, 130, 133.

Brown, L., cited, 65.

Brunnow, cited, 106.

Bryce, J., cited, 161 f., 196.

Buckle, cited, 2.

Buddhism, and civilization, 206, 260 ;

European characteristics of, 163.

Burans, in Siberia, 14.5.

Bushmen, 25.

Business, effect on wages in Connecticut, 64; in Florida, 74 f.; at Pittsburgh, 77.

Cairo, rainfall of, 273 .

Calcutta, humidity, 140.

Calendar, of Mayas, 240, 263. 
California, as a center of civilization, $256 \mathrm{f}$.; changes of climate in, $5,228,230,237,243$; civilization and energy, 199, 203; eminent persons in, 213; illiteracy in, 191; influence of cities in, 199; insanity in, 134; lakes in, 224, $233 \mathrm{f}$; relation to ideal climate, 134 .

Cambodia, storms and ruins in, 275.

Campeche, malaria in, 240.

Canada, energy in, 143, 202; compared with Bahamas, 27; with South Africa, 26; civilization in, 196; diversity of opinion as to, $169,177,180$; relation to ideal climate, 133; storms in, 263.

Cape Colony, 25.

Cape Horn, storminess at, 140 .

Carbon dioxide, emission at high altitudes, 50; and temperature, $106 \mathrm{ff}$.

Carnegie Institution of Washington, 4, 5, 230.

Carpenters, at Jacksonville, Fla., 72.

Carthage, European character of, 164.

Caspian Sea, variations in, 229, 237.

Cattell, J. McK., 102.

Cause of climatic changes, $244 \mathrm{ff}$.

Census, of U. S. used in map-making, $17,183 \mathrm{ff}$; statistics as to farmers, $18 \mathrm{ff}$.

Centers of civilization, $251 \mathrm{ff}$.

Central America, 5; civilization and energy in, 204; missionaries in, 48; compared with Indo-China, 275.

Central Asia, expeditions to, 4.

Ceylon, ruins in, 274.

Chad, fluctuations of Lake, 238.

Chamberlin', T. C., cited, 224.
Changes of climate, at present, 245 ; difficulty of problem, 222; geological, $223 \mathrm{ff}$.

Changes of temperature from day to day, 8, $113 \mathrm{ff}$; distribution of, 131 ff., 139 f.

Character, origin of, 48 ; statistical tests of, $188 \mathrm{ff}$.

Chemical activity, law of, 106; of light, 83.

Chemical evidence, 233.

Cherokees, agriculture among, 284.

Chicago, 214.

Children, immunity to disease, 39 ; mortality among, 68; percentage in school, $192 \mathrm{ff}$.; scarcity among best families, 216; tests of negro versus white, 12; unruliness in America, 286; of white races in tropics, $42 \mathrm{f}$.

Chili, relation to ideal climate, 130 .

China, a center of civilization, $259 \mathrm{f}$., 262; effect of America on, 255; effect of climate on, 147, 201, 237, 249, 268, 287; European character of, 164; rank in civilization, $168 \mathrm{f}$. Chinese Turkestan, dead forests in, 226 ; effect of aridity, 140; expeditions to, 4 ; ruins in, 231 ; monotony of, 135.

Chlorine, in Owens Lake, 233; in Pyramid and Winnemucca, 235.

Christianity, and civilization, 206; and negroes, 17.

Christmas, effect on wages, 64 .

Cigar factories, effect of days of week, 98; white versus colored labor, 13.

Cigar-makers, shiftlessness of, 75 .

Circulation, effect of temperature on, 116, 121.

Cities, death rate in, 187. 
Civilization compared with climatic energy, 7, 199 ff., 201, 239 f.; conditions of, 2, $199 \mathrm{ff}$.; definition of, 150, 158, $162 \mathrm{f}$., $164 \mathrm{f}$; distribution of, 148, $251 \mathrm{ff}$; effect upon lower races, 37 ; and government, 207 ; map of (see $M a p$ ) ; past distribution of, 222 , $251 \mathrm{ff}$., $276 \mathrm{ff}$.; and race, 205; and religion, 206.

Clear weather, effect of, $121 \mathrm{ff}$.

Climate (see also Seasons, Temperature, Atmospheric pressure, $\mathrm{Hu}$ midity, etc.), effect on racial character, 11-34; effect of the seasons, $49 \mathrm{ff}$.; ideal, $129 \mathrm{ff}$.; difficulty of reconstructing past, $3 \mathrm{f}$, 222; magnitude of effects of, 124 ff.; place among factors in civilization, 278; summary of investigations, 1-10; summary of conclusions, 218; versus weather, 111.

Climatic changes, deforestation hypothesis, 225; in geological times, $223 \mathrm{ff}$; growth of idea of, $4 \mathrm{ff}$; hypothesis of uniformity, 226; progressive desiccation hypothesis, 226; pulsatory hypothesis, 5, 229 ; solar hypothesis of, 244 ff.

Climatic energy, ancient distribution of, 263; compared with civilization, $199 \mathrm{ff}$.; map of, $137 \mathrm{ff}$.; map of in U. S., 184, $186 \mathrm{ff}$.

Climatic hypothesis of civilization, objections to, $271 \mathrm{ff}$; dangers of, 285.

Clothing, effect of compared with climate, 126.

Cloudiness, effect on man, 112, $121 \mathrm{ff}$.

Coca leaf, in Peru, 276.

Cold, effect on physical activity, 116 ; on mental activity, 117.

Cold-blooded animals, relation to temperature, 107.
Colds, effect of dryness on, 87, 289.

Colombia, civilization and energy in, 204.

Colonies, relation to civilization, 202.

Colonists, in North and South of U. S., $22 \mathrm{f}$.

Colonization, in tropics, $38 \mathrm{f}$., $42 \mathrm{f}$., $136,144,214 \mathrm{ff}$.

Colorado, education in, 194; storms versus rainfall in, 272.

Color line, in Bahamas, 14; in Florida cigar factories, 13.

Columbia, S. C., cotton mills in, 71; tests of negro children at, 12 .

Compass plant, 113.

Complexion, of women in Bahamas, 31 ; in Florida, 32.

Congo, effect of humidity, 140, 142; monotony of, 132.

Conjugation, in paramœcium, 104.

Connecticut, average temperature, 59 (fig.); effect of temperature, 100, 114 ff., 137; eminent persons in, $213 \mathrm{ff}$.; factory operatives in, 8, 53 ff., 59; illiteracy in, 191.

Consumption in relation to climate, $65 \mathrm{f}$.

Contributors, to map of civilization, 149 f., 156, 196.

Copenhagen, school children in, $69 \mathrm{f}$.; tests of strength at, 102.

Copper, in early America, 280.

Corpuscles, red, at high altitudes, $50 \mathrm{f}$.

Correction of curves, $58 \mathrm{ff}$., 79, 102.

Corsica, rank in civilization, 167.

Cotton, as money crop, 18; and war of 1914, 71.

"Crackers," origin of, 24, 216.

Crayfish, and temperature, 106.

Creole regions of U. S., 180.

Cuba, opinions as to, $175,180$. 
Cubans, in Florida cigar factories, 13, 73, 98; sensitiveness to climate, 101.

Cuzco, temperature of, 275.

Cycles, climatic, $248 \mathrm{f}$.

Cyclonic storms (see also Storms, and Storminess), in China, and Japan, 147 ; and civilization, 7; and daily changes, $131 \mathrm{ff}$; distribution of, 132; nature of, $111 \mathrm{f}$; and sunspots, $245 \mathrm{ff}$; in tropics, 136.

Dakotas, civilization in, 177, 197; education in, $193 \mathrm{f}$.; eminent persons in, 217.

Dampness, variability of, 131. (See Humidity.)

Davis, W. M., 4.

Day of week, effect on wages, 94 .

Day workers, effect of week on, 97 .

Dead Sea, as a measure of climate, 224, 247.

Death, due to temperature, 107.

Death rate, effect of dryness on, 87; in Japan, 68; in Massachusetts in 1911, 90; in New York, 68; in U. S., 184, $186 \mathrm{ff}$.

Deforestation, an abandoned hypothesis, $225 \mathrm{f}$.

Delaware, eminent persons in, 213.

Delhi, 260.

Denmark, rank in civilization, 166; tests of strength in, 51, 68, 102.

Denver, effect of wind in, 112.

Desert Botanical Laboratory, 5 .

Desert winds, effect on human actions, 47.

Deserts, ancient rainfall of, 273; evidences of desiccation in, 225 .

Desiccation of Asia, 6; evidences of, $225 \mathrm{ff}$; ; and sunspots, $248 \mathrm{ff}$.

Dexter, cited, 7, 112.

Digger Indians, 278.
Diseases, in Bahamas, 28, 30; in Central America, $239 \mathrm{f}$; and climate, 24; effect upon temper, 43; among Mayas, 242; relation to dry houses, 289; relation to energy, 188; in tropics, 37, $39 \mathrm{f}$.

Douglass, A. E., cited, 229.

Drakenberg mountains, 24 .

Dress, and morality, 46.

Drunkenness, in tropics, 41, $44 \mathrm{ff}$.

Dry season, value in tropics, 243.

Dryness. (See Aridity, and Humidity.)

Dynamometer, tests with, 51 .

East Indians, character of, 35 .

Ecuador, civilization and energy in, 204; temperature of, 136.

Education, effect on negroes, 16; as test of civilization, 192; in U. S., $192 \mathrm{ff} ., 197$.

Efficiency, and climate, 49 ff., 139; tests in Connecticut, $53 \mathrm{ff}$.

Egypt, ancient storminess of, $267 \mathrm{f}$., 272; civilization and energy in, $6,164,202,259,261$; effect on Teutons versus negroes, 11, 33.

Egyptian Sudan, aridity of, 140, 142.

Electricity of air, 7.

Eminent persons, distribution of in U. S., $208 \mathrm{ff}$.

Energy, ancient distribution of, 6, 263; a condition of civilization, 207; effect on eminence, 211, $217 \mathrm{ff}$; map of climatic, 8, 137; of Mayas, 242.

England, effect of climate on, 287; experiments on $\mathrm{CO}_{2}, 108 \mathrm{f}$; rank in civilization, 166; ideal climate, $129 \mathrm{ff} ., 123,135$; rain in 14th century, 236.

English, marks in, $78 \mathrm{ff}$. 
English, as colonists in tropics, 27 ; in South Africa, 24 ff. (See also Anglo-Saxons, British, and Teutons.)

Environment, versus heredity, $11 \mathrm{ff}$.

Eskimos, inefficiency of, $143 \mathrm{f}$.

Eugenics, 216.

Eurasia, storminess of, $266 \mathrm{ff}$.

Europe, barbarian invasions of, 6; civilization and energy in, $162 \mathrm{ff}$., 165, 201, $251 \mathrm{ff}$; distribution of seasonal changes, 132; ideal climate, $130 \mathrm{ff}$.; storminess and sunspots in, 133, 236, $245 \mathrm{f}$., 267; war of 1914, 25 .

Europeans, effect of migrations of, 205 ; in tropical lands, 35.

Exiles, effect of climate on Russian, $145 \mathrm{f}$.

Experiments, difficulty of climatic, $126 \mathrm{f}$.

Extremes of temperature, effect of, $92 \mathrm{ff}$.

Factories, in Connecticut, 53 ff.; in Florida, 32; effect of changes of temperature in, $114 \mathrm{ff}$., $289 \mathrm{f}$.; investigation of, 8 .

Farmers, health in tropics, 40 ; white versus colored, $18 \mathrm{ff}$.

Ferrell, J. A., cited, 28.

Finland, rank in civilization, 167.

Five Nations, 277 .

Flint tools, 280; among Mayas, 241.

Floods in France, 236.

Florida, effect of climate, 32, 100, $118 \mathrm{ff}$; f factories in, 8, 98; illiteracy in, 191; negro versus white farmers, $18 \mathrm{ff}$; wages in, $71 \mathrm{ff}$.

Food, compared with climate, $126 \mathrm{f}$.

Forests, effect on rainfall, 225; in tropics, 41, 239.

Fraas, 0., 6.
France, effect of climate on, 287; rank in civilization, 167.

Fresno, temperature of, 130.

Gale, H. S., cited, $233 \mathrm{f}$.

Gambling, in tropics, 41.

Gautama, 163, 260.

Genius, distribution of, $207 \mathrm{f}$.

Geographers, opinion of map of civilization, $157,161 \mathrm{f}$.

Geography, effect on civilization, 167 ; methods of reasoning, $220 \mathrm{f}$.

Geological changes of climate, $223 \mathrm{ff}$.

"Geopsychische Erscheinungen," 7, 50.

Georgia, climate compared with Florida, 32; complexity of, 161; cotton mills in, 71; education in, 195; emigration from during Revolution, 27; eminent persons in, 213; illiteracy in, 191; negro education in, 195; negro versus white farmers, 18 ff.; storms versus rainfall in, 272.

Germans, opinion as to civilization, 177.

Germany, ancient climate of, 236, 268; effect of climate on, 287; rank in civilization, 166 ; relation to ideal climate, 133, 135.

Girls, sensitiveness to climate, 92, $100 \mathrm{f} ., 114,116,119$. (See also Women.)

Glacial period, 223; causes of, 237, 238, 247.

Gouldsbury, cited, 46 .

Governments, and civilization, 207.

Grass, relation to early civilization, $282 \mathrm{f}$.

Great Lakes, storminess near, 140.

Great Salt Lake, strands of, 237. 
Greece, ancient climate of, 6, 248, $268 \mathrm{f}$.; center of civilization, 163 , 262.

Greek Christianity, and civilization, 206.

Greenland, diversity of opinion as to, 167, 169, 180.

Gregory, H. E., cited, 51.

Grenfell, cited, 144.

Grippe, effect of dry houses on, 289.

Guatemala, currency in, 44; drunkenness in, $44 \mathrm{f}$.; ruins, 5, $239 \mathrm{f}$.

Hampton Institute, 16.

Hann, J., cited, 138, 141.

Health, relation to energy, 188.

Heat, effect on physical activity, $90 \mathrm{ff} ., 101,116,137$; and mental activity, 117.

Hebrides, temperature of, 130.

Hebron, 243.

Hellman, cited, 245.

Hellpach, cited, 7, 47, 50, 123.

Heredity, compared with opportunity, 217; versus environment, $11 \mathrm{ff}$. (See also Inheritance.)

Highlands, effect on civilization, 136, 204, $275 \mathrm{f}$.; effect on storms, $265 \mathrm{f}$; versus lowlands in tropics, 42, 136.

Himalayas, effect on storms, 268.

Hinduism, in America, 262.

Hindus versus Europeans, 163.

Historical changes of climate, $225 \mathrm{ff}$.

Hoboken, suicide in, 134.

Holland, rank in civilization, 166; storms in 14th century, 236.

Hookworm, 24, 39, 216.

Hope Fontein, temperature of, 275.

Horse races, in mountains, 51 ; used as climatic figure, 127.

Hottentots, 25.

Houses, effect of confinement in, 84 f., 87; wrong method of heating, 289.
Huguenots, inheritance from, 215.

Humboldt, 49.

Humidity, effect on cotton weaving, 71 ; on death rate in Japan, 69; on map of energy, $140 \mathrm{f}$; on tobacco, 75 ; indoor versus out-ofdoor, $85 \mathrm{ff}$.; in Japan, 147; relation to ideal climate, 131; and temperature in Manchester, 108. (See also Relative Humidity and Dampness.)

Humor, among negroes, 12.

Hurricanes, in tropics, 136.

Iceland, rank in civilization, 167, $169,180$.

Ice sheets, 223.

Idaho, civilization of, 177; eminent persons in, 217; illiteracy in, 191; life insurance in, 187.

Ideal climate, $129 \mathrm{ff}$.

Illinois, eminent persons in, 213; negro versus white farmers, $19 \mathrm{ff}$.

Illiteracy, as a test of civilization, 190.

Immigrants, effect of American climate on, 286 ; problem of U. S., $214 \mathrm{ff}$; in tropics versus north, $38 \mathrm{f}$.

Immorality, in tropics, 45.

Incas, civilization of, 240, 277.

Inclination to work versus capacity, 73, 102.

India, British children in, 37; British domination, 37 ; character of people, 35, 163; civilization and energy in, $201 \mathrm{f}$., 259, 262 ; humidity versus aridity, 140, 142; effect of Japan upon, $255 \mathrm{f}$.; migrations from, 274 ; storms in, $249,267 \mathrm{f}$.

Indian Meteorological Service, 249.

Indiana, eminent persons in, 213; negro versus white farmers, $19 \mathrm{ff}$. 
Indians, of Central America, $239 \mathrm{f}$; civilization in North America, 277; horse races among, 51 ; inheritance of, 214.

Indo-China, civilization and energy in, 201, 259; compared with Central America, 275; ruins in, 274.

Industry, in tropics, $41 \mathrm{ff}$.

Inefliciency, and drunkenness, 45. (See also Inertia, Laziness, Industry.)

Inertia, in Bahamas, $29 \mathrm{f}$; in Siberia, $146 \mathrm{f}$.; tropical, 33, 35, $41 \mathrm{ff}$.

Infusoria. (See Paramocium.)

Inheritance, effect on ability, $22 \mathrm{f}$., $211 \mathrm{ff}$; relation to climate, 202. (See Heredity.)

Initiative, lack of in Siberia, 146.

Insanity, and climate, 134.

Intermarriage, in Bahama Islands, 28.

Invasion, of Europe by barbarians, 6.

Iowa, character of immigration, 215; eminent persons in, 213; opinions as to civilization of, 177 .

Ireland, humidity of, 131, 140, 142, 287; rank in civilization, $166 \mathrm{f}$,, 168.

Iron, importance to civilization, $280 \mathrm{ff}$.

Iroquois, 278.

Irrigation, effect on education, 194; in Syria, etc., 226.

Ispahan, rainfall of, 273.

Italians, in brass factory, $56 \mathrm{f} ., 100$.

Italy, civilization in, 167, 201, 262 ; climate of, 269 ; morality in, 47 ; storm center, 267.

Jacksonville, Fla., cigar factories at, 13, $72 \mathrm{ff}$.

Jamaica, negroes in, 36.

James, W. B., cited, 121.
Japan, civilization and energy in, 143, 147, 201, 255 f., 262 ; complexity of people, 161; death rate in, 68; rank in civilization, $168 \mathrm{f}$.; storminess in, 133, 249, 268; Teutonic blood in, 206.

$J$ apanese race, and civilization, 206. Java, civilization and energy in, 202. Jefferson, M., cited, 188, 192.

Jewish atrocities in Russia, 167.

Jews, civilization of, 163, 261.

Johnson, D. W., cited, 232.

Jones, J. C., cited, 234.

Kansas, civilization in, 197.

Kentucky, eminent persons in, 216; illiteracy in, 191; negro versus white farmers, $19 \mathrm{ff}$.

Khartum, effect of dryness, 140.

Kidneys, diseased, effect on paramœcium, 106.

Korea, climatic energy in, 143.

Kropotkin, cited, 4, 6.

Kullmer, C. J., cited, 7, 245, 264, 272 ; scale of storms, 140.

Labor, in tropics, 36, 38; method of determining efficiency of, 141 .

Labrador, fisherman, 144.

Lakes, concentration as climatic evidence, $233 \mathrm{ff}$. (See also Strands.)

Latin America, and Christianity, 206; civilization and climate in, 204; racial character of, 37.

Latins, and civilization, 206. (See also Romance.)

Laziness, in Bahamas, $30 \mathrm{ff}$; in tropics, $41 \mathrm{ff}$.

Lehmann, cited, 7, 51, 69, 77, 102, 112.

Length of day, effect of, 84 .

Letters, a test of civilization, 189.

Life insurance, statistics of, $186 \mathrm{ff}$.

Light, effect on cigar making, 73 f.; effect on human activity, 83. 
Lincolnshire, storms in 14th century, 236.

Liverpool, temperature of, 130.

Livingstone, D., cited, 46.

Loess, origin of, 247.

London, climatic excellence of, $129 \mathrm{f}$; ; effect of temperature, 139; murders in, 286.

Lop Nor, fluctuations of, 237.

Loram, cited, 13.

Los $\Lambda$ ngeles aqueduct, 233; suicide in, 134; temperature of, 130.

Louisiana, illiteracy in, 191; negro education in, 195; civilization of, 180; school attendance in, 192.

Loyalists, in Bahamas, versus Canada, 27.

Lumber industry in Bahamas, 15.

MacDougal, D. T., cited, 5, $103 \mathrm{f}$.

McHattie, quoted, 28.

Maine, eminent persons in, 212; handicaps of, 217 .

Malaria, in Bahamas, 28; in Central America, $239 \mathrm{f}$; ; in South, 24; in tropics, 38.

Malay Peninsula, character of people, 35 .

Malta, course of storms near, 249.

Manchester, experiments in, $108 \mathrm{f}$.

"Manchester Memoirs," cited, 108.

Manufactures, as a test of civilization, $189 \mathrm{f}$.

Manufacturing, effect on death rate, 187.

Map of civilization, $148 \mathrm{ff}$; method of preparing, 151, 164 f.; purpose of, 151; reliability of, $180,188 \mathrm{ff}$.

Map of climatic energy, $137 \mathrm{ff}$.; test of, $183 \mathrm{ff}$.

Maritime climate in Connecticut, 93.

Maritime Provinces, civilization of, 177.

Marriage, dangers of modern system, 216 .
Maryland, effect of temperature in, $117 \mathrm{f}$.

Massachusetts, death rate in 1911, 90; eminent men in, 208, $210 \mathrm{ff}$., 214 ; good fortune of, 218; illiteracy in, 191; insanity in, 134; negro education in, 195; railroads in, 189; rank in civilization, 196; schools in, $192 \mathrm{f}$.

Massaua, effect of heat, 139.

Mathematics, marks in, $78 \mathrm{ff}$.

Mayas, civilization of, 164, 263; dates, $242 \mathrm{f}$; relation to storms, 267 ; ruins of, 5, $239 \mathrm{f}$; skill of, $240 \mathrm{ff}$.

Mayo, cited, 13.

Medes, effect of Mesopotamia upon, $257 \mathrm{f}$.

Mediterranean Sea, relation to civilization, 262; rainfall of, 272; storminess in past times, 249, 267.

Melon, wild, 113.

Men, resistance to climate, 100, 114, $116,119$.

Mental activity, effect of climate on, 32, $77 \mathrm{ff} ., 101 \mathrm{ff} ., 117$; mental versus physical optimum, $109 \mathrm{f}$.; supreme importance of, 216; white versus black, 12.

Mescal, 44.

Mesopotamia, civilization of, 164, $257 \mathrm{f}$., 261; ancient climate of, 267, 268; storminess in, 249, 273. Metabolism, and temperature, $106 \mathrm{ff}$. Metal, absence among Mayas, 241.

Mexicans, education in U. S., 195; illiteracy of, 191; inheritance of, 214.

Mexico, civilization in, 175, 204, 263 ; effect of climate, 291 ; climatic investigations in, 5; drunkenness in, 44.

Mexico, storminess in Gulf of, 249. 
Michigan, negro versus white farmers, 19 ff.

Middle Atlantic states, colonists of, 23, 215.

Migrations, effect of climate on, 6, 290.

Mind, effect of tropics on, $42 \mathrm{ff}$.

Miners, and life insurance, 187.

Minnesota, illiteracy in, 191; civilization of, 177.

Missionaries, character of, 47; cited as to morality, 46; in Turkey and China, 255.

Mississippi, education in, 195; illiteracy in, 191; negro versus white farmers, $19 \mathrm{ff}$.

Mohammedanism, and civilization, 206.

Monarchies and civilization, 207.

Money, in Guatemala, 44.

Mongolia, climatic energy in, 144.

Mono Lake, strands, 237.

Monotony, effect upon activity, 52.

Montana, eminent persons in, 217; life insurance in, 187; civilization of, 177 .

Moraines, as a measure of climate, 224.

Moral character, effect of race contact on, 38 .

Moral responsibility, relation to climate, 287, 293.

Mormonism, 197; effect on education, 194.

Morse, J., cited, 12.

Mortality, in Japan, 68; in New York, 68; in U. S., 184, 186 ff.

Mountaineers, cause of strength of, 51.

Mountains, effect on South, 216.

Mucous membranes, effect of dryness on, 87, 289.

Murders, in U. S. versus England, 286.
Nansen, F., cited, 146.

Natal, 25.

Nationality of contributors to map of civilization, 156; of piece workers, 55.

Natural selection, in tropics, 40, 42.

Nearing, S., cited, $207 \mathrm{ff}$.

Nebraska, eminent persons in, 210, $213 \mathrm{f}$.; energy compared with eminence, 217; civilization of, 177 .

Nebular hypothesis, relation to climatic changes, 223.

Negroes, character of, 16; compared with Teutons, $11 \mathrm{ff} ., 24 \mathrm{ff}$; education, 192, 195; effect of United States upon, $35 \mathrm{f}$; in Florida cigar factories, 73; school attendance of, 192; tests at Columbia, S. C., 12.

Nervousness and climate, $134 \mathrm{f}$. ; in Europe, 146; and storms, 52; in tropics, $42 \mathrm{f}$.

Nevada, civilization in, 197; education in, 194; energy compared with eminence, 217; illiteracy in, 191 ; railroads in, 189.

New Britain, factory operatives in, 8, $53 \mathrm{ff} ., 114 \mathrm{ff}$.

New England, early settlers, 23 f.; extreme seasons, 93; effect on immigrants, 38; eminent men in, 208, 211 ff., 214 f.; energy compared with eminence, 217 ; factory operatives in, $53 \mathrm{ff}$.; illiteracy in, 191.

Newfoundland, civilization of, 177, 180; fishermen, 144; rank in civilization, 167.

New Hampshire, eminent persons in, 212.

New Haven, factory operatives in, $8,53 \mathrm{ff} ., 114 \mathrm{ff}$.

New Jersey, negro versus white farmers, $19 \mathrm{ff}$. 
New Mexico, civilization, 196; education in, 193, 195; eminent persons in, 210, $213 \mathrm{f}$.; illiteracy in, 191.

New York State, death rate in, 68, 187; effect of temperature in, $117 \mathrm{f}$.; eminent persons in, $211 \mathrm{f}$.; insanity in, 134; negro versus white farmers, $19 \mathrm{ff}$; negroes in high schools, $13 \mathrm{f}$.

New York State Commission on Ventilation, 73, 101.

New Zealand, civilization of, 256; climatic energy in, 143; relation to ideal climate, $130 \mathrm{f}$.; storminess of, 133.

North Africa, rainfall and sunspots in, 247.

North America, civilization in, 172 ff.; climatic energy in, 143; domestic animals in, $282 \mathrm{f}$; former storminess of, 267; seasonal changes, 132; rank in civilization, 169.

North Carolina, eminent persons in, 213,217 , negro versus white farmers, $19 \mathrm{ff}$.

North Dakota. (See Dakotas.)

Norway, effect of altitude in, 51 .

Norwegians, compared with Siberians, 146.

Nova Scotia, civilization of, 177 .

Oakland, suicide in, 134.

Objections to climatic hypothesis, 222, $271 \mathrm{ff}$.

Ocean, relation to ideal climate, 130.

Ohio, eminent persons in, 213; negro versus white farmers, $19 \mathrm{ff}$.

Oklahoma, illiteracy in, 191.

Old age, time of mortality, 68 .

Opinion, use in map-making, $148 \mathrm{ff}$. Opportunity, effect on eminence, $211,216 \mathrm{ff}$.
Optimum, of humidity, 87.

Optimum temperature, of crayfish, 106; of infusoria, 106; law of, 110 ; of man, 108; of North versus South, 100; of plants, $103 \mathrm{f}$; versus changes, 120.

Orange River Colony, 25.

Oregon, eminent persons in, $213 \mathrm{f}$; illiteracy in, 191.

Ostiaks, inefficiency of, 144.

Owens Lake, as climatic evidence, $233 \mathrm{f}$.

Oxygen, absorption at high altitudes, 50.

Pacific coast of America, civilization of, 175, $256 \mathrm{f}$.; climatic energy in, 143; energy and eminence, 217 ; ideal climate, $130 \mathrm{f}$.

Palestine, changes of climate in, 224, 231, 243, 267; civilization, 261 ; expedition to, 5 .

Palm, as evidence of climatic stability, 231.

Panama, health at, 40, 240.

Paramœecium, relation to temperature, $104 \mathrm{ff}$.

Patagonia, relation to ideal climate, $130 \mathrm{f}$.

"Pedagogical Seminary," 12.

Pedersen, cited, 7, 51, 69, 77, 102, 112.

Peking, cold waves in, 147.

Pellagra, 39.

Penck, A., cited, 5, 237 f., 247.

Pennsylvania, character of immigration, 215; eminent persons in, 213; negro versus white farmers, $19 \mathrm{ff}$; seasonal variations in wages in, $75 \mathrm{ff}$.

Permian glaciation, 223.

Persia, civilization of, $259 \mathrm{f}$., 262; palm trees in, 232; storminess in, 249,267 , $273 \mathrm{f}$., wind in, $112 \mathrm{f}$. 
Peru, civilization in, 204, 240, 262, 275.

Peten, malaria in, 240.

Pfeffer, cited, 104.

Philippines, civilization and energy in, 202.

Phœnicia, ancient climate of, 273; civilization, 261.

Physical conditions versus esthetic, 123; versus mental, in Bahamas, 32 ; versus social among negroes, $36 \mathrm{f}$.

Physiological effect of changes of tcmperature, $166 \mathrm{f}$; of climate, $50 \mathrm{ff}$.; of optimum temperature, $107 \mathrm{ff}$; relation to character, 41 ; versus psychological effects, 123.

"Physiology of Plants," by Pfeffer, cited, 104.

Piece-workers, in Connecticut, $53 \mathrm{ff}$.; effect of week on, $97 \mathrm{f}$. (See also Wages, and Factory Operatives.)

Pilgrims, contribution to North, 22 f., 214.

Pittsburgh, wages at, $59,75 \mathrm{ff}$.

Plains, and civilization, 257, $261 \mathrm{f}$.

Planetesimal hypothesis, 224.

Plants and temperature, 103.

Pocy, cited, 245.

Poisons, due to high temperature, 107.

Political equality in tropics, 38.

Polygamy, 197.

Poor whites, in Bahamas, 14, 27; in cotton mills, 71; origin of, 33, 216 ; in South Africa, 25.

"Popular Science Monthly," 12, 207.

Population, increase in tropics, 37.

Port Said, rainfall of, 273.

Practice, correction for, 102 ; effect of upon wages, 60 .

Premium work, 62 .

Pressure of atmosphere. (See Barometric changes.)
Progressive desiccation hypothesis, 226.

Promotions of white children versus colored, 13.

Protestant Christianity and civilization, 206.

Protoplasm, relation to temperature, 104.

Psychological effects of climate, 50 ff., 123.

Public opinion, in tropics, 48. (See also Social restraints.)

Pulmonary tuberculosis, and weight, $65 \mathrm{f}$.

Pulsatory hypothesis, 5, 6, $229 \mathrm{ff}$.

Pumpelly, R., 4.

Puritans, contribution to North, 23; eminence of descendants, 214; slavery among, 23.

Puitter, cited, 106 f.

Pyramid Lake, climatic evidence of, 233 f.; strands, 237.

Quakers, inheritance from, 214.

Qualitative method of research, 220.

Quantitative method of research, $220 \mathrm{f}$.

Quintana Roo, malaria in, 240.

Quito, temperature of, 136, 139.

Race, and climate, 117, $201 \mathrm{f}$.; compared with civilization, $205 \mathrm{f}$.; differences of, 163; effect on education, 194; and illiteracy, 191 ; versus place, $11 \mathrm{ff}$.; prejudice, 165.

Racial character of continents, 165 .

Railroads, as a test of civilization, 189.

Rainfall, causes of variations, $225 \mathrm{ff}$., $246 \mathrm{f}$.; of past times, $272 \mathrm{ff}$.; versus storminess, $272 \mathrm{f}$.

Rajputana, rank in civilization, 169. Ranch life, effect on education, 194 . Range of temperature, effect of, 112. 
Rätzel, 49.

Reading, in warm climates, 32.

Reclus, 4.

Red Sea, effect of heat, 139.

Relative efficiency, and temperature, 139.

Relative humidity. (See Humidity.)

Religion, and civilization, $206 \mathrm{f}$.

Religious refugees, inheritance from, 215.

Reproduction, in paramœecium, 104.

Republics, and civilization, 207.

Rhode Island, eminent persons in, $213 \mathrm{f}$; railroads in, 189.

Rhodes, civilization of, 262.

Rhodesia, 25; ancient civilization in, 275 ; morality in, 46.

Rivers, composition of water, 233.

Roads, effect on education, 193.

Rockefeller International Health Commission, 28.

Rocky Mountain states, civilization of, 177, 180, 197; education in, $193 \mathrm{f}$.

Rodishev, cited, 146.

Romance nations, rank in civilization, 167, 177.

Romans, attempts to get water, $226 \mathrm{f}$.; European character of, 163.

Roman Catholicism, and civilization, 206.

Rome, civilization of, 262.

Roumania, civilization and energy in, 201.

Rum, in tropics, 44.

Russia, climatic energy in, 145, 287; rank in civilization, 167 .

Sabæans, civilization of, 259.

Sacramento, suicide in, 134.

Saint Louis, suicide in, 134.

Saint Paul, European character of, 163.
Salt lakes, as measure of climate, 224.

San Diego, suicide in, 134 ; temperature of, 130.

Sand dunes, as climatic evidence, 238.

San Francisco, effect of heat, 139 ; relation to ideal climate, 134, 139; suicide in, 134; temperature of, 130.

Sanitation, relation to climate, 24, 188.

Saranac Lake, tubercular sanitarium at, $65 \mathrm{f}$.

Sardinia, rank in civilization, 167.

Saskatchewan, civilization in, 177, 180, 202.

School children, white versus black, $12 \mathrm{f}$.; effect of wind on, 112.

Schools, in U. S., $192 \mathrm{ff}$.

Scotland, humidity of, 131; rank in civilization, 166.

Screws, packing, 55 .

Scythians, effect of Mesopotamia upon, 258.

Seacoast, effect on health, 41, 292.

Searles Lake, as measure of climate, 224 .

Seasonal range of temperature, 131 f., 136.

Seasons, effect of, $49 \mathrm{ff} ., 52,57 \mathrm{ff}$., $77 \mathrm{ff} ., 139$.

Seattle, temperature of, 130.

Seistan, effect of wind in, 113.

Self-control, in tropics, $43 \mathrm{ff}$., 276.

Seminoles, 278.

Semites, effect of Mesopotamia upon, $257 \mathrm{f}$.

Sequoia, as index of climatic changes, 230.

Settlers, in North and South, $22 \mathrm{f}$.

Sex, and sensitiveness to climate, 100, 114, 116, 119. 
Sexes, relation of in tropics, 38,41 , $45 \mathrm{ff}$.

Sheane, cited, 46 .

Sheep, wild, 283.

Shifting of climatic zones, 5, $220 \mathrm{ff}$., $238 \mathrm{ff}$; effect on disease, 242; effect on agriculture, 242.

Shifting, of centers of civilization, $251 \mathrm{ff}$.

Shifting, of storm belt, $264 \mathrm{ff}$.

Siam, civilization and energy in, $201 \mathrm{f}$.

Siberia, civilization and energy in, 201 ; climatic energy in, $145 \mathrm{ff}$; inefficiency in, 144.

Sierra Nevadas, lakes near, $233 \mathrm{ff}$.

Sioux, 278.

Sirocco, effect on character, 47 .

Slaves, in Bahamas, 29; among Puritans, 23; effect on South, $22 \mathrm{f}$.

Slavs, and civilization, 167 f., 206.

Sleepiness, due to climate, 50 .

Smoke Creek Desert, 235.

"Smokes" in cigar factories, 75 .

Smoothing, of curves, 58.

Social environment, effect on negroes, $36 \mathrm{f}$.

Social restraints, in tropics, $45 \mathrm{ff}$.

Sodium in Owens Lake, 234; in Pyramid and Winnemucca, 234 $\mathrm{f}$. Soil, denudation of, 225.

"Solar hypothesis," 244.

South, advantages of, 18; attitude of volume toward, 17; causes of backwardness, $22 \mathrm{ff}$; civilization and energy in, 180, 203, 218; education in, $192 \mathrm{ff}$; illiteracy in, 191; lack of opportunities in, 216; mortality in, $187 \mathrm{f}$.

South Africa, civilization and energy in, 202; economic problem of, 49; Teutons versus negroes, $24 \mathrm{ff}$.
South America, civilization in, 171, 204; climatic energy in, 143; horse racing in, 51; storminess of, 133; relation to ideal climate, $130 \mathrm{f}$.

South American Indians, character of, $35 \mathrm{f}$.

South Carolina, cotton mills in, 71 ; eminent persons in, 210, 213, 215, 217, 218; illiteracy in, 191; negro versus white farmers, $18 \mathrm{ff}$; negro education in, 195; school attendance in, 193.

South Dakota. (See Dakotas.)

Spain, rank in civilization, 167.

Spaniards, in Florida cigar factories, 73; in South America, 204.

Spanish blood, advantages of in Mexico, 214.

Spleen, effect of malaria upon, 39.

"Spring fever," 102.

Statistics, use in map-making, $148 \mathrm{ff}$., $183 \mathrm{ff}$.

Stevens, cited, 26.

Stone implements, $280 \mathrm{f}$.

Storm belt, shifting of, $264 \mathrm{ff}$.

Storm tracks, modern location of, $263 \mathrm{ff}$.

Storminess, distribution of, $263 \mathrm{ff}$; method of computing effect, 140; in past times, $267 \mathrm{f}$.; versus rain. fall, $272 \mathrm{f}$.; in Russia, 145; and sunspots, $245 \mathrm{ff}$.

Storms, effect on activity, 50, 123; effect on nerves, 52; nature of, $111 \mathrm{f}$.; in 14th century, 236. (See also Cyclonic Storm.)

Strands, as climatic evidence, $235 \mathrm{ff}$., $247 \mathrm{ff}$.

Strength, seasonal variations in Denmark, $69 \mathrm{f}$.

Strong, cited, 12.

Students, effect of heat on, 101; effect of seasons on, $77 \mathrm{ff}$.; investigation of marks of, 8 . 
Subtropical storm belt, 266, 275.

Sudan, effect of aridity, 140, 142.

Sumer and Accad, 257.

Summers, hot, $90 \mathrm{ff}$.; value of vacations in, 88.

Sun, cause of climatic phenomena, $244 \mathrm{ff}$.

Sunspots, relation to climate, $244 \mathrm{ff}$; and storms, $267 \mathrm{ff}$., $272 \mathrm{ff}$.

Sweden, cold in 14th century, 236.

Swedish bath, 121.

Syria, ancient climate of, 267, 273; civilization in, 261; forests in, 226; irrigation in, 226; rainfall and sunspots, $247 \mathrm{f}$.; storminess in, 249; Teutonic blood in, 206.

Syrian Desert, rank in civilization, 169.

Takla-Makan Desert, monotony of, 135.

Tampa, Fla., cigar factories at, 14, 73 ff., 96.

Teheran, rainfall of, 273 .

Temper, in tropics, 41, $43 \mathrm{f}$.

Temperature. (See also Changes of Temperature); in Connecticut, 59 (fig.); and $\mathrm{CO}_{2}, 106 \mathrm{ff}$; and cotton weaving, 71 ; method of computing effect, $138 \mathrm{f}$; ; and organic activity, 8, $89 \mathrm{ff} ., 94,98 \mathrm{ff}$.; range of, 112.

Ten Kate, H., cited, 160.

Tennessee, civilization in, 197; eminent persons in, 216; negro versus white farmers, $19 \mathrm{ff}$.

Teutons, and civilization, 167, 205; compared with negroes, $11 \mathrm{ff}$., 24. $\mathrm{ff}$; character of, 16 . (See also Anglo-Saxons, British, and English.)

Texas, civilization in, 197, 199; education in, 195; illitcracy in, 191.
Thomson, cited, $108 \mathrm{f}$.

Tibet, climatic energy in, 144; effect on civilization, 260.

"Through Siberia," cited, 146.

Thunder storms, in tropics, 136.

Tobacco, as money crop, 18; factories, in N. C., 70, 75.

Tools, importance to civilization, $280 \mathrm{ff}$; among Mayas, 241.

Torrid zone, civilization in, 239.

Transvaal, 25.

Trees, as evidence of shifting of zones, 243; and high winds, 113; as index of climatic changes, 229.

Tropical highlands, 144, 275.

Tropical hurricanes, relation to sunspots, $24.5 \mathrm{f}$.

Tropics, effect on white man, $35 \mathrm{ff}$; improvements in, 291; inertia, 33; labor in, 36; life insurance in, 187; light in, 83 ; relation to ideal climate, 136.

Truckee River, salt in, 234.

Tuberculosis, and weight, $65 \mathrm{f}$; ; and life insurance, 187.

Turkestan, climatic energy in, 144; expeditions to, 4.

Turkey, Amerícans in, 255; first storm, 52; heat in, 47.

Typewriting, effect of seasons on, 102.

Uniformity, bad effect of, 114 ff., $120,136$.

United States versus Asia climatically, 231; areas of high energy in, $142 \mathrm{f}$.; civilization and energy in, 171, 196 ff., 199 ff., 202 ff., 252 ff.; climatic investigations in, 5; climate and rate of work in, $49 \mathrm{ff}$.; climatic variety of, 137; ability in, $208 \mathrm{ff}$.; education in, $192 \mathrm{ff}$.; effect upon negroes, $35 \mathrm{f}$; ; aridity 
and map of, 141; effect of climatic hypothesis upon, 286; harmful winters in, 288; illiteracy in, 190; mortality in, $186 \mathrm{ff}$.; North compared with South, 17; political contribution of, 253; Pre-Columbian civilization in, $276 \mathrm{ff}$; rainfall and sunspots in, $247 \mathrm{ff}$; relation to ideal climate, $130 \mathrm{f}$; statistical advantages of, 149, $183 \mathrm{ff}$.; storms in, $132 \mathrm{f}$., 249, 266 ; white versus colored farmers, 18 ff.; work at Panama, 40.

United States Commissioner of Education, 192.

Unruliness, among school children, 122.

Utah, civilization in, 197; eminent persons in, 217; illiteracy in, 191; school attendance in, $192 \mathrm{ff}$.

Vacations, best season for, 94; effect on energy, 88.

Van't Hoff's law, 106.

Variability of climate, value of, 32; law of, 120. (See Changes of temperature.)

Vedas, character of authors, 163.

Vegetation, relation to civilization, $280 \mathrm{ff}$.; of tropics, 239.

Venezuela, civilization and energy in, 204.

Ventilation, New York State Commission on, 73, 101.

Vera Cruz, effect of climate, 291.

"Vergleichende Physiologie," cited, 106.

Vermont, eminent persons in, 212.

Violence, and heat, 47.

Virginia, factory operatives in, 8; illiteracy in, 191.

Vitality, in U. S., 186 ff.
Wages, effect of heat on, $90 \mathrm{ff}$.; effect of war on, 70; and overhead charges, 62; among pieceworkers, $53 \mathrm{ff}$; seasonal variations of, $57 \mathrm{ff}$.; in tropical countries, 36 ; of whites versus negroes, $13 \mathrm{ff}$.

War, of $1914,25,70,251$; relation to centers of civilization, 251, $261 \mathrm{f}$; ; of Secession, 22.

Washington State, education in, 193.

Washington, D. C., colored pupils at, 12.

Water supply, historic changes in, 225.

"Weather Influences," cited, 7, 112.

Weather, effect of, 52; versus climate, 111; and work, $111 \mathrm{ff}$.

Week, days of, 94 .

Weight, and climate, $65 \mathrm{f}$.

West Indies, civilization in, 175.

West Point, changes of temperature in, $117 \mathrm{f}$; ; effect of seasons on marks at, $77 \mathrm{ff}$; marks at, 8, $78 \mathrm{f}$; vacation at, 117 .

West Virginia, eminent persons in, 216.

Wet weather. (See Humidity.)

"Wetter und Arbeit," 7.

Wheat, and temperature, 103, 116.

"White and Black," cited, 26.

White children compared with colored, 12.

White colonists in tropics, $35 \mathrm{ff}$., $38 \mathrm{f}$., 144, $239 \mathrm{ff}$.; effect on natives, $35 \mathrm{ff}$.

"Who's Who in America," $208 \mathrm{ff}$., $213 \mathrm{f}$.

Will power, supreme importance of, 216 ; in tropics, $41 \mathrm{ff}$.

Winds, effect on man, $112 \mathrm{f}$; ; relation to ideal climate, 130. 
Wind of 120 days, 113.

Winnemucca Lake, $233 \mathrm{f}$.

Winnipeg, civilization of, 177 .

Winston-Salem, N. C., 70.

Winters, cold, 93; effect upon activity, 52; effect of close houses in, $84 \mathrm{ff}$., $288 \mathrm{f}$; value of vacations in, 88.

Wisconsin, character of immigration, 215; negro versus white farmers, $19 \mathrm{ff}$.

Woodruff, C. W., cited, 83.

Woodruff, L. L., cited, 104.

Women, in Bahamas, $30 \mathrm{f}$; as pieceworkers, $55 \mathrm{ff}$; in tropics, $46 \mathrm{f}$.

Work, effect of climate on, $49 \mathrm{ff}$; and weather, $111 \mathrm{ff}$.; time of fastest, 52.
Workmen, white versus colored, $13 \mathrm{f}$.

Writing, among Mayas, 240.

Wyoming, education in, 194; eminent persons in, 217; civilization of, 177 .

Yale Expedition to Palestine, 5.

Yale University, and Acadia College, 177.

Yangtse basin, civilization in, 260; ancient storminess of, 268.

Yemen, ancient civilization in, 275.

Yucatan, changes of climate in, 5; European character of early, 164; ruins, $239 \mathrm{f}$; storm center, 267.

Zones, shifting of climatic, 5 .

Zulus, 24; immorality among, 46. 
PRINTED IN THE UNITED STATES OF AMERICA 




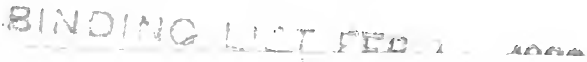 \\ Huntington, Ellsworth}

GF

31

H8

1922

Civilization and climate $2 d$ ed.

\author{
PLEASE DO NOT REMOVE
}

CARDS OR SLIPS FROM THIS POCKET

UNIVERSITY OF TORONTO LIBRARY 
